CENTRO UNIVERSITÁRIO FEI

GABRIELA MESSIAS DE MELO

DENSIDADE E PROPRIEDADES VOLUMÉTRICAS DE SOLUÇÕES AQUOSAS CONTENDO SACARÍDEOS E LÍQUIDO IÔNICO

São Bernardo do Campo 
GABRIELA MESSIAS DE MELO

\title{
DENSIDADE E PROPRIEDADES VOLUMÉTRICAS DE SOLUÇÕES AQUOSAS CONTENDO SACARÍDEOS E LÍQUIDO IÔNICO
}

\author{
Dissertação apresentada ao Centro \\ Universitário FEI, como parte dos requisitos \\ necessários para obtenção do título de Mestrado \\ em Engenharia Química, orientada pelo Prof. \\ Dr. Ricardo Belchior Torres.
}

São Bernardo do Campo 
Messias de Melo, Gabriela.

Densidade e propriedades volumétricas de soluções aquosas contendo sacarídeos e líquidos iônicos / Gabriela Messias de Melo. São Bernardo do Campo, 2019.

135 p. : il.

Dissertação - Centro Universitário FEI.

Orientador: Prof. Dr. Ricardo Belchior

Torres.

Elaborada pelo sistema de geração automática de ficha catalográfica da FEI com os dados fornecidos pelo(a) autor(a). 
Título do Trabalho: Densidade e propriedades volumétricas de soluções aquosas contendo sacarídeos e líquido iônico.

Área de Concentração: Engenharia Química

Orientador: Prof. Dr. Ricardo Belchior Torres

Data da realização da defesa: 19/09/2019

\section{ORIGINAL ASSINADA}

Avaliação da Banca Examinadora:

São Bernardo do Campo,

\section{MEMBROS DA BANCA EXAMINADORA}

Prof. Dr. Ricardo Belchior Torres

Prof. Dr. Ronaldo Gonçalves dos Santos

Profa Dra Cristiane Reis Martins
Ass.:

Ass.:

Ass.:

A Banca Julgadora acima-assinada atribuiu ao aluno o seguinte resultado:

\section{VERSÃO FINAL DA DISSERTAC̄̃̃O}

APROVO A VERSÃO FINAL DA DISSERTAÇÃO EM OUE FORAM INCLUÍDAS AS RECOMENDAÇÕES DA BANCA EXAMINADORA
Aprovação do Coordenador do Programa de Pós-graduação

Prof. Dr. Ricardo Belchior Torres 


\section{AGRADECIMENTOS}

Agradeço primeiramente aos meus pais, Débora e Claudiney, sou grata pelo incentivo e esforço mútuo de ambos para que tornassem esse sonho possível. Ao meu filho, Enzo, que sempre compreendeu minha ausência para dedicar ao estudo. Ao meu irmão, Matheus, por todo incentivo e apoio.

Aos meus familiares e amigos pela força e pelas amizades incondicionais.

Agradeço ao Prof. Dr. Ricardo Belchior Torres pela orientação e paciência no decorrer do curso.

Agradeço a Dra. Heloisa Emi Hoga, por todo o apoio e conhecimento passado durante os experimentos laboratoriais.

Aos professores do mestrado do Centro Universitário da FEI que deram o seu melhor para passar o conhecimento a todos ao seu redor.

Aos técnicos e integrantes do Centro de Laboratórios Químicos (CLQ) do Centro Universitário da FEI, pelo suporte e boa vontade.

Ao Centro Universitário da FEI, seu corpo docente, direção e administração por todo respaldo durante a realização do curso.

$\mathrm{E}$ a todos que direta ou indiretamente fizeram parte da minha formação, o meu muito obrigado. 
"Que todos os nossos esforços estejam sempre focados no desafio à impossibilidade. Todas as grandes conquistas humanas vieram daquilo que parecia impossivel." (Charles Chaplin). 


\section{RESUMO}

O presente estudo apresenta dados experimentais originais de densidade de soluções aquosas de líquidos iônico contendo sacarídeos a diferentes temperaturas, composições, e à pressão ambiente. Os sacarídeos estudados foram a $\mathrm{D}(+)$-xilose, $\mathrm{D}(+)$-glicose e a sacarose, e suas concentrações nas soluções variaram entre 0,015 e $1,7 \mathrm{~mol} \mathrm{~kg}^{-1}$. O líquido iônico investigado foi o dicianamida de 1-etil-3-metilimidazólio [EMIM][DCA], cujas concentrações nas soluções aquosas foram de 0,$025 ; 0,050 ; 0,075$ e $0,1 \mathrm{~mol}_{\mathrm{kg}^{-1}}$. A faixa de temperatura estudada variou entre 283,15 e 303,15 K. As medidas experimentais de densidade das soluções foram obtidas usando um densímetro de oscilação mecânica fabricado pela Anton Paar (Modelo DMA 4500). Fazendo uso do formalismo termodinâmico, os resultados de densidade foram usados para calcular propriedades volumétricas, dentre elas, o volume molar aparente, o volume molar à diluição infinita e o volume de transferência dos sacarídeos da água para as soluções aquosas. Os valores da densidade das soluções aumentaram com o aumento da concentração do sacarídeo e do líquido iônico, e diminuíram com o aumento da temperatura. Os volumes molares aparentes e os volumes molares aparentes à diluição infinita aumentaram com o aumento da temperatura e da molalidade do sacarídeo seguindo a ordem: Sacarose $>\mathrm{D}(+)$ glicose $>\mathrm{D}(+)$-xilose. $\mathrm{O}$ comportamento do volume molar de transferência dos sacarídeos da água para as soluções iônicas foram discutidos em termos de interações hidrofílicas, hidrofóbicas e iônicas.

Palavras-chave: Densidade. Propriedades volumétricas. Sacarídeos. Líquido iônico. 


\begin{abstract}
The present study presents new experimental data for density of aqueous solutions of ionic liquids containing saccharides at different temperatures, compositions, and at ambient pressure. The saccharides studied were $\mathrm{D}(+)$-xylose, $\mathrm{D}(+)$-glucose and sucrose, and their concentrations in solutions ranged from 0.015 to $1.7 \mathrm{~mol} \mathrm{~kg}^{-1}$. The ionic liquid investigated was 1-ethyl-3-methylimidazolium dicyanamide [EMIM][DCA], whose concentrations in aqueous solutions were $0.025 ; 0.050 ; 0.075$ and $0.1 \mathrm{molkg}^{-1}$. The temperature range studied ranged from 283.15 to $303.15 \mathrm{~K}$. Experimental density measurements of the solutions were obtained using a mechanical oscillation densimeter manufactured by Anton Paar (Model DMA 4500). Using thermodynamic formalism, the density results were used to calculate volumetric properties, including apparent molar volume, infinite dilution molar volume and saccharide transfer volume from water to aqueous solutions. The density values of the solutions increased with increasing concentration of saccharide and ionic liquid, and decreased with increasing temperature. Apparent molar volumes and apparent molar volumes at infinite dilution increased with increasing temperature and molarity of the saccharide as follows: Sucrose $>\mathrm{D}(+)$-glucose $>\mathrm{D}(+)$-xylose. The behavior of molar volume transfer of saccharides from water to ionic solutions was discussed in terms of hydrophilic, hydrophobic and ionic interactions.
\end{abstract}

Keywords: Density. Volumetric Properties. Saccharides. Ionic Liquid. 


\section{LISTA DE ILUSTRAÇÕES}

Figura 1 - Fluxograma de desenvolvimento da Dissertação .................................................. 22

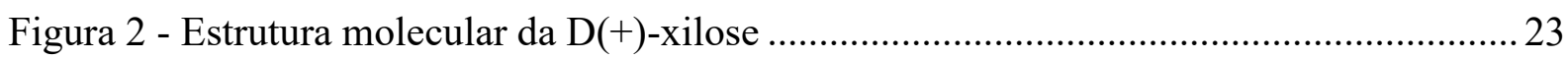

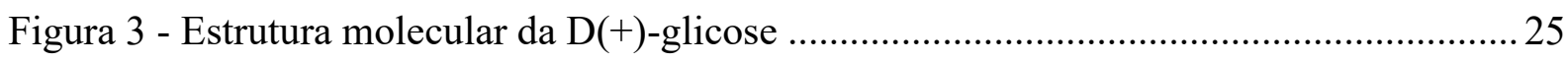

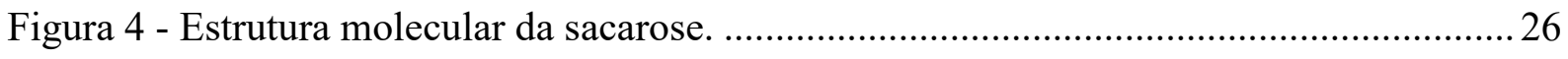

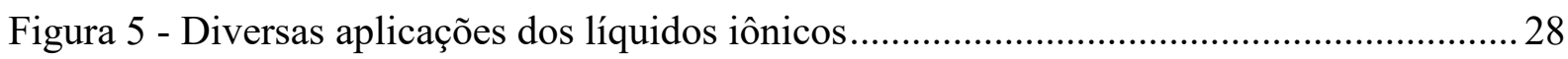

Figura 6 - Estrutura molecular do Dicianamida de 1-etil-3-metilimidazólio ...........................29

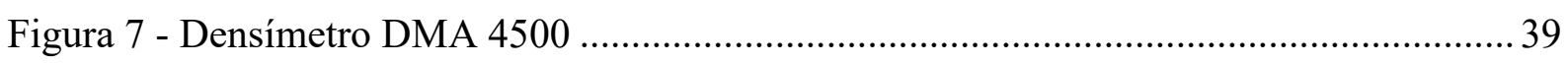

Figura 8 - Ilustração indicando entrada e saída de amostra no densímetro DMA 4500.......... 39

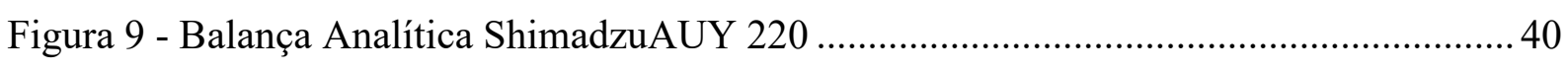

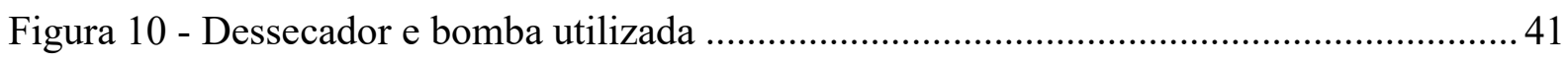

Figura 11 - Gloverbox utilizada para manuseio do líquido iônico ........................................ 41

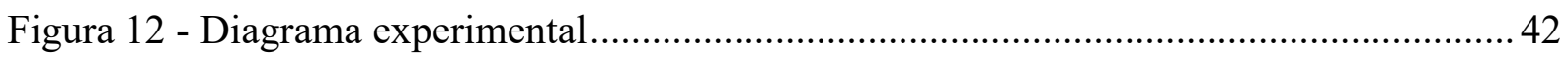

Figura 13 - Densidade das soluções de glicose em água pura, em função da molalidade da glicose, a diferentes temperaturas: $\square 283,15 \mathrm{~K}$; $\bigcirc 288,15 \mathrm{~K} ; \diamond 293,15 \mathrm{~K} ; \triangle 298,15 \mathrm{~K}$; $\times$ 303,15 K. As linhas representam as tendências dos resultados obtidos experimentalmente ... 43 Figura 14 - Densidade das soluções de glicose com concentração iônica de $0,025 \mathrm{~mol} \cdot \mathrm{kg}^{-1}$, em função da molalidade da glicose, a diferentes temperaturas e pressão atmosférica: $\square 283,15 \mathrm{~K}$; 288,15 K; $\diamond 293,15 \mathrm{~K} ; \triangle 298,15 \mathrm{~K} ; \times 303,15 \mathrm{~K}$. As linhas representam as tendências dos resultados obtidos experimentalmente.

Figura 15 - Densidade das soluções de glicose com concentração iônica de $0,050 \mathrm{~mol} \cdot \mathrm{kg}^{-1}$, em função da molalidade da glicose, a diferentes temperaturas e pressão atmosférica: $\square 283,15 \mathrm{~K}$; $\bigcirc 288,15 \mathrm{~K} ; \diamond 293,15 \mathrm{~K} ; \triangle 298,15 \mathrm{~K} ; \times 303,15 \mathrm{~K}$. As linhas representam as tendências dos resultados obtidos experimentalmente.

Figura 16 - Densidade das soluções de glicose com concentração iônica de $0,075 \mathrm{~mol} \cdot \mathrm{kg}^{-1}$, em função da molalidade da glicose, a diferentes temperaturas e pressão atmosférica: $\square 283,15 \mathrm{~K}$; $\bigcirc 288,15 \mathrm{~K} ; \diamond 293,15 \mathrm{~K} ; \triangle 298,15 \mathrm{~K} ; \times 303,15 \mathrm{~K}$. As linhas representam as tendências dos resultados obtidos experimentalmente.

Figura 17 - Densidade das soluções de glicose com concentração iônica de $0,10 \mathrm{~mol} \cdot \mathrm{kg}^{-1}$, em função da molalidade da glicose, a diferentes temperaturas e pressão atmosférica: $\square 283,15 \mathrm{~K}$; $\bigcirc 288,15 \mathrm{~K} ; \diamond 293,15 \mathrm{~K} ; \triangle 298,15 \mathrm{~K} ; \times 303,15 \mathrm{~K}$. As linhas representam as tendências dos resultados obtidos experimentalmente. 
Figura 18 - Densidade das soluções de xilose em água pura, em função da molalidade da xilose, a diferentes temperaturas: $\square 283,15 \mathrm{~K}$; $\bigcirc 288,15 \mathrm{~K}$; $\diamond 293,15 \mathrm{~K} ; \triangle 298,15 \mathrm{~K} ; \times 303,15 \mathrm{~K}$. As linhas representam as tendências dos resultados obtidos experimentalmente ..... 46 Figura 19 - Densidade das soluções de xilose com concentração iônica de $0,025 \mathrm{~mol} \cdot \mathrm{kg}^{-1}$, em função da molalidade da xilose, a diferentes temperaturas e pressão atmosférica: $\square 283,15 \mathrm{~K}$; 288,15 K; $\diamond 293,15 \mathrm{~K} ; \triangle 298,15 \mathrm{~K} ; \times 303,15 \mathrm{~K}$. As linhas representam as tendências dos resultados obtidos experimentalmente.

Figura 20 - Densidade das soluções de xilose com concentração iônica de $0,050 \mathrm{~mol} \cdot \mathrm{kg}^{-1}$, em função da molalidade da xilose, a diferentes temperaturas e pressão atmosférica: $\square 283,15 \mathrm{~K}$; $\bigcirc 288,15 \mathrm{~K} ; \diamond 293,15 \mathrm{~K} ; \triangle 298,15 \mathrm{~K} ; \times 303,15 \mathrm{~K}$. As linhas representam as tendências dos resultados obtidos experimentalmente.

Figura 21 - Densidade das soluções de xilose com concentração iônica de $0,075 \mathrm{~mol} \cdot \mathrm{kg}^{-1}$, em função da molalidade da xilose, a diferentes temperaturas e pressão atmosférica: $\square 283,15 \mathrm{~K}$; 288,15 K; $\diamond 293,15 \mathrm{~K} ; \triangle 298,15 \mathrm{~K} ; \times 303,15 \mathrm{~K}$. As linhas representam as tendências dos resultados obtidos experimentalmente.

Figura 22 - Densidade das soluções de xilose com concentração iônica de $0,10 \mathrm{~mol} \cdot \mathrm{kg}^{1}$, em função da molalidade da xilose, a diferentes temperaturas e pressão atmosférica: $\square 283,15 \mathrm{~K}$; $\bigcirc 288,15 \mathrm{~K} ; \diamond 293,15 \mathrm{~K} ; \triangle 298,15 \mathrm{~K} ; \times 303,15 \mathrm{~K}$. As linhas representam as tendências dos resultados obtidos experimentalmente. 48

Figura 23 - Densidade das soluções de sacarose em água pura, em função da molalidade da sacarose, a diferentes temperaturas: $\square 283,15 \mathrm{~K} ; \bigcirc 288,15 \mathrm{~K} ; \diamond 293,15 \mathrm{~K} ; \triangle 298,15 \mathrm{~K}$; × 303,15 K. As linhas representam as tendências dos resultados obtidos experimentalmente ... 49 Figura 24 - Densidade das soluções de sacarose com concentração iônica de $0,025 \mathrm{~mol} \cdot \mathrm{kg}^{1}$, em função da molalidade da sacarose, a diferentes temperaturas e pressão atmosférica: $\square 283,15$ $\mathrm{K} ; \bigcirc 288,15 \mathrm{~K} ; \diamond 293,15 \mathrm{~K} ; \triangle 298,15 \mathrm{~K} ; \times 303,15 \mathrm{~K}$. As linhas representam as tendências dos resultados obtidos experimentalmente 50

Figura 25 - Densidade das soluções de sacarose com concentração iônica de $0,050 \mathrm{~mol} \cdot \mathrm{kg}^{-1}$, em função da molalidade da sacarose, a diferentes temperaturas e pressão atmosférica: $\square 283,15$ $\mathrm{K} ; \bigcirc 288,15 \mathrm{~K} ; \diamond 293,15 \mathrm{~K} ; \triangle 298,15 \mathrm{~K} ; \times 303,15 \mathrm{~K}$. As linhas representam astendências dos resultados obtidos experimentalmente.

Figura 26 - Densidade das soluções de sacarose com concentração iônica de $0,075 \mathrm{~mol} \cdot \mathrm{kg}^{1}$, em função da molalidade da sacarose, a diferentes temperaturas e pressão atmosférica: $\square 283,15$ $\mathrm{K} ; \bigcirc 288,15 \mathrm{~K} ; \diamond 293,15 \mathrm{~K} ; \triangle 298,15 \mathrm{~K} ; \times 303,15 \mathrm{~K}$. As linhas representam as tendências dos resultados obtidos experimentalmente 
Figura 27 - Densidade das soluções de sacarose com concentração iônica de $0,10 \mathrm{~mol} \cdot \mathrm{kg}^{1}$, em função da molalidade da sacarose, a diferentes temperaturas e pressão atmosférica $\square 283,15 \mathrm{~K}$; 288,15 K; $\diamond 293,15 \mathrm{~K} ; \triangle 298,15 \mathrm{~K} ; \times 303,15 \mathrm{~K}$. As linhas representam as tendências dos resultados obtidos experimentalmente.

Figura 28 - Volume molar aparente da glicose em água pura, em função da molalidade da glicose, a diferentes temperaturas e pressão atmosférica: $\square 283,15 \mathrm{~K} ; \bigcirc 288,15 \mathrm{~K}$; $\diamond 293,15$ K; $\triangle 298,15 \mathrm{~K} ; \times 303,15 \mathrm{~K}$. As linhas representam as tendências dos resultados obtidos experimentalmente. 52

Figura 29 - Volume molar aparente da glicose em solução iônica de $0,025 \mathrm{~mol} \cdot \mathrm{kg}^{-1}$, em função da molalidade da glicose, a diferentes temperaturas e pressão atmosférica: $\square 283,15 \mathrm{~K}$; 288,15 K; $\diamond 293,15 \mathrm{~K} ; \triangle 298,15 \mathrm{~K} ; \times 303,15 \mathrm{~K}$. As linhas representam as tendências dos resultados obtidos experimentalmente. 53

Figura 30 - Volume molar aparente da glicose em solução iônica de $0,050 \mathrm{~mol} \cdot \mathrm{kg}^{-1}$, em função da molalidade da glicose, a diferentes temperaturas e pressão atmosférica: $\square 283,15 \mathrm{~K}$; $\bigcirc$ 288,15 K; $\diamond 293,15 \mathrm{~K} ; \triangle 298,15 \mathrm{~K} ; \times 303,15 \mathrm{~K}$. As linhas representam as tendências dos resultados obtidos experimentalmente.

Figura 31 - Volume molar aparente da glicose em solução iônica de $0,075 \mathrm{~mol} \cdot \mathrm{kg}^{-1}$, em função da molalidade da glicose, a diferentes temperaturas e pressão atmosférica: $\square 283,15 \mathrm{~K}$; 288,15 K; $\diamond 293,15 \mathrm{~K} ; \triangle 298,15 \mathrm{~K} ; \times 303,15 \mathrm{~K}$. As linhas representam as tendências dos resultados obtidos experimentalmente.

Figura 32 - Volume molar aparente da glicose em solução iônica de $0,10 \mathrm{~mol} \cdot \mathrm{kg}^{-1}$, em função da molalidade da glicose, a diferentes temperaturas e pressão atmosférica: $\square 283,15 \mathrm{~K}$; 288,15 K; $\diamond 293,15 \mathrm{~K} ; \triangle 298,15 \mathrm{~K} ; \times 303,15 \mathrm{~K}$. As linhas representam as tendências dos resultados obtidosexperimentalmente......

Figura 33 - Volume molar aparente da xilose em água pura, em função da molalidade da xilose, a diferentes temperaturas e pressão atmosférica: $\square 283,15 \mathrm{~K}$; $\bigcirc 288,15 \mathrm{~K}$; $\diamond 293,15 \mathrm{~K}$; $\triangle$ $298,15 \mathrm{~K} ; \times 303,15 \mathrm{~K}$. As linhas representam as tendências dos resultados obtidos experimentalmente.

Figura 34 - Volume molar aparente da xilose em solução iônica de $0,025 \mathrm{~mol} \cdot \mathrm{kg}^{-1}$, em função da molalidade da xilose, a diferentes temperaturas e pressão atmosférica: $\square 283,15 \mathrm{~K}$; 288,15 K; $\diamond 293,15 \mathrm{~K} ; \triangle 298,15 \mathrm{~K} ; \times 303,15 \mathrm{~K}$. As linhas representam as tendências dos resultados obtidos experimentalmente. 56

Figura 35 - Volume molar aparente da xilose em solução iônica de $0,050 \mathrm{~mol} \cdot \mathrm{kg}^{-1}$, em função da molalidade da xilose, a diferentes temperaturas e pressão atmosférica: $\square 283,15 \mathrm{~K}$; 
288,15 K; $\diamond 293,15 \mathrm{~K} ; \triangle 298,15 \mathrm{~K} ; \times 303,15 \mathrm{~K}$. As linhas representam as tendências dos resultados obtidos experimentalmente.

Figura 36 - Volume molar aparente da xilose em solução iônica de $0,075 \mathrm{~mol} \cdot \mathrm{kg}^{-1}$, em função da molalidade da xilose, a diferentes temperaturas e pressão atmosférica: $\square 283,15 \mathrm{~K}$; 288,15 K; $\diamond 293,15 \mathrm{~K} ; \triangle 298,15 \mathrm{~K} ; \times 303,15 \mathrm{~K}$. As linhas representam as tendências dos resultados obtidos experimentalmente. 57

Figura 37 - Volume molar aparente da xilose em solução iônica de $0,10 \mathrm{~mol} \cdot \mathrm{kg}^{-1}$, em função da molalidade da xilose, a diferentes temperaturas e pressão atmosférica: $\square 283,15 \mathrm{~K}$; $\bigcirc 288,15$ $\mathrm{K} ; \diamond 293,15 \mathrm{~K} ; \triangle 298,15 \mathrm{~K} ; \times 303,15 \mathrm{~K}$. As linhas representam as tendências dos resultados obtidos experimentalmente. 57

Figura 38 - Volume molar aparente da sacarose em água pura, em função da molalidade da sacarose, a diferentes temperaturas e pressão atmosférica: $\square 283,15 \mathrm{~K} ; \bigcirc 288,15 \mathrm{~K} ; \diamond 293,15$ $\mathrm{K} ; \triangle 298,15 \mathrm{~K} ; \times 303,15 \mathrm{~K}$. As linhas representam as tendências dos resultados obtidos experimentalmente. 58

Figura 39 - Volume molar aparente da sacarose em solução iônica de $0,025 \mathrm{~mol} \cdot \mathrm{kg}^{-1}$, em função da molalidade da sacarose, a diferentes temperaturas e pressão atmosférica: $\square 283,15 \mathrm{~K}$; 288,15 K; $\diamond 293,15 \mathrm{~K} ; \triangle 298,15 \mathrm{~K} ; \times 303,15 \mathrm{~K}$. As linhas representam as tendências dos resultados obtidos experimentalmente.

Figura 40 - Volume molar aparente da sacarose em solução iônica de $0,050 \mathrm{~mol} \cdot \mathrm{kg}^{-1}$, em função da molalidade da sacarose, a diferentes temperaturas e pressão atmosférica: $\square 283,15 \mathrm{~K}$; $288,15 \mathrm{~K} ; \diamond 293,15 \mathrm{~K} ; \triangle 298,15 \mathrm{~K} ; \times 303,15 \mathrm{~K}$. As linhas representam as tendências dos resultados obtidos experimentalmente.

Figura 41 - Volume molar aparente da sacarose em solução iônica de $0,075 \mathrm{~mol} \cdot \mathrm{kg}^{-1}$, em função da molalidade da sacarose, a diferentes temperaturas e pressão atmosférica: $\square 283,15 \mathrm{~K}$; 288,15 K; $\diamond 293,15 \mathrm{~K} ; \triangle 298,15 \mathrm{~K} ; \times 303,15 \mathrm{~K}$. As linhas representam as tendências dos resultados obtidos experimentalmente. 60

Figura 42 - Volume molar aparente da sacarose em solução iônica de $0,10 \mathrm{~mol} \cdot \mathrm{kg}^{-1}$, em função da molalidade da sacarose, a diferentes temperaturas e pressão atmosférica: $\square 283,15 \mathrm{~K}$; 288,15 K; $\diamond 293,15 \mathrm{~K} ; \triangle 298,15 \mathrm{~K} ; \times 303,15 \mathrm{~K}$.. As linhas representam as tendências dos resultados obtidos experimentalmente.

Figura 43 - Volume molar aparente da glicose em água pura, em função da raiz quadrada da molalidade da glicose, a diferentes temperaturas e pressão atmosférica: $\square$ 283,15 K; $\bigcirc 288,15$ $\mathrm{K} ; \diamond 293,15 \mathrm{~K} ; \triangle 298,15 \mathrm{~K} ; \times 303,15 \mathrm{~K}$. As linhas representam a correlação usando a equação (20) 
Figura 44 - Volume molar aparente da glicose em solução iônica de $0,025 \mathrm{~mol} \cdot \mathrm{kg}^{-1}$, em função da raiz quadrada da molalidade da glicose, a diferentes temperaturas e pressão atmosférica: 283,15 K; $\bigcirc 288,15 \mathrm{~K} ; \diamond 293,15 \mathrm{~K} ; \triangle 298,15 \mathrm{~K} ; \times 303,15 \mathrm{~K}$. As linhas representam a correlação usando a equação (20).

Figura 45 - Volume molar aparente da glicose em solução iônica de $0,050 \mathrm{~mol} \cdot \mathrm{kg}^{-1}$, em função da raiz quadrada da molalidade da glicose, a diferentes temperaturas e pressão atmosférica: 283,15 K; $\bigcirc 288,15 \mathrm{~K} ; \diamond 293,15 \mathrm{~K} ; \triangle 298,15 \mathrm{~K} ; \times 303,15 \mathrm{~K}$. As linhas representama correlação usando a equação (20). 63

Figura 46 - Volume molar aparente da glicose em solução iônica de $0,075 \mathrm{~mol} \cdot \mathrm{kg}^{-1}$, em função da raiz quadrada da molalidade da glicose, a diferentes temperaturas e pressão atmosférica: $283,15 \mathrm{~K} ; \bigcirc 288,15 \mathrm{~K} ; \diamond 293,15 \mathrm{~K} ; \triangle 298,15 \mathrm{~K} ; \times 303,15 \mathrm{~K}$. As linhas representam a correlação usando a equação (20). 64

Figura 47 - Volume molar aparente da glicose em solução iônica de $0,10 \mathrm{~mol} \cdot \mathrm{kg}^{-1}$, em função da raiz quadrada da molalidade da glicose, a diferentes temperaturas e pressão atmosférica: 283,15 K; $\bigcirc 288,15 \mathrm{~K} ; \diamond 293,15 \mathrm{~K} ; \triangle 298,15 \mathrm{~K} ; \times 303,15 \mathrm{~K}$. As linhas representam a correlação usando a equação (20). 


\section{LISTA DE TABELAS}

Tabela 1 - Interações do modelo "Cosphere Overlap"

Tabela 2 - Equações de ajuste usando a equação (20) para as soluções de glicose em água pura, a diferentes temperaturas....

Tabela 3 - Volumes molares aparentes à diluição infinita da glicose em água pura, a diferentes temperaturas.

Tabela 4 - Equações de ajuste usando a equação (20) para as soluções de glicose em solução iônica de $0,025 \mathrm{~mol} \cdot \mathrm{kg}^{-1}$, a diferentes temperaturas

Tabela 5 - Equações de ajuste usando a equação (20) para as soluções de glicose em solução iônica de $0,050 \mathrm{~mol} \cdot \mathrm{kg}^{-1}$, a diferentes temperaturas

Tabela 6 - Equações de ajuste usando a equação (20) para as soluções de glicose em solução iônica de $0,075 \mathrm{~mol} \cdot \mathrm{kg}^{-1}$, a diferentes temperaturas

Tabela 7 - Equações de ajuste usando a equação (20) para as soluções de glicose em solução iônica de $0,10 \mathrm{~mol} \cdot \mathrm{kg}^{-1}$, a diferentes temperaturas

Tabela 8 - Volumes molares aparentes à diluição infinita da glicose em solução iônica de 0,025 $\mathrm{mol} \cdot \mathrm{kg}^{-1}$, a diferentes temperaturas.

Tabela 9 - Volumes molares aparentes à diluição infinita da glicose em solução iônica de 0,050 $\mathrm{mol} \cdot \mathrm{kg}^{-1}$, a diferentes temperaturas.

Tabela 10 - Volumes molares aparentes à diluição infinita da glicose em solução iônica de 0,075 $\mathrm{mol} \cdot \mathrm{kg}^{-1}$, a diferentes temperaturas.

Tabela 11 - Volumes molares aparentes à diluição infinita da glicose em solução iônica de 0,10 $\mathrm{mol} \cdot \mathrm{kg}^{-1}$, a diferentes temperaturas.

Tabela 12 - Volumes de transferência da glicose da água para solução iônica de $0,025 \mathrm{~mol} \cdot \mathrm{kg}^{-1}$ a diferentes temperaturas.

Tabela 13 - Volumes de transferência da glicose da água para solução iônica de $0,050 \mathrm{~mol} \cdot \mathrm{kg}^{-1}$ a diferentes temperaturas.

Tabela 14 - Volumes de transferência da glicose da água para solução iônica de 0,075 mol.kg-

1 , a diferentes temperaturas.

Tabela 15 - Volumes de transferência da glicose da água para solução iônica de $0,10 \mathrm{~mol} \cdot \mathrm{kg}^{-1}$, a diferentes temperaturas.

Tabela 16 - Equações de ajuste usando a equação (20) para as soluções de xilose em água pura, a diferentes temperaturas. 
Tabela 17 - Volumes molares aparentes à diluição infinita da xilose em água pura, a diferentes temperaturas.

Tabela 18 - Equações de ajuste usando a equação (20) para as soluções de xilose em solução iônica de $0,025 \mathrm{~mol} \cdot \mathrm{kg}^{-1}$, a diferentes temperaturas

Tabela 19 - Equações de ajuste usando a equação (20) para as soluções de xilose em solução iônica de $0,050 \mathrm{~mol} \cdot \mathrm{kg}^{-1}$, a diferentes temperaturas.

Tabela 20 - Equações de ajuste usando a equação (20) para as soluções de xilose em solução iônica de $0,075 \mathrm{~mol} \cdot \mathrm{kg}^{-1}$, a diferentes temperaturas

Tabela 21 - Equações de ajuste usando a equação (20) para as soluções de xilose em solução iônica de $0,10 \mathrm{~mol} \cdot \mathrm{kg}^{-1}$, a diferentes temperaturas

Tabela 22 - Volumes molares aparentes à diluição infinita da xilose em solução iônica de 0,025 $\mathrm{mol} \cdot \mathrm{kg}^{-1}$, a diferentes temperaturas.

Tabela 23 - Volumes molares aparentes à diluição infinita da xilose em solução iônica de 0,050 $\mathrm{mol} \cdot \mathrm{kg}^{-1}$, a diferentes temperaturas.

Tabela 24 - Volumes molares aparentes à diluição infinita da xilose em solução iônica de 0,075 $\mathrm{mol} \cdot \mathrm{kg}^{-1}$, a diferentes temperaturas.

Tabela 25 - Volumes molares aparentes à diluição infinita da xilose em solução iônica de 0,10 $\mathrm{mol} \cdot \mathrm{kg}^{-1}$, a diferentes temperaturas.

Tabela 26 - Volumes de transferência da xilose da água para solução iônica de $0,025 \mathrm{~mol} \cdot \mathrm{kg}^{-1}$, a diferentes temperaturas.

Tabela 27 - Volumes de transferência da xilose da água para solução iônica de 0,050 mol. $\mathrm{kg}^{-1}$, a diferentes temperaturas.

Tabela 28 - Volumes de transferência da xilose da água para solução iônica de $0,075 \mathrm{~mol} \cdot \mathrm{kg}^{-1}$, a diferentes temperaturas.

Tabela 29 - Volumes de transferência da xilose da água para solução iônica de $0,10 \mathrm{~mol} \cdot \mathrm{kg}^{-1}$, a diferentes temperaturas.

Tabela 30 - Equações de ajuste usando a equação (20) para as soluções de sacarose em água pura, a diferentes temperaturas.....

Tabela 31 - Volumes molares aparentes à diluição infinita da sacarose em água pura, a diferentes temperaturas

Tabela 32 - Equações de ajuste usando a equação (20) para as soluções de sacarose em solução iônica de $0,025 \mathrm{~mol} \cdot \mathrm{kg}^{-1}$, a diferentes temperaturas

Tabela 33 - Equações de ajuste usando a equação (20) para as soluções de sacarose em solução iônica de $0,050 \mathrm{~mol} \cdot \mathrm{kg}^{-1}$, a diferentes temperaturas 
Tabela 34 - Equações de ajuste usando a equação (20) para as soluções de sacarose em solução iônica de $0,075 \mathrm{~mol} \cdot \mathrm{kg}^{-1}$, a diferentes temperaturas

Tabela 35 - Equações de ajuste usando a equação (20) para as soluções de sacarose em solução iônica de $0,10 \mathrm{~mol} \cdot \mathrm{kg}^{-1}$, a diferentes temperaturas

Tabela 36 - Volumes molares aparentes à diluição infinita da sacarose em solução iônica de $0,025 \mathrm{~mol} \cdot \mathrm{kg}^{-1}$, a diferentes temperaturas 85

Tabela 37 - Volumes molares aparentes à diluição infinita da sacarose em solução iônica de $0,050 \mathrm{~mol} \cdot \mathrm{kg}^{-1}$, a diferentes temperaturas

Tabela 38 - Volumes molares aparentes à diluição infinita da sacarose em solução iônica de $0,075 \mathrm{~mol} \cdot \mathrm{kg}^{-1}$, a diferentes temperaturas

Tabela 39 - Volumes molares aparentes à diluição infinita da sacarose em solução iônica de $0,10 \mathrm{~mol} \cdot \mathrm{kg}^{-1}$, a diferentes temperaturas.

Tabela 40 - Volumes de transferência da sacarose da água para solução iônica de 0,025 $\mathrm{mol} \cdot \mathrm{kg}^{-1}$, a diferentes temperaturas.

Tabela 41 - Volumes de transferência da sacarose da água para solução iônica de 0,050 $\mathrm{mol} \cdot \mathrm{kg}^{-1}$, a diferentes temperaturas.

Tabela 42 - Volumes de transferência da sacarose da água para solução iônica de 0,075 $\mathrm{mol} \cdot \mathrm{kg}^{-1}$, a diferentes temperaturas.

Tabela 43 - Volumes de transferência da sacarose da água para solução iônica de 0,10 $\mathrm{mol} \cdot \mathrm{kg}^{-1}$, a diferentes temperaturas. 87

Tabela 44 - Valores do volume de transferência da $\mathrm{D}(+)$-glicose da água para solução iônica

Tabela 45 - Valores do volume de transferência da $\mathrm{D}(+)$-xilose da água para solução iônica 88 Tabela 46-Valores do volume de transferência da sacarose da água para solução. 


\section{SUMÁRIO}

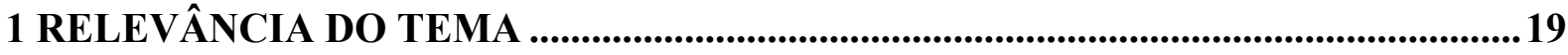

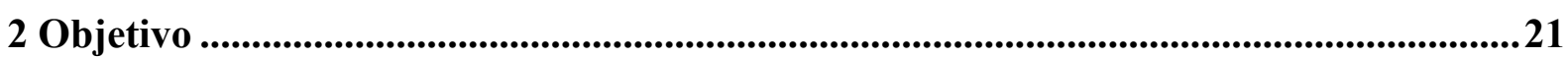

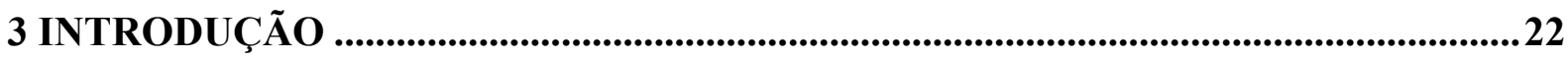

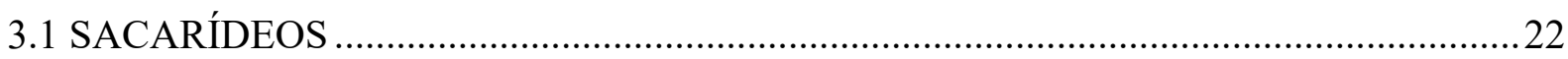

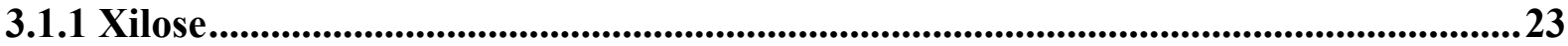

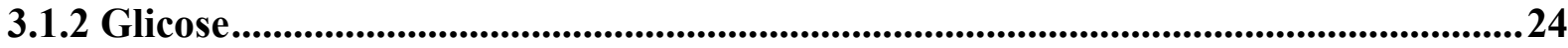

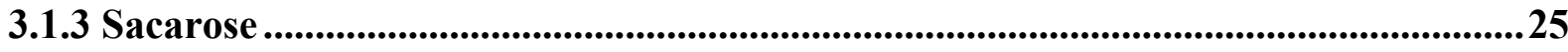

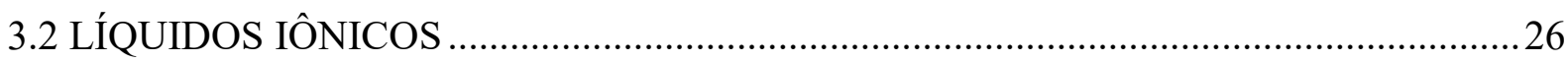

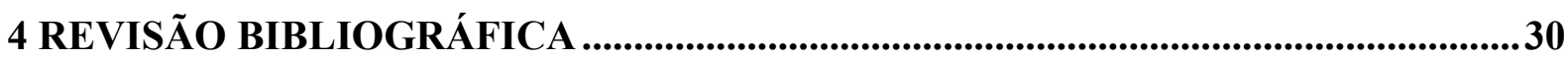

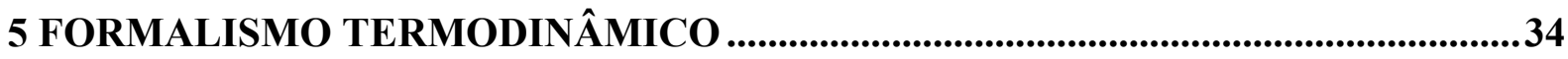

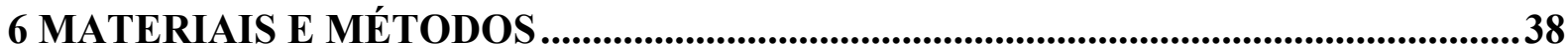

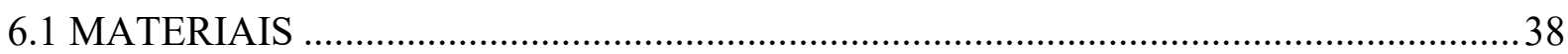

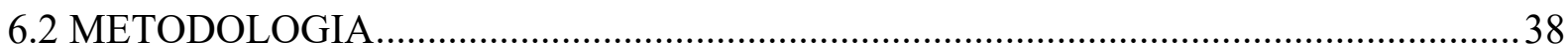

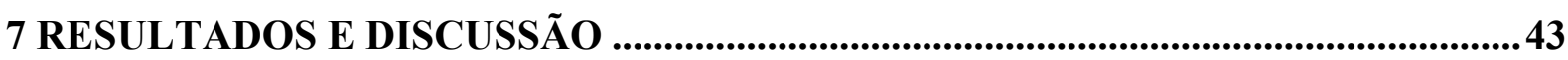

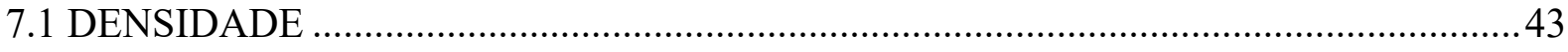

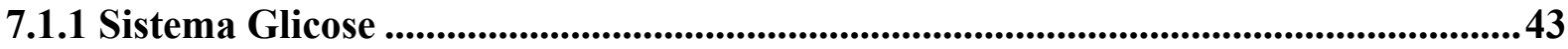

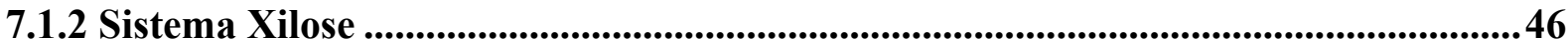

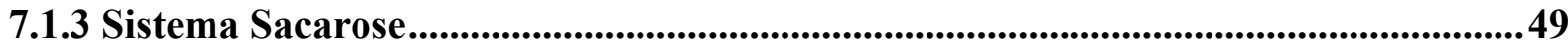

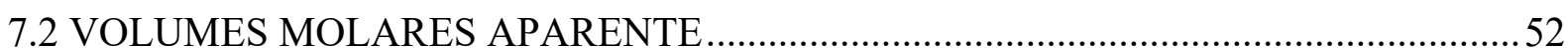

7.2.1 Sistema Glicose ...................................................................................................................52

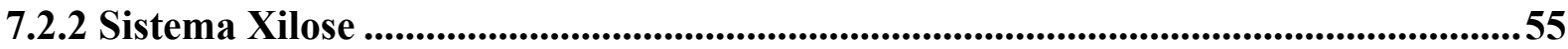

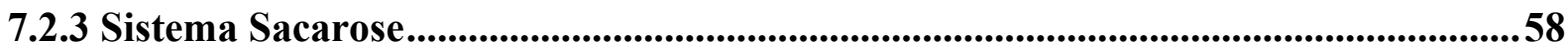

7.3 VOLUME MOLAR APARENTE À DILUIÇÃO INFINITA .........................................61

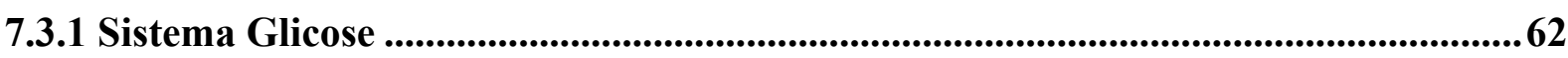

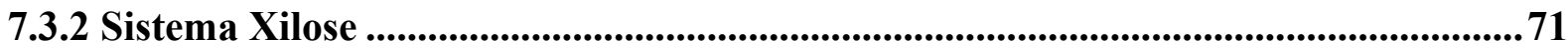

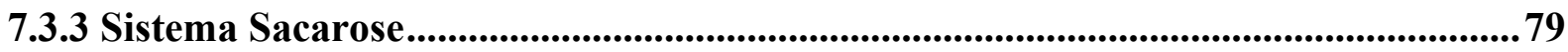

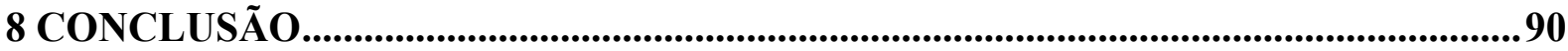

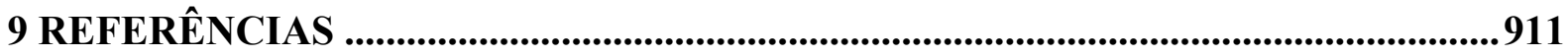

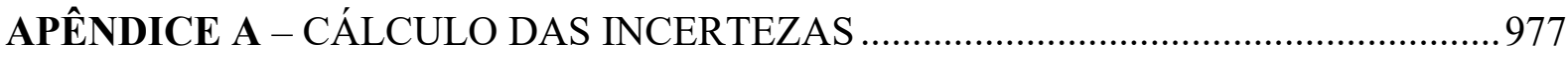


APÊNDICE B - TABELA - DENSIDADES ÁGUA E SOLUÇÕES IÔNICAS PURAS. 1000 APÊNDICE C - TABELA - SISTEMA XILOSE ……………………………………....1033

APÊNDICE D - TABELA - SISTEMA GLICOSE......................................................1133

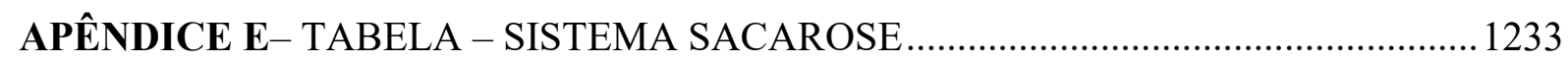




\section{RELEVÂNCIA DO TEMA}

O conhecimento de propriedades substâncias químicas e seu comportamento em soluções podem auxiliar a desenvolver processos mais seguros e menos nocivos ao meio ambiente. Um ponto de partida para alcançar esse objetivo pode ser a substituição de solventes moleculares convencionais por solventes considerados "solventes verdes". Os líquidos iônicos representam uma categoria de solventes que se enquadram nesse grupo de solventes.

Os líquidos iônicos à temperatura ambiente têm despertado o interesse da comunidade científica e industrial devido às suas propriedades únicas. Merecem destaques a alta estabilidade química e térmica, alta condutividade elétrica, pressão de vapor desprezível e boa solubilidade em compostos orgânicos, tanto em espécies polares como apolares (MARSH; BOXALL;LICHTENTHALER, 2004; PLECHKOVA; SEDDON, 2008). Esses compostos têm sido utilizados em uma grande variedade de aplicações tais como catálises, sínteses orgânicas, extração, processos eletroquímicos e processos de separação (VERMA et al, 2019; SMIRNOVA; SAFONOVA, 2010; PLECHKOVA; SEDDON, 2008; ZHAO; XIA; MA, 2005; BUZZEO et al, 2004; WASSERSCHEID; KEIM, 2000; WASSERSCHEID; WELTON, 2003). Em virtude da sua estabilidade ao ar e à umidade, os líquidos iônicos à base de imidazólio são os mais estudados e, portanto, os que mais têm encontrados aplicações.

Os sacarídeos possuem importante função energética celular e apresentam grandes aplicações na produção de produtos químicos, fármacos, alimentos, combustíveis, no processo de fermentação, entre outras. Um exemplo específico é o uso da xilose como matéria-prima para a produção do xilitol, um adoçante conhecido na indústria de alimentos. Outro exemplo é o uso da glicose para produção de sacarose, também utilizado como adoçante na indústria de alimentos. Grande parte do uso de carboidratos na indústria é feito na forma de solução aquosa, devido ao grande caráter hidrofílico das moléculas dessas espécies químicas (DHONDGE et al., 2017).

O estudo de propriedades volumétricas de sistemas contendo carboidratos é importante para tentar elucidar fenômenos estruturais, físicos e químicos entre as espécies presentes nos sistemas estudados. As propriedades termodinâmicas de sacarídeos em sistemas aquosos contendo líquidos iônicos podem proporcionar informações valiosas a respeito de interações soluto-soluto e soluto-solvente, e como essas interações podem influenciar propriedades estruturais em muitos processos químicos (TOME, et al, 2012; OHNO; FUKUMOTO, 2007; SORENSON, et al, 1999). Isto é, é possível compreender mudanças estruturais no volume do 
solvente e do soluto, assim como, tentar obter informações sobre a natureza das interações entre o soluto e o solvente. Estas propriedades desempenham um papel fundamental no estudo das condições de reação, tais como a viabilidade e otimização de processos industriais empregados. Portanto, o conhecimento de propriedades termodinâmicas de sistemas contendo biomoléculas e líquidos iônicos são de grande importância no desenvolvimento e aperfeiçoamento de processos biotecnológicos e industriais. 


\section{OBJETIVO}

O presente estudo teve como objetivo entender possível efeitos estruturais, físicos e químicos em sistemas líquidos aquosos contendo sacarídeos e líquidos iônicos por meio de um estudo termodinâmico.

Para alcançar tal objetivo, foram determinados dados experimentais originais de densidade de soluções aquosas de líquido iônico contendo sacarídeos a diferentes temperaturas, composições, e à pressão ambiente. Os sacarídeos estudados foram a $\mathrm{D}(+)$-xilose, $\mathrm{D}(+)$-glicose e a sacarose, e suas concentrações nas soluções variaram entre 0,015 e 1,7 $\mathrm{mol} \mathrm{kg}^{-1}$. O líquido iônico investigado foi o dicianamida de 1-etil-3-metilimidazólio [EMIM][DCA], cujas concentrações nas soluções aquosas foram de 0,$025 ; 0,050 ; 0,075$ e $0,1 \mathrm{~mol} \mathrm{~kg}^{-1}$. A faixa de temperatura estudada variou entre 283,15 e 303,15 K. Fazendo uso do formalismo termodinâmico, os resultados de densidade foram usados para calcular propriedades volumétricas, dentre elas, o volume molar aparente, o volume molar à diluição infinita e o volume de transferência dos sacarídeos da água para as soluções aquosas. 


\section{INTRODUÇÃO}

Levando em consideração a relevância do tema apresentado no tópico anterior, a seguir é apresentada uma breve introdução aos sacarídeos e ao líquido iônico utilizados nesse trabalho. Figura 1 - Fluxograma de desenvolvimento da Dissertação.

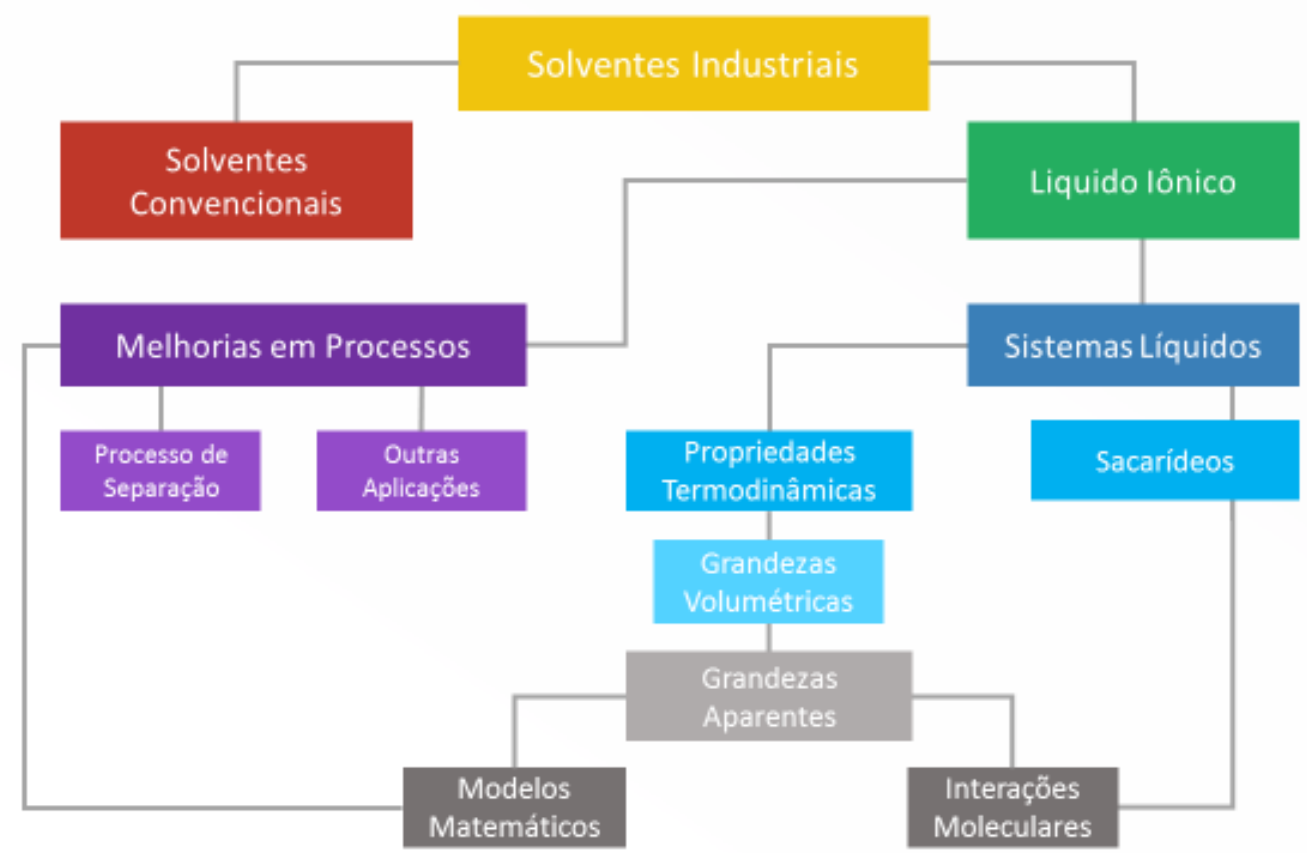

Fonte: Autor

\subsection{SACARÍDEOS}

Os sacarídeos são as biomoléculas mais abundantes na natureza, juntamente com os aminoácidos, os lipídeos e os nucleotídeos, formam a química da matéria viva na Terra. Também conhecidos como carboidratos ou açúcares, são importantes devido à sua capacidade de coordenação, homoquiralidade (desviam a luz polarizada para um mesmo lado, sendo todos dextrogiros), estéreo especificidade e baixa toxicidade. São classificados de acordo com sua complexidade, como: (1) monossacarídeos, dos quais se derivam todas as outras classes, sendo eles de dois tipos, aldoses e cetoses. São exemplos de monossacarídeos a glicose e a xilose; (2) dissacarídeos, formados pela união de dois monossacarídeos através de ligações glicosídicas, as quais se ligam através das hidroxilas presentes nas suas estruturas. Seu principal representante é a sacarose; (3) e os polissacarídeos, os quais são formados pela ligação de milhares de monossacarídeos. Os mais importantes são formados pela polimerização da glicose como o amido, glicogênio e a celulose (BANIPAL; KAUR; BANIPAL, 2015). 
O grande interesse nos estudos de sacarídeos deve-se às suas importantes funções em áreas relacionadas à biologia, medicina, catálise e meio ambiente. Sua importância em fenômenos biológicos, os quais incluem impressões digitais e engenharia de DNA e RNA, sinalização, comunicação molecular e celular, são consequência da flexibilidade conformacional das moléculas dos sacarídeos. Estes compostos são agentes estabilizantes bem conhecidos para proteínas e enzimas. Os dissacarídeos, por exemplo, protegem proteínas e camadas fosfolipídicas durante a desidratação extrema. A hidratação de sacarídeos é de extrema importância para o entendimento do papel de glicoproteínas e glicolipídios no reconhecimento molecular. Soluções sacarídeas são utilizadas em processos alimentícios como na cristalização e desidratação em processos de osmose. Outra aplicação de grande importância para os sacarídeos são sua conversão em biocombustíveis e outros biomateriais. O bioetanol pode ser produzido pela fermentação dos monossacarídeos a partir de matérias-primas enzimaticamente hidrolisadas como a cana-de-açúcar, milho, algas e outros tipos de fontes naturais (BANIPAL et al, 2010; BANIPAL; AGGARWAL; BANIPAL, 2015/2016; BI; ZHOU; ROW, 2010).

\subsubsection{Xilose}

A xilose é definida como um monossacarídeo do tipo aldopentose, isto é, possuem 5 átomos de carbono em sua composição e um grupo funcional aldeído, sua fórmula química é $\mathrm{C}_{5} \mathrm{H}_{10} \mathrm{O}_{5}$. A figura 2 apresenta a estrutura da $\mathrm{D}(+)$-xilose.

Figura 2 - Estrutura molecular da $\mathrm{D}(+)$-xilose

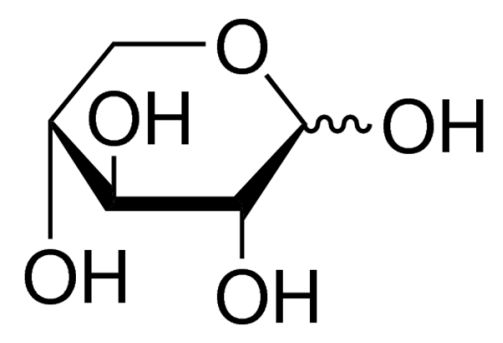

Fonte: Sigma Aldrich

A D-xilose é o segundo monossacarídeo mais abundante no material lignocelulósico. Ela é a matéria-prima do xilitol, adoçante de alto valor tanto para a indústria alimentícia quanto para a farmacêutica. Tem sido considerada uma fonte atrativa de carbono para a produção de biocombustíveis e produtos químicos através da fermentação, obtida pela hidrólise enzimática de matérias-primas naturais. Entretanto, o produto resultante contém tanto xilose como glicose, 
e devido a presença da glicose, o uso da xilose para produção de etanol não é eficiente em escala industrial, pois há uma necessidade de separação dos dois compostos. A xilose também é utilizada para a produção de furfural, o qual tem encontrado aplicação na preparação de materiais poliméricos não petrolíferos, produtos químicos de alto valor agregados e combustíveis líquidos. Estudos na literatura têm mostrado a possibilidade da obtenção do furfural a partir da xilose em presença de líquidos iônicos (BI; ZHOU; ROW, 2010; MOHAN; GOUD; BANERJEE, 2015).

\subsubsection{Glicose}

A glicose é um carboidrato classificado como monossacarídeo do tipo aldo-hexose, pois possuem em sua composição química seis carbonos e um grupo aldeído, possuindo sua forma molecular tanto cíclica como linear. Conhecida popularmente como açúcar de uva ou açúcar de milho, a glicose é um dos principais produtos da fotossíntese encontrada na forma natural em frutas e mel, também é o principal açúcar livre circulando no sangue de animais superiores, sendo fonte de energia na função celular e importante na regulação do metabolismo na síntese de moléculas mais complexas como a gordura. A glicose dá origem a outros compostos como o amido que vem da união de milhares de moléculas lineares de glicose. Quando combinada com outro monossacarídeo como a frutose, a glicose dá origem a sacarose, e faz parte da composição de outros compostos como, por exemplo, a celulose (FANG et al. 2011).

Estudos atuais envolvendo o uso da glicose na produção de químicos verdes envolvem a produção de glicose a partir da hidrólise da biomassa, conhecida como matéria-prima ideal para a produção de produtos químicos, como furânicos e ácidos orgânicos, podendo atingir seletividades elevadas e ótimo rendimento quando catalisadas por cloretos metálicos em líquido iônico. Outro estudo nesse segmento é a hidrólise da celulose em glicose, dando origem a vários biocombustíveis, produtos químicos, alimentos e medicamentos. Todavia, alguns desses procedimentos apresentam desvantagens como alto custo e dificuldade de separação (YU, WU, 2011; ZANG; FANG; 2012). 
A figura 3 apresenta a estrutura molecular da $\mathrm{D}(+)$-glicose.

Figura 3 - Estrutura molecular da $\mathrm{D}(+)$-glicose

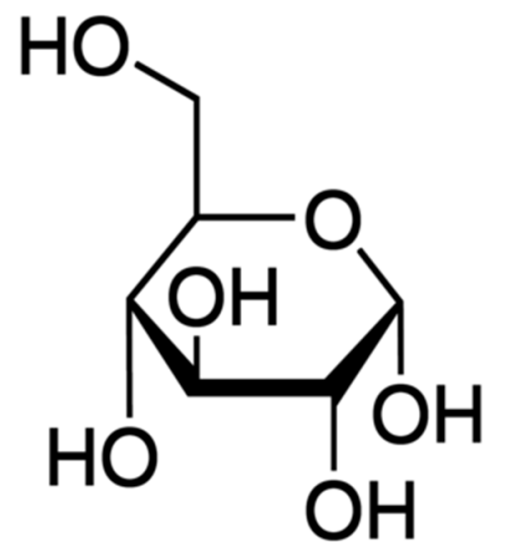

Fonte: Sigma Aldrich

\subsubsection{Sacarose}

A sacarose, cuja fórmula estrutural é $\mathrm{C}_{12} \mathrm{H}_{22} \mathrm{O}_{11}$, é um dissacarídeo formado por uma molécula de glicose e uma de frutose através de uma ligação glicosídica. Encontra-se em abundância na cana-de-açúcar, frutas e beterraba. Quando comparado à glicose, a sacarose possui menor viscosidade e menor solubilidade, e por possui sabor mais adocicada, é mais utilizada pela indústria alimentícia.

Entre as várias fontes de carbono renovável, a sacarose derivada de cana-de-açúcar ou beterraba é um dos materiais mais adequados para uso como substrato de fermentação, sendo relativamente barata e abundante, podendo representar uma fonte sustentável para a produção de produtos químicos. O maior uso da sacarose é na indústria de alimentos e bebidas, mas também é utilizado na indústria de fármacos. $\mathrm{O}$ melaço, que é um subproduto do refino do açúcar, possui altas concentrações de açúcares incluindo a sacarose, utilizados na produção de bioetanol, aminoácidos e outros bioquímicos. No Brasil é obtida pela cristalização da cana-deaçúcar com concentração de 14 a $24 \%$ de sacarose. Na Europa, ela é comumente obtida através da beterraba com concentração de 14 a 18 \% de sacarose (CRESTANI et al, 2018; ARIKAWA; MATSUMOTO; FUJUKI, 2017).

A hidrólise da sacarose por ácidos diluídos dá origem ao açúcar invertido, isto é, a mistura equimolar de D-glicose e D-frutose, possuindo orientação levógira, mais adocicado que a sacarose pura, também utilizada na fabricação de produtos. A reação é chamada de inversão 
e é monomolecular, ou seja, a fração da sacarose presente é constante. Assim, a velocidade da reação depende exclusivamente da concentração de sacarose. A inversão da sacarose pode ser efetuada também enzimaticamente.

A figura 4 apresenta a conformação da molécula de sacarose.

Figura 4 - Estrutura molecular da sacarose.

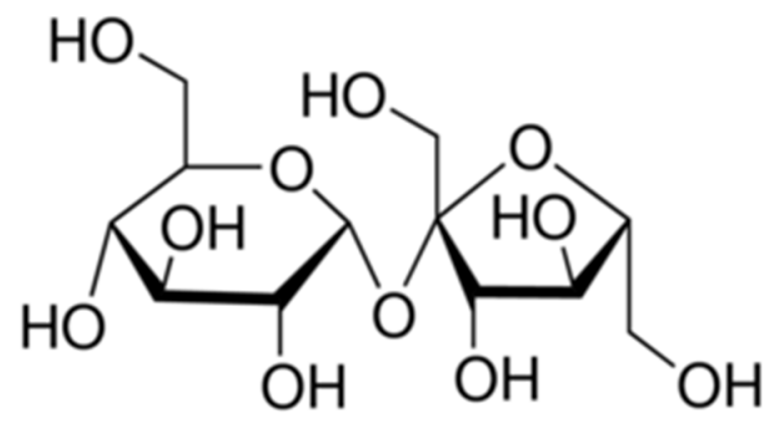

Fonte: Sigma Aldrich

\subsection{LÍQUIDOS IÔNICOS}

A literatura define líquidos iônicos (ILs) como sais cujo ponto de fusão é inferior a $100^{\circ} \mathrm{C}$. Essas espécies químicas são constituídas por um cátion orgânico (normalmente imidazólio, piridínio, pirrolidínio, tetraalquilfosfônio, amônio quaternário, entre outros) e um ânion inorgânico (como halogeneto, hexafluorofosfato, tetrafluoroborato, trifluorometanossulfonato, acetato, dicianamida, alquilsulfato). Dentre os líquidos iônicos, merecem destaque os líquidos iônicos a temperatura ambiente (Room Temperature Ionic Liquids - RTILs). As principais propriedades desses compostos são: baixo ponto de fusão, baixa volatilidade, pressão de vapor desprezível, alta estabilidade térmica, pouco inflamáveis, grande capacidade de solubilizar solventes orgânicos polares, não polares ou poliméricos, dentre outras. Talvez a característica mais relevante dos RTILs seja a capacidade de síntese, isto é, as suas propriedades podem ser estrategicamente ajustadas pela escolha do cátion ou ânion para atender uma aplicação específica (MARSH; BOXALL; LICHTENTHALER, 2004).

Devido às suas propriedades, os líquidos iônicos são considerados como "solventes verdes" e potenciais substitutos dos solventes orgânicos convencionais em sínteses químicas, processos de separação, nanotecnologia e bioindústrias. Outras aplicações encontradas para os líquidos iônicos são em tratamentos de resíduos nucleares, processos voltados a energia, catalisadores e em reações químicas, como eletrólitos em eletroquímica, combustíveis e células solares, imobilização de enzimas em tecnologias de separação (solventes orgânicos 
convencionais podem inativar enzimas devido as alterações de polaridade e $\mathrm{pH}$ ), como cristais líquidos ou modelos para a síntese de mesoporos, entre outras diversas aplicações (WASSERSCHEID; KEIM, 2000; WASSERSCHEID; WELTON, 2003; PLECHKOVA; SEDDON, 2008). Os estudos recentes em relação aos líquidos iônicos estão sendo direcionados para obter melhores e menores combinações entre os cátions e ânions. Entre os ânions, os haletos são fortemente higroscópicos, isto é, possuem grande capacidade de absorver a umidade do ar, tendo limitações e aplicações específicas. Ânions complexos, tais como bis(trifluorometanossulfonil)amida [NTf2]-, trifluorometanossulfonato [OTf]-, dicianamida, tosilato ou $n$-alquilsulfonato são relativamente estáveis na condição de hidrólise e podem ser melhores alternativas (SUNEETHA et al. 2017).

Em processos envolvendo biomassa, o uso de líquidos iônicos pode ser uma alternativa para dissolvê-la devido à forte ligação de hidrogênio entre o ânion do IL e os átomos de hidrogênio presentes nas hidroxilas da biomassa. $O$ cátion apresenta um papel secundário tendo efeito de afinidade pela coordenação dos átomos de oxigênio do grupo hidroxila da biomassa. Os líquidos iônicos são capazes de dissolver biopolímeros e carboidratos, catalisar a produção de monômeros transformando-os como uma alternativa de aplicação em processos de biorefinamento. O uso de ILs nesses processos tem possibilitado a redução de consumo energético, menor consumo de água e menor investimento em equipamentos. Entretanto, para viabilizar o processo, torna-se imperativo a necessidade de reciclagem do líquido iônico. Com relação a reações enzimáticas, os líquidos iônicos podem ser usados em reações catalíticas apresentando uma conversão mais alta e mais estável em enzimas como a $\alpha$-quimotripsina, CAL-B e Bacillus Stearothermophilus. Contudo, em outras enzimas apresenta baixa solubilidade no substrato hidrofílico, diminuindo sua taxa de reação e produtividade (CARNEIRO; RODRIGUEZ; MACEDO, 2013; KIM et al; 2012) 
Figura 5 - Diversas aplicações dos líquidos iônicos

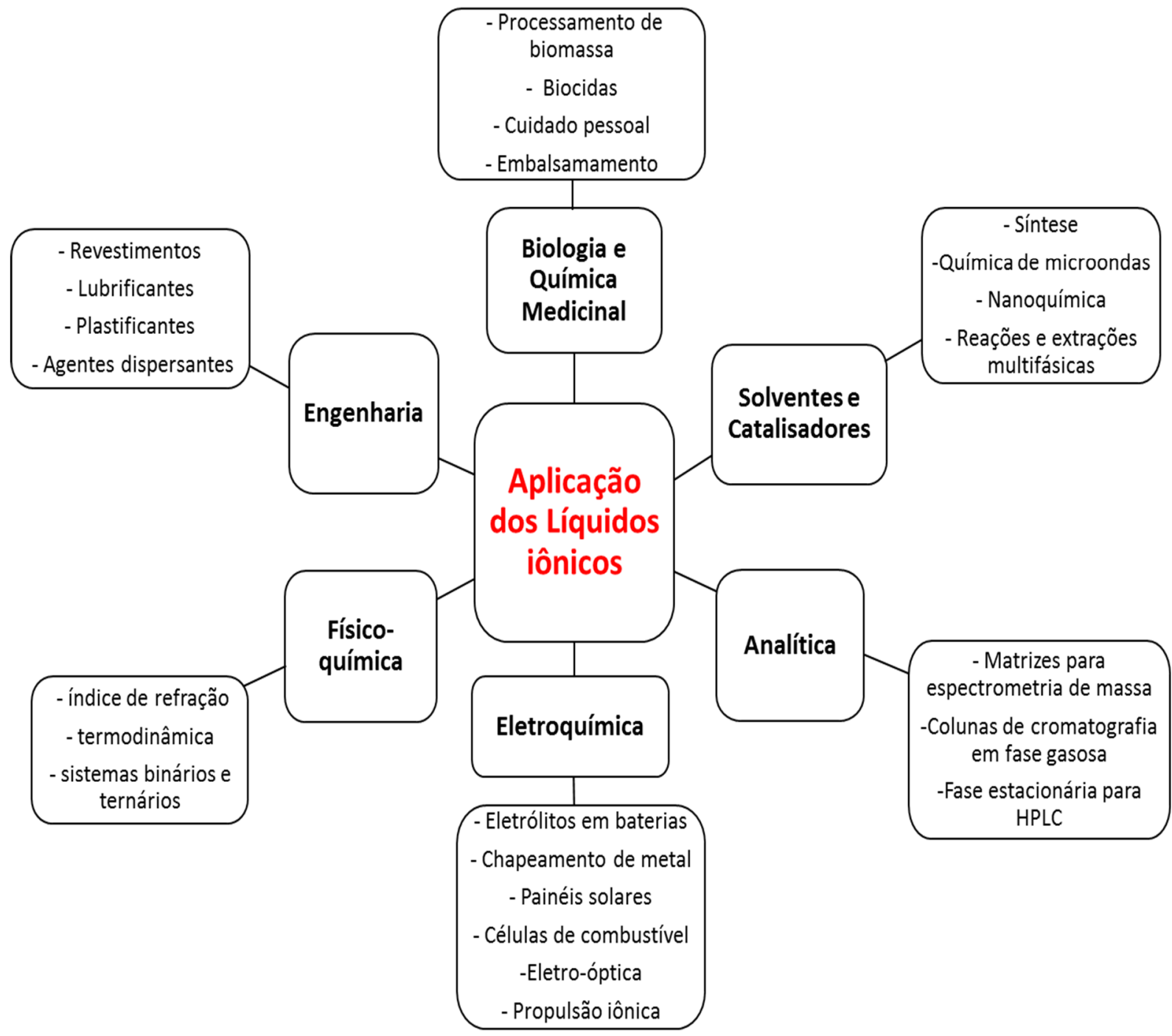

Fonte: Adaptada de<https://scientificusblogpt.files.wordpress.com/2014/02/ionic-liquids-apis.jpg > acessado em fevereiro de 2019.

O líquido iônico utilizado no presente estudo foi a dicianamida de 1-etil-3metilimidazólio, conhecido como [EMIM][DCA] (Figura 5). Ele possui fórmula empírica $\mathrm{C}_{8} \mathrm{H}_{11} \mathrm{~N}_{5}$, com massa molar de 177,21 g.mol ${ }^{-1}$ e densidade relativa de $1,060 \mathrm{~g} \cdot \mathrm{cm}^{-3}$ a $25^{\circ} \mathrm{C}$. Não apresenta heteroátomos, é líquido à temperatura ambiente, higroscópico, completamente solúvel em água e isopropanol, possui alta estabilidade térmica (decomposição à $548 \mathrm{~K}$ ), baixo ponto de fusão (252 K) e baixa viscosidade (0,021 Pa× a 293 K) (ORCHILLÉS et al. 2012). 
Figura 6 - Estrutura molecular do dicianamida de 1-etil-3-metilimidazólio

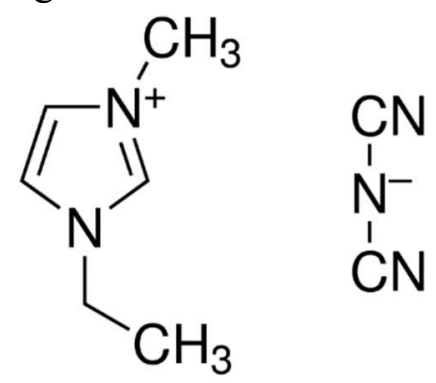

Fonte: Sigma Aldrich

Neste líquido iônico, o ânion é a dicianamida e o cátion, o 1-etil-3-metilimidazólio. Entre as diversas opções de líquidos iônicos, o [EMIN] [DCA] seria uma alternativa para dissolver monossacarídeos pelo curto tamanho da cadeia alquílica nos cátions, baixa viscosidade, hidrofilicidade, interagindo mais fortemente com os carboidratos através das ligações de hidrogênio com as hidroxilas presentes neles. (CARNEIRO; RODRIGUEZ; MACEDO; 2012/2013) 


\section{REVISÃO BIBLIOGRÁFICA}

Este capítulo tem como objetivo apresentar estudos encontrados na literatura de propriedades volumétricas contendo sacarídeos em soluções aquosas de líquidos iônicos a diferentes concentrações, temperaturas e pressões. Embora seja possível encontrar muitos estudos envolvendo propriedades volumétricas de soluções aquosas de sacarídeos em sais orgânicos e inorgânicos, estudos com líquidos iônicos são raros.

Zamani, Naderi e Sadeghi (2018) estudaram a interação de carboidratos em soluções aquosas de brometo de 1-decil-3-metilimidazólio ([C10mim] [Br]) através de medidas experimentais de propriedades volumétricas, acústicas, condutimétricas e tensiométricas. As medidas foram realizadas na concentração de $[\mathrm{C} 10 \mathrm{mim}][\mathrm{Br}]$ de $0,5 \mathrm{~mol} \mathrm{~kg}^{-1}$. Os carboidratos estudados foram: rafinose, lactose, sacarose, glicose, manose, arabinose, xilose e ribose. Todos os carboidratos estudados tiveram efeitos "soulting out", favorecendo a formação de micelas e as suas capacidades de reduzir a concentração micelar crítica (CMC) do [C10mim] $[\mathrm{Br}] \mathrm{em}$ solução aquosa aumenta com o aumento da hidrofobicidade do carboidrato.

Banipal et al (2017) estudaram o comportamento volumétrico da D-xilose e D-glicose entre outros sacarídeos (solutos polihidroxilados) em soluções aquosas de brometo de cetiltrimetilamônio, CTAB, cuja composição é constituída de uma mistura de diferentes sais de amônio quaternário. Os dados de densidade foram obtidos através de um densímetro digital de oscilação mecânica e utilizados para obter o volume molar aparente, o volume parcial molar e os volumes de transferência da água para as soluções salinas. Os autores observaram que os valores da densidade aumentaram com a concentração de CTAB e diminuíram com o aumento da temperatura. Foi observado também que os valores do volume molar parente aumentaram com o aumento da concentração de CTAB e da temperatura, mas diminuíram com o aumento da molalidade dos sacarídeos. Os autores sugeriram que os valores obtidos para o volume molar à diluição infinita representam uma das interações de solutos e solventes, enquanto a constante $S_{v}$ determinaria a natureza das interações soluto-soluto. No estudo, os valores negativos de $\mathrm{S}_{\mathrm{v}}$ indicam fracas interações soluto-soluto. Os valores dos volumes molares à diluição infinita foram positivos para todos os solutos estudados e aumentaram com o aumento da temperatura e concentração da solução de CTAB. O Volume molar à diluição infinita também aumentou com o aumento da massa molar dos solutos polihidroxilados na sequência: glicose $>$ xilose. Os volumes parciais molares de transferência à diluição infinita dos solutos estudados da água para a solução aquosa de CTBA foram positivos e aumentaram com a massa molar do soluto. 
Paduszynski, Okuniewski e Domanska (2016) realizaram um estudo de propriedades termodinâmicas de sistemas aquosos contendo glicose e diferentes líquidos iônicos. Todos os líquidos iônicos apresentaram o ânion dicianamida e o cátion imidazólio contendo os grupamentos alilo, 2-hidroxietilo, 3-cianopropilo e 2-cloroetilo. Dentre as propriedades estudadas, a densidade foi determinada, em diferentes temperaturas através da técnica de densitometria mecânica, utilizando um densímetro fabricado pela Anton Paar (Modelo 4500). Os autores concluíram que a densidade diminuiu com o aumento da temperatura e com a mudança dos diferentes cátions na seguinte sequência: $[\mathrm{C} 1 \mathrm{C}=\mathrm{CC} 1 \mathrm{Im}]^{+}<[\mathrm{C} 3 \mathrm{CNC} 1 \mathrm{Im}]^{+}<$ $[\mathrm{C} 2 \mathrm{OHC} 1 \mathrm{Im}]^{+}<[\mathrm{C} 2 \mathrm{ClC} 1 \mathrm{Im}]^{+}$. Os volumes molares aparentes seguiram a sequência: $[\mathrm{C} 2 \mathrm{OHC} 1 \mathrm{Im}]^{+}<[\mathrm{C} 1 \mathrm{C}=\mathrm{CC} 1 \mathrm{Im}]^{+}<[\mathrm{C} 2 \mathrm{ClC} 1 \mathrm{Im}]^{+}<[\mathrm{C} 3 \mathrm{CNC} 1 \mathrm{Im}]^{+}$. Esse comportamento foi atribuído a diferentes tipos de interações entre o grupamento hidroxila presente na glicose e os diferentes tipos de íons presentes nos líquidos iônicos. As influências do tamanho dos íons presentes nos líquidos iônicos também parecem ser um fator importante no valor dos volumes molares aparentes.

Em 2015, Singh et al realizaram estudos de propriedades volumétricas de soluções de líquidos iônicos contendo sacarídeos. Os monossacarídeos estudados foram duas pentoses, a D-ribose (Rib) e a D-arabinose (Arb), e o líquido iônico foi baseado no cátion imidazólio, o brometo de 1-butil-3-metilimidazólio ([Bmin][Br]. Os resultados experimentais foram usados para calcular os volumes molares aparentes, volume parcial à diluição infinita e os volumes de transferência do líquido iônico da água para as soluções sacarídeas. Para ambos os sistemas estudados, a densidade aumentou com o aumento da concentração de líquido iônico e da concentração de monossacarídeo, e diminuiu com o aumento da temperatura. Os volumes molares aparentes, calculados fazendo uso do formalismo termodinâmicos, diminuíram com o aumento da concentração de $[\mathrm{Bmim}][\mathrm{Br}]$ mas aumentaram com o aumento da temperatura. Os autores concluíram que as interações soluto-cosoluto presente nas soluções mais fortes para o sistema contendo a ribose do que para arabinose, sendo explicado em termos de estruturas estereoquímicas. A ribose apresenta interações específicas axiais-equatoriais-axiais das hidroxilas com os íons de [Bmim][Br]. Os valores negativos de $S_{\mathrm{v}}$ indicam que as interações íon-íon são mais fracas, enquanto valores positivos de $S_{\mathrm{V}}$ indicam que essas interações são mais fortes. No estudo, todos os valores de $S_{\mathrm{v}}$ obtidos foram negativos, inclusive para as soluções aquosas brometo de 1-butil-3-metilimidazólio, indicando que as interações íon-solvente são mais fortes que as interações íon-íon. Já para o volume molar de transferência, os valores foram positivos tanto com o aumento da concentração dos monossacarídeos quanto com o aumento da temperatura. Constatou-se uma dependência não linear do volume de transferência coma a 
temperatura. Os valores positivos sugerem a dominância de interações hidrofílicas-iônicas entre monossacarídeos e o $[\mathrm{Bmim}][\mathrm{Br}]$, interagindo mais fortemente com a Ribose do que com a Arbinose. As interações específicas entre íons de [Bmim] $[\mathrm{Br}]$ e a sequência axial-equatorialaxial de grupos hidroxilas da Ribose também pode explicar o alto valor do volume molar de transferência encontrado no estudo.

Singh, Chotaray e Gardas (2016) realizaram medidas de densidade e velocidade do som de sacarose em soluções aquosas do líquido iônico prótico formiato de 3-hidroxipropril amônio (3HPAF) a diferentes temperaturas $T=(293,15,298,15,303,15,308,15,313,15$ e 318,15) K e a $p=101,3 \mathrm{kPa}$. As medidas foram realizadas utilizando um analisador de densidade e velocidade do som fabricado pela Anton Paar (Modelo DAS 5000). Os resultados experimentais foram utilizados para calcular os volumes molares aparentes, as compressibilidades isentrópicas aparentes, os volumes parciais molares de transferência e as compressibilidades isentrópicas parciais molares de transferência da sacarose da água para a solução iônica. A influência do líquido iônico sobre a solvatação da sacarose foi estudada baseada nas grandezas de transferência. Os valores das compressibilidades isentrópicas parciais molares de transferência foram positivos enquanto os volumes parciais molares de transferência assumiram valores positivos e negativos. Os valores dessas duas grandezas aumentaram com o aumento da concentração do líquido iônico. Os autores atribuíram esse comportamento à predominância de interações hidrofóbicas. Os autores estenderam o estudo para o líquido iônico 3hydropropilamônio acetato

Zafarani-Moattar, Shekaari e Agha (2015) determinaram dados de densidade, velocidade do som e viscosidade de sacarose em soluções aquosas de do líquido iônico brometo de1-butil-3-metil-imidasólio a pressão ambiente de diferentes temperaturas e concentrações. Esses resultados foram usados para calcular várias grandezas dentre elas: o volume molar aparente, o volume de transferência da sacarose da água para a solução aquosa de líquido iônico, a compressibilidade isentrópica, o número de hidratação de moléculas de água em torno da sacarose, e o coeficiente-B de viscosidade. A partir dos valores positivos dos volumes de transferência da sacarose da água para as soluções aquosas de líquido iônico, os autores concluíram que as interações são predominantemente do tipo interações hidrofílica-iônica entre a sacarose e o líquido iônico. Com o aumento da concentração do líquido iônico, as interações entre a sacarose e o líquido iônico aumentaram diminuindo a interação entre a sacarose e a água.

Jin e Chen (2012) determinaram dados experimentais de glicose em soluções aquosas do líquido iônico tetrafluoroborato de1-butil-3-metilimidazólio [Bmim] $\left[\mathrm{BF}_{4}\right]$ em diferentes concentrações e à temperatura de $298,15 \mathrm{~K}$. Os resultados experimentais foram usados para 
calcular os volumes molares aparentes, volumes parciais molares à diluição infinita e os volumes de transferência da glicose da água para a solução contendo o líquido iônico. Os valores dos volumes de transferência foram positivos e aumentaram com o aumento da concentração da glicose e do líquido iônico.

Zafarani-Moattar, Shekaari, Mazaher e Agha (2019) estudaram as propriedades volumétricas da sacarose em líquidos iônicos aquosos (brometo de 1-octil-3-metil imidazólio e cloreto de 1-octil-3-metil imidazólio) em diversas temperaturas a fim de obter informações sobre suas interações. A densidade foi determinada e os volumes molares aparentes $\left(V_{\phi}\right)$ para a sacarose nessas soluções foram calculadas. Nas soluções ternárias, as soluções líquidas iônicas aquosas foram consideradas como solvente, por extrapolação dos valores de volume molar aparente, os valores para diluição infinita e volume molar parcial padrão pode ser obtido. Com os resultados obtidos, foi possível observar que os valores de volume molar parcial padrão aumentaram com a concentração dos líquidos iônicos, sendo explicado pela formação de ligações de hidrogênio entre os grupos hidroxila da sacarose e os líquidos iônicos estudados, e ao aumento da solvatação dos solutos em concentrações mais elevadas de cossoluto. Com os líquidos iônicos estudados foi possível concluir que com o aumento da afinidade dos líquidos iônicos pela água, suas tendências para interagir com a sacarose diminuem. Com a menor hidratação, existe a maior liberdade para interagir com o sacarídeo e os valores obtidos neste estudo atendem a essa expectativa. Os valores de volume molar parcial aumentaram com o aumento da temperatura, sendo esse comportamento atribuído à redução da eletrostrição que libera algumas moléculas de água para o volume, aumentando a temperatura. As moléculas de água liberadas têm mais contribuição nos valores em comparação com as da camada de hidratação, portanto os valores aumentam. Nas soluções contendo líquido iônico, água e sacarose, valores de $S$ v são positivos e pequenos que indicam interações atraentes fracas entre moléculas de sacarose. Os valores de volume molar de transferência são todos positivos, indicando que as interações hidrofílicas-iônicas são mais fortes do que outras interações conforme o modelo de sobreposição coesfera. Com o aumento da molalidade do líquido iônico, os valores aumentam, o que significa o fortalecimento das interações hidrofílicas-iônicas. Foi constatado neste estudo que a presença dos líquidos iônicos estudados não afeta as qualidades de sabor da sacarose. 


\section{FORMALISMO TERMODINÂMICO}

O formalismo termodinâmico para os cálculos das grandezas volumétricas é o mesmo do que aquele apresentado no trabalho de Mille, 2016.

Para soluções que apresentam baixas concentrações, a aproximação de McMillanMayer (MCMILLAN; MAYER, 1945) permite calcular o volume molar aparente conforme a equação (1):

$$
\mathrm{V}_{f_{s}}=\left(\frac{\mathrm{M}_{\mathrm{S}}}{\rho}\right)-\frac{1000 \times\left(\rho-\rho_{0}\right)}{\mathrm{m}_{\mathrm{s}} \times \rho \times \rho_{0}}
$$

na qual, $V_{\mathrm{fs}}$ é o volume molar aparente $\left(\mathrm{cm}^{3} \cdot \mathrm{mol}^{-1}\right), M_{\mathrm{s}}$ e $M_{\mathrm{IL}}$ são as massas molares do sacarídeo e da solução iônica $\left(\mathrm{g} \cdot \mathrm{mol}^{-1}\right), m_{\mathrm{sa}}$ e $m_{I L}$ são as molalidades do sacarídeo e do líquido iônico em água $\left(\mathrm{mol} \cdot \mathrm{kg}^{-1}\right), \rho$ e $\rho_{\mathrm{o}}$ representam as densidades da solução e densidade da solução sem o sacarídeo $\left(\mathrm{g} \cdot \mathrm{cm}^{-3}\right)$.

Para os casos em que se possuem altas concentrações de cossoluto, é conveniente a utilização da concentração do soluto em relação à massa de solução (cossoluto e água). Sendo assim, a equação (2) é mais apropriada:

$$
\mathrm{V}_{f_{s}}=\left(\frac{\mathrm{M}_{s}}{\rho}\right)-\frac{1000 \times\left(\rho-\rho_{0}\right)}{\mathrm{m}_{\mathrm{s}} \times \rho \times \rho_{0}}
$$

em que, $m_{S}$ é a molalidade do sacarídeo em solução iônica $\left(\mathrm{mol} \cdot \mathrm{kg}^{-1}\right), M_{\mathrm{S}}$ é a massa molar do sacarídeo, $\rho$ e $\rho_{\mathrm{o}}$ são as densidades da solução e densidade das soluções em sacarídeos, respectivamente $\left(\mathrm{g} \cdot \mathrm{cm}^{-3}\right)$ (DE VISSER; PERRON; DESNOYERS, 1977).

A massa molar é obtida a partir da equação (3):

$$
M=\sum_{i=1}^{i=m} n_{i} ¥ \bar{M}_{i},
$$

na qual, $M$ é uma propriedade extensiva e $\overline{M_{l}}$ é a grandeza parcial molar correspondente.

A equação (4) descreve a relação entre $V$ e $V_{\Phi \mathrm{j}}$, grandeza molar aparente do componente $j$ (ACREE, 1984):

$$
V=n_{j} ¥ V_{f_{j}} \sum_{i=1, i \pi j}^{i=m} n_{i} ¥ M_{i}^{0} \text {, }
$$


em que, $M_{i}^{0}$ é a grandeza molar do componente puro $i$.

A equação (5) mostra que à diluição infinita, o volume molar aparente é igual ao volume molar.

$$
V_{f_{s}}=\frac{V-\sum_{i=1, i \pi j}^{i=m} n_{i} ¥ M_{i}^{0}}{n_{j}}
$$

A partir da equação (5), é possível definir o volume molar aparente do sacarídeo, considerando um mol de uma solução binária (sacarídeo e solução iônica), pela equação (6):

$$
V_{f_{s}}=\frac{V_{m}-x_{0} ¥ V_{0}^{0}}{x_{s}},
$$

na qual, $V_{\mathrm{m}}$ é o volume molar da solução, $V_{0}^{0}$ é o volume molar da solução iônica, $\mathrm{x}_{\mathrm{s}} \mathrm{e} x_{0}$ são as frações molares do sacarídeo e das soluções iônicas, respectivamente.

O volume molar pode ser obtido em função da densidade conforme a equação (7).

$$
V_{m_{i}}=\frac{M_{i}}{r_{i}}
$$

em que, $M_{i}$ é a massa molar e $\rho_{i}$ é a densidade, ambas da espécie $i$.

A combinação da equação (3) com a equação (7), leva a equação (8).

$$
V_{m}=\frac{x_{s} ¥ M_{s}+x_{0} ¥ M_{0}}{r},
$$

em que, $V_{m}$ e $\rho$ representam o volume molar e a densidade da solução contendo sacarídeo, respectivamente. $M_{S}, M_{o}, x_{S}$ e $x_{o}$ representam a massa molar do sacarídeo, a massa molar da solução iônica, a fração molar do sacarídeo e a fração molar da solução iônica.

Combinando as equações (6) e (8), obtém-se a equação (9):

$$
V_{m}=\frac{x_{s} ¥ M_{s}}{x_{s} ¥ r}+\frac{x_{0} ¥ M_{0}}{x_{s} ¥ r}-\frac{x_{0} ¥ M_{0}}{x_{s} ¥ r}
$$

Simplificando a equação anterior, obtém-se a equação (10):

$$
V_{m}=\frac{M_{s}}{r}+\frac{x_{0} ¥ M_{0}}{x_{s} ¥ r}-\frac{x_{0} ¥ M_{0}}{x_{s} ¥ r}
$$


As equações (11) e (12) definem $x_{0}$ e $x_{\mathrm{s}}$ :

$$
\begin{aligned}
& x_{0}=\frac{n_{0}}{n_{s}+n_{0}} \\
& x_{s}=\frac{n_{s}}{n_{s}+n_{0}}
\end{aligned}
$$

A partir das equações (11) e (12), obtém-se a equação (13):

$$
\frac{x_{0}}{x_{s}}=\frac{n_{0}}{n_{s}}
$$

na qual, $n_{\mathrm{o}}$ e $n_{s}$ representam o número de moles da solução iônica e o número de moles de sacarídeo, respectivamente.

A massa de solução iônica pode ser definida pela equação (14):

$$
m_{0}=n_{0} ¥ M_{0}
$$

Define-se a molalidade do sacarídeo em solução iônica $\left(m_{s}\right)$ pela equação $(15)$, como:

$$
m_{s}=\frac{n_{s}}{m_{0}}=\frac{n_{s}}{n_{0} ¥ M_{0}}
$$

A equação (16) é obtida através da combinação das equações de (13) a (15):

$$
V_{f_{s}}=\frac{M_{s}}{r}+\frac{1}{m ¥ r}-\frac{1}{m ¥ r_{0}}
$$

Rearranjando os termos da equação anterior, é possível escrever as equações (17), (18) e (19):

$$
\begin{aligned}
V_{f_{s}} & =\frac{M_{s}}{r}+\frac{1}{m} ¥\left(\frac{1}{r}-\frac{1}{r_{0}}\right) \\
V_{f_{s}} & =\frac{M_{s}}{r}+\frac{1}{m} ¥\left(\frac{r_{0}-r}{r ¥ r_{0}}\right) \\
V_{f_{s}} & =\frac{M_{s}}{r}-\frac{r_{0}-r}{m ¥ r ¥ r_{0}}
\end{aligned}
$$

Tendo em vista que as unidades de massas são dadas em gramas e a molalidade das equações em mol· $\mathrm{kg}^{-1}$, é necessário fazer um ajuste de unidade, para obter a equação (2): 


$$
V_{f_{s}}=\left(\frac{M_{s}}{r}\right)-\frac{1000 ¥\left(r-r_{0}\right)}{m_{s} ¥ r ¥ r_{0}} \text {. }
$$

Para o cálculo do volume molar aparente do sacarídeo à diluição infinita $\left(\mathrm{cm}^{3} \cdot \mathrm{mol}^{-1}\right)$, podemos fazer uso da equação (20)

$$
V_{f_{s}}=V_{f_{s}}^{0}+S_{V} ¥ m^{\frac{1}{2}},
$$

na qual, $V_{\phi S}^{0}$ é o volume molar do sacarídeo à diluição infinita, $S_{V}$ é uma constante e $m$ é a molalidade. Com o valor de $S_{\mathrm{V}}$ é possível compreender a natureza das interações entre solutosoluto.

Assim, os volumes molares à diluição infinita $\left(V_{\phi S}^{0}\right)$ podem ser calculados a partir da extrapolação do volume molar aparente quando a molalidade, $m$, for nula. Através da equação da reta obtida graficamente, é possível obter os valores de $V_{\phi \mathrm{S}}^{0}$ e da constante $S_{\mathrm{V}}$.

Com os resultados dos volumes molares à diluição infinita $\left(V_{\phi \mathrm{S}}^{0}\right)$, é possível estudar o volume de transferência do sacarídeo da água para solução iônica, através da equação (21)

$$
\mathrm{D} V_{t s}^{0}=V_{f_{S}(\text { soluçãoiônica })}^{0}-V_{f_{S}(\text { água })}^{0}
$$

em que é $\Delta V_{\mathrm{tS}}^{0}$ é o volume de transferência do sacarídeo da água para a solução iônica $\left(\mathrm{cm}^{3} \cdot \mathrm{mol}^{-1}\right)$, e $\mathrm{V}_{f_{S}(\text { soluçãoionica })}^{0}$ e $\mathrm{V}_{f_{S}(\text { água })}^{0}$ são os volumes molares do sacarídeo à diluiçãa infinita na solução iônica e na água $\left(\mathrm{cm}^{3} \cdot \mathrm{mol}^{-1}\right)$, respectivamente (BANIPAL et al., 2002; BANIPAL; CHAHAL; BANIPAL, 2010; BANIPAL; CHAHAL NEE HUNDAL; BANIPAL, 2010; KAUR; BANIPAL, 2004; BANIPAL; SINGH; BANIPAL, 2010, SHEKAARI; KAZEMPOUR, 2012; ZHUO et al., 2009).

Com o volume molar de transferência é possível determinar a natureza das interações entre o soluto e o solvente. Os resultados podem ser interpretados segundo o modelo "cosphere overlap": interações hidrofóbicas-iônicas, interações hidrofílicas-iônicas, interações hidrofóbicas-hidrofóbicas e interações hidrofílicas-hidrofóbicas (DESNOYERS et al, 1969). 


\section{MATERIAIS E MÉTODOS}

Neste capítulo são apresentados os materiais (equipamentos e reagentes) e a metodologia utilizada no presente estudo.

\subsection{MATERIAIS}

Os reagentes utilizados no presente foram: $\mathrm{D}(+)$-glicose (Merck, anhydrous for biochemistry, CAS 50-99-7); Sacarose (Merck, for biochemistry, CAS 57-50-1 ); D(+)-xilose (Sigma-Aldrich, $\geq 99 \%$, CAS 58-86-6); Dicianamida de 1-etil-3-metilimidazólio, (Aldrich, $\geq$ 98\%, CAS 370865-89-7); Água desmineralizada.

\subsection{METODOLOGIA}

A metodologia utilizada para as medidas de densidade foi a densitometria de oscilação mecânica e o equipamento usado foi um densímetro de oscilação mecânica (modelo DMA 4500, fabricado pela Anton Paar) (Figura 7) instalado no laboratório de combustíveis no Centro Universitário da FEI. As soluções foram preparadas por pesagem dos componentes, utilizando pipetas automáticas e uma balança analítica digital com resolução de 0,0001gfabricada pela Shimadzu (Modelo AUY 220) (Figura 10). As amostras foram injetadas no equipamento utilizando seringas plásticas especiais de $5 \mathrm{~cm}^{3}$. A figura 8 ilustra a injeção das amostras no densímetro. 
Figura 7 - Densímetro DMA 4500

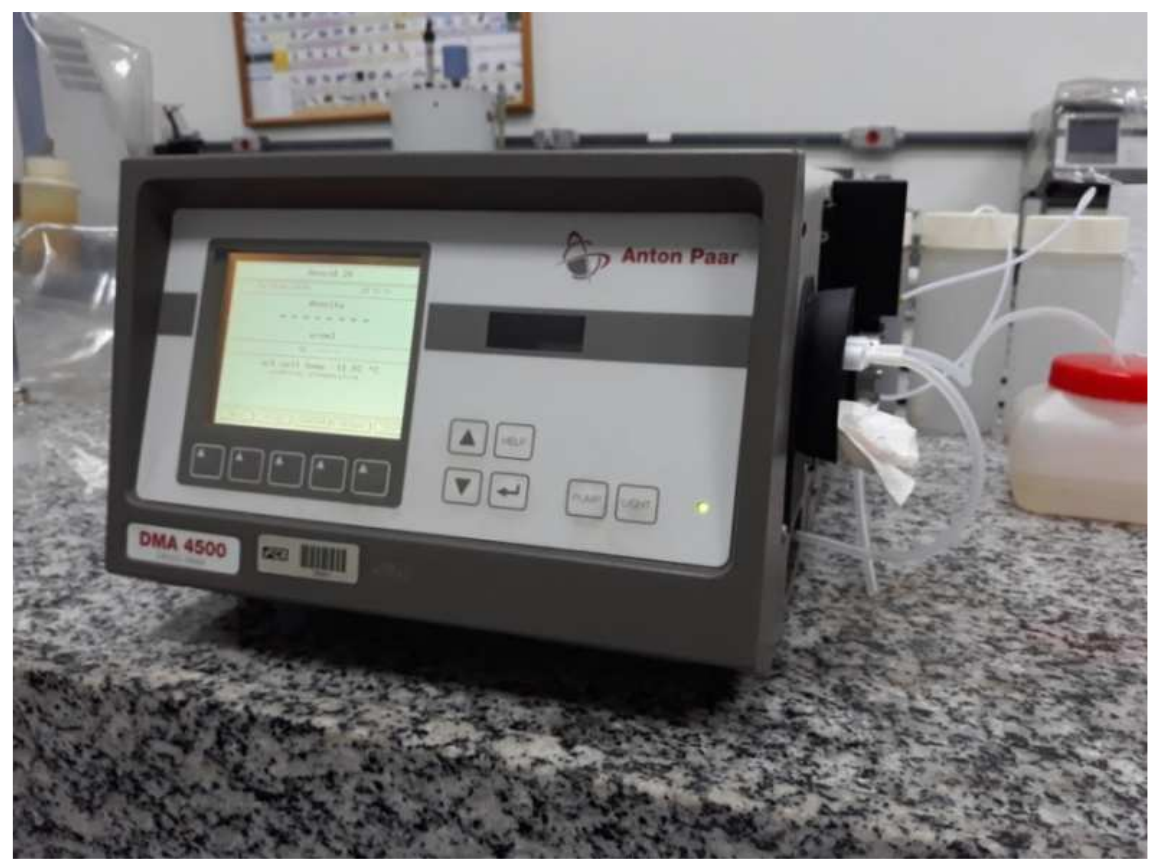

Fonte: Autor

Figura 8 - Ilustração indicando entrada e saída de amostra no densímetro DMA 4500

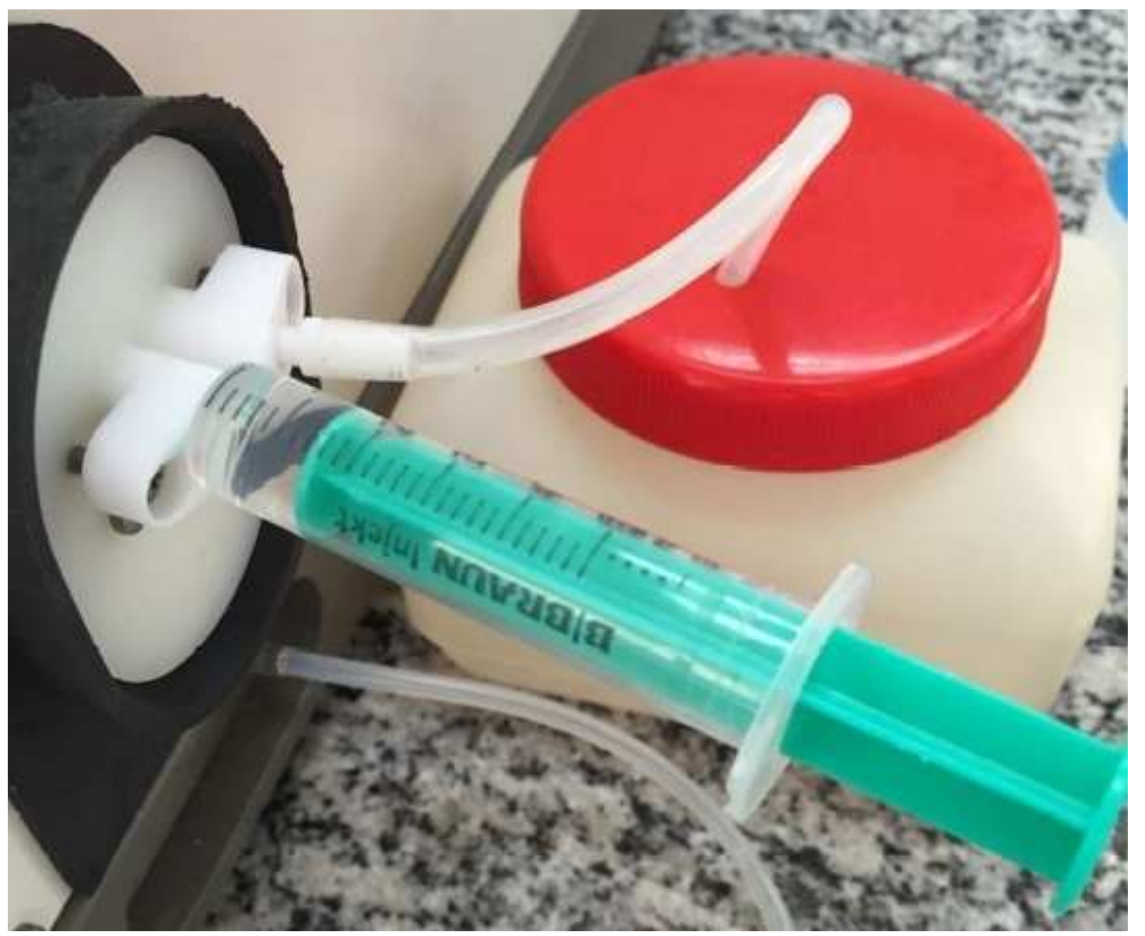

Fonte: Autor 
Figura 9 - Balança Analítica ShimadzuAUY 220

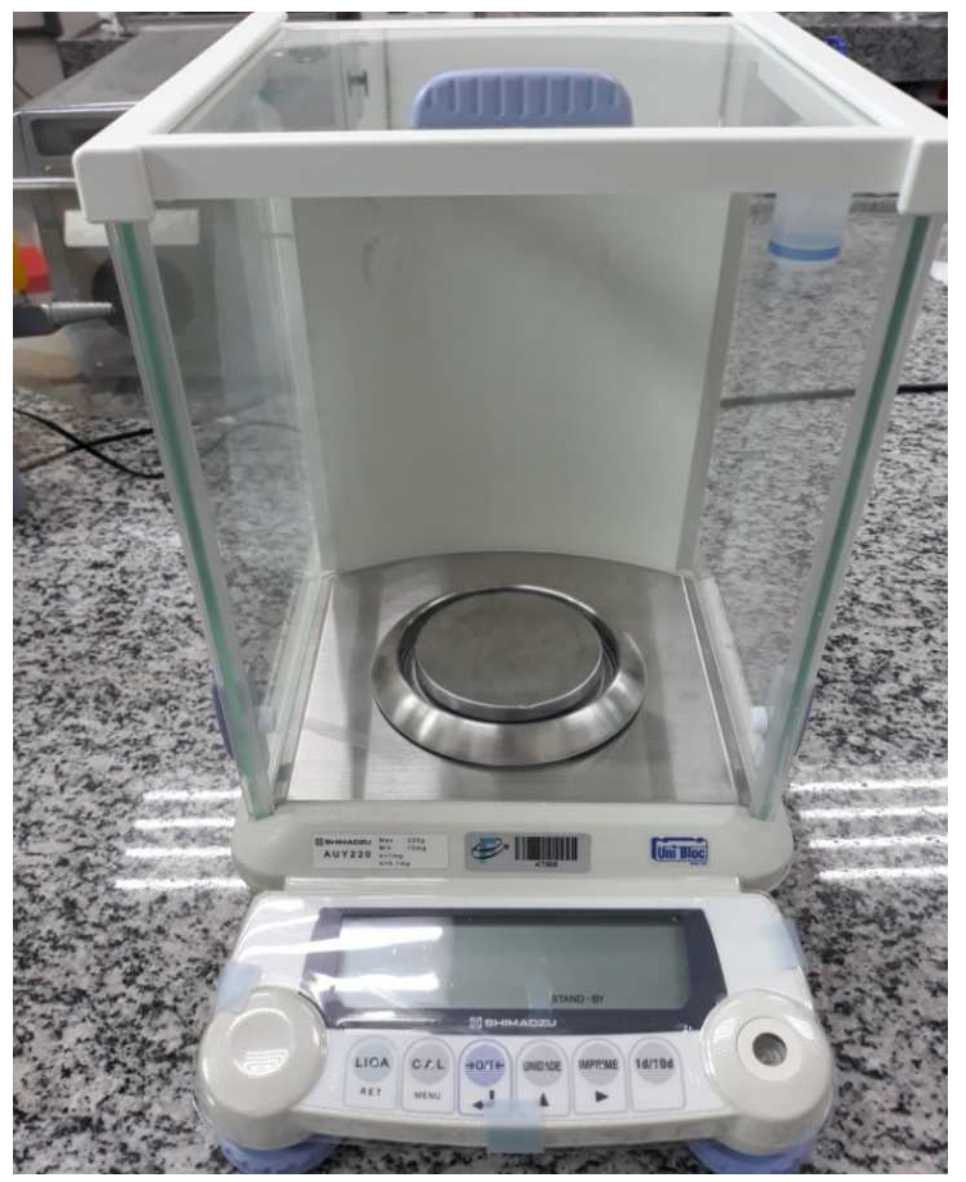

Fonte: Autor

As incertezas na molalidade e no volume molar aparente foram, respectivamente, de $0,0001 \mathrm{~mol} \cdot \mathrm{kg}^{-1}$ e $0,01 \mathrm{~cm}^{3} \cdot \mathrm{mol}^{-1}$. (Apêndice A)

O densímetro possui um tubo oscilador em formato "U", provido de dois sensores Pt100, os quais controlam a temperatura. O equipamento possui uma bomba interna que possibilita a secagem do tubo oscilador e pode ser acionada manualmente com a opção de desligamento automático ou manual.

Antes de iniciar as medidas de densidade dos sistemas estudados, tomou-se o cuidado de secar os sacarídeos em dessecador (Figura 10) e o líquido iônico foi mantido e manuseado em uma gloverbox (Figura 11). 
Figura 10 - Dessecador e bomba utilizada

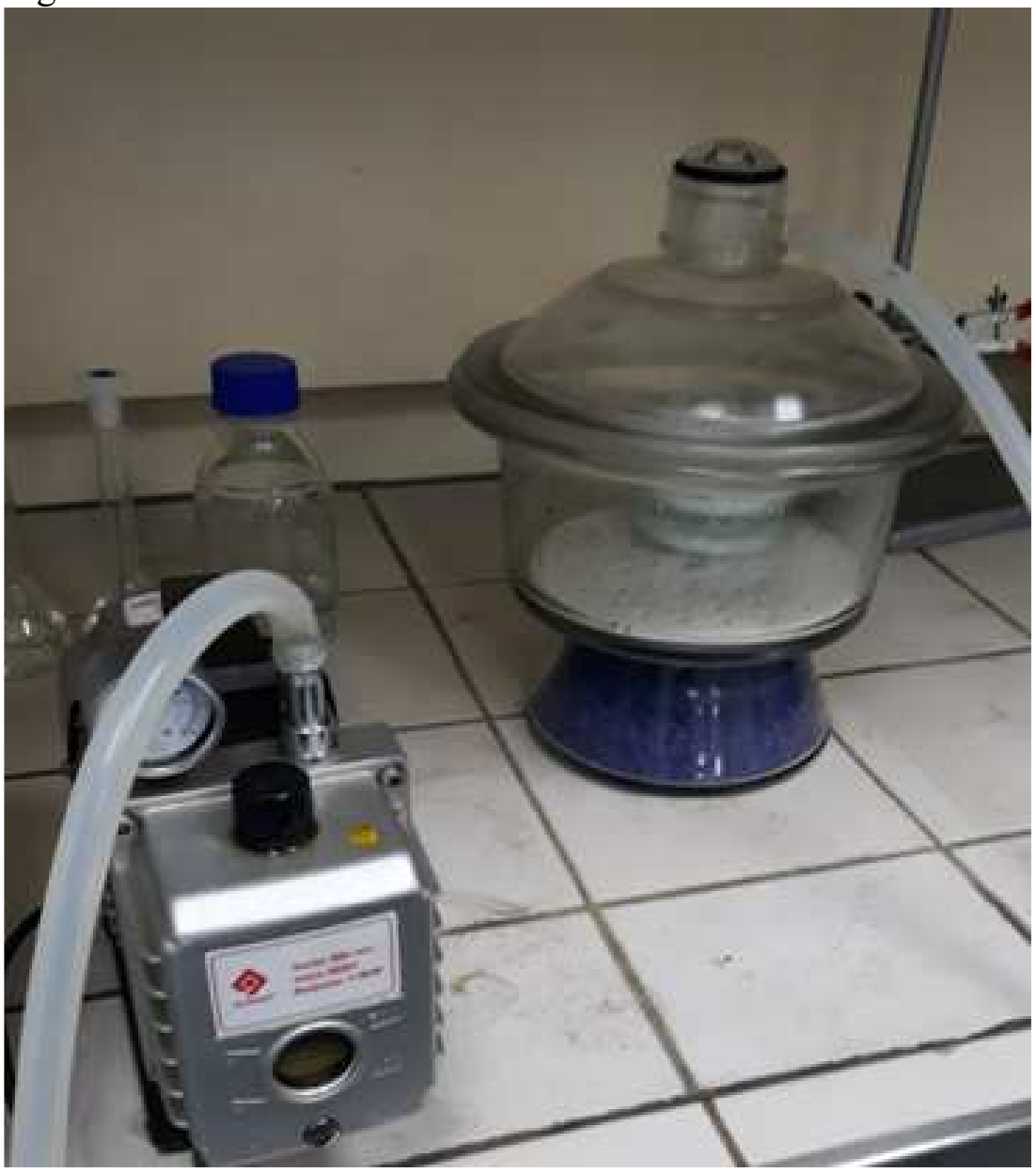

Fonte: Autor

Figura 11 - Gloverbox utilizada para manuseio do líquido iônico

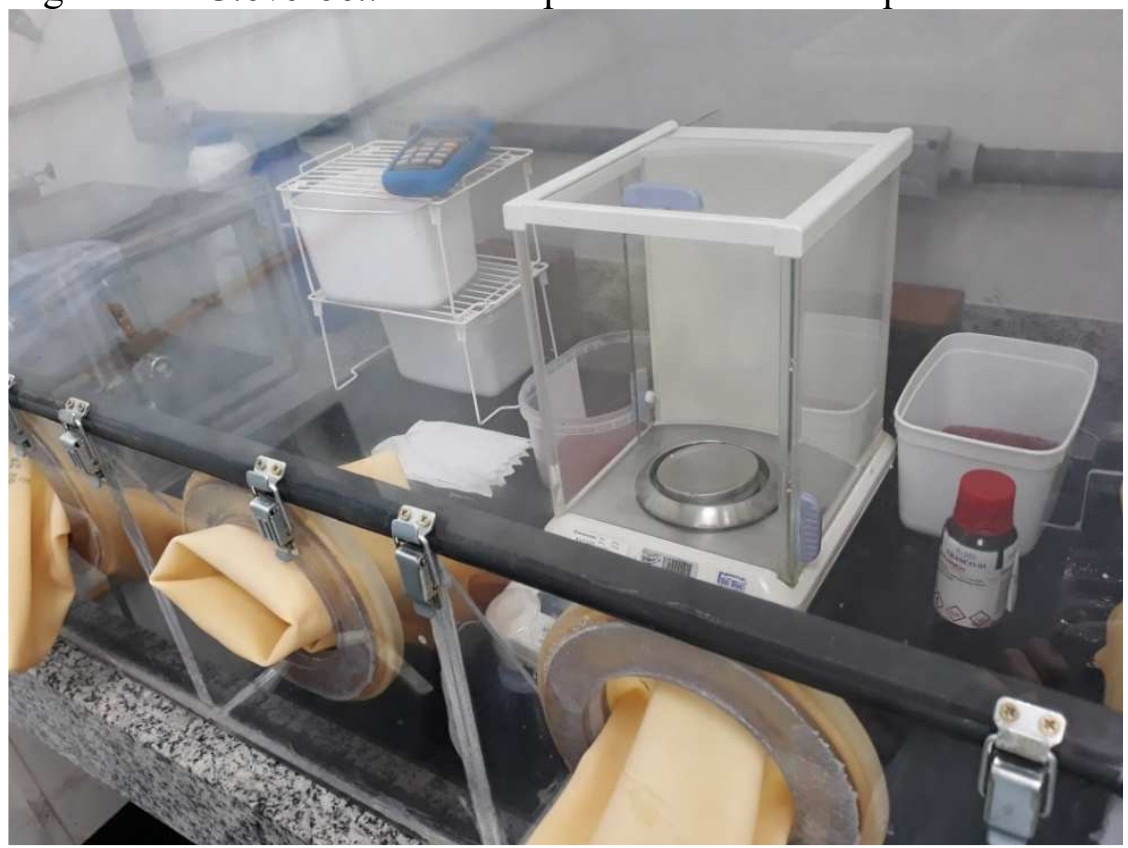

Fonte: Autor 
Inicialmente, mediu-se a densidade da água desmineralizada, obtida através de osmose reversa, em todas as temperaturas estudadas $(283,15 ; 288,15 ; 293,15 ; 298,15$ e $303,15 \mathrm{~K})$. Ao introduzir as amostras no equipamento, tomou-se o cuidado para evitar a formação de bolhas que poderiam prejudicar a leitura das densidades, devido à instabilidade no tubo oscilador. As temperaturas foram ajustadas manualmente no equipamento. Após as leituras das densidades de cada amostra nas diferentes temperaturas, o tubo oscilador foi lavado com etanol e em seguida seco com acetona e com a bomba de ar interna do equipamento.

As soluções aquosas de líquido iônico foram preparadas nas concentrações de 0,025; 0,$050 ; 0,075$ e $0,1 \mathrm{~mol} \cdot \mathrm{kg}^{-1}$. As soluções de sacarídeos foram preparadas nas molalidades de 0,$015 ; 0,10 ; 0,30 ; 0 ; 50 ; 0,70 ; 0,90 ; 1,10 ; 1,30 ; 1,50 \mathrm{e} 1,70 \mathrm{~mol} \cdot \mathrm{kg}^{-1}$. Todas as amostras foram pesadas e deixadas em repouso por no mínimo duas horas para completa solubilização do sacarídeo na solução.

Figura 12 - Diagrama experimental

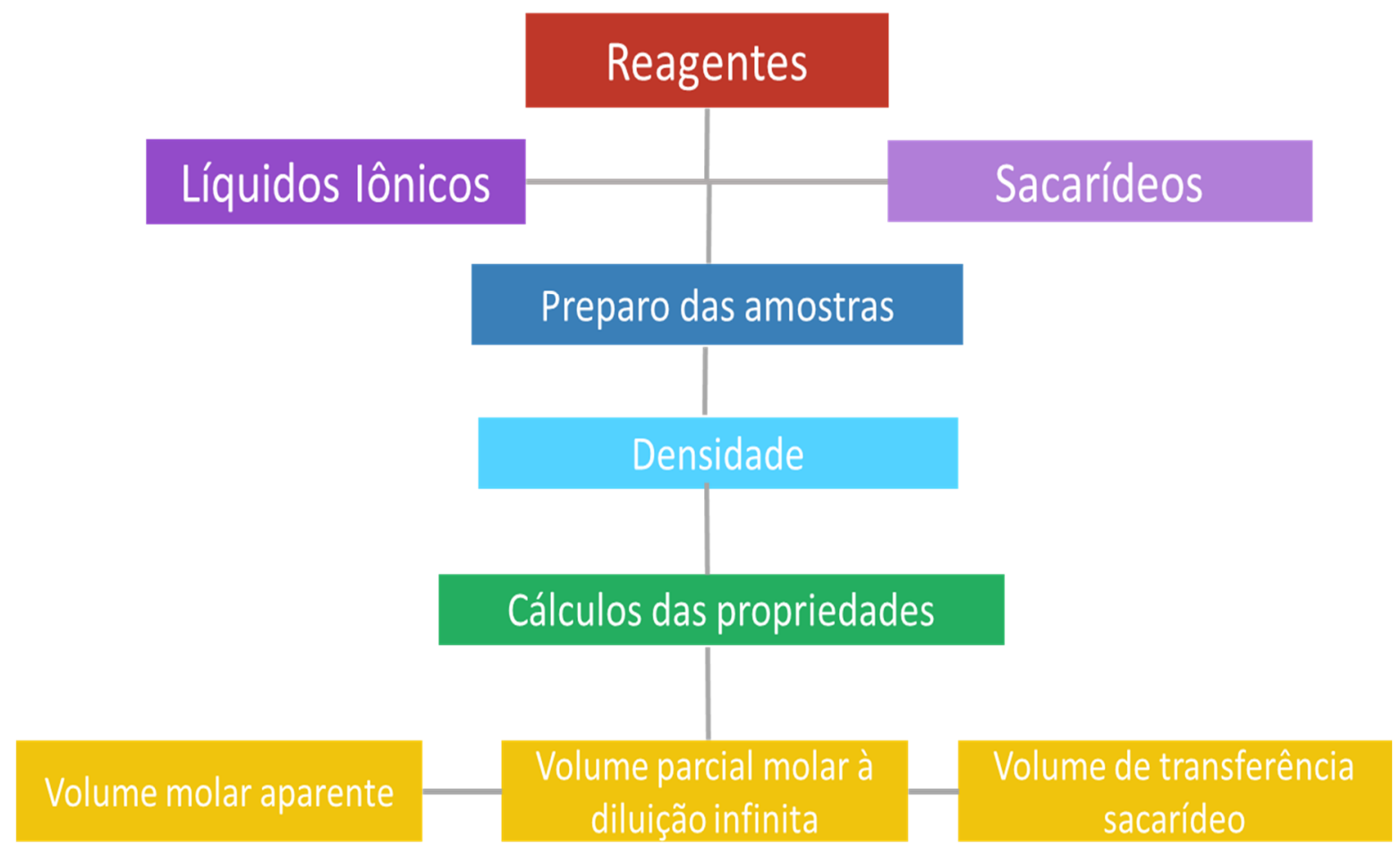




\section{RESULTADOS E DISCUSSÃO}

O presente capítulo tem como objetivo apresentar os resultados de densidade, volume molar aparente, volume molar aparente à diluição infinita e volume de transferência dos sacarídeos da água para soluções iônicas de EMIM DCA.

\subsection{DENSIDADE}

Inicialmente, foram realizadas medidas das densidades da água pura e das soluções iônicas, nas temperaturas de 283,15, 288,15, 293,15, 298,15 e 303,15 K. Estes valores encontram-se no APÊNDICE B. A seguir, foram determinadas as densidades das soluções de sacarídeos em água pura e em diferentes concentrações de soluções iônicas e temperaturas.

\subsubsection{Sistema Glicose}

As figuras 13 - 18 apresentam o comportamento da densidade das soluções de glicose em água pura e nas soluções iônicas de concentração de $0,025,0,05,0,075$ e $0,1 \mathrm{~mol} \cdot \mathrm{kg}^{-1}$, respectivamente, em função da molalidade da glicose, a diferentes temperaturas.

Figura 13 - Densidade das soluções de glicose em água pura, em função da molalidade da glicose, a diferentes temperaturas: $\square 283,15 \mathrm{~K} ; \bigcirc 288,15 \mathrm{~K} ; \diamond 293,15 \mathrm{~K} ; \triangle 298,15 \mathrm{~K}$; $\times 303,15 \mathrm{~K}$. As linhas representam as tendências dos resultados obtidos experimentalmente

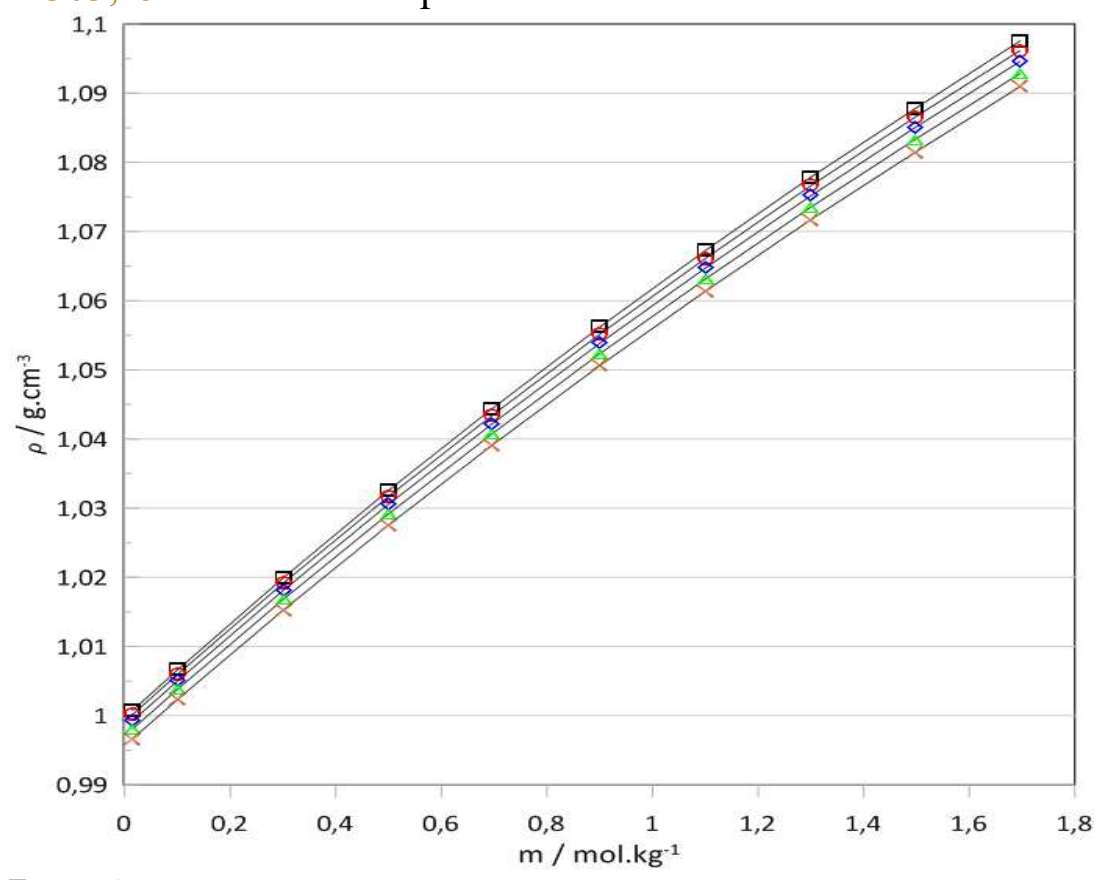

Fonte: Autor 
Figura 14 - Densidade das soluções de glicose com concentração iônica de $0,025 \mathrm{~mol} \cdot \mathrm{kg}^{-1}$, em função da molalidade da glicose, a diferentes temperaturas e pressão atmosférica: $\square 283,15 \mathrm{~K}$; $\bigcirc 288,15 \mathrm{~K} ; \diamond 293,15 \mathrm{~K} ; \triangle 298,15 \mathrm{~K} ; \times 303,15 \mathrm{~K}$. As linhas representam as tendências dos resultados obtidos experimentalmente

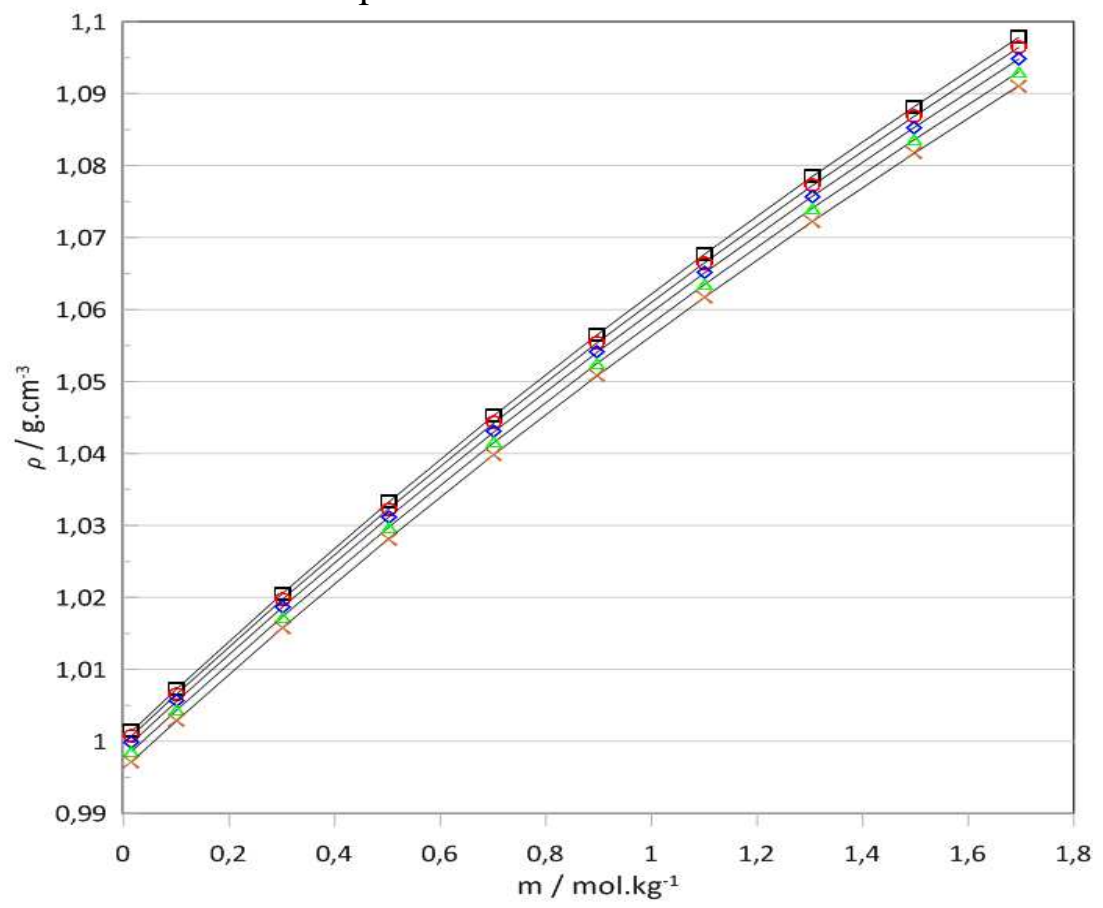

Fonte: Autor

Figura 15 - Densidade das soluções de glicose com concentração iônica de $0,050 \mathrm{~mol} \cdot \mathrm{kg}^{-1}$, em função da molalidade da glicose, a diferentes temperaturas e pressão atmosférica: $\square 283,15 \mathrm{~K}$; $\bigcirc 288,15 \mathrm{~K} ; \diamond 293,15 \mathrm{~K} ; \triangle 298,15 \mathrm{~K} ; \times 303,15 \mathrm{~K}$. As linhas representam as tendências dos resultados obtidos experimentalmente

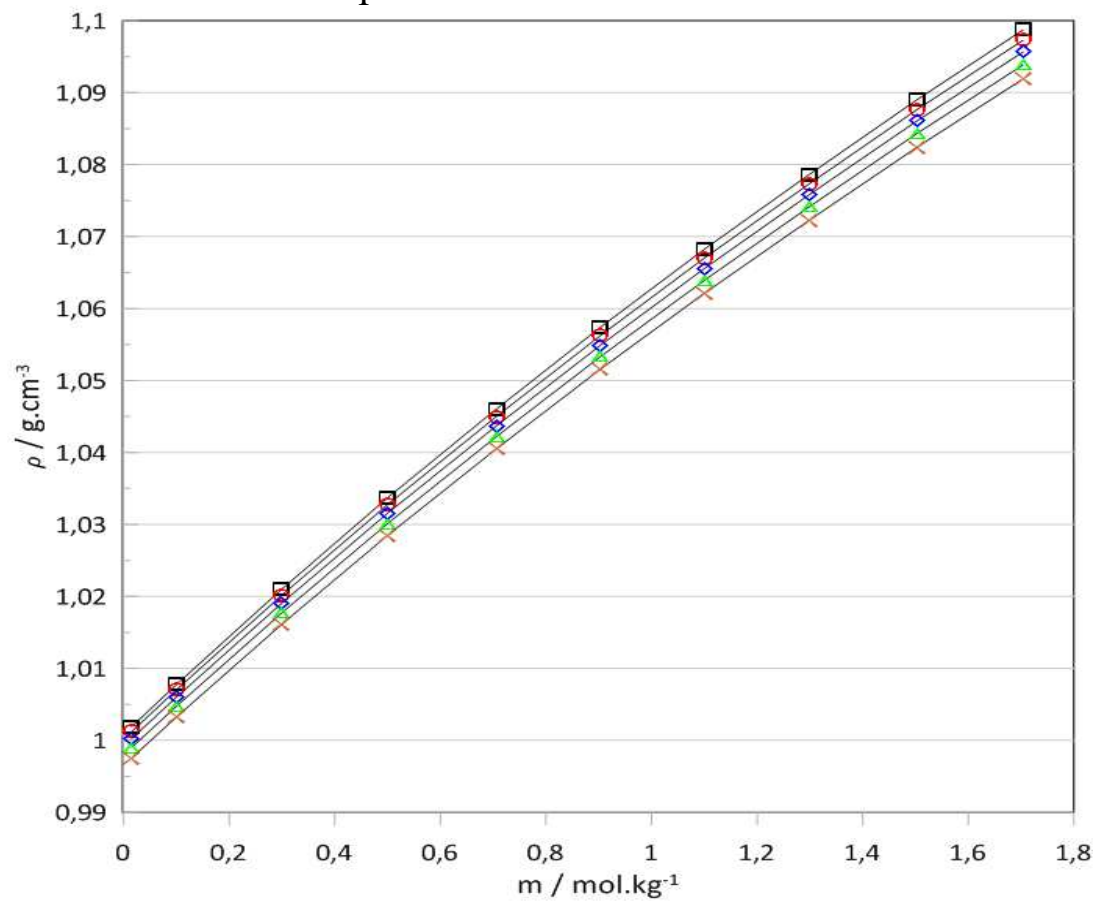

Fonte: Autor 
Figura 16 - Densidade das soluções de glicose com concentração iônica de $0,075 \mathrm{~mol} \cdot \mathrm{kg}^{-1}$, em função da molalidade da glicose, a diferentes temperaturas e pressão atmosférica: $\square 283,15 \mathrm{~K}$; $\bigcirc 288,15 \mathrm{~K} ; \diamond 293,15 \mathrm{~K} ; \triangle 298,15 \mathrm{~K} ; \times 303,15 \mathrm{~K}$. As linhas representam as tendências dos resultados obtidos experimentalmente

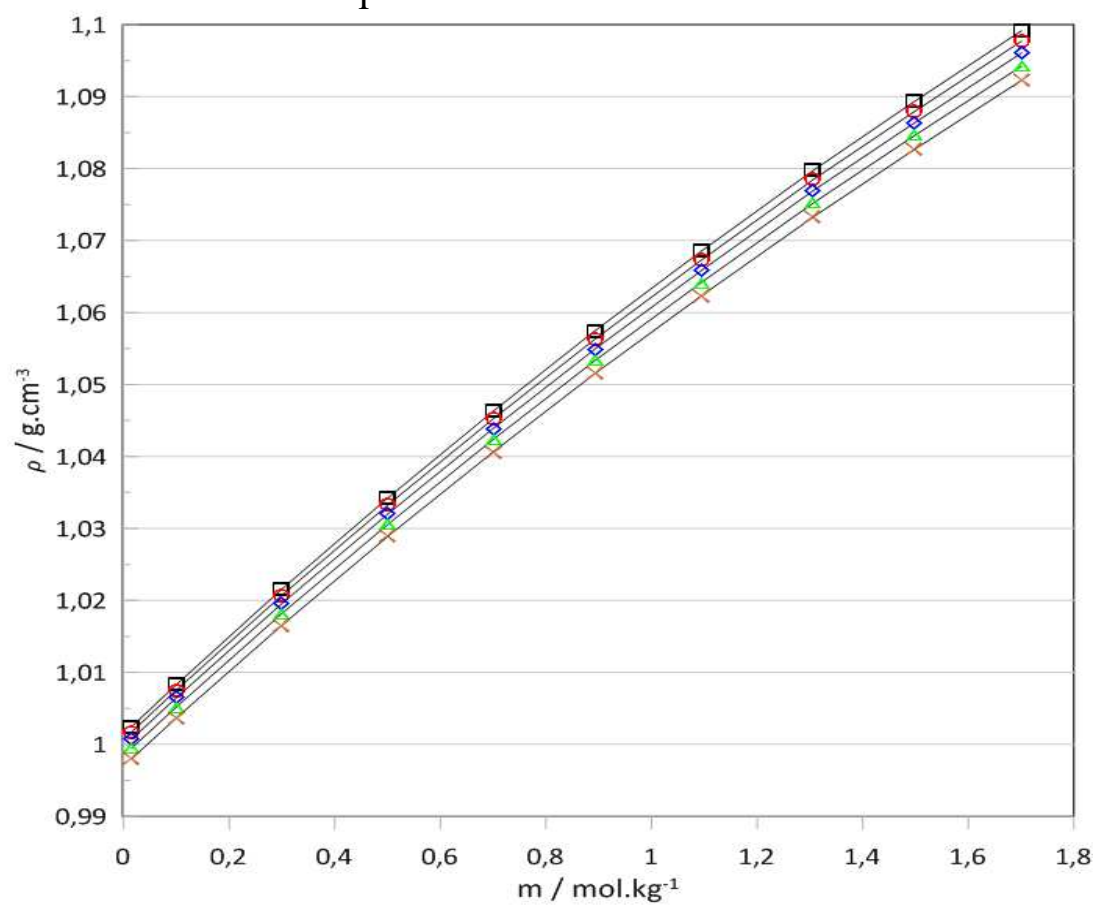

Fonte: Autor

Figura 17 - Densidade das soluções de glicose com concentração iônica de $0,10 \mathrm{~mol} \cdot \mathrm{kg}^{-1}$, em função da molalidade da glicose, a diferentes temperaturas e pressão atmosférica: $\square 283,15 \mathrm{~K}$; $\bigcirc 288,15 \mathrm{~K} ; \diamond 293,15 \mathrm{~K} ; \triangle 298,15 \mathrm{~K} ; \times 303,15 \mathrm{~K}$. As linhas representam as tendências dos resultados obtidos experimentalmente

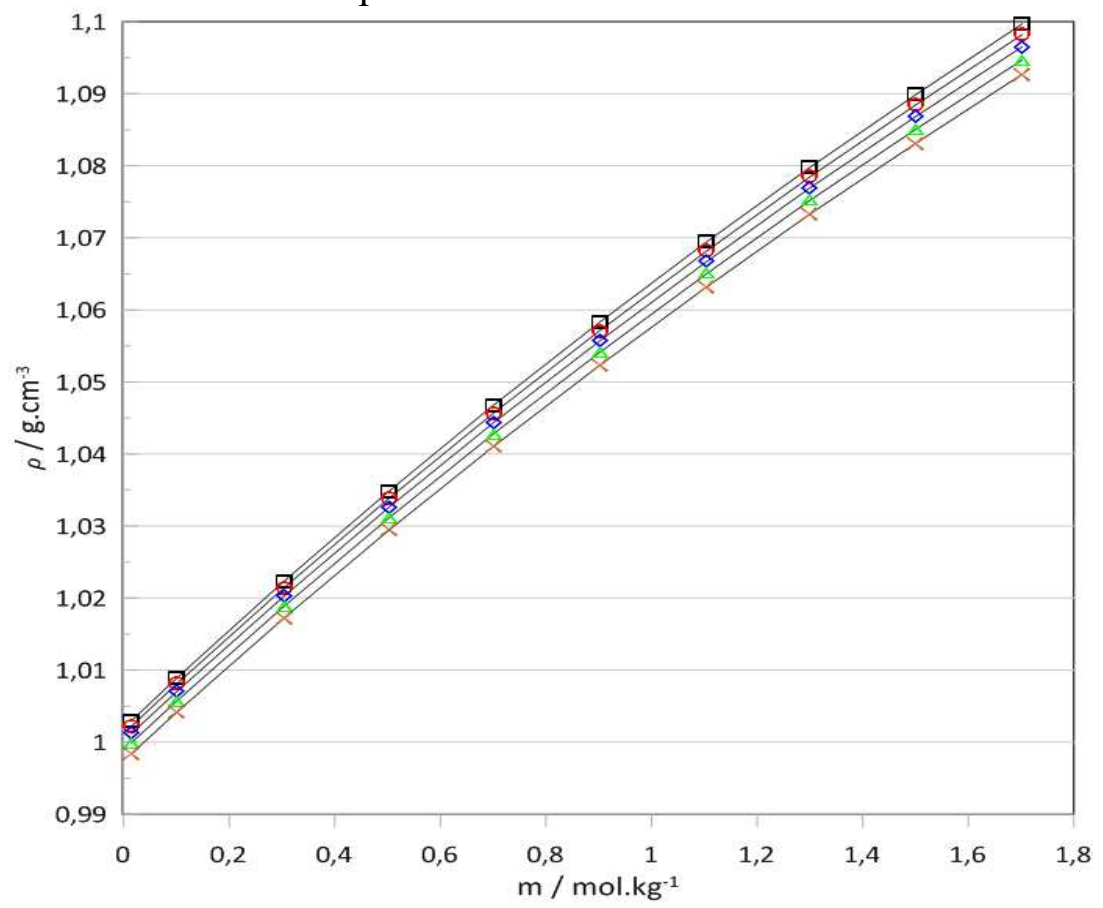

Fonte: Autor 
Para o sistema glicose, os valores de densidade diminuíram com o aumento de temperatura, tanto em água pura, quanto nas soluções iônicas. Com o aumento da molalidade da glicose e da concentração do líquido iônico também houve um aumento da densidade das soluções.

\subsubsection{Sistema Xilose}

As figuras 18 -22apresentam o comportamento da densidade das soluções de xilose em água pura e nas soluções iônicas de concentração de $0,025,0,05,0,075$ e $0,1 \mathrm{~mol} \cdot \mathrm{kg}^{-1}$, respectivamente, em função da molalidade da xilose, a diferentes temperaturas.

Figura 18 - Densidade das soluções de xilose em água pura, em função da molalidade da xilose, a diferentes temperaturas: $\square 283,15 \mathrm{~K} ; \bigcirc 288,15 \mathrm{~K} ; \diamond 293,15 \mathrm{~K} ; \triangle 298,15 \mathrm{~K} ; \times 303,15 \mathrm{~K}$. As linhas representam as tendências dos resultados obtidos experimentalmente

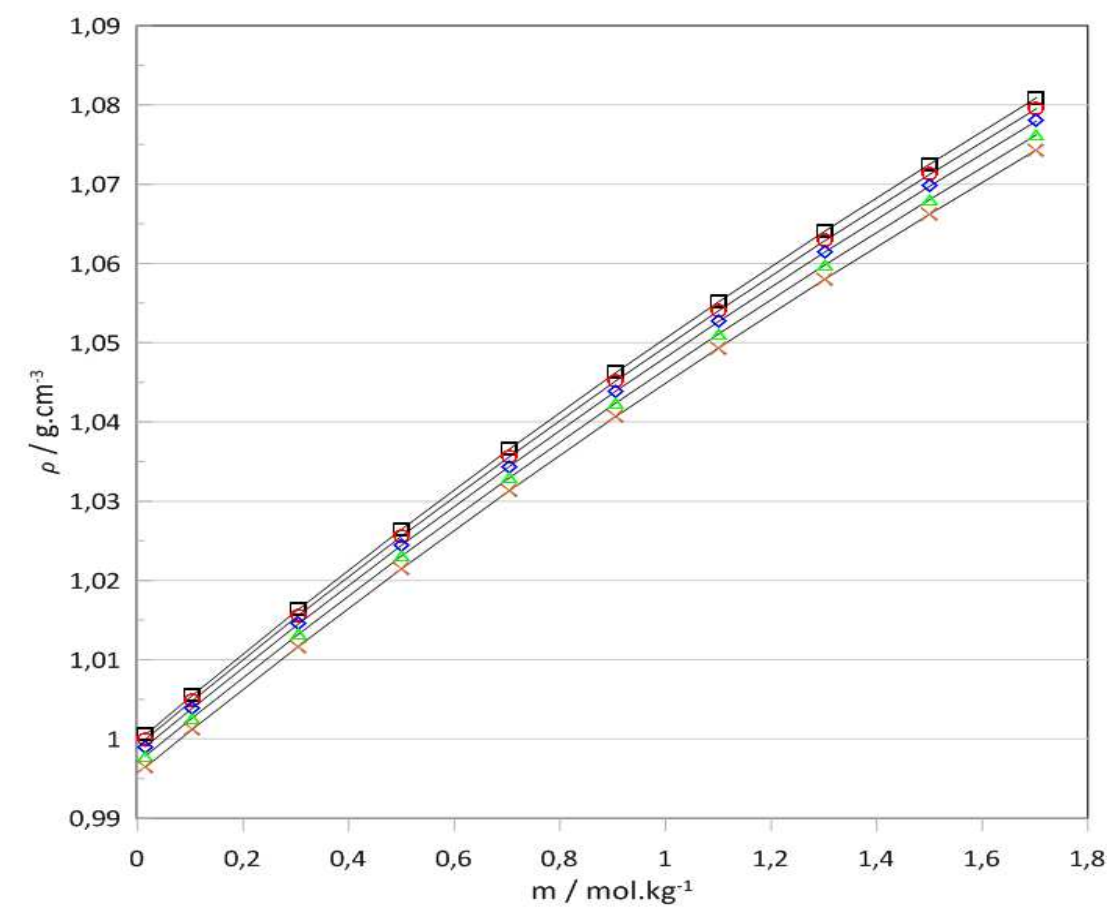

Fonte: Autor 
Figura 19 - Densidade das soluções de xilose com concentração iônica de $0,025 \mathrm{~mol} \cdot \mathrm{kg}^{-1}$, em função da molalidade da xilose, a diferentes temperaturas e pressão atmosférica: $\square 283,15 \mathrm{~K}$; $\bigcirc 288,15 \mathrm{~K} ; \diamond 293,15 \mathrm{~K} ; \triangle 298,15 \mathrm{~K} ; \times 303,15 \mathrm{~K}$. As linhas representam as tendências dos resultados obtidos experimentalmente

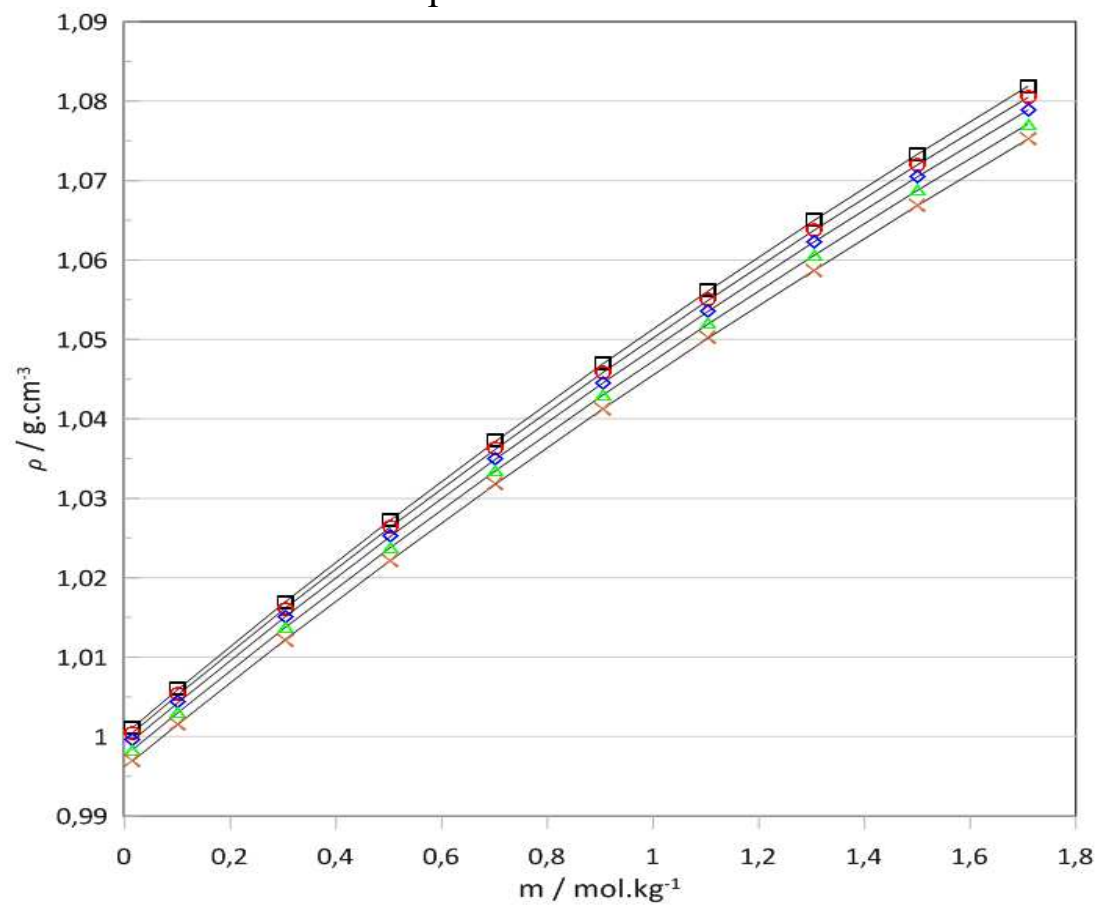

Fonte: Autor

Figura 20 - Densidade das soluções de xilose com concentração iônica de $0,050 \mathrm{~mol} \cdot \mathrm{kg}^{-1}$, em função da molalidade da xilose, a diferentes temperaturas e pressão atmosférica: $\square 283,15 \mathrm{~K}$; $\bigcirc 288,15 \mathrm{~K} ; \diamond 293,15 \mathrm{~K} ; \triangle 298,15 \mathrm{~K} ; \times 303,15 \mathrm{~K}$. As linhas representam as tendências dos resultados obtidos experimentalmente

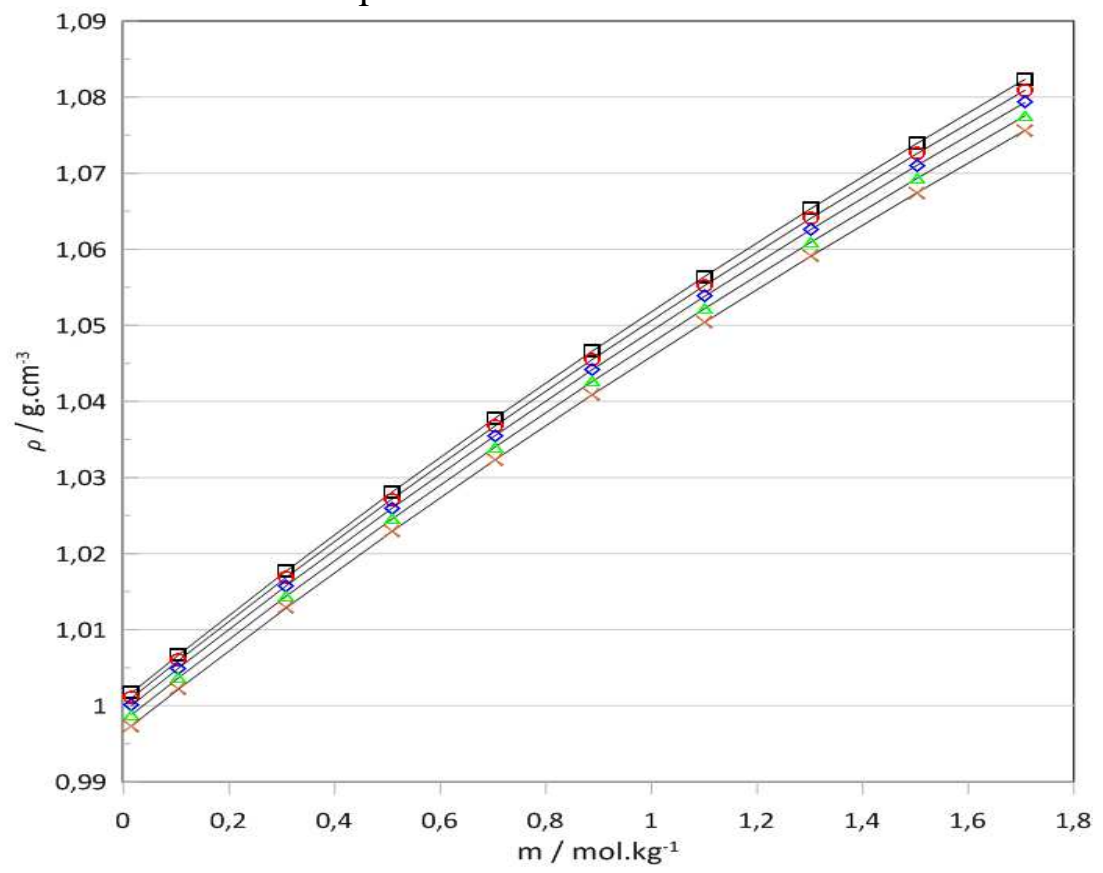

Fonte: Autor 
Figura 21 - Densidade das soluções de xilose com concentração iônica de $0,075 \mathrm{~mol} \cdot \mathrm{kg}^{-1}$, em função da molalidade da xilose, a diferentes temperaturas e pressão atmosférica: $\square 283,15 \mathrm{~K}$; $\bigcirc 288,15 \mathrm{~K} ; \diamond 293,15 \mathrm{~K} ; \triangle 298,15 \mathrm{~K} ; \times 303,15 \mathrm{~K}$. As linhas representam as tendências dos resultados obtidos experimentalmente

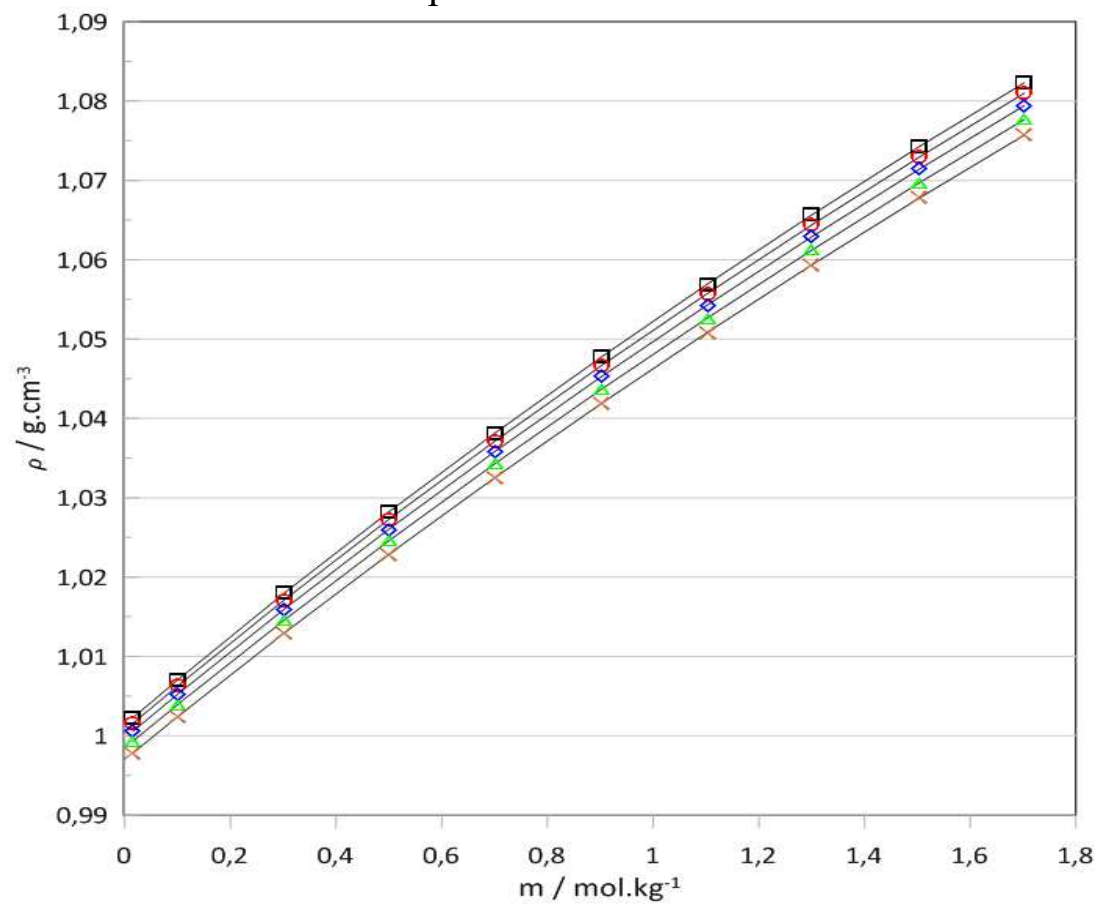

Fonte: Autor

Figura 22 - Densidade das soluções de xilose com concentração iônica de $0,10 \mathrm{~mol} \cdot \mathrm{kg}^{1}$, em função da molalidade da xilose, a diferentes temperaturas e pressão atmosférica: $\square 283,15 \mathrm{~K}$; $\bigcirc 288,15 \mathrm{~K} ; \diamond 293,15 \mathrm{~K} ; \triangle 298,15 \mathrm{~K} ; \times 303,15 \mathrm{~K}$. As linhas representam as tendências dos resultados obtidos experimentalmente

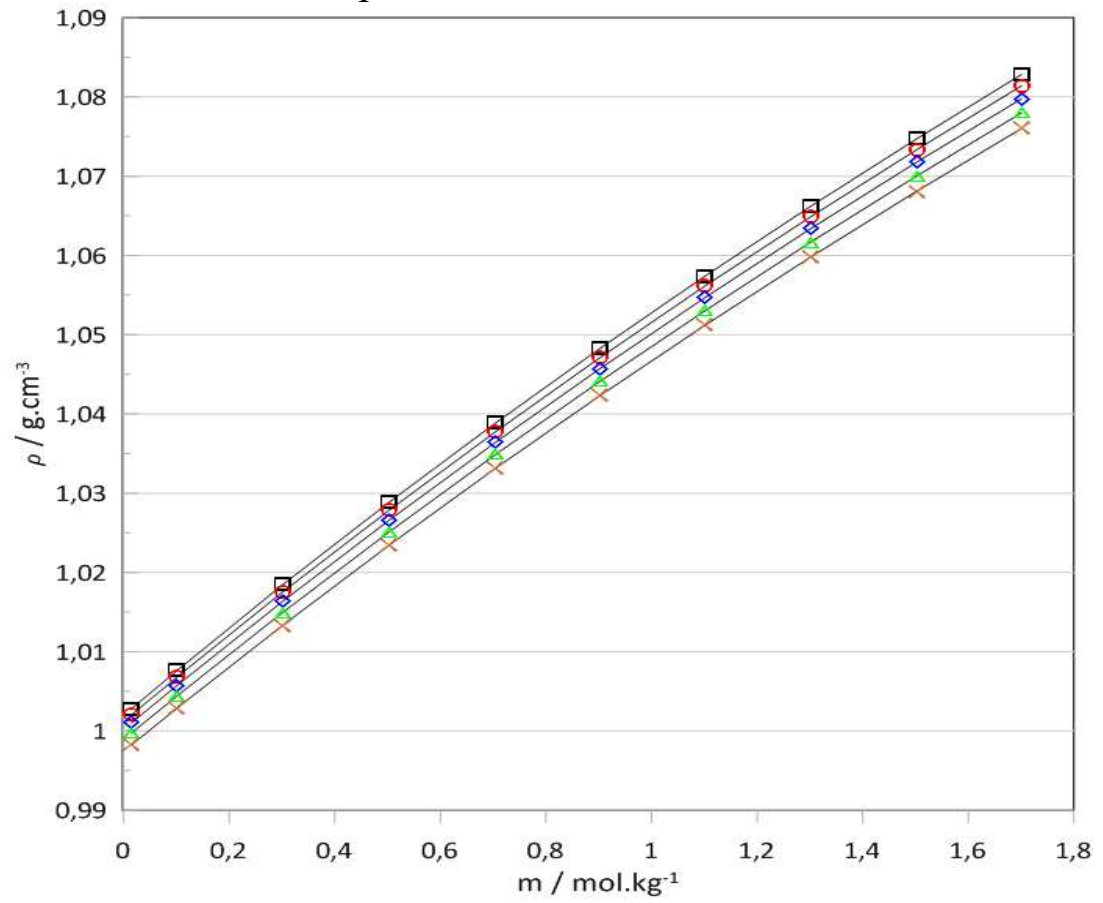

Fonte: Autor 
Para o sistema xilose, os valores de densidade diminuíram com o aumento de temperatura, tanto em água pura, quanto nas soluções iônicas. Com o aumento da molalidade da xilose e da concentração do líquido iônico também houve um aumento da densidade das soluções.

\subsubsection{Sistema Sacarose}

As figuras 23 - 27 apresentam o comportamento da densidade das soluções de sacarose em água pura e nas soluções iônicas de concentração de $0,025,0,05,0,075$ e $0,1 \mathrm{~mol} \cdot \mathrm{kg}^{-1}$, respectivamente, em função da molalidade da sacarose, a diferentes temperaturas.

Figura 23 - Densidade das soluções de sacarose em água pura, em função da molalidade da sacarose, a diferentes temperaturas: $\square 283,15 \mathrm{~K} ; \bigcirc 288,15 \mathrm{~K} ; \diamond 293,15 \mathrm{~K} ; \triangle 298,15 \mathrm{~K}$; × $303,15 \mathrm{~K}$. As linhas representam as tendências dos resultados obtidos experimentalmente

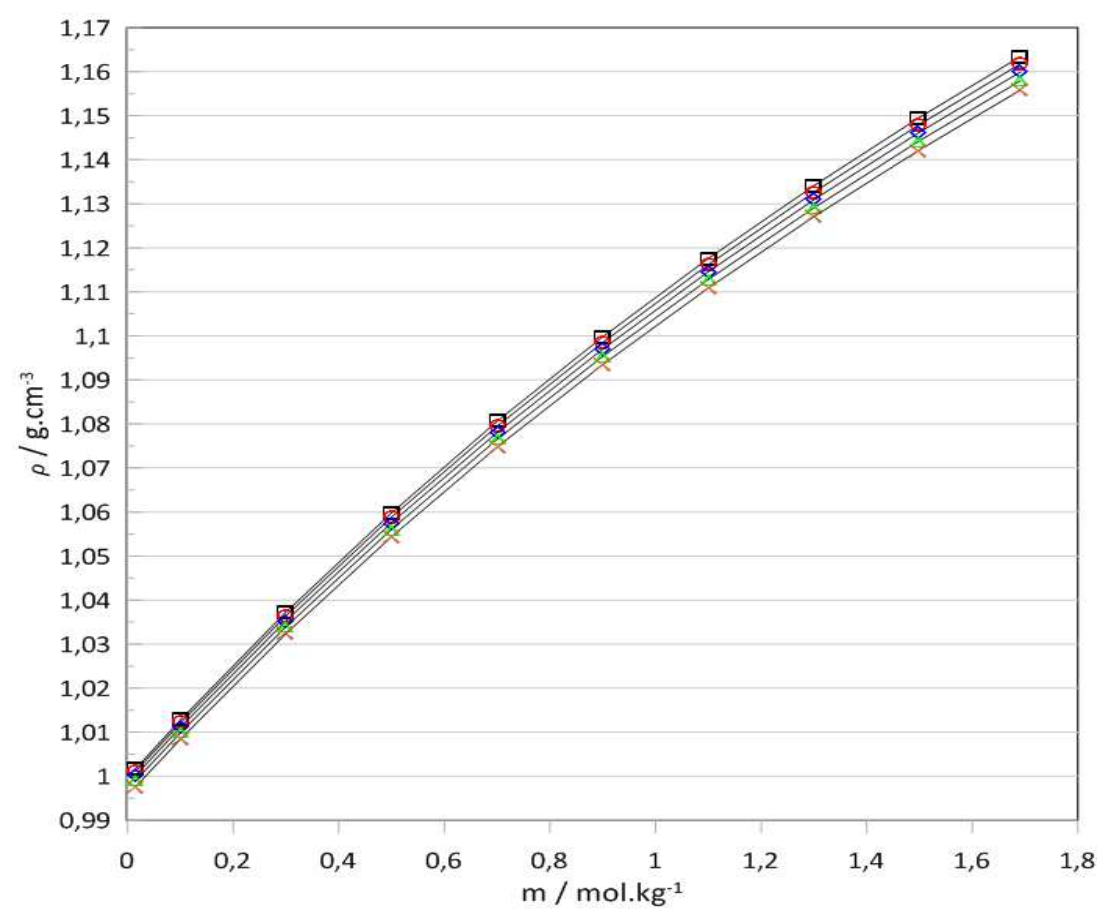

Fonte: Autor 
Figura 24 - Densidade das soluções de sacarose com concentração iônica de $0,025 \mathrm{~mol} \cdot \mathrm{kg}^{1}$, em função da molalidade da sacarose, a diferentes temperaturas e pressão atmosférica: $\square 283,15$ $\mathrm{K} ; \bigcirc 288,15 \mathrm{~K} ; \diamond 293,15 \mathrm{~K} ; \triangle 298,15 \mathrm{~K} ; \times 303,15 \mathrm{~K}$. As linhas representam as tendências dos resultados obtidos experimentalmente

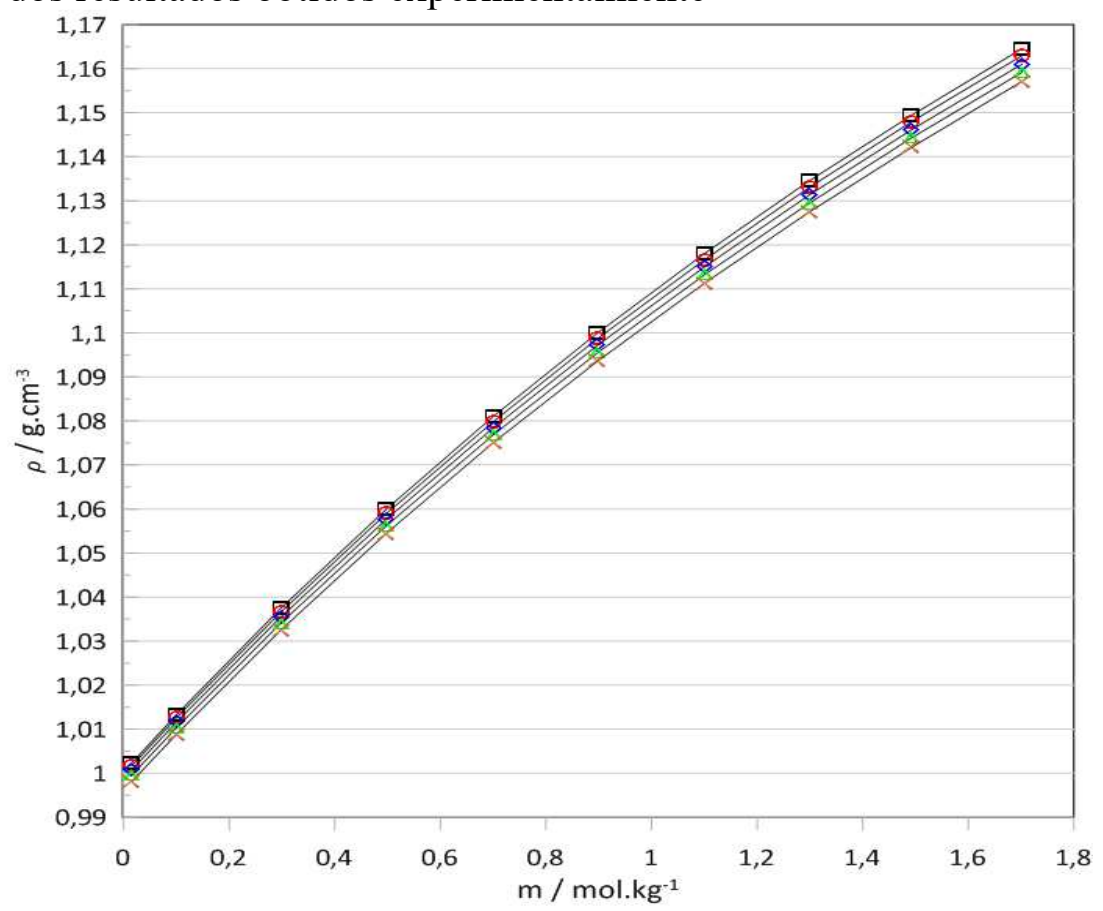

Fonte: Autor

Figura 25 - Densidade das soluções de sacarose com concentração iônica de $0,050 \mathrm{~mol} \cdot \mathrm{kg}^{-1}$, em função da molalidade da sacarose, a diferentes temperaturas e pressão atmosférica: $\square 283,15$ $\mathrm{K} ; \bigcirc 288,15 \mathrm{~K} ; \diamond 293,15 \mathrm{~K} ; \triangle 298,15 \mathrm{~K} ; \times 303,15 \mathrm{~K}$. As linhas representam astendências dos resultados obtidos experimentalmente

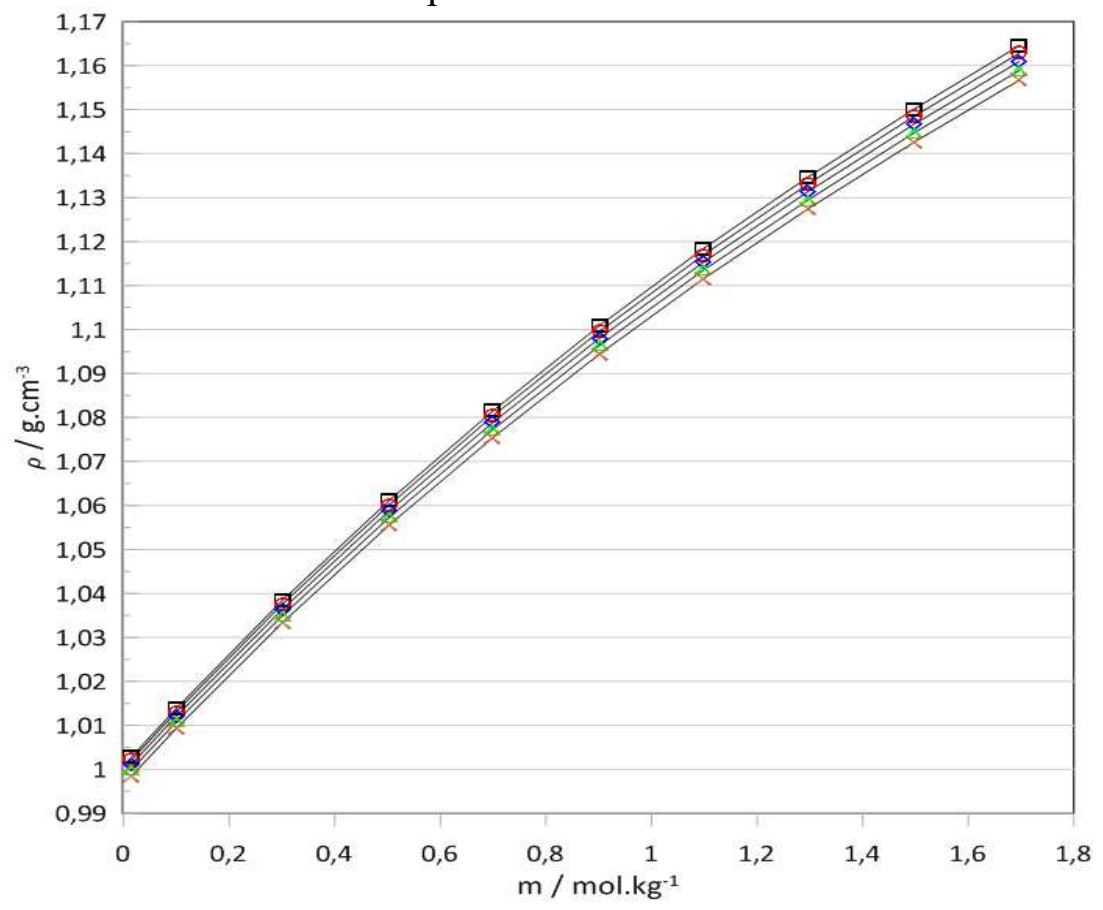

Fonte: Autor 
Figura 26 - Densidade das soluções de sacarose com concentração iônica de $0,075 \mathrm{~mol} \cdot \mathrm{kg}^{1}$, em função da molalidade da sacarose, a diferentes temperaturas e pressão atmosférica: $283,15 \mathrm{~K} ; \bigcirc 288,15 \mathrm{~K} ; \diamond 293,15 \mathrm{~K} ; \triangle 298,15 \mathrm{~K} ; \times 303,15 \mathrm{~K}$. As linhas representam as tendências dos resultados obtidos experimentalmente

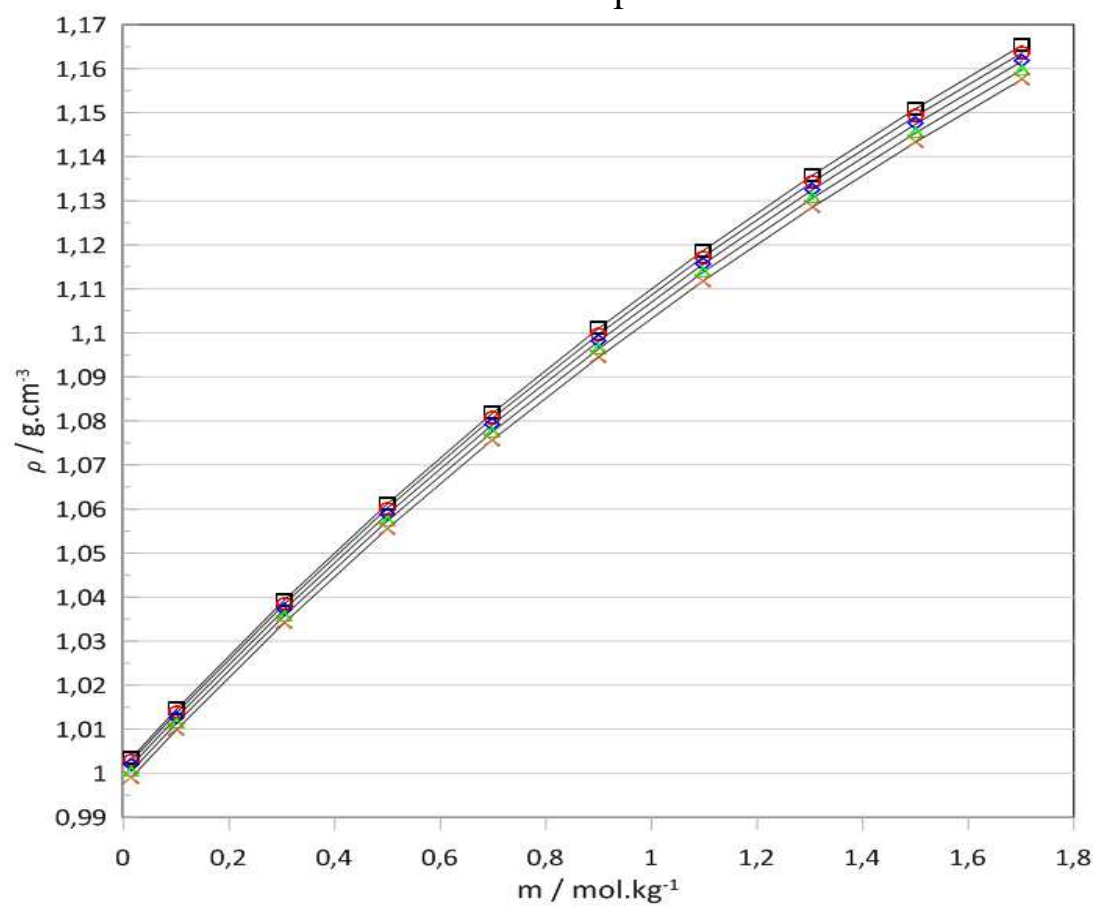

Fonte: Autor

Figura 27 - Densidade das soluções de sacarose com concentração iônica de $0,10 \mathrm{~mol} \cdot \mathrm{kg}^{1}$, em função da molalidade da sacarose, a diferentes temperaturas e pressão atmosférica: $\square 283,15$ $\mathrm{K} ; \bigcirc 288,15 \mathrm{~K} ; \diamond 293,15 \mathrm{~K} ; \triangle 298,15 \mathrm{~K} ; \times 303,15 \mathrm{~K}$. As linhas representam as tendências dos resultados obtidos experimentalmente

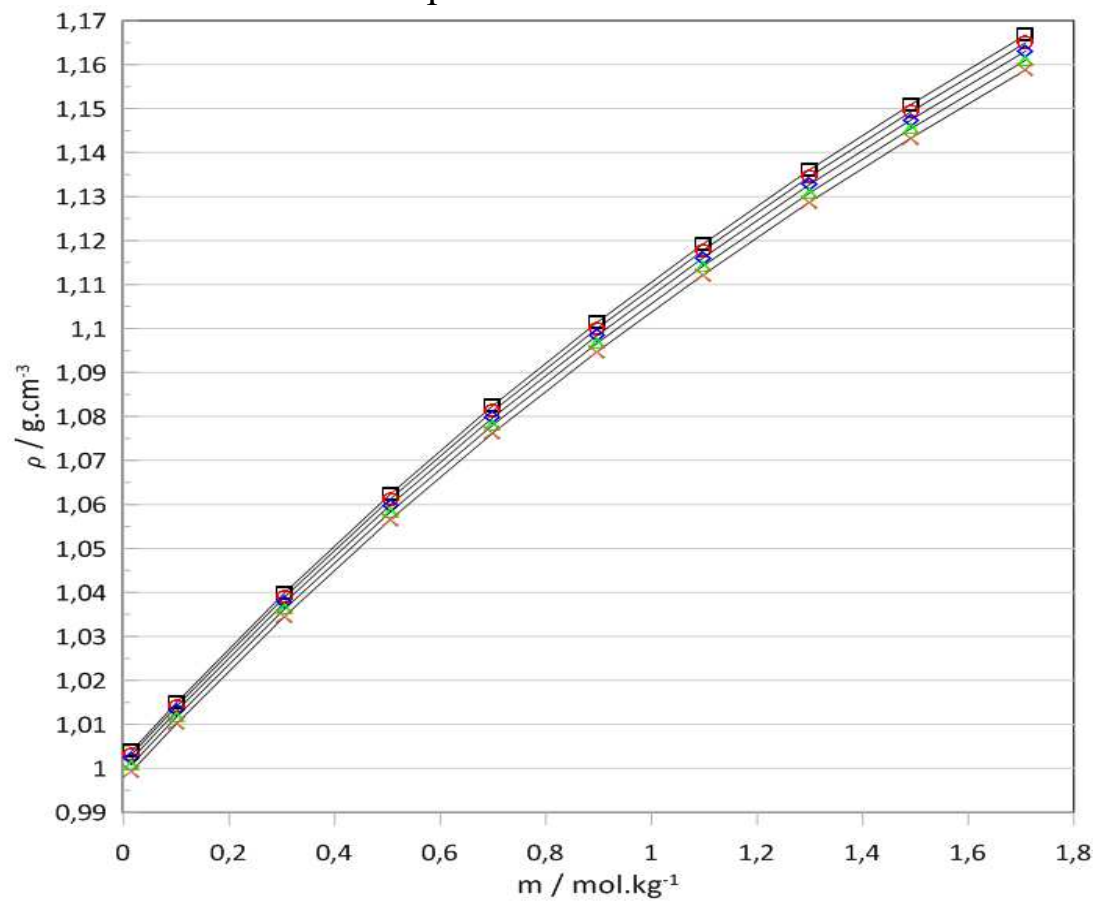

Fonte: Autor 
Para o sistema sacarose, os valores de densidade diminuíram com o aumento de temperatura, tanto em água pura, quanto nas soluções iônicas. Com o aumento da molalidade da sacarose e da concentração do líquido iônico também houve um aumento da densidade das soluções.

\subsection{VOLUMES MOLARES APARENTE}

Fazendo uso da equação (2), foi possível calcular os volumes molares aparentes dos sistemas de sacarídeos na água e nas diferentes concentrações soluções iônicas, a diferentes temperaturas.

$$
V_{f_{S}}=\left(\frac{M_{S}}{r}\right)-\frac{1000 ¥\left(r-r_{0}\right)}{m_{s a} ¥ r ¥ r_{0}}
$$

\subsubsection{Sistema Glicose}

As figuras 28-32 apresentam o comportamento do volume molar aparente das soluções de glicose em água pura e nas soluções iônicas de concentração de 0,025, 0,05, 0,075 e 0,1 $\mathrm{mol} \cdot \mathrm{kg}^{-1}$, em função da molalidade da glicose, a diferentes temperaturas.

Figura 28 - Volume molar aparente da glicose em água pura, em função da molalidade da glicose, a diferentes temperaturas e pressão atmosférica: $\square 283,15 \mathrm{~K} ; \bigcirc 288,15 \mathrm{~K} ; \diamond 293,15$ $\mathrm{K} ; \triangle 298,15 \mathrm{~K} ; \times 303,15 \mathrm{~K}$. As linhas representam as tendências dos resultados obtidos experimentalmente

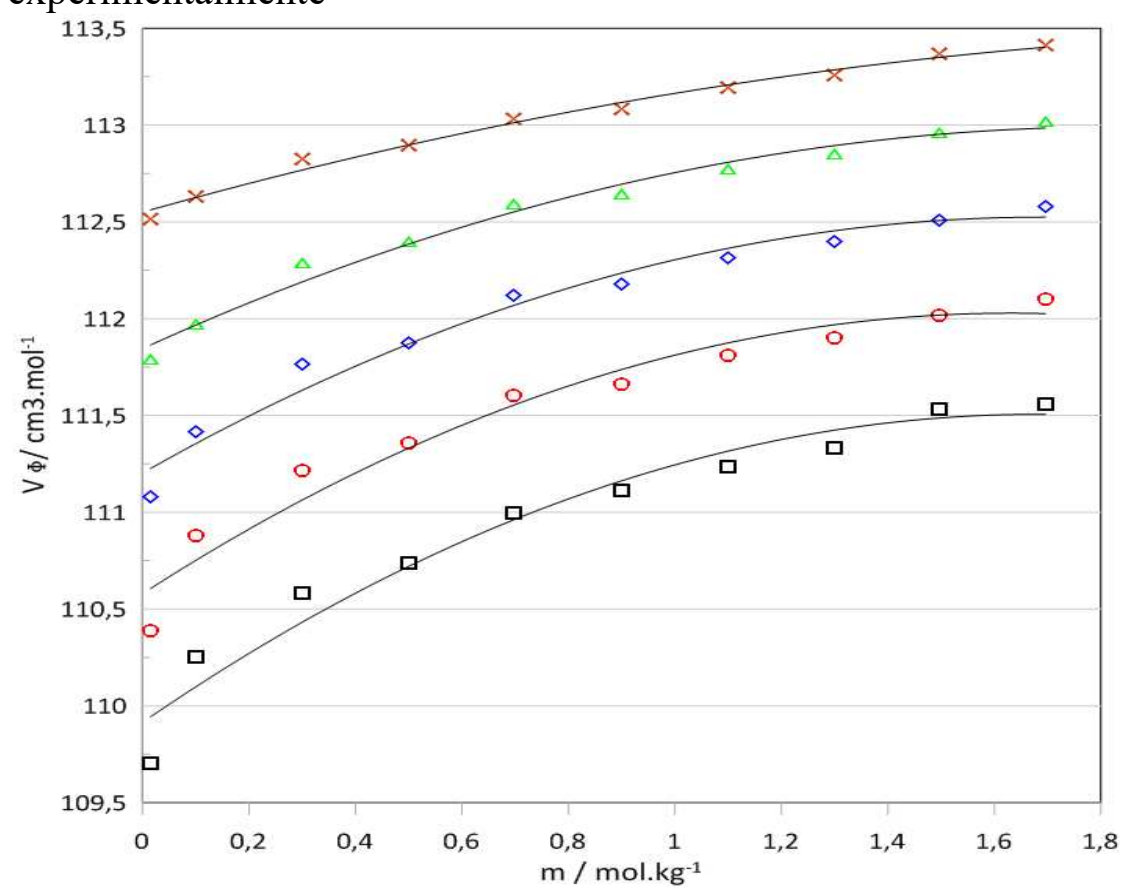

Fonte: Autor 
Figura 29 - Volume molar aparente da glicose em solução iônica de $0,025 \mathrm{~mol} \cdot \mathrm{kg}^{-1}$, em função da molalidade da glicose, a diferentes temperaturas e pressão atmosférica: $\square 283,15 \mathrm{~K}$; $\bigcirc$ $288,15 \mathrm{~K} ; \diamond 293,15 \mathrm{~K} ; \triangle 298,15 \mathrm{~K} ; \times 303,15 \mathrm{~K}$. As linhas representam as tendências dos resultados obtidos experimentalmente

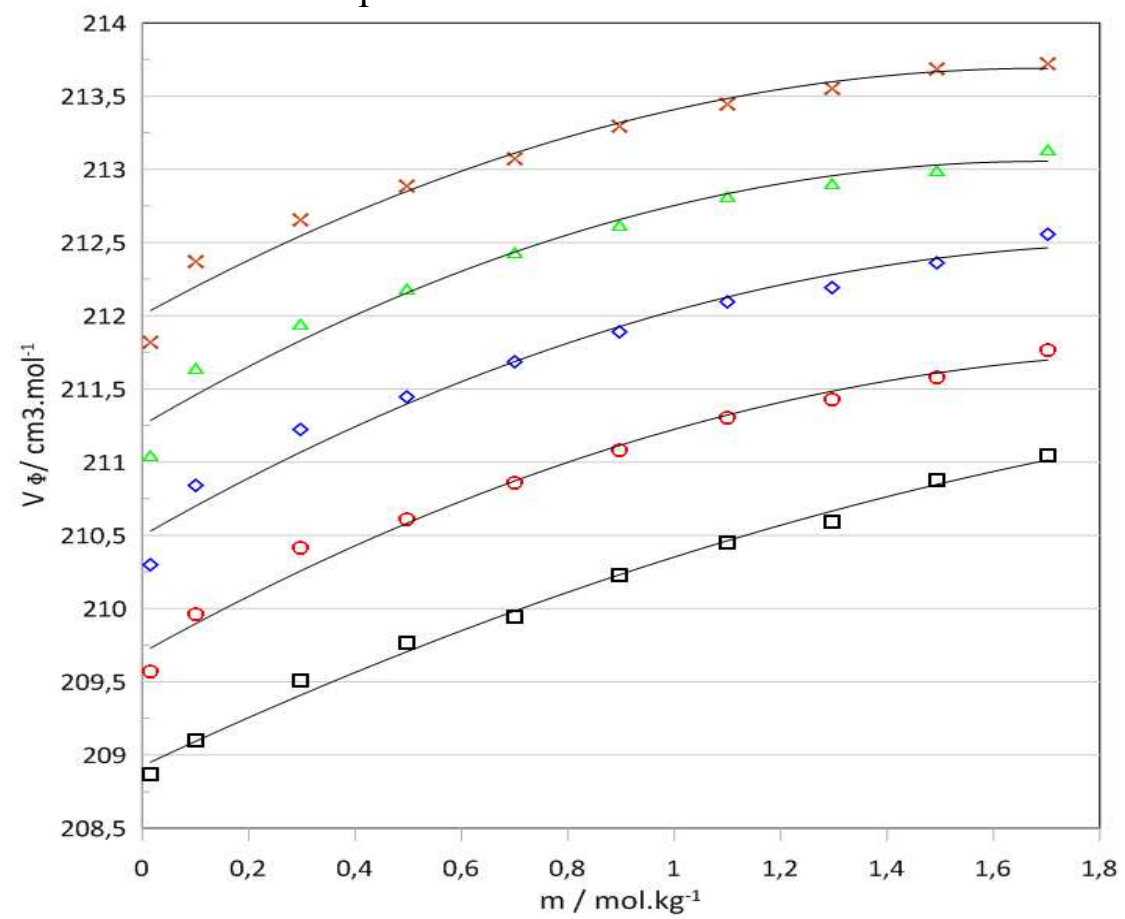

Fonte: Autor

Figura 30 - Volume molar aparente da glicose em solução iônica de $0,050 \mathrm{~mol} \cdot \mathrm{kg}^{-1}$, em função da molalidade da glicose, a diferentes temperaturas e pressão atmosférica: $\square 283,15 \mathrm{~K}$; $\bigcirc$ $288,15 \mathrm{~K} ; \diamond 293,15 \mathrm{~K} ; \triangle 298,15 \mathrm{~K} ; \times 303,15 \mathrm{~K}$. As linhas representam as tendências dos resultados obtidos experimentalmente

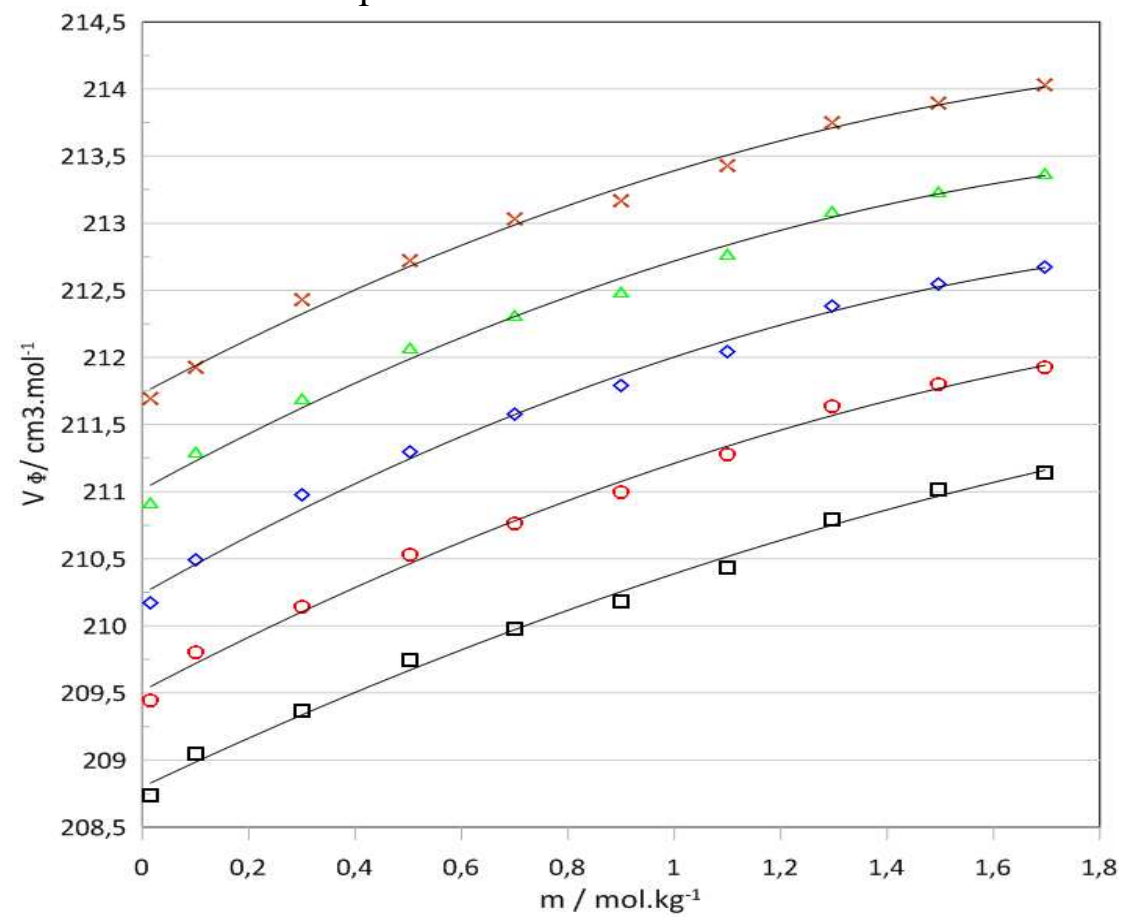

Fonte: Autor 
Figura 31 - Volume molar aparente da glicose em solução iônica de $0,075 \mathrm{~mol} \cdot \mathrm{kg}^{-1}$, em função da molalidade da glicose, a diferentes temperaturas e pressão atmosférica $\square 283,15 \mathrm{~K}$; $\bigcirc 288,15$ $\mathrm{K} ; \diamond 293,15 \mathrm{~K} ; \triangle 298,15 \mathrm{~K} ; \times 303,15 \mathrm{~K}$. As linhas representam as tendências dos resultados obtidos experimentalmente

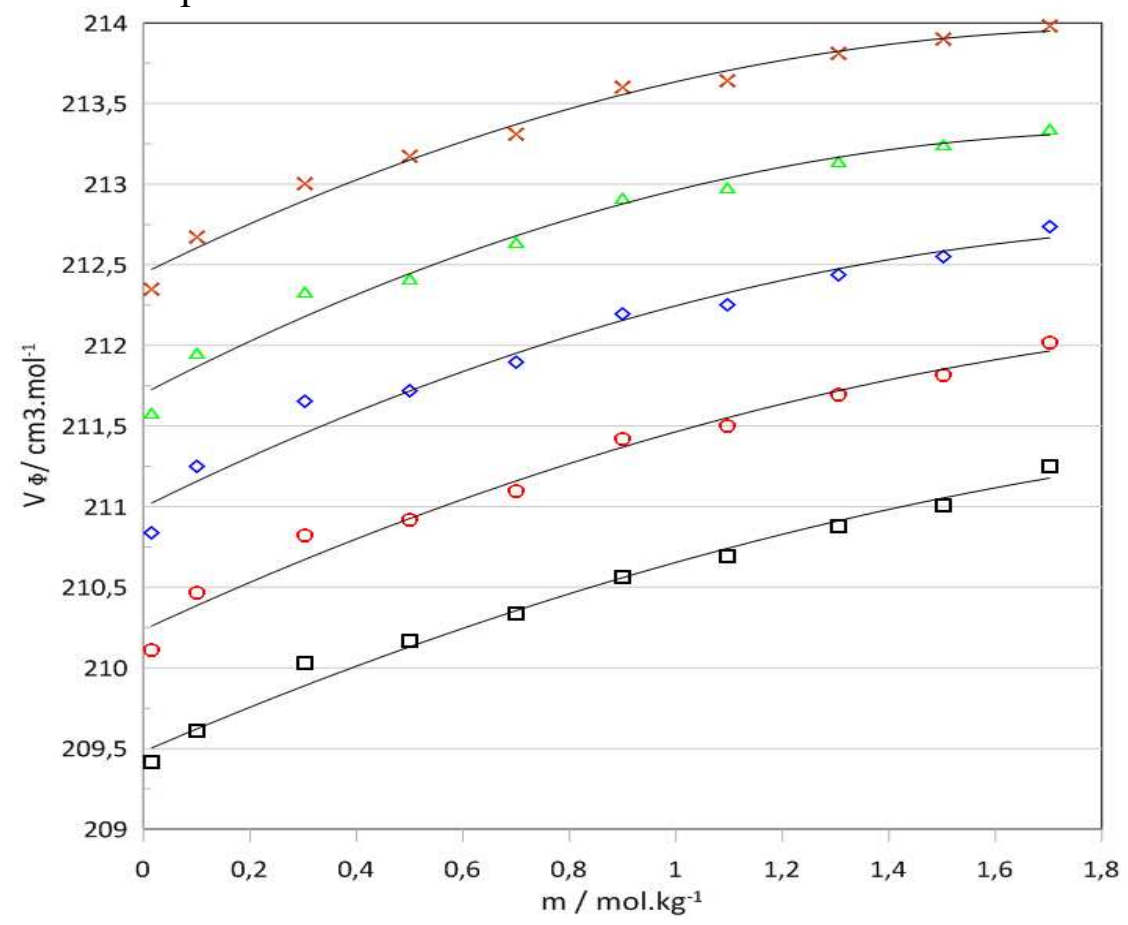

Fonte: Autor

Figura 32 - Volume molar aparente da glicose em solução iônica de $0,10 \mathrm{~mol} \cdot \mathrm{kg}^{-1}$, em função da molalidade da glicose, a diferentes temperaturas e pressão atmosférica: $\square 283,15 \mathrm{~K}$; $\bigcirc$ 288,15 K; $\diamond 293,15 \mathrm{~K} ; \triangle 298,15 \mathrm{~K} ; \times 303,15 \mathrm{~K}$. As linhas representam as tendências dos resultados obtidos experimentalmente

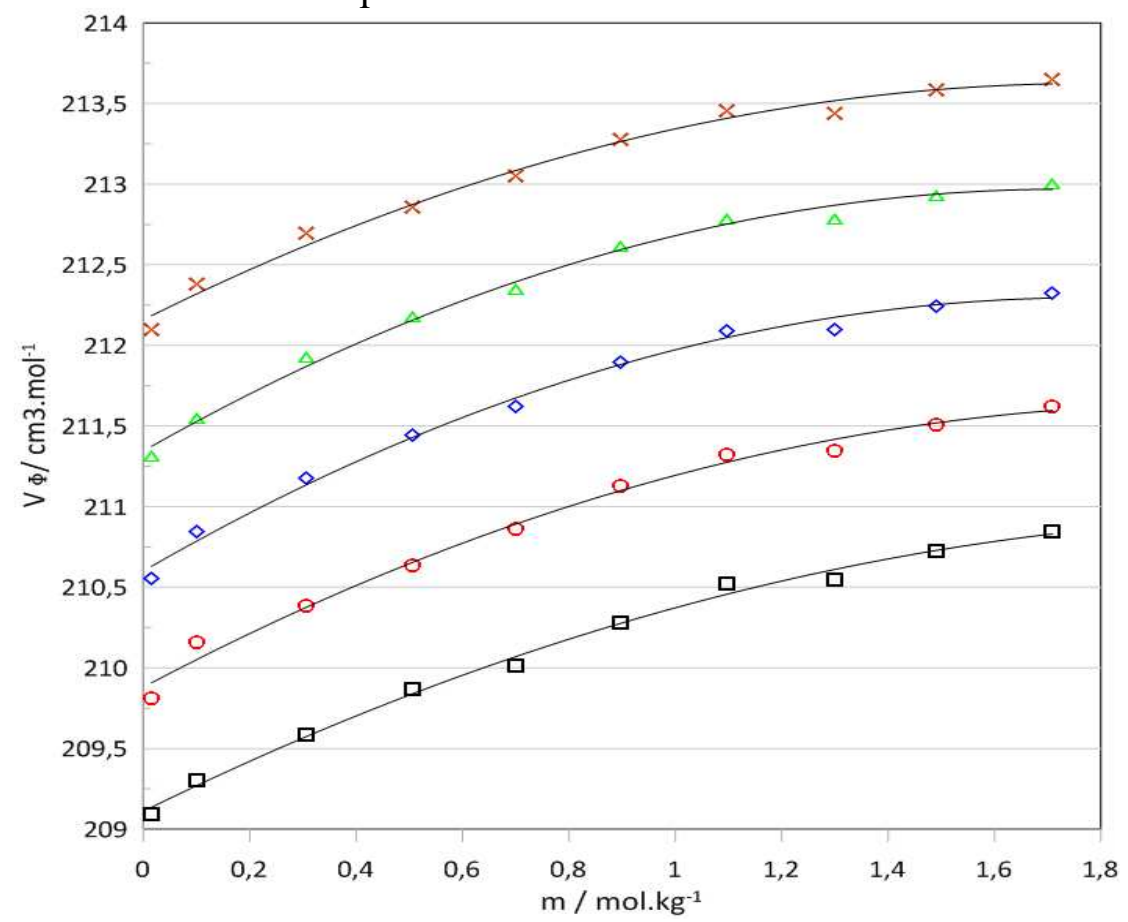

Fonte: Autor 
Os valores do volume molar aparente da glicose aumentaram com o aumento da temperatura para todos os sistemas estudados. Também foi possível observar um valor crescente de volume molar aparente com o aumento da molalidade da glicose.

\subsubsection{Sistema Xilose}

As figuras 33-37 apresentam o comportamento do volume molar aparente das soluções de xilose em água pura e nas soluções iônicas de concentração de $0,025,0,05,0,075$ e 0,1 $\mathrm{mol} \cdot \mathrm{kg}^{-1}$, em função da molalidade da xilose, a diferentes temperaturas.

Figura 33 - Volume molar aparente da xilose em água pura, em função da molalidade da xilose, a diferentes temperaturas e pressão atmosférica: $\square 283,15 \mathrm{~K} ; \bigcirc 288,15 \mathrm{~K}$; $\diamond 293,15 \mathrm{~K}$; $\triangle$ $298,15 \mathrm{~K} ; \times 303,15 \mathrm{~K}$. As linhas representam as tendências dos resultados obtidos experimentalmente

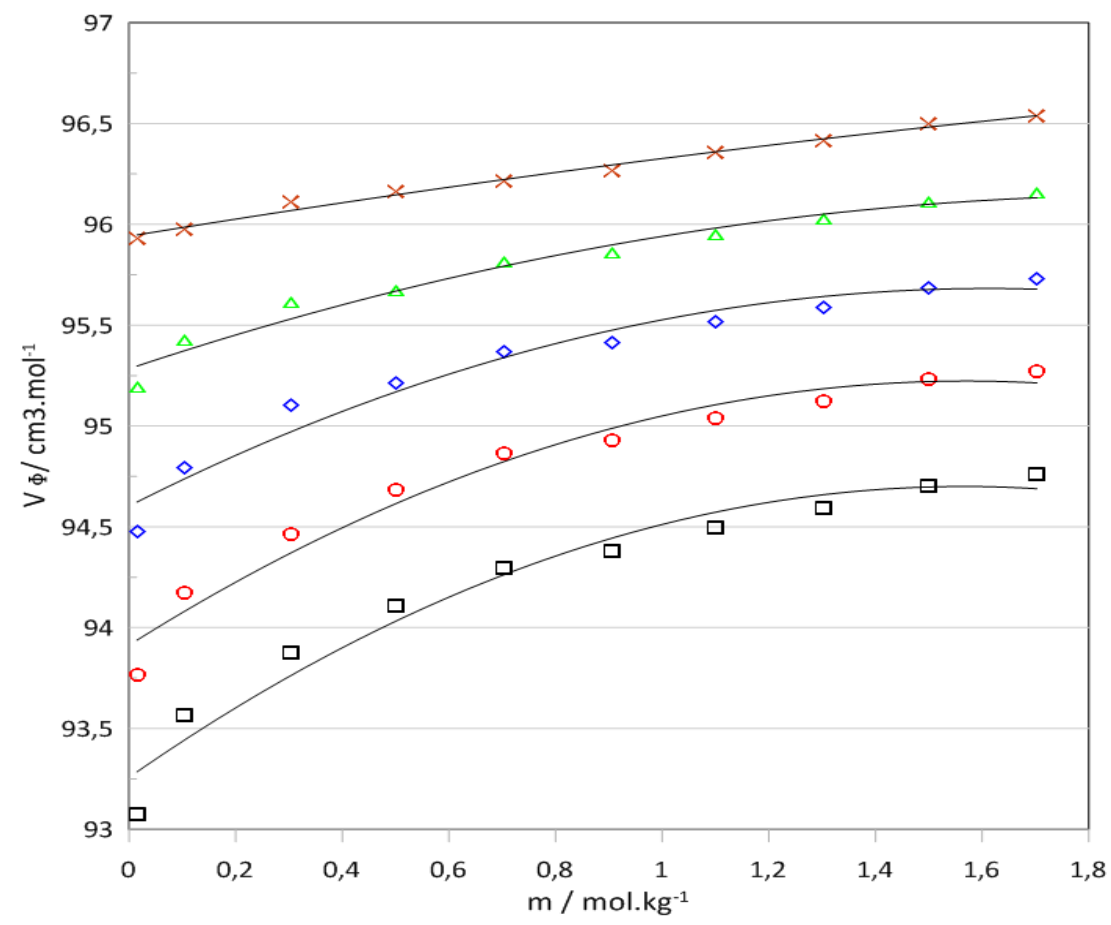

Fonte: Autor 
Figura 34 - Volume molar aparente da xilose em solução iônica de $0,025 \mathrm{~mol} \cdot \mathrm{kg}^{-1}$, em função da molalidade da xilose, a diferentes temperaturas e pressão atmosférica: $\square 283,15 \mathrm{~K}$; $\bigcirc$ $288,15 \mathrm{~K} ; \diamond 293,15 \mathrm{~K} ; \triangle 298,15 \mathrm{~K} ; \times 303,15 \mathrm{~K}$. As linhas representam as tendências dos resultados obtidos experimentalmente

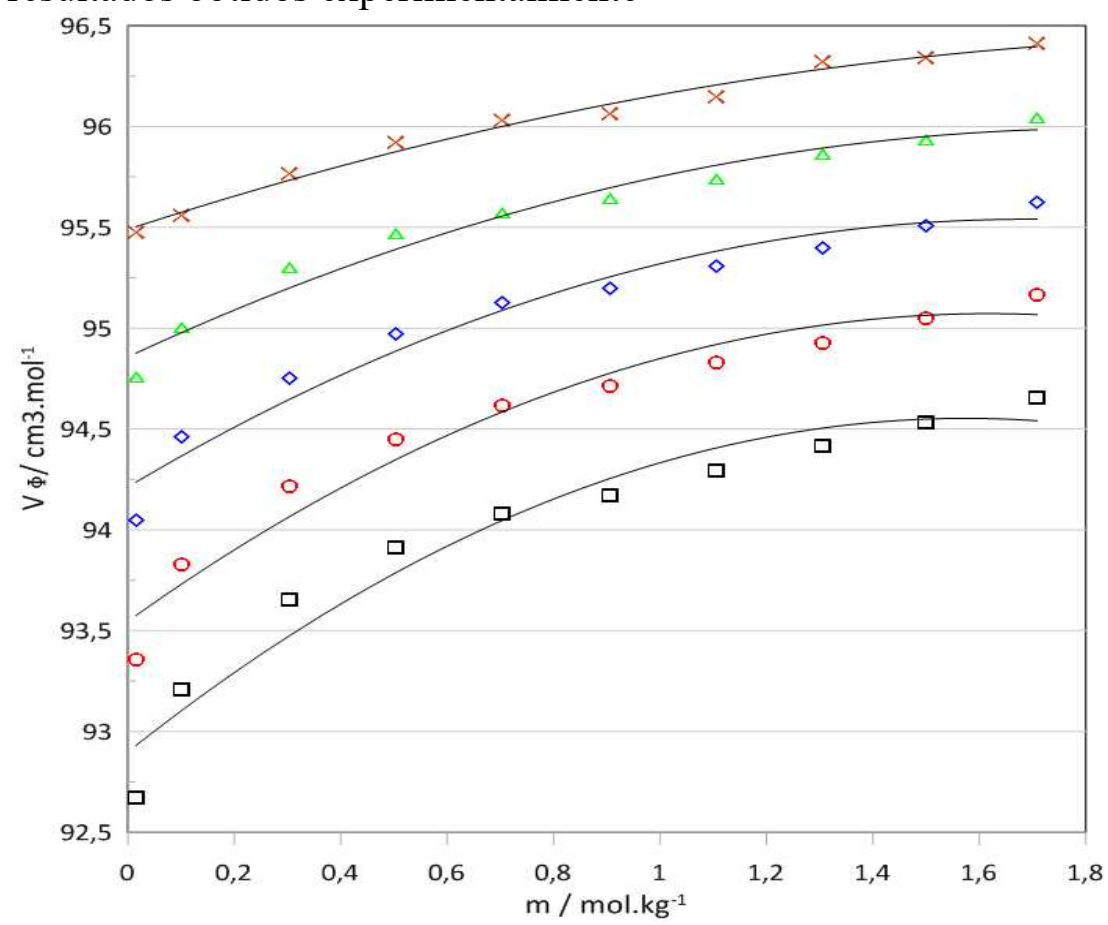

Fonte: Autor

Figura 35 - Volume molar aparente da xilose em solução iônica de $0,050 \mathrm{~mol} \cdot \mathrm{kg}^{-1}$, em função da molalidade da xilose, a diferentes temperaturas e pressão atmosférica: $\square 283,15 \mathrm{~K}$; $\bigcirc$ 288,15 K; $\diamond 293,15 \mathrm{~K} ; \triangle 298,15 \mathrm{~K} ; \times 303,15 \mathrm{~K}$. As linhas representam as tendências dos resultados obtidos experimentalmente

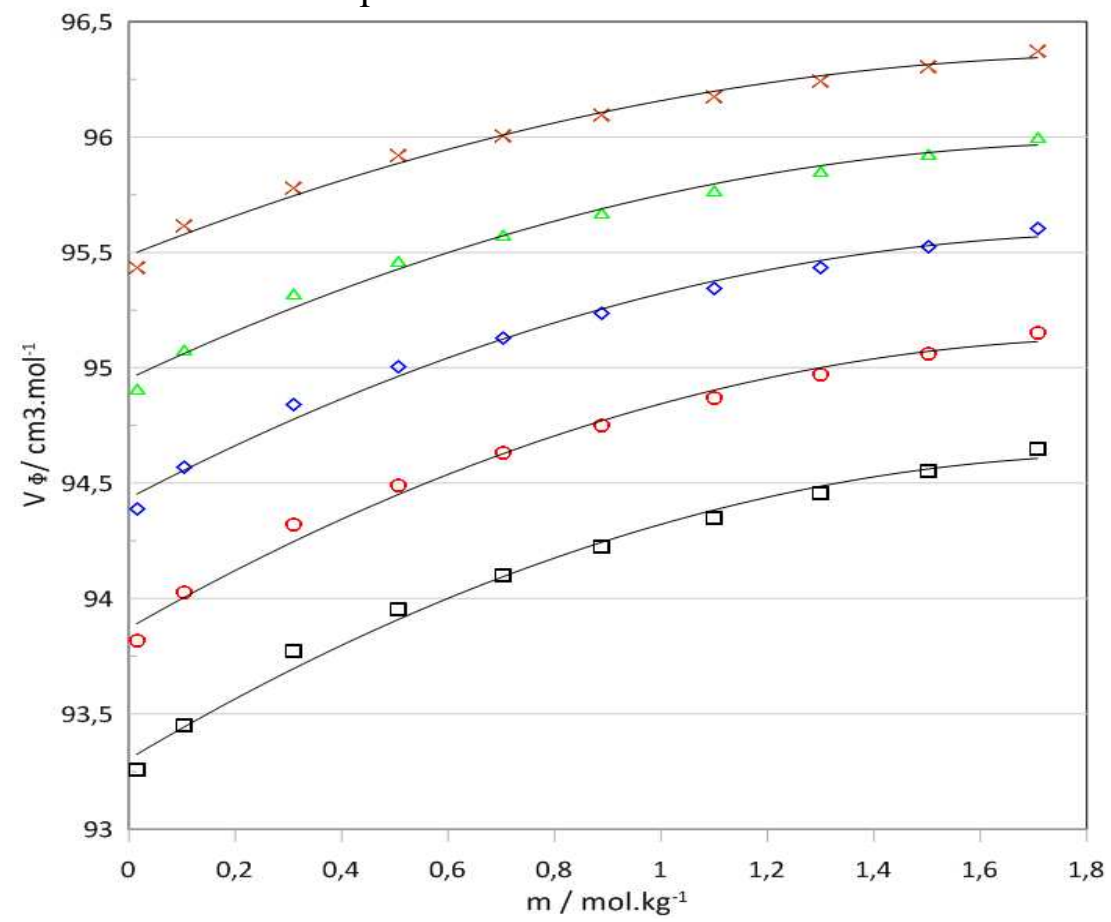

Fonte: Autor 
Figura 36 - Volume molar aparente da xilose em solução iônica de $0,075 \mathrm{~mol} \cdot \mathrm{kg}^{-1}$, em função da molalidade da xilose, a diferentes temperaturas e pressão atmosférica: $\square 283,15 \mathrm{~K}$; $\bigcirc$ $288,15 \mathrm{~K} ; \diamond 293,15 \mathrm{~K} ; \triangle 298,15 \mathrm{~K} ; \times 303,15 \mathrm{~K}$. As linhas representam as tendências dos resultados obtidos experimentalmente

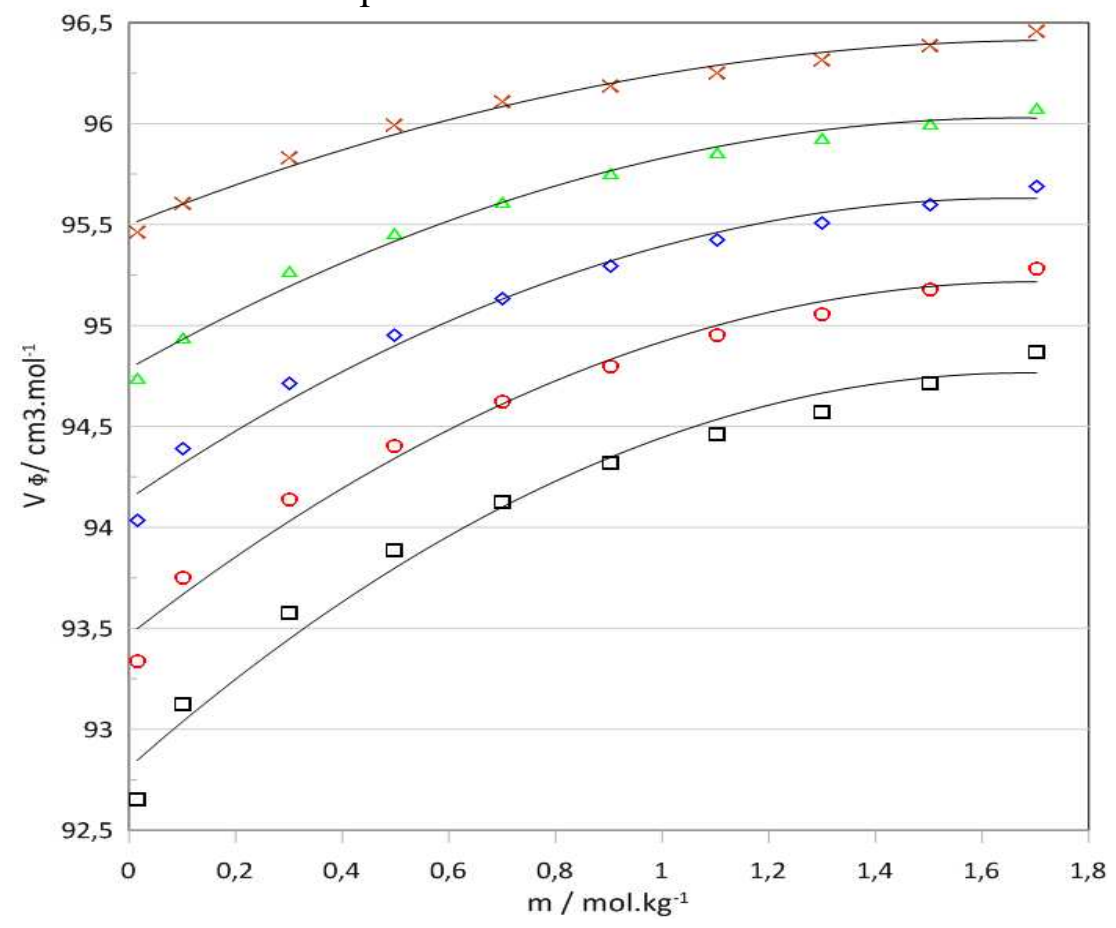

Fonte: Autor

Figura 37 - Volume molar aparente da xilose em solução iônica de $0,10 \mathrm{~mol} \cdot \mathrm{kg}^{-1}$, em função da molalidade da xilose, a diferentes temperaturas e pressão atmosférica: $\square 283,15 \mathrm{~K}$; $\bigcirc 288,15$ $\mathrm{K} ; \diamond 293,15 \mathrm{~K} ; \triangle 298,15 \mathrm{~K} ; \times 303,15 \mathrm{~K}$. As linhas representam as tendências dos resultados obtidos experimentalmente

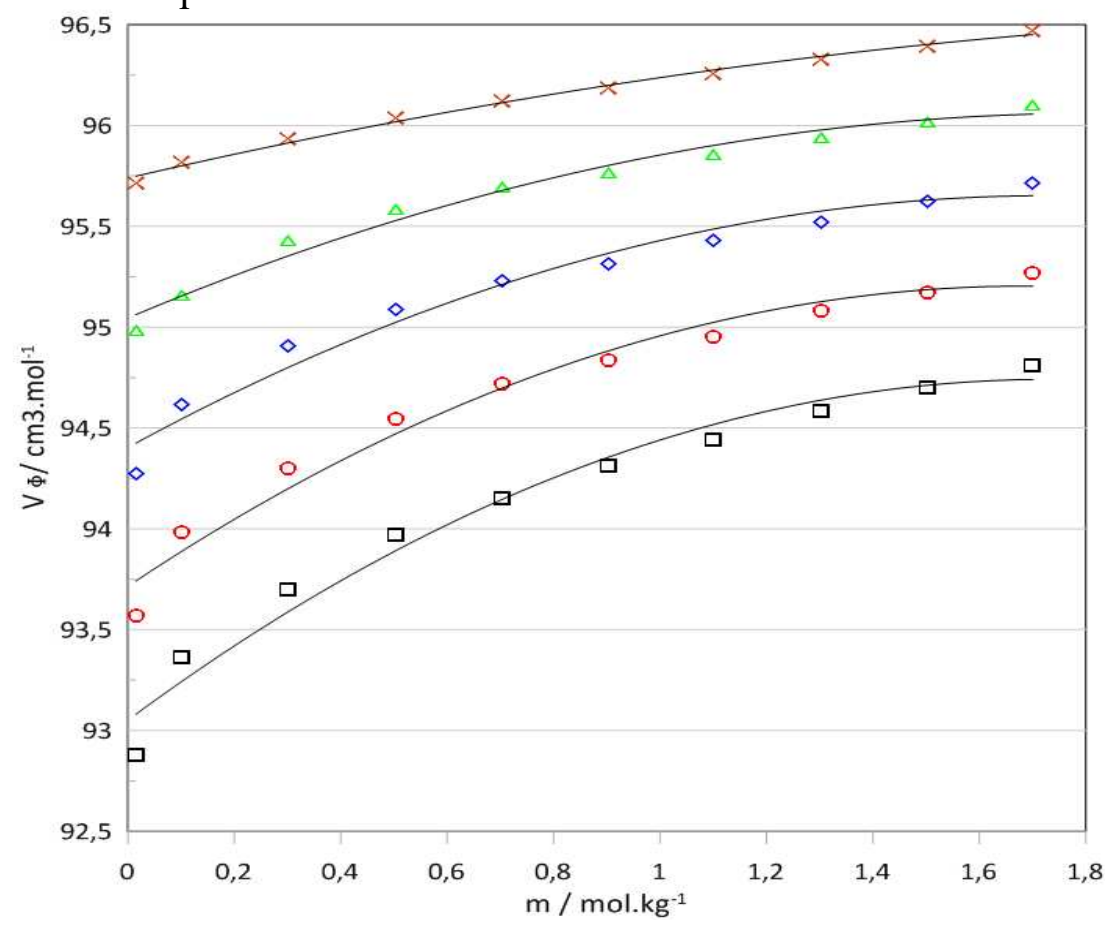

Fonte: Autor 
Os valores do volume molar aparente da xilose aumentaram com o aumento da temperatura para todos os sistemas estudados. Também foi possível observar um valor crescente de volume molar aparente com o aumento da molalidade da xilose.

\subsubsection{Sistema Sacarose}

As figuras 38 - 42 apresentam o comportamento do volume molar aparente das soluções de sacarose em água pura e nas soluções iônicas de concentração de $0,025,0,05,0,075$ e 0,1 $\mathrm{mol} \cdot \mathrm{kg}^{-1}$, em função da molalidade da sacarose, a diferentes temperaturas.

Figura 38 - Volume molar aparente da sacarose em água pura, em função da molalidade da sacarose, a diferentes temperaturas e pressão atmosférica: $\square 283,15 \mathrm{~K} ; \bigcirc 288,15 \mathrm{~K} ; \diamond 293,15$ $\mathrm{K} ; \triangle 298,15 \mathrm{~K} ; \times 303,15 \mathrm{~K}$. As linhas representam as tendências dos resultados obtidos experimentalmente

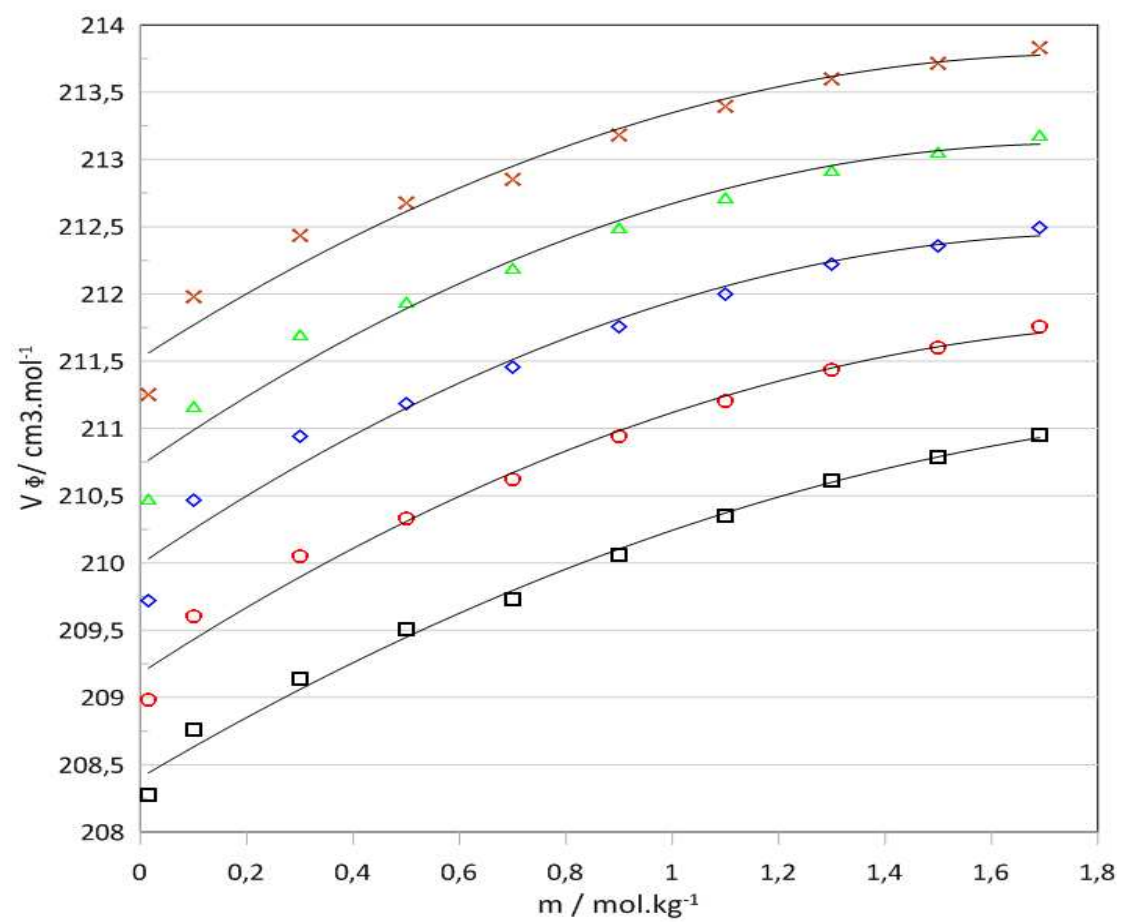

Fonte: Autor 
Figura 39 - Volume molar aparente da sacarose em solução iônica de $0,025 \mathrm{~mol} \cdot \mathrm{kg}^{-1}$, em função da molalidade da sacarose, a diferentes temperaturas e pressão atmosférica: $\square 283,15 \mathrm{~K}$; $\bigcirc$ $288,15 \mathrm{~K} ; \diamond 293,15 \mathrm{~K} ; \triangle 298,15 \mathrm{~K} ; \times 303,15 \mathrm{~K}$. As linhas representam as tendências dos resultados obtidos experimentalmente

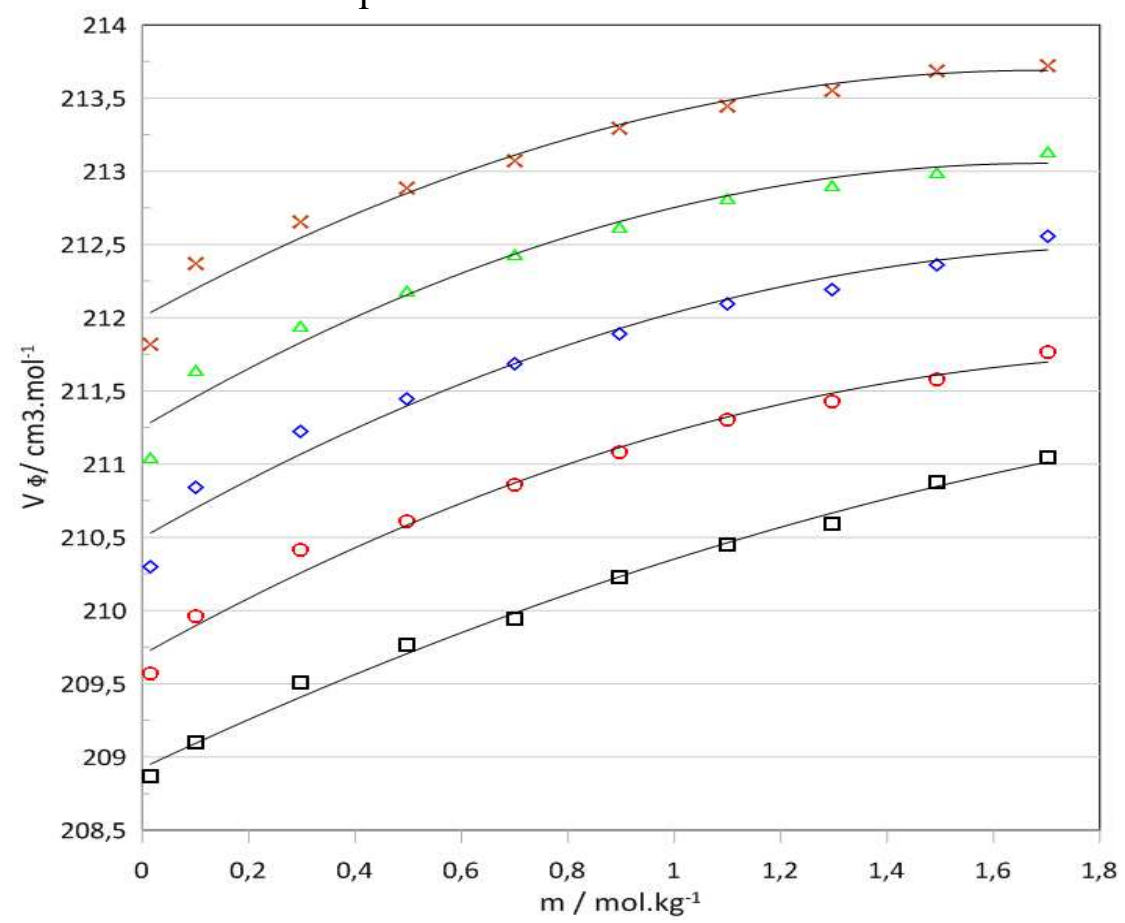

Fonte: Autor

Figura 40 - Volume molar aparente da sacarose em solução iônica de $0,050 \mathrm{~mol} \cdot \mathrm{kg}^{-1}$, em função da molalidade da sacarose, a diferentes temperaturas e pressão atmosférica: $\square 283,15 \mathrm{~K}$; $\bigcirc$ 288,15 K; $\diamond 293,15 \mathrm{~K} ; \triangle 298,15 \mathrm{~K} ; \times 303,15 \mathrm{~K}$. As linhas representam as tendências dos resultados obtidos experimentalmente

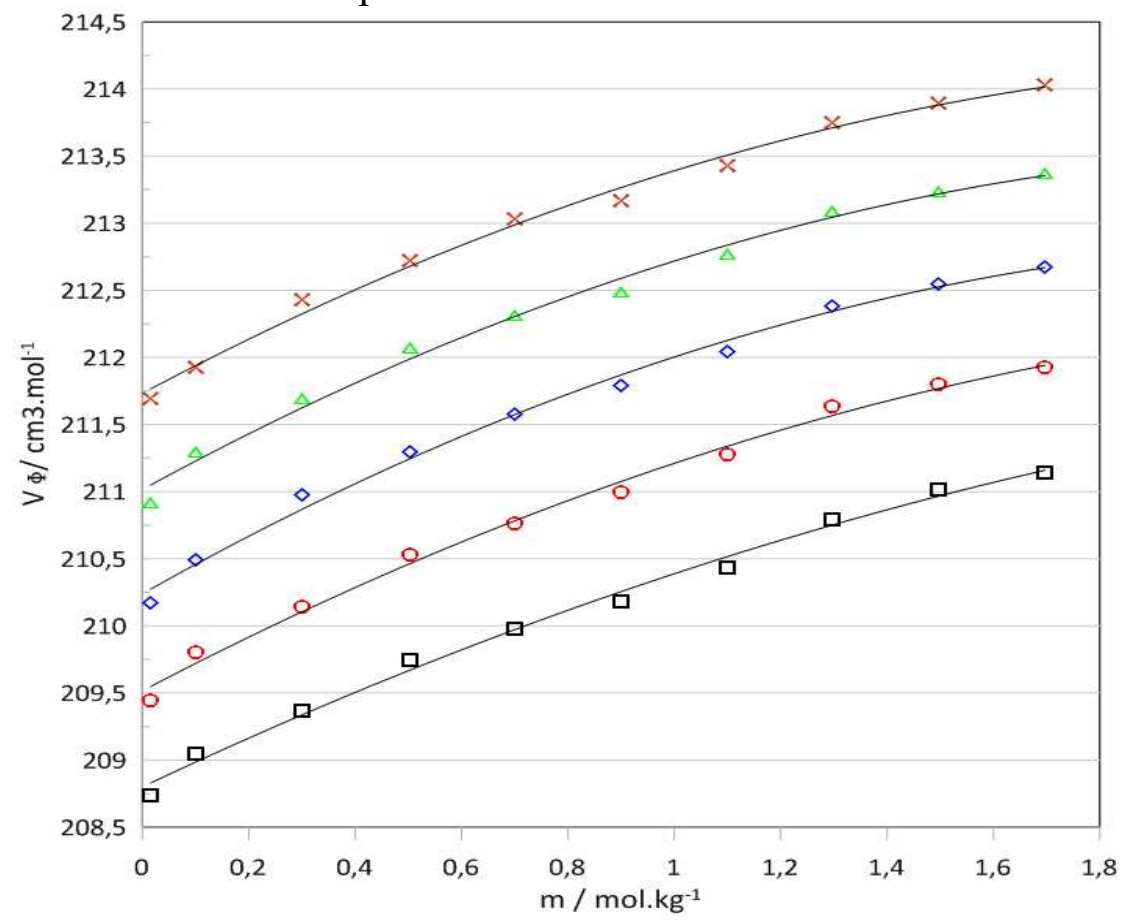

Fonte: Autor 
Figura 41 - Volume molar aparente da sacarose em solução iônica de $0,075 \mathrm{~mol} \cdot \mathrm{kg}^{-1}$, em função da molalidade da sacarose, a diferentes temperaturas e pressão atmosférica: $\square 283,15 \mathrm{~K}$; $\bigcirc$ $288,15 \mathrm{~K} ; \diamond 293,15 \mathrm{~K} ; \triangle 298,15 \mathrm{~K} ; \times 303,15 \mathrm{~K}$. As linhas representam as tendências dos resultados obtidos experimentalmente

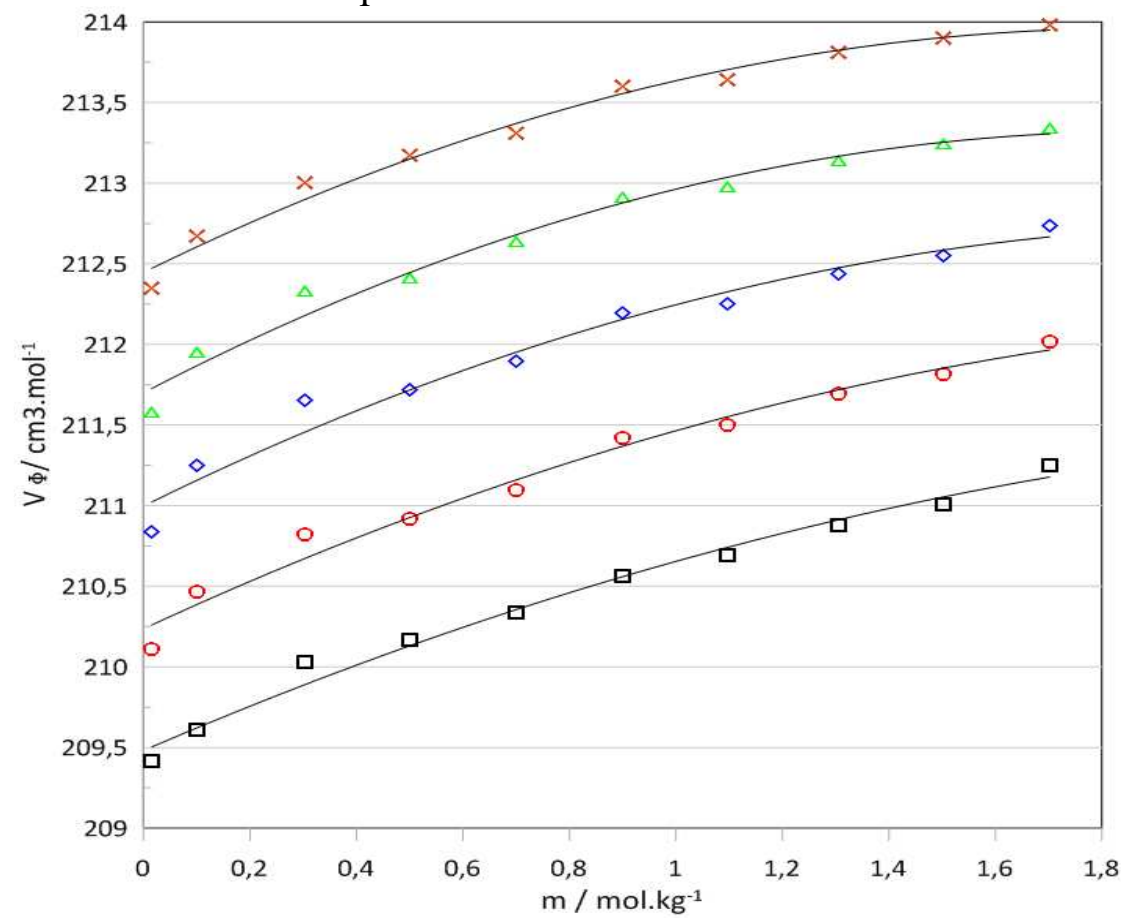

Fonte: Autor

Figura 42 - Volume molar aparente da sacarose em solução iônica de $0,10 \mathrm{~mol} \cdot \mathrm{kg}^{-1}$, em função da molalidade da sacarose, a diferentes temperaturas e pressão atmosférica: $\square$ 283,15 K; О288,15 K; $\diamond 293,15 \mathrm{~K} ; \triangle 298,15 \mathrm{~K} ; \times 303,15 \mathrm{~K}$. As linhas representam as tendências dos resultados obtidos experimentalmente

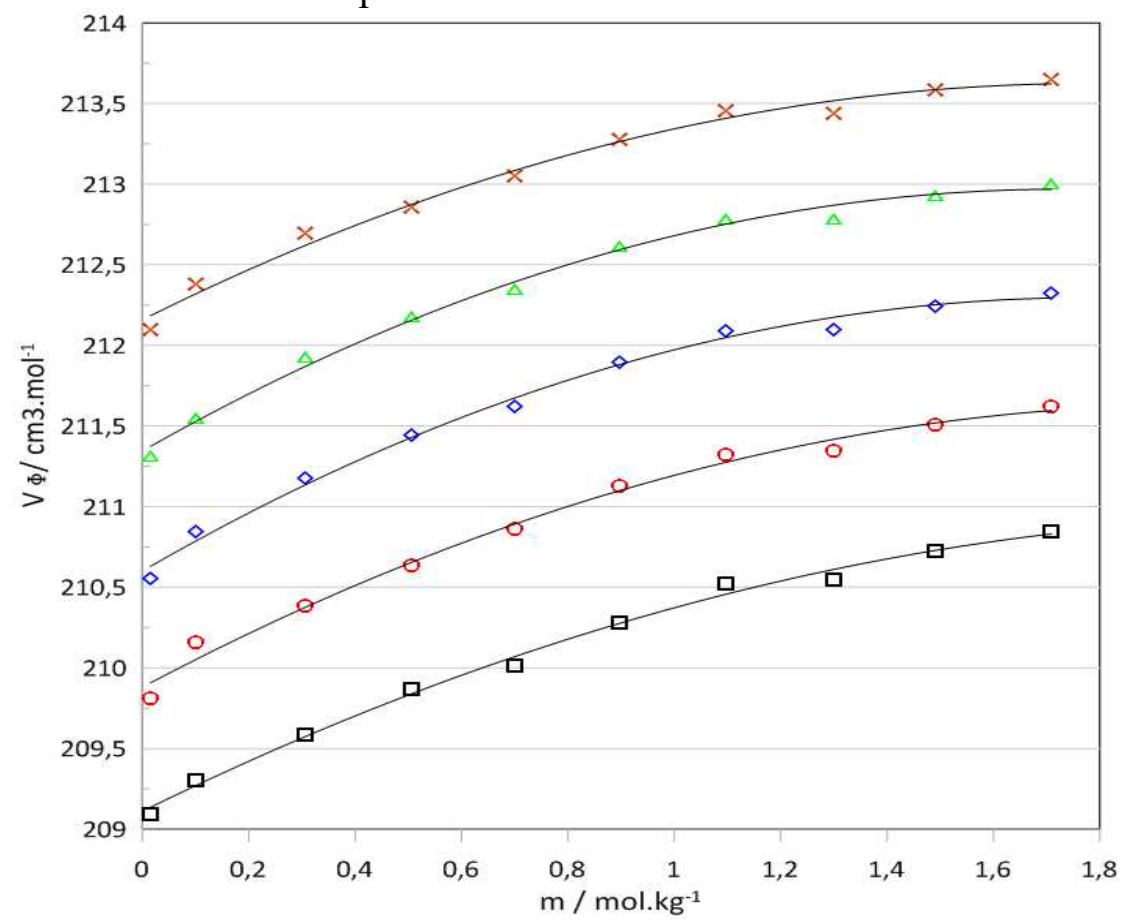

Fonte: Autor 
Os valores do volume molar aparente da sacarose aumentaram com o aumento da temperatura para todos os sistemas estudados. Também foi possível observar um valor crescente de volume molar aparente com o aumento da molalidade da sacarose.

Em relação aos três sistemas estudados neste tópico, quando comparado uns com os outros, observou-se que quanto maior a cadeia carbônica do sacarídeo, maiores foram os valores dos volumes molares aparentes, obedecendo a seguinte ordem: Sacarose $>\mathrm{D}(+)$-glicose $>\mathrm{D}(+)$ xilose.

\subsection{VOLUME MOLAR APARENTE À DILUIÇÃO INFINITA}

Fazendo uso da equação (20), os valores dos volumes molares aparentes foram correlacionados com a raiz quadrada da molalidade para a obtenção dos volumes molares aparente à diluição infinita. A extrapolação dos valores dos volumes molares aparentes no valor da molalidade igual a zero leva aos valores desejados.

$$
V_{f_{s}}=V_{f_{S}}^{0}+S_{V} ¥ m^{\frac{1}{2}}
$$

A partir dos valores de volume molar aparente à diluição infinita em água pura e em soluções iônica, foi possível obter o volume de transferência do sacarídeo da água para solução iônica, através da equação (21).

$$
\mathrm{D} V_{t s}^{0}=V_{f_{S}(\text { soluçãoiônica })}^{0}-V_{f_{S}(a ́ g u a)}^{0}
$$

Conforme mencionado anteriormente, os valores encontrados de volume de transferência podem ser interpretados segundo o modelo "cosphere overlap". Segundo esse modelo as interações entre os sacarídeos e o líquido iônico poderiam ser classificadas de acordo com a tabela 1 . 
Tabela 1 - Interações do modelo "Cosphere Overlap"

\begin{tabular}{|c|c|c|c|}
\hline Interação & Tipo & Onde ocorrem & Valores \\
\hline $\begin{array}{l}\text { Hidrofóbicas- } \\
\text { iônicas }\end{array}$ & (i) & $\begin{array}{l}\text { Entre os grupamentos alquilas do sacarídeo e os íons de } \\
\qquad \text { líquido iônico }\end{array}$ & $(-)$ \\
\hline $\begin{array}{c}\text { Hidrofílicas- } \\
\text { iônicas }\end{array}$ & (ii) & $\begin{array}{c}\text { Entre os grupamentos hidrofílico }-\mathrm{OH},-\mathrm{C}=\mathrm{O} \text { e }-\mathrm{O}-\mathrm{do} \\
\text { sacarídeo e os íons do líquido iônico }\end{array}$ & $(+)$ \\
\hline $\begin{array}{l}\text { Hidrofóbicas- } \\
\text { hidrofóbicas }\end{array}$ & (iii) & $\begin{array}{l}\text { Entre os grupamentos alquilas do sacarídeo e } \\
\text { grupamentos alquilas do líquido iônico }\end{array}$ & $(-)$ \\
\hline $\begin{array}{l}\text { Hidrofílicas- } \\
\text { hidrofílicas }\end{array}$ & (iv) & $\begin{array}{l}\text { Entre os grupamentos hidrofílicos do sacarídeo e } \\
\text { grupamentos hidrofóbicos do líquido iônico }\end{array}$ & $(-)$ \\
\hline
\end{tabular}

Fonte: Autor

\subsubsection{Sistema Glicose}

As figuras 43 - 47 apresentam o comportamento da correlação do volume molar aparente das soluções de glicose em água pura e nas soluções iônicas de concentração de $0,025,0,05$, 0,075 e $0,1 \mathrm{~mol} \cdot \mathrm{kg}^{-1}$, descrita pela equação (20), a diferentes temperaturas.

Figura 43 - Volume molar aparente da glicose em água pura, em função da raiz quadrada da molalidade da glicose, a diferentes temperaturas e pressão atmosférica: $\square 283,15 \mathrm{~K}$; $\bigcirc 288,15$ $\mathrm{K} ; \diamond 293,15 \mathrm{~K} ; \triangle 298,15 \mathrm{~K} ; \times 303,15 \mathrm{~K}$. As linhas representam a correlação usando a equação (20)

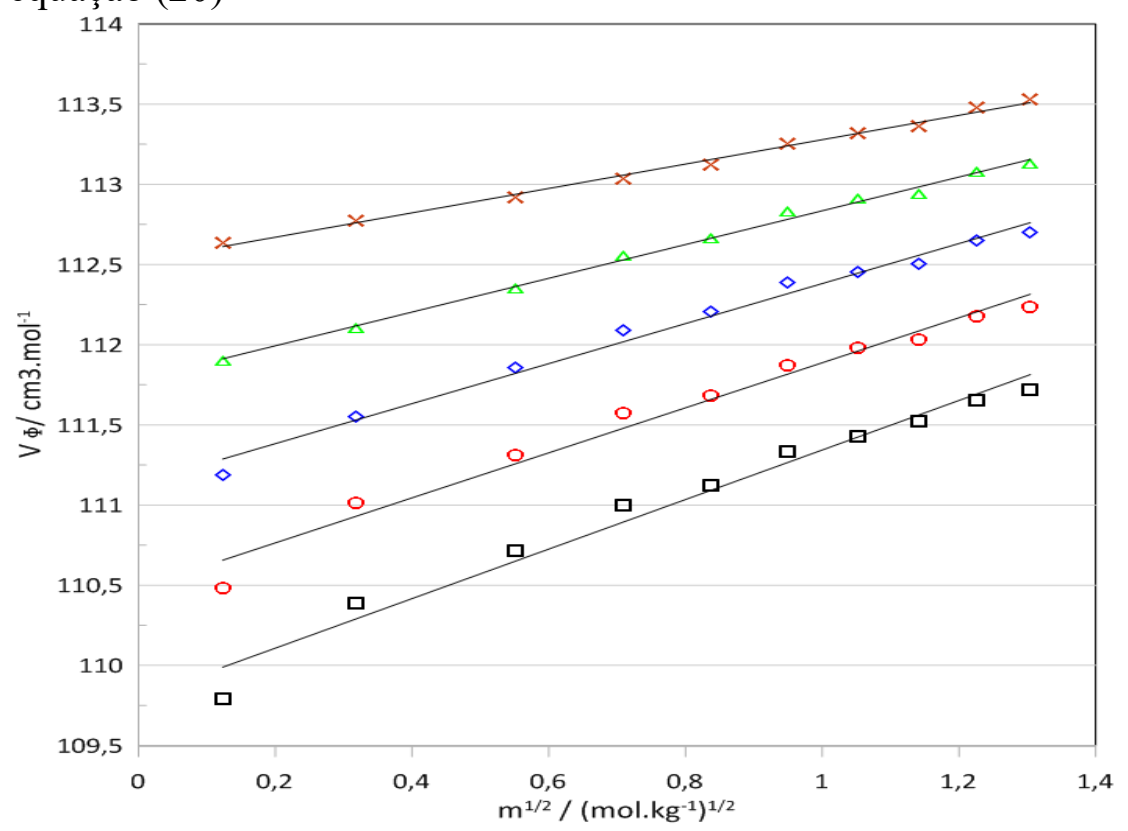

Fonte: Autor 
Figura 44 - Volume molar aparente da glicose em solução iônica de $0,025 \mathrm{~mol} \cdot \mathrm{kg}^{-1}$, em função da raiz quadrada da molalidade da glicose, a diferentes temperaturas e pressão atmosférica: $283,15 \mathrm{~K} ; \bigcirc 288,15 \mathrm{~K} ; \diamond 293,15 \mathrm{~K} ; \triangle 298,15 \mathrm{~K} ; \times 303,15 \mathrm{~K}$. As linhas representam a correlação usando a equação (20)

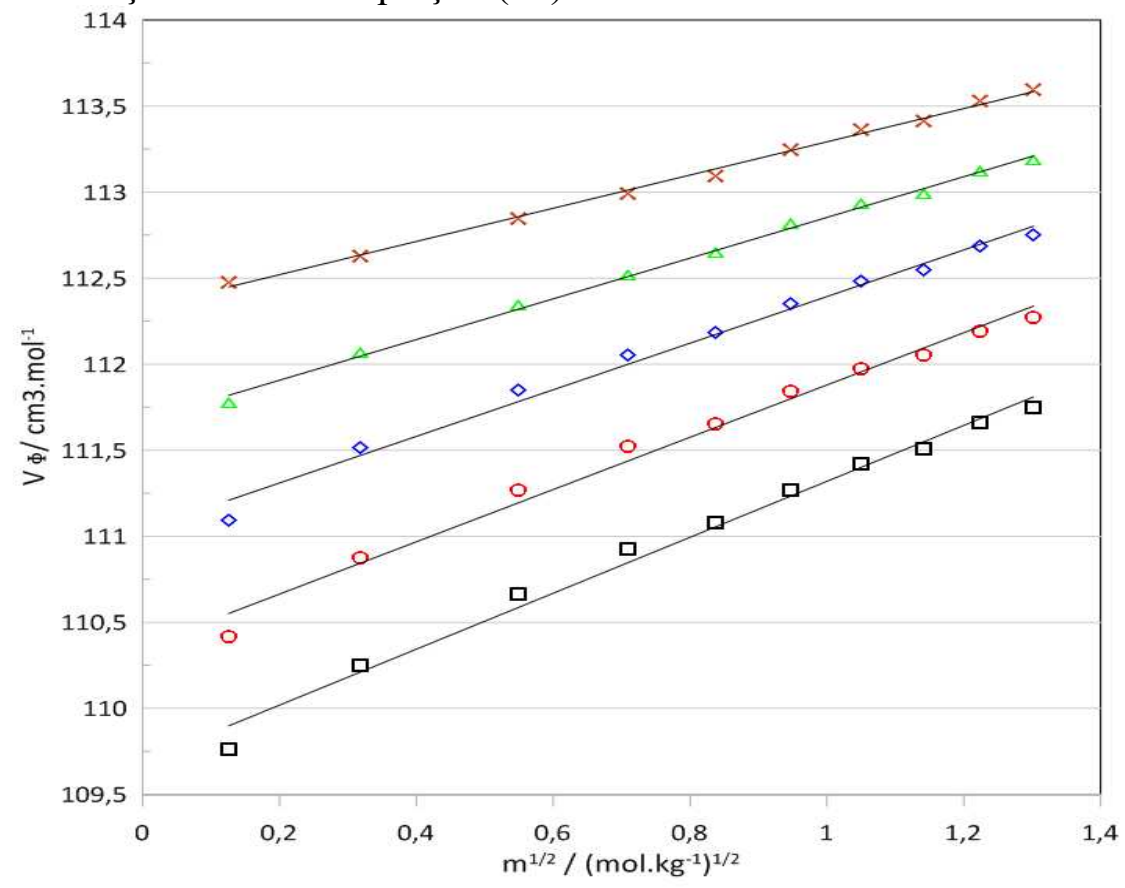

Fonte: Autor

Figura 45 - Volume molar aparente da glicose em solução iônica de $0,050 \mathrm{~mol} \cdot \mathrm{kg}^{-1}$, em função da raiz quadrada da molalidade da glicose, a diferentes temperaturas e pressão atmosférica: $283,15 \mathrm{~K} ; \bigcirc 288,15 \mathrm{~K} ; \diamond 293,15 \mathrm{~K} ; \triangle 298,15 \mathrm{~K} ; \times 303,15 \mathrm{~K}$. As linhas representam a correlação usando a equação (20)

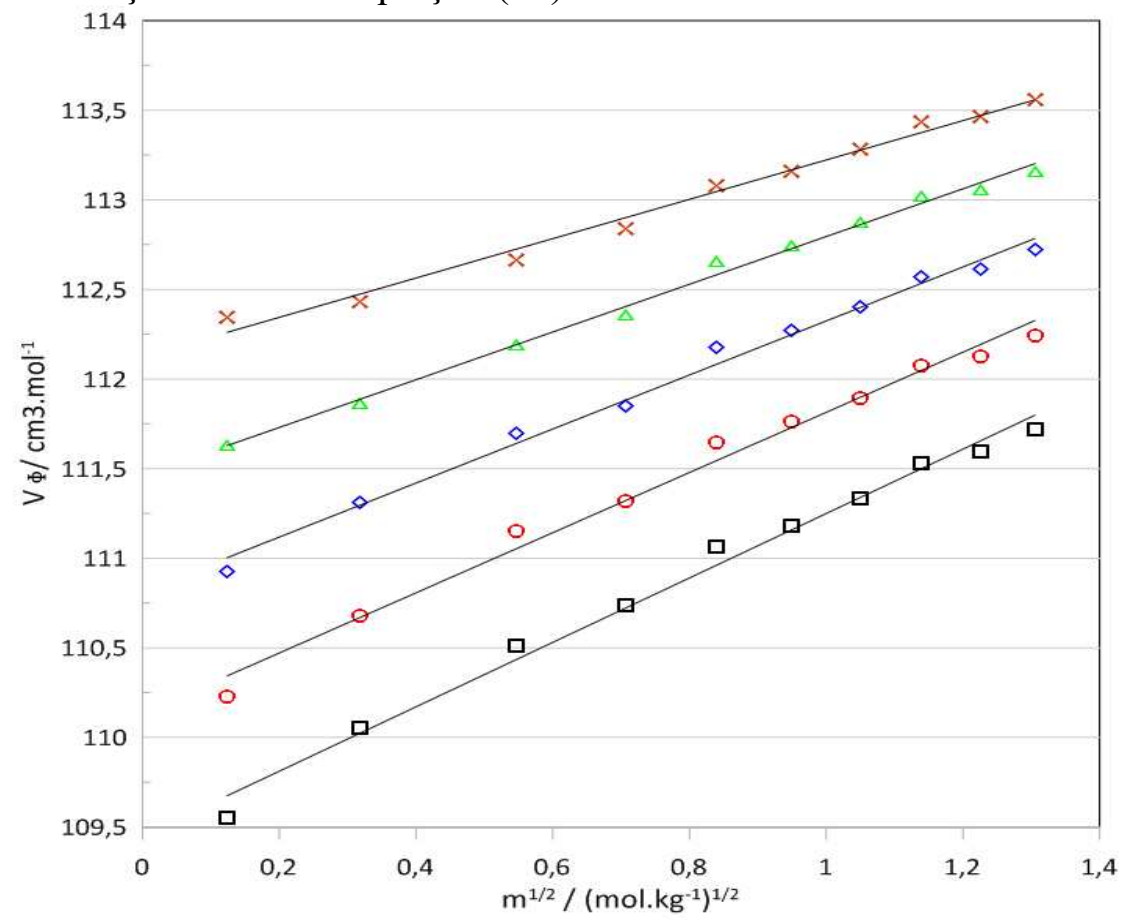

Fonte: Autor 
Figura 46 -Volume molar aparente da glicose em solução iônica de $0,075 \mathrm{~mol} \cdot \mathrm{kg}^{-1}$, em função da raiz quadrada da molalidade da glicose, a diferentes temperaturas e pressão atmosférica: $283,15 \mathrm{~K} ; \bigcirc 288,15 \mathrm{~K} ; \diamond 293,15 \mathrm{~K} ; \triangle 298,15 \mathrm{~K} ; \times 303,15 \mathrm{~K}$. As linhas representam a correlação usando a equação (20)

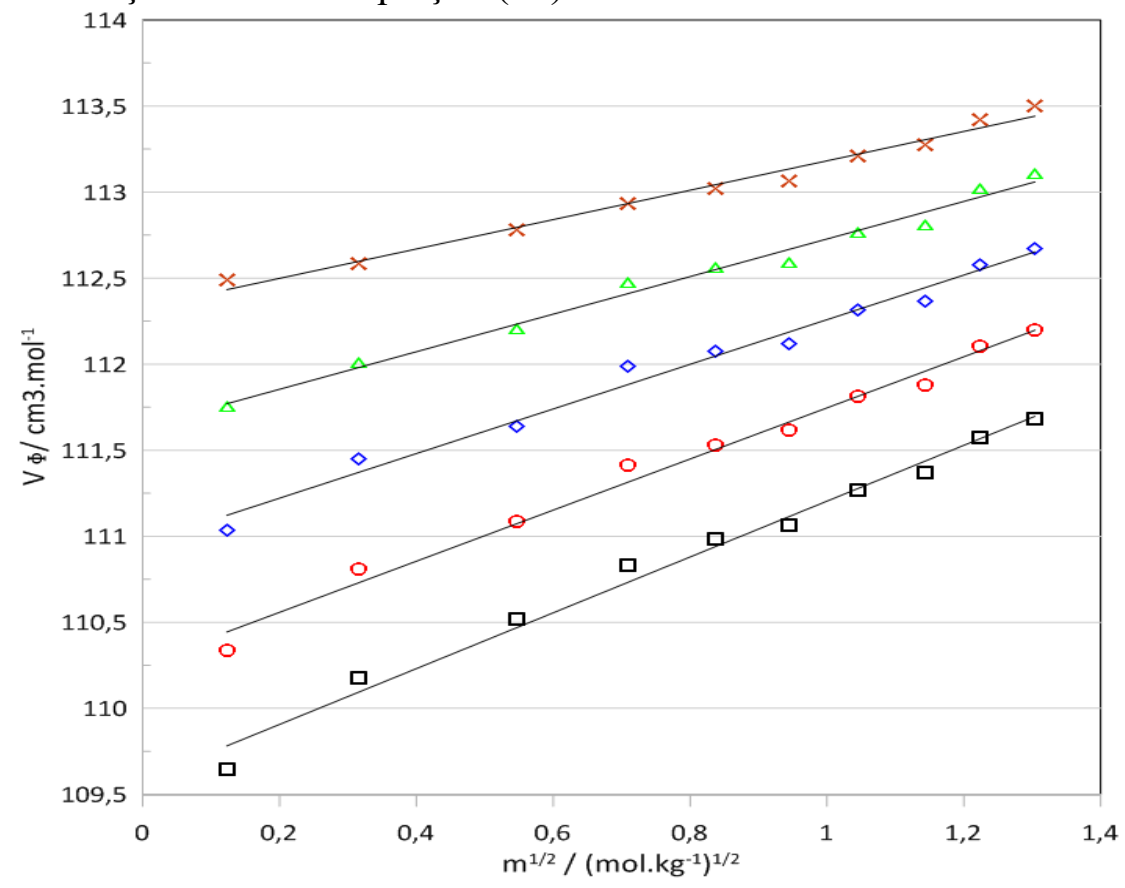

Fonte: Autor

Figura 47 - Volume molar aparente da glicose em solução iônica de $0,10 \mathrm{~mol} \cdot \mathrm{kg}^{-1}$, em função da raiz quadrada da molalidade da glicose, a diferentes temperaturas e pressão atmosférica: $283,15 \mathrm{~K} ; \bigcirc 288,15 \mathrm{~K} ; \diamond 293,15 \mathrm{~K} ; \triangle 298,15 \mathrm{~K} ; \times 303,15 \mathrm{~K}$. As linhas representam a correlação usando a equação (20)

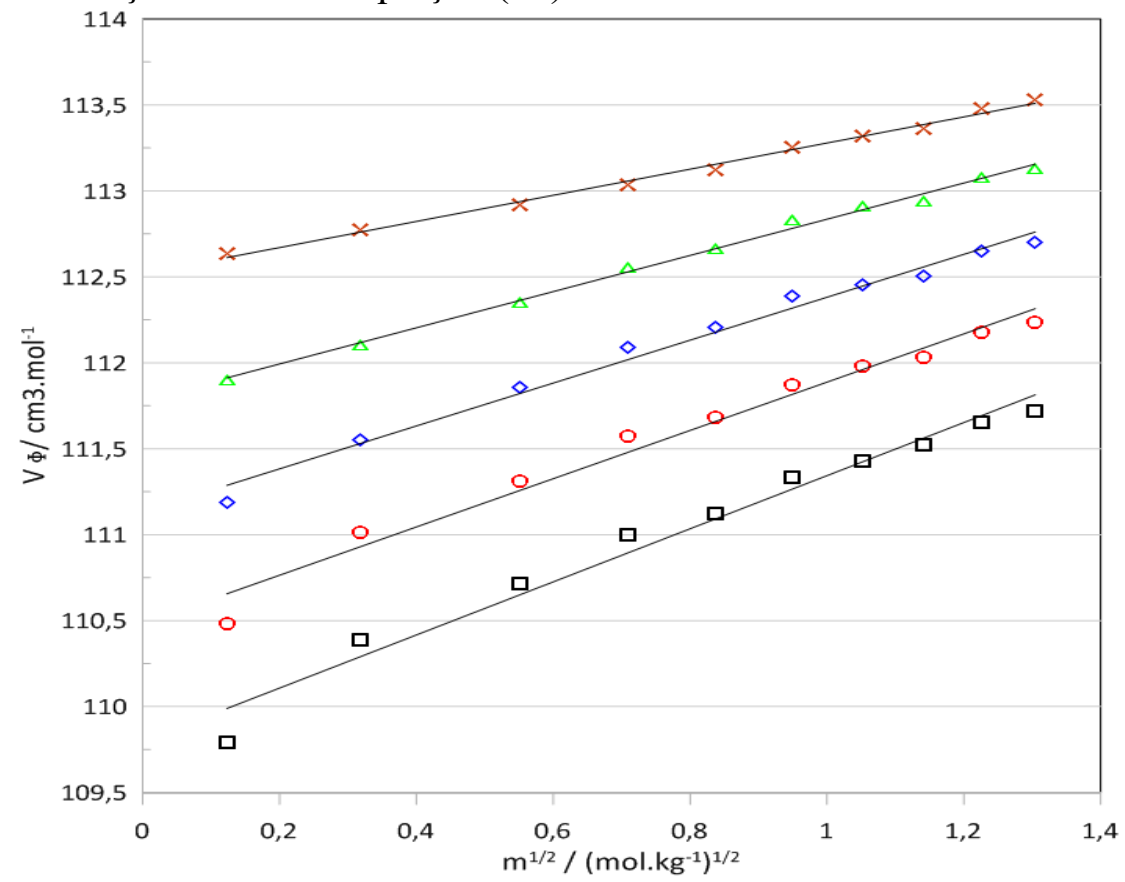

Fonte: Autor 
As tabelas 2 e 3 apresentam, respectivamente, as equações que descrevem as correlações do volume molar aparente da glicose em água pura e os valores do volume molar aparente à diluição infinita da glicose em água pura.

As tabelas 4-7 apresentam as equações que descrevem as correlações do volume molar aparente da glicose nas soluções iônica de concentração de $0,025,0,05,0,075$ e $0,1 \mathrm{~mol} \cdot \mathrm{kg}^{-1}$, como uma função da molalidade.

As tabelas 8-11 apresentam os valores do volume molar aparente à diluição infinita da glicose nas soluções iônicas de concentração de $0,025,0,05,0,075$ e $0,1 \mathrm{~mol} \cdot \mathrm{kg}^{-1}$, respectivamente, a diferentes temperaturas.

As tabelas 12-15 apresentam os valores dos volumes de transferência da glicose da água para as soluções iônicas de concentração de $0,025,0,05,0,075$ e $0,1 \mathrm{~mol} \cdot \mathrm{kg}^{-1}$, a diferentes temperaturas.

Tabela 2 - Equações de ajuste usando a equação (20) para as soluções de glicose em água pura, a diferentes temperaturas

\begin{tabular}{ccc}
\hline $\mathrm{T} / \mathrm{K}$ & \multicolumn{1}{c}{ Equação } & $\mathrm{R}^{2}$ \\
\hline 283,15 & $\mathrm{~V}_{f_{S}}=109,680868+1,494340 ¥ m^{\frac{1}{2}}$ & 0,982198 \\
288,15 & $\mathrm{~V}_{f_{s}}=110,373749+1,366272 ¥ m^{\frac{1}{2}}$ & 0,980508 \\
293,15 & $\mathrm{~V}_{f_{s}}=111,010387+1,236263 ¥ m^{\frac{1}{2}}$ & 0,990199 \\
298,15 & $\mathrm{~V}_{f_{s}}=111,668802+1,049890 ¥ m^{\frac{1}{2}}$ & 0,995744 \\
303,15 & $\mathrm{~V}_{f_{S}}=112,395131+0,765781 ¥ m^{\frac{1}{2}}$ & 0,993478 \\
\hline
\end{tabular}

Fonte: Autor

Para as soluções de glicose em água pura à baixas temperaturas os ajustes da reta não são tão satisfatórios quanto para altas temperaturas. 
Tabela 3 - Volumes molares aparentes à diluição infinita da glicose em água pura, a diferentes temperaturas

\begin{tabular}{cc}
\hline $\mathrm{T} / \mathrm{K}$ & $\mathrm{V}_{\mathrm{f}_{\mathrm{s}} \text { (agua) }}^{0} / \mathrm{cm}^{3} \cdot \mathrm{mol}^{-1}$ \\
\hline 283,15 & $V_{f_{s}}^{0}=109,68$ \\
288,15 & $V_{f_{s}}^{0}=110,37$ \\
293,15 & $V_{f_{s}}^{0}=111,01$ \\
298,15 & $V_{f_{s}}^{0}=111,67$ \\
303,15 & $V_{f_{s}}^{0}=112,40$ \\
\hline
\end{tabular}

Fonte: Autor

Tabela 4 - Equações de ajuste usando a equação (20) para as soluções de glicose em solução iônica de $0,025 \mathrm{~mol} \cdot \mathrm{kg}^{-1}$, a diferentes temperaturas

$\mathrm{T} / \mathrm{K} \quad$ Equação $\quad \mathrm{R}^{2}$

\begin{tabular}{llc}
\hline 283,15 & $\mathrm{~V}_{f_{S}}=109,693736+1,625686 ¥ m^{\frac{1}{2}}$ & 0,988817 \\
288,15 & $\mathrm{~V}_{f_{s}}=110,360527+1,518815 ¥ m^{\frac{1}{2}}$ & 0,987432 \\
293,15 & $\mathrm{~V}_{f_{S}}=111,038986+1,518815 ¥ m^{\frac{1}{2}}$ & 0,988693 \\
298,15 & $\mathrm{~V}_{f_{S}}=111,670391+1,182665 ¥ m^{\frac{1}{2}}$ & 0,997284 \\
303,15 & $\mathrm{~V}_{f_{s}}=112,327598+0,964732 ¥ m^{\frac{1}{2}}$ & 0,996550 \\
\hline
\end{tabular}

Fonte: Autor

Para as soluções de glicose em solução iônica de $0,025 \mathrm{~mol} \cdot \mathrm{kg}^{-1}$ à baixas temperaturas os ajustes da reta não são tão satisfatórios quanto para altas temperaturas.

Tabela 5 - Equações de ajuste usando a equação (20) para as soluções de glicose em solução iônica de $0,050 \mathrm{~mol} \cdot \mathrm{kg}^{-1}$, a diferentes temperaturas

\begin{tabular}{ccc}
\hline $\mathrm{T} / \mathrm{K}$ & \multicolumn{1}{c}{ Equação } & $\mathrm{R}^{2}$ \\
\hline 283,15 & $\mathrm{~V}_{f_{S}}=109,452082+1,797455 ¥ m^{\frac{1}{2}}$ & 0,990552 \\
288,15 & $\mathrm{~V}_{f_{S}}=110,135489+1,678761 ¥ m^{\frac{1}{2}}$ & 0,988667 \\
293,15 & $\mathrm{~V}_{f_{S}}=110,816694+1,507521 ¥ m^{\frac{1}{2}}$ & 0,991300 \\
298,15 & $\mathrm{~V}_{f_{S}}=111,463649+1,331734 ¥ m^{\frac{1}{2}}$ & 0,994327 \\
303,15 & $\mathrm{~V}_{f_{S}}=112,124786+1,097880 ¥ m^{\frac{1}{2}}$ & 0,987090 \\
\hline
\end{tabular}

Fonte: Autor 
Para as soluções de glicose em solução iônica de $0,050 \mathrm{~mol} \cdot \mathrm{kg}^{-1}$ os ajustes da reta não possuem um comportamento uniforme.

Tabela 6 - Equações de ajuste usando a equação (20) para as soluções de glicose em solução iônica de $0,075 \mathrm{~mol} \cdot \mathrm{kg}^{-1}$, a diferentes temperaturas

\begin{tabular}{ccc}
\hline $\mathrm{T} / \mathrm{K}$ & Equação & $\mathrm{R}^{2}$ \\
\hline 283,15 & $\mathrm{~V}_{f_{S}}=109,582188+1,621872 ¥ m^{\frac{1}{2}}$ & 0,987179 \\
288,15 & $\mathrm{~V}_{f_{S}}=110,261122+1,485041 ¥ m^{\frac{1}{2}}$ & 0,987634 \\
293,15 & $\mathrm{~V}_{f_{S}}=110,962150+1,296549 ¥ m^{\frac{1}{2}}$ & 0,983434 \\
298,15 & $\mathrm{~V}_{f_{S}}=111,635908+1,091642 ¥ m^{\frac{1}{2}}$ & 0,986747 \\
303,15 & $\mathrm{~V}_{f_{S}}=112,328123+0,853765 ¥ m^{\frac{1}{2}}$ & 0,984722 \\
\hline
\end{tabular}

Fonte: Autor

Para as soluções de glicose em solução iônica de $0,075 \mathrm{~mol} \cdot \mathrm{kg}^{-1} \mathrm{os}$ ajustes da reta não possuem valores satisfatórios.

Tabela 7 - Equações de ajuste usando a equação (20) para as soluções de glicose em solução iônica de $0,10 \mathrm{~mol} \cdot \mathrm{kg}^{-1}$, a diferentes temperaturas

\begin{tabular}{ccc}
\hline $\mathrm{T} / \mathrm{K}$ & Equação & $\mathrm{R}^{2}$ \\
\hline 283,15 & $\mathrm{~V}_{f_{S}}=109,798684+1,544695 ¥ m^{\frac{1}{2}}$ & 0,976637 \\
288,15 & $\mathrm{~V}_{f_{S}}=110,483322+1,404077 ¥ m^{\frac{1}{2}}$ & 0,977219 \\
293,15 & $\mathrm{~V}_{f_{S}}=111,133416+1,247902 ¥ m^{\frac{1}{2}}$ & 0,986521 \\
298,15 & $\mathrm{~V}_{f_{S}}=111,782670+1,052538 ¥ m^{\frac{1}{2}}$ & 0,996002 \\
303,15 & $\mathrm{~V}_{f_{s}}=112,518443+0,760137 ¥ m^{\frac{1}{2}}$ & 0,994499 \\
\hline
\end{tabular}

Fonte: Autor

Para as soluções de glicose em solução iônica de $0,10 \mathrm{~mol} \cdot \mathrm{kg}^{-1}$ à baixas temperaturas os ajustes da reta não são tão satisfatórios quanto para altas temperaturas. 
Tabela 8 - Volumes molares aparentes à diluição infinita da glicose em solução iônica de 0,025 mol $\cdot \mathrm{kg}^{-1}$, a diferentes temperaturas

\begin{tabular}{cc}
\hline $\mathrm{T} / \mathrm{K}$ & $\mathrm{V}_{f_{s} \text { (soluçãoiônica) }}^{0} / \mathrm{cm}^{3} \cdot \mathrm{mol}^{-1}$ \\
\hline 283,15 & $V_{f_{s}^{0}}^{0}=109,69$ \\
288,15 & $V_{f_{s}}^{0}=110,36$ \\
293,15 & $V_{f_{s}}^{0}=111,04$ \\
298,15 & $V_{f_{s}}^{0}=111,67$ \\
303,15 & $V_{f_{s}}^{0}=112,33$ \\
\hline
\end{tabular}

Fonte: Autor

Tabela 9 - Volumes molares aparentes à diluição infinita da glicose em solução iônica de 0,050 mol $\cdot \mathrm{kg}^{-1}$, a diferentes temperaturas

$\mathrm{T} / \mathrm{K} \quad \mathrm{V}_{f_{s} \text { (soluçãoiônica) }}^{0} / \mathrm{cm}^{3} \cdot \mathrm{mol}^{-1}$

\begin{tabular}{ll}
283,15 & $V_{f_{s}}^{0}=109,45$ \\
288,15 & $V_{f_{s}}^{0}=110,13$ \\
293,15 & $V_{f_{s}}^{0}=110,82$ \\
298,15 & $V_{f_{s}}^{0}=111,46$ \\
303,15 & $V_{f_{s}}^{0}=112,12$ \\
\hline
\end{tabular}

Fonte: Autor

Tabela 10 - Volumes molares aparentes à diluição infinita da glicose em solução iônica de 0,075 $\mathrm{mol} \cdot \mathrm{kg}^{-1}$, a diferentes temperaturas

\begin{tabular}{cc}
\hline $\mathrm{T} / \mathrm{K}$ & $\mathrm{V}_{f_{s} \text { (soluçãoînica) }}^{0} / \mathrm{cm}^{3} \cdot \mathrm{mol}^{-1}$ \\
\hline 283,15 & $V_{f_{s}}^{0}=109,58$ \\
288,15 & $V_{f_{s}}^{0}=110,26$ \\
293,15 & $V_{f_{s}}^{0}=110,96$ \\
298,15 & $V_{f_{s}}^{0}=111,64$ \\
303,15 & $V_{f_{s}}^{0}=112,33$ \\
\hline
\end{tabular}


Tabela 11 - Volumes molares aparentes à diluição infinita da glicose em solução iônica de 0,10 $\underline{\mathrm{mol} \cdot \mathrm{kg}^{-1} \text {, a diferentes temperaturas }}$

$\mathrm{T} / \mathrm{K}$

$\mathrm{V}_{f_{s} \text { (soluçãoiônica) }}^{0} / \mathrm{cm}^{3} \cdot \mathrm{mol}^{-1}$

283,15

$V_{f_{s}}^{0}=109,80$

288,15

$V_{f_{s}}^{0}=110,48$

293,15

$V_{f_{s}}^{0}=111,13$

298,15

$V_{f_{s}}^{0}=111,78$

303,15

$V_{f_{s}}^{0}=112,51$

Fonte: Autor

Tabela 12 - Volumes de transferência da glicose da água para solução iônica de $0,025 \mathrm{~mol} \cdot \mathrm{kg}^{-1}$ a diferentes temperaturas

\begin{tabular}{|c|c|c|c|}
\hline $\mathrm{T} / \mathrm{K}$ & $\mathrm{V}_{f_{s} \text { (soluçãoiônica) }}^{0} / \mathrm{cm}^{3} \cdot \mathrm{mol}^{-1}$ & $\mathrm{~V}_{f_{\mathrm{s}} \text { (água) }}^{0} / \mathrm{cm}^{3} \cdot \mathrm{mol}^{-1}$ & $\Delta \mathrm{V}_{\mathrm{ts}} / \mathrm{cm}^{3} \cdot \mathrm{mol}^{-1}$ \\
\hline 283,15 & $V_{f_{s}}^{0}=109,69$ & $V_{f_{s}}^{0}=109,68$ & 0,01 \\
\hline 288,15 & $V_{f_{s}}^{0}=110,36$ & $V_{f_{s}}^{0}=110,37$ & $-0,01$ \\
\hline 293,15 & $V_{f_{s}}^{0}=111,04$ & $V_{f_{s}}^{0}=111,01$ & 0,03 \\
\hline 298,15 & $V_{f_{s}}^{0}=111,67$ & $V_{f_{s}}^{0}=111,67$ & 0,00 \\
\hline 303,15 & $V_{f_{s}}^{0}=112,33$ & $V_{f_{s}}^{0}=112,40$ & $-0,07$ \\
\hline
\end{tabular}

Fonte: Autor

Tabela 13 - Volumes de transferência da glicose da água para solução iônica de $0,050 \mathrm{~mol} \cdot \mathrm{kg}^{-1}$ a diferentes temperaturas

\begin{tabular}{|c|c|c|c|}
\hline $\mathrm{T} / \mathrm{K}$ & $\mathrm{V}_{f_{s} \text { (soluçãiônica) }}^{0} / \mathrm{cm}^{3} \cdot \mathrm{mol}^{-1}$ & $\mathrm{~V}_{f_{\mathrm{s}} \text { (água) }}^{0} / \mathrm{cm}^{3} \cdot \mathrm{mol}^{-1}$ & $\Delta \mathrm{V}_{\mathrm{ts}} / \mathrm{cm}^{3} \cdot \mathrm{mol}^{-1}$ \\
\hline 283,15 & $V_{f_{s}}^{0}=109,45$ & $V_{f_{s}}^{0}=109,68$ & $-0,23$ \\
\hline 288,15 & $V_{f_{s}}^{0}=110,13$ & $V_{f_{s}}^{0}=110,37$ & $-0,24$ \\
\hline 293,15 & $V_{f_{s}}^{0}=110,82$ & $V_{f_{s}}^{0}=111,01$ & $-0,19$ \\
\hline 298,15 & $V_{f_{s}}^{0}=111,46$ & $V_{f_{s}}^{0}=111,67$ & $-0,21$ \\
\hline 303,15 & $V_{f_{s}}^{0}=112,12$ & $V_{f_{s}}^{0}=112,40$ & $-0,28$ \\
\hline
\end{tabular}

Fonte: Autor 
Tabela 14 - Volumes de transferência da glicose da água para solução iônica de 0,075 mol.kg1 , a diferentes temperaturas

\begin{tabular}{|c|c|c|c|}
\hline $\mathrm{T} / \mathrm{K}$ & $\mathrm{V}_{f_{s} \text { (soluçãoiônica) }}^{0} / \mathrm{cm}^{3} \cdot \mathrm{mol}^{-1}$ & $\mathrm{~V}_{f_{\mathrm{s}} \text { (água) }}^{0} / \mathrm{cm}^{3} \cdot \mathrm{mol}^{-1}$ & $\Delta \mathrm{V}_{\mathrm{ts}} / \mathrm{cm}^{3} \cdot \mathrm{mol}^{-1}$ \\
\hline 283,15 & $V_{f_{s}}^{0}=109,58$ & $V_{f_{s}}^{0}=109,68$ & $-0,10$ \\
\hline 288,15 & $V_{f_{s}}^{0}=110,26$ & $V_{f_{s}}^{0}=110,37$ & $-0,11$ \\
\hline 293,15 & $V_{f_{s}}^{0}=110,96$ & $V_{f_{s}}^{0}=111,01$ & $-0,05$ \\
\hline 298,15 & $V_{f_{s}}^{0}=111,64$ & $V_{f_{s}}^{0}=111,67$ & $-0,03$ \\
\hline 303,15 & $V_{f_{s}}^{0}=112,33$ & $V_{f_{s}}^{0}=112,40$ & $-0,07$ \\
\hline
\end{tabular}

Fonte: Autor

Tabela 15 - Volumes de transferência da glicose da água para solução iônica de 0,10 mol. $\mathrm{kg}^{-1}$, a diferentes temperaturas

\begin{tabular}{|c|c|c|c|}
\hline $\mathrm{T} / \mathrm{K}$ & $\mathrm{V}_{f_{s} \text { (soluçãoionica) }}^{0} / \mathrm{cm}^{3} \cdot \mathrm{mol}^{-1}$ & $\mathrm{~V}_{f_{\mathrm{s}} \text { (água) }}^{0} / \mathrm{cm}^{3} \cdot \mathrm{mol}^{-1}$ & $\Delta \mathrm{V}_{\mathrm{ts}} / \mathrm{cm}^{3} \cdot \mathrm{mol}^{-1}$ \\
\hline 283,15 & $V_{f_{s}}^{0}=109,80$ & $V_{f_{s}}^{0}=109,68$ & 0,12 \\
\hline 288,15 & $V_{f_{s}}^{0}=110,48$ & $V_{f_{s}}^{0}=110,37$ & 0,11 \\
\hline 293,15 & $V_{f_{s}}^{0}=111,13$ & $V_{f_{s}}^{0}=111,01$ & 0,12 \\
\hline 298,15 & $V_{f_{s}}^{0}=111,78$ & $V_{f_{s}}^{0}=111,67$ & 0,11 \\
\hline 303,15 & $V_{f_{s}}^{0}=112,51$ & $V_{f_{s}}^{0}=112,40$ & 0,11 \\
\hline
\end{tabular}

Fonte: Autor

O parâmetro $S_{\mathrm{v}}$ na equação 20 indica as interações entre as moléculas dos sacarídeos. À diluição infinita a interação soluto-soluto desaparece e, portanto, o volume molar aparente à diluição infinita é uma medida da interação soluto-solvente (ROMERO; NEGRETE, 2004; MANIN et al, 2010).A magnitude dos valores de $S_{\mathrm{v}}$ para todos os sistemas glicose estudados é pequena, o que indica que possivelmente que as interações glicose-glicose são fracas e diminuem com o aumento da temperatura.Com base no modelo de "cosphere overlap" (DESNOYERS et al, 1969), para o sistema contendo glicose, não é possível fazer alguma afirmação tendo em vista que os resultados mostraram valores positivos e negativos para os volumes de transferência. 


\subsubsection{Sistema Xilose}

As figuras 48 - 52 apresentam o comportamento da correlação do volume molar aparente das soluções de xilose em água pura e nas soluções iônicas de concentração de $0,025,0,05$, 0,075 e $0,1 \mathrm{~mol} \cdot \mathrm{kg}^{-1}$, respectivamente, descrita pela equação (20), a diferentes temperaturas.

Figura 48 - Volume molar aparente da xilose em água pura, em função da raiz quadrada da molalidade da xilose, a diferentes temperaturas e pressão atmosférica: $\square 283,15 \mathrm{~K}$; $\bigcirc 288,15$ $\mathrm{K} ; \diamond 293,15 \mathrm{~K} ; \triangle 298,15 \mathrm{~K} ; \times 303,15 \mathrm{~K}$. As linhas representam a correlação usando a equação (20)

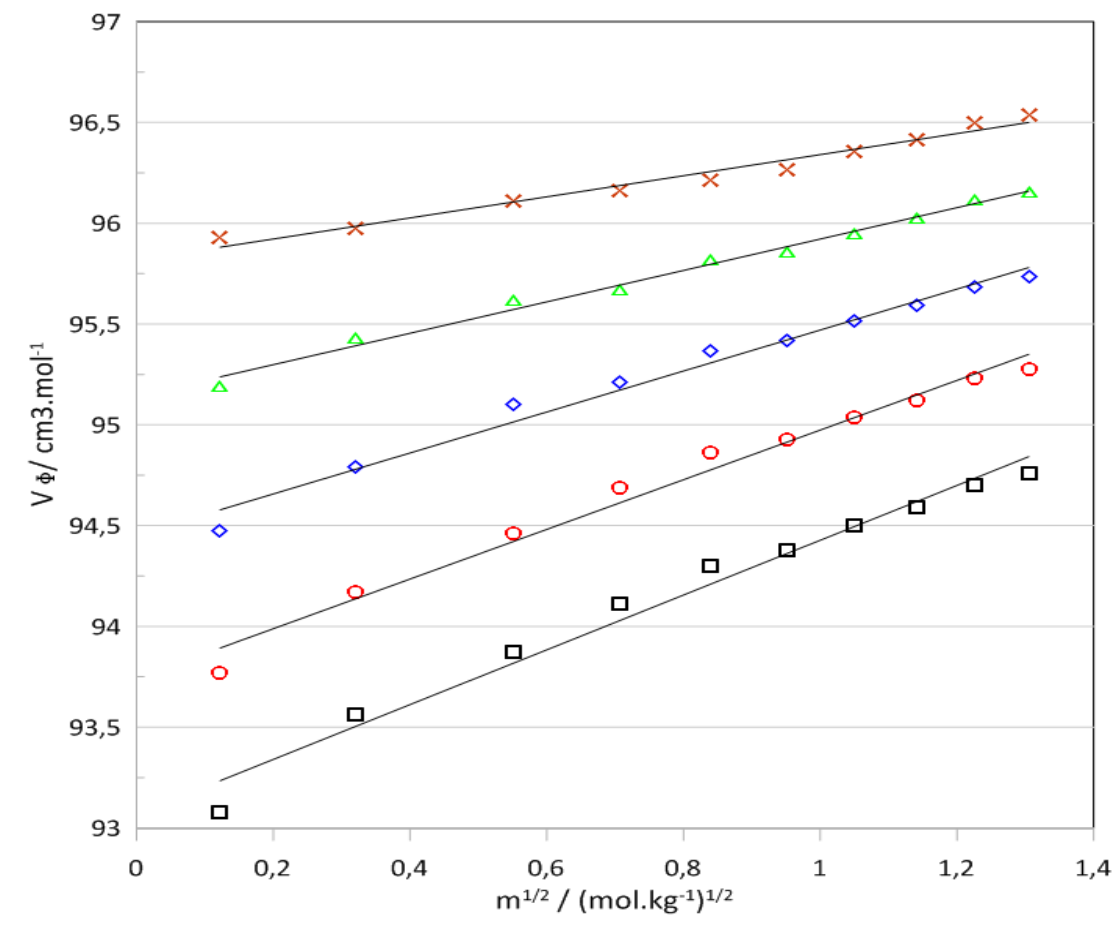

Fonte: Autor 
Figura 49 - Volume molar aparente da xilose em solução iônica de $0,025 \mathrm{~mol} \cdot \mathrm{kg}^{-1}$, em função da raiz quadrada da molalidade da xilose, a diferentes temperaturas e pressão atmosférica: $283,15 \mathrm{~K} ; \bigcirc 288,15 \mathrm{~K} ; \diamond 293,15 \mathrm{~K} ; \triangle 298,15 \mathrm{~K} ; \times 303,15 \mathrm{~K}$. As linhas representam a correlação usando a equação (20)

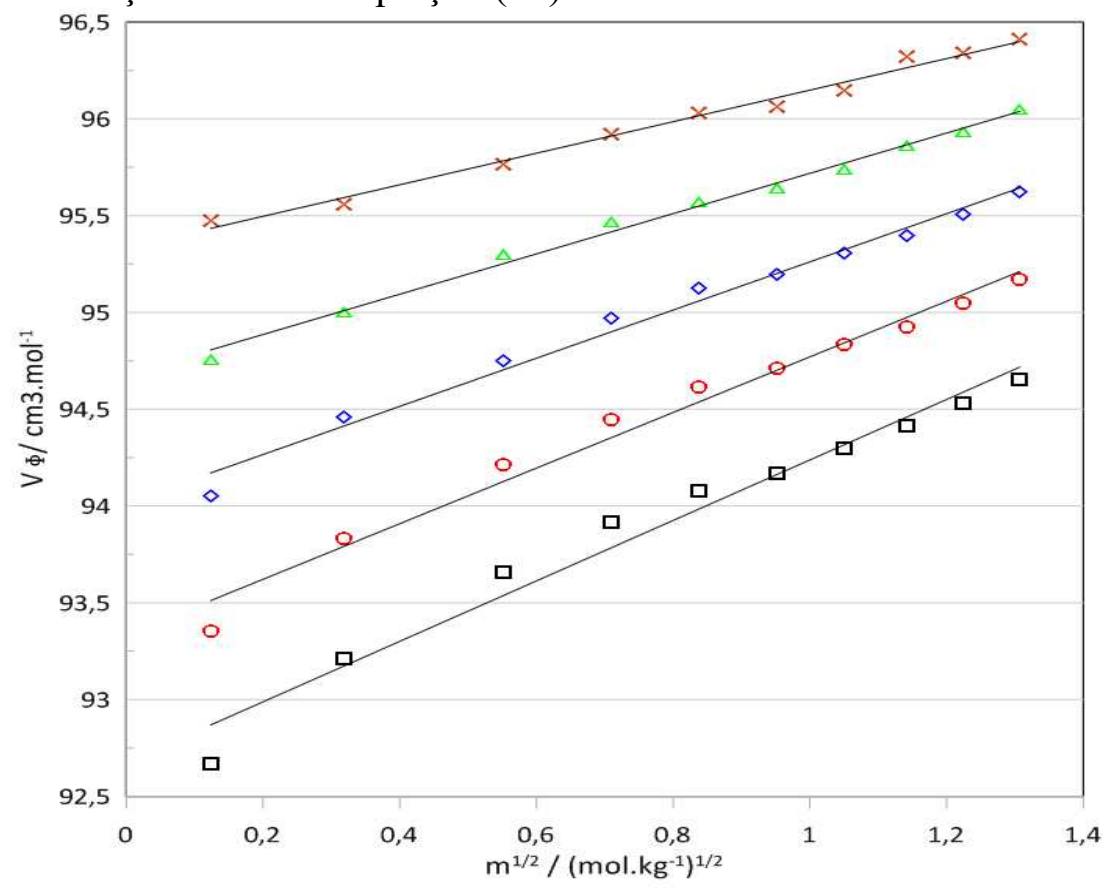

Fonte: Autor

Figura 50 - Volume molar aparente da xilose em solução iônica de $0,050 \mathrm{~mol} \cdot \mathrm{kg}^{-1}$, em função da raiz quadrada da molalidade da xilose, a diferentes temperaturas e pressão atmosférica: $283,15 \mathrm{~K} ; \bigcirc 288,15 \mathrm{~K} ; \diamond 293,15 \mathrm{~K} ; \triangle 298,15 \mathrm{~K} ; \times 303,15 \mathrm{~K}$. As linhas representam a correlação usando a equação (20)

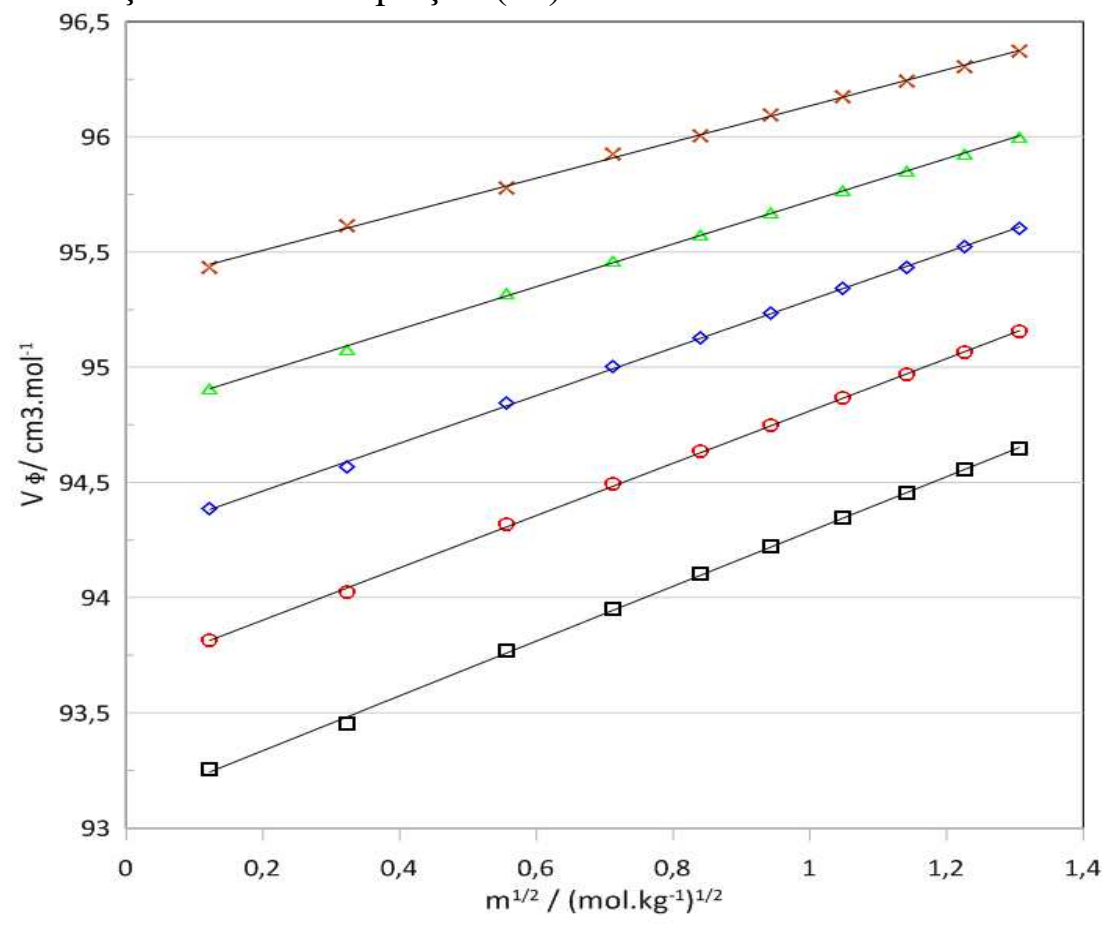

Fonte: Autor 
Figura 51 - Volume molar aparente da xilose em solução iônica de $0,075 \mathrm{~mol} \cdot \mathrm{kg}^{-1}$, em função da raiz quadrada da molalidade da xilose, a diferentes temperaturas e pressão atmosférica: $283,15 \mathrm{~K} ; \bigcirc 288,15 \mathrm{~K} ; \diamond 293,15 \mathrm{~K} ; \triangle 298,15 \mathrm{~K} ; \times 303,15 \mathrm{~K}$. As linhas representam a correlação usando a equação (20)

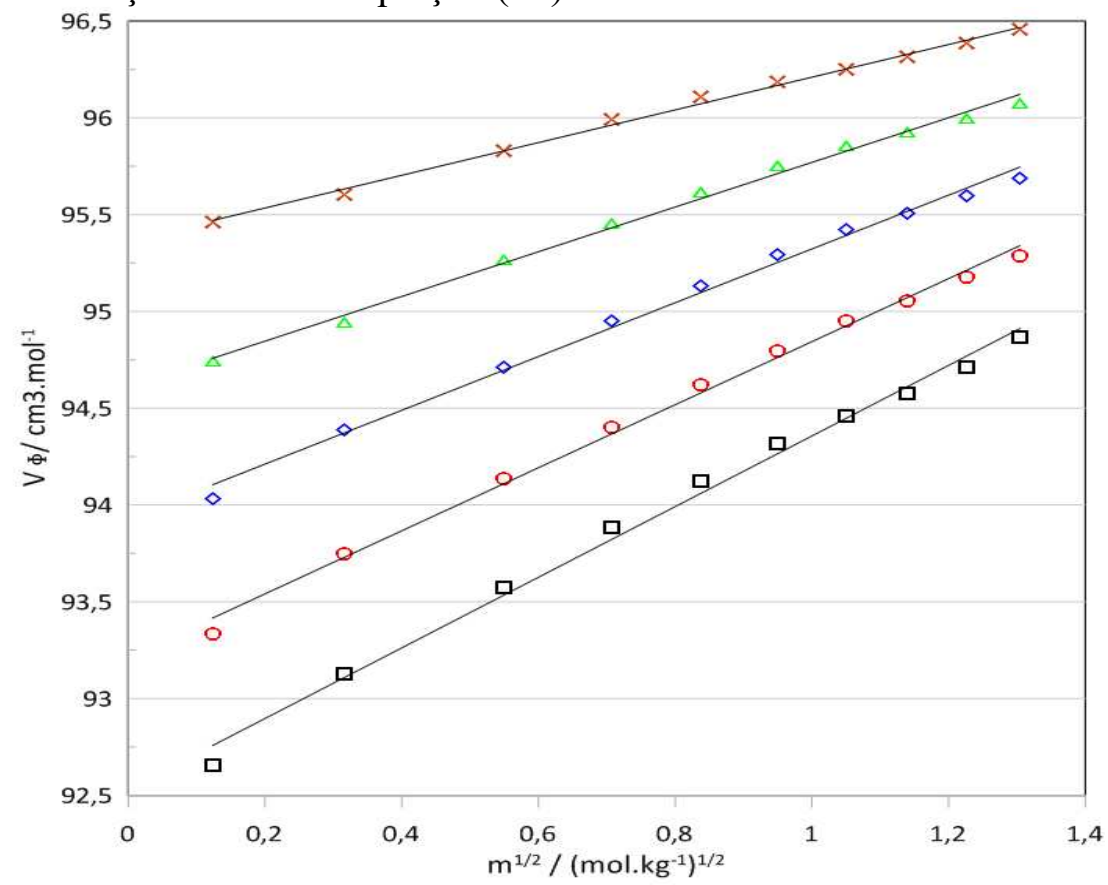

Fonte: Autor

Figura 52 - Volume molar aparente da xilose em solução iônica de $0,10 \mathrm{~mol} \cdot \mathrm{kg}^{-1}$, em função da raiz quadrada da molalidade da xilose, a diferentes temperaturas e pressão atmosférica: $283,15 \mathrm{~K} ; \bigcirc 288,15 \mathrm{~K} ; \diamond 293,15 \mathrm{~K} ; \triangle 298,15 \mathrm{~K} ; \times 303,15 \mathrm{~K}$. As linhas representam a correlação usando a equação (20)

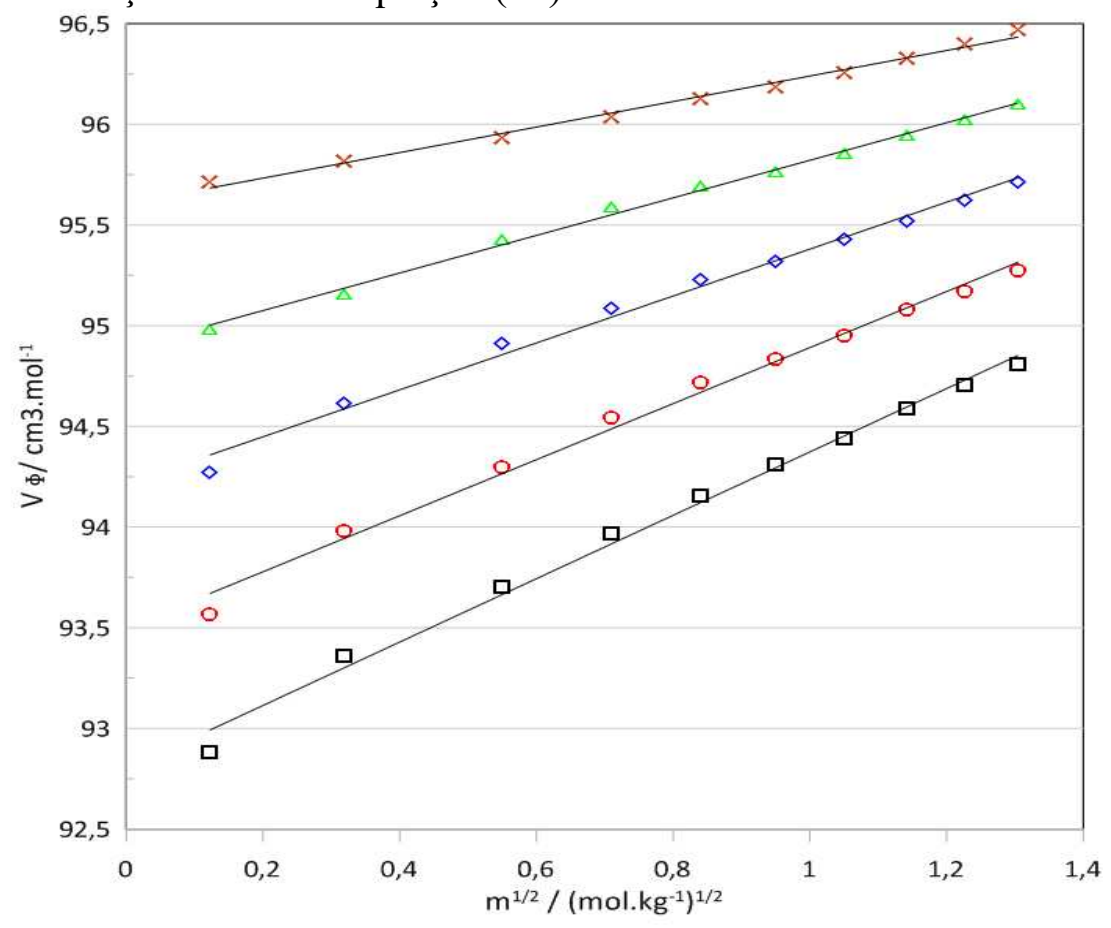

Fonte: Autor 
As tabelas 16 e 17 apresentam, respectivamente, as equações que descrevem as correlações do volume molar aparente da xilose em água pura e os valores do volume molar aparente à diluição infinita da glicose em água pura.

As tabelas 18 - 21 apresentam as equações que descrevem as correlações do volume molar aparente da xilose nas soluções iônica de concentração de 0,025, 0,05, 0,075 e 0,1 mol $\cdot \mathrm{kg}^{-1}$, como uma função da molalidade.

As tabelas 22 - 25 apresentam os valores do volume molar aparente à diluição infinita da glicose nas soluções iônicas de concentração de $0,025,0,05,0,075$ e $0,1 \mathrm{~mol} \cdot \mathrm{kg}^{-1}$, respectivamente, a diferentes temperaturas.

As tabelas 26 - 29 apresentam os valores dos volumes de transferência da xilose da água para as soluções iônicas de concentração de $0,025,0,05,0,075$ e $0,1 \mathrm{~mol} \cdot \mathrm{kg}^{-1}$, a diferentes temperaturas.

Tabela 16 - Equações de ajuste usando a equação (20) para as soluções de xilose em água pura, a diferentes temperaturas

\begin{tabular}{ccc}
\hline $\mathrm{T} / \mathrm{K}$ & \multicolumn{1}{c}{ Equação } & $\mathrm{R}^{2}$ \\
\hline 283,15 & $\mathrm{~V}_{f_{S}}=93,068524+1,359031 ¥ m^{\frac{1}{2}}$ & 0,978990 \\
288,15 & $\mathrm{~V}_{f_{S}}=93,742339+1,231760 ¥ m^{\frac{1}{2}}$ & 0,982152 \\
293,15 & $\mathrm{~V}_{f_{S}}=94,454039+1,016150 ¥ m^{\frac{1}{2}}$ & 0,981654 \\
298,15 & $\mathrm{~V}_{f_{S}}=95,142676+0,778952 ¥ m^{\frac{1}{2}}$ & 0,991633 \\
303,15 & $\mathrm{~V}_{f_{S}}=95,817242+0523152 ¥ m^{\frac{1}{2}}$ & 0,974066 \\
\hline
\end{tabular}

Fonte: Autor

Para as soluções de xilose em água pura os valores de ajuste da reta não apresentam uma uniformidade, apresentando somente um resultado satisfatório em 298,15 K. 
Tabela 17 - Volumes molares aparentes à diluição infinita da xilose em água pura, a diferentes temperaturas

\begin{tabular}{cc}
\hline $\mathrm{T} / \mathrm{K}$ & $\mathrm{V}_{f_{\mathrm{s}} \text { (água) }}^{0} / \mathrm{cm}^{3} \cdot \mathrm{mol}^{-1}$ \\
\hline 283,15 & $V_{f_{s}}^{0}=93,07$ \\
288,15 & $V_{f_{s}}^{0}=93,74$ \\
293,15 & $V_{f_{s}}^{0}=94,45$ \\
298,15 & $V_{f_{s}}^{0}=95,14$ \\
303,15 & $V_{f_{s}}^{0}=95,82$ \\
\hline
\end{tabular}

Fonte: Autor

Tabela 18 - Equações de ajuste usando a equação (20) para as soluções de xilose em solução iônica de $0,025 \mathrm{~mol} \cdot \mathrm{kg}^{-1}$, a diferentes temperaturas

\begin{tabular}{ccc}
\hline $\mathrm{T} / \mathrm{K}$ & \multicolumn{1}{c}{ Equação } & $\mathrm{R}^{2}$ \\
\hline 283,15 & $\mathrm{~V}_{f_{S}}=92,676029+1,561758 ¥ m^{\frac{1}{2}}$ & 0,974086 \\
288,15 & $\mathrm{~V}_{f_{S}}=93,333830+1,436534 ¥ m^{\frac{1}{2}}$ & 0,980971 \\
293,15 & $\mathrm{~V}_{f_{S}}=94,016833+1,244364 ¥ m^{\frac{1}{2}}$ & 0,985189 \\
298,15 & $\mathrm{~V}_{f_{s}}=94,677565+1,041031 ¥ m^{\frac{1}{2}}$ & 0,992944 \\
303,15 & $\mathrm{~V}_{f_{S}}=95,333415+0,814952 ¥ m^{\frac{1}{2}}$ & 0,988518 \\
\hline
\end{tabular}

Fonte: Autor

Para as soluções de xilose em solução iônica de $0,025 \mathrm{~mol} \cdot \mathrm{kg}^{-1}$, os valores de ajuste da reta não apresentam uma uniformidade, apresentando somente um resultado satisfatório em $298,15 \mathrm{~K}$.

Tabela 19 - Equações de ajuste usando a equação (20) para as soluções de xilose em solução iônica de $0,050 \mathrm{~mol} \cdot \mathrm{kg}^{-1}$, a diferentes temperaturas.

\begin{tabular}{ccc}
\hline $\mathrm{T} / \mathrm{K}$ & \multicolumn{1}{c}{ Equação } & $\mathrm{R}^{2}$ \\
\hline 283,15 & $\mathrm{~V}_{f_{s}}=93,128419+1,169423 ¥ m^{\frac{1}{2}}$ & 0,964660 \\
288,15 & $\mathrm{~V}_{f_{s}}=93,702987+1,112927 ¥ m^{\frac{1}{2}}$ & 0,965025 \\
293,15 & $\mathrm{~V}_{f_{s}}=94,279573+1,012983 ¥ m^{\frac{1}{2}}$ & 0,969830 \\
298,15 & $\mathrm{~V}_{f_{s}}=94,823149+0,902569 ¥ m^{\frac{1}{2}}$ & 0,986976 \\
303,15 & $\mathrm{~V}_{f_{s}}=95,376685+0,765886 ¥ m^{\frac{1}{2}}$ & 0,996159 \\
\hline
\end{tabular}


Para as soluções de xilose em solução iônica de $0,050 \mathrm{~mol} \cdot \mathrm{kg}^{-1}$, os valores de ajuste da reta apresentam em sua maioria resultados não satisfatórios, somente sendo satisfatório em sua temperatura mais alta.

Tabela 20 - Equações de ajuste usando a equação (20) para as soluções de xilose em solução iônica de $0,075 \mathrm{~mol} \cdot \mathrm{kg}^{-1}$, a diferentes temperaturas

\begin{tabular}{ccc}
\hline $\mathrm{T} / \mathrm{K}$ & \multicolumn{1}{c}{ Equação } & $\mathrm{R}^{2}$ \\
\hline 283,15 & $\mathrm{~V}_{f_{s}}=93,335472+1,056049 ¥ m^{\frac{1}{2}}$ & 0,983116 \\
288,15 & $\mathrm{~V}_{f_{s}}=93,915715+0,997247 ¥ m^{\frac{1}{2}}$ & 0,983855 \\
293,15 & $\mathrm{~V}_{f_{s}}=94,493442+0,891259 ¥ m^{\frac{1}{2}}$ & 0,986375 \\
298,15 & $\mathrm{~V}_{f_{s}}=95,049528+0,772984 ¥ m^{\frac{1}{2}}$ & 0,996691 \\
303,15 & $\mathrm{~V}_{f_{s}}=95,601520+0,625402 ¥ m^{\frac{1}{2}}$ & 0,987972 \\
\hline
\end{tabular}

Fonte: Autor

Para as soluções de xilose em solução iônica de $0,075 \mathrm{~mol} \cdot \mathrm{kg}^{-1}$, os valores de ajuste da reta não apresentam uma uniformidade, apresentando em sua maioria resultados não satisfatórios.

Tabela 21 - Equações de ajuste usando a equação (20) para as soluções de xilose em solução iônica de $0,10 \mathrm{~mol} \cdot \mathrm{kg}^{-1}$, a diferentes temperaturas

\begin{tabular}{ccc}
\hline $\mathrm{T} / \mathrm{K}$ & \multicolumn{1}{c}{ Equação } & $\mathrm{R}^{2}$ \\
\hline 283,15 & $\mathrm{~V}_{f_{S}}=93,044386+1,311185 ¥ m^{\frac{1}{2}}$ & 0,984823 \\
288,15 & $\mathrm{~V}_{f_{s}}=94,759847+1,029014 ¥ m^{\frac{1}{2}}$ & 0,985629 \\
293,15 & $\mathrm{~V}_{f_{s}}=94,203533+1,147980 ¥ m^{\frac{1}{2}}$ & 0,988005 \\
298,15 & $\mathrm{~V}_{f_{s}}=94,759847+1,029014 ¥ m^{\frac{1}{2}}$ & 0,996111 \\
303,15 & $\mathrm{~V}_{f_{s}}=95,321786+0,877352 ¥ m^{\frac{1}{2}}$ & 0,998022 \\
\hline
\end{tabular}

Fonte: Autor

Para as soluções de xilose em solução iônica de $0,10 \mathrm{~mol} \cdot \mathrm{kg}^{-1}$, os valores de ajuste da reta apresentam resultados satisfatórios somente em temperaturas mais altas. 
Tabela 22 - Volumes molares aparentes à diluição infinita da xilose em solução iônica de 0,025 $\underline{\mathrm{mol} \cdot \mathrm{kg}^{-1}, \text { a diferentes temperaturas }}$

$\begin{array}{lc}\mathrm{T} / \mathrm{K} & \mathrm{V}_{f_{s} \text { (soluçãoiônica) }}^{0} / \mathrm{cm}^{3} \cdot \mathrm{mol}^{-1} \\ 283,15 & V_{f_{s}}^{0}=92,68 \\ 288,15 & V_{f_{s}}^{0}=93,33 \\ 293,15 & V_{f_{s}}^{0}=94,02 \\ 298,15 & V_{f_{s}}^{0}=94,68 \\ 303,15 & V_{f_{s}}^{0}=95,33\end{array}$

Fonte: Autor

Tabela 23 - Volumes molares aparentes à diluição infinita da xilose em solução iônica de 0,050 $\underline{\mathrm{mol} \cdot \mathrm{kg}^{-1} \text {, a diferentes temperaturas }}$

$\mathrm{T} / \mathrm{K} \quad \mathrm{V}_{f_{s} \text { (soluçãoiônica) }}^{0} / \mathrm{cm}^{3} \cdot \mathrm{mol}^{-1}$

\begin{tabular}{ll}
283,15 & $V_{f_{s}}^{0}=93,13$ \\
288,15 & $V_{f_{s}}^{0}=93,70$ \\
293,15 & $V_{f_{s}}^{0}=94,28$ \\
298,15 & $V_{f_{s}}^{0}=94,82$ \\
303,15 & $V_{f_{s}}^{0}=95,38$ \\
\hline
\end{tabular}

Fonte: Autor

Tabela 24 - Volumes molares aparentes à diluição infinita da xilose em solução iônica de 0,075 $\mathrm{mol} \cdot \mathrm{kg}^{-1}$, a diferentes temperaturas

\begin{tabular}{cc}
\hline $\mathrm{T} / \mathrm{K}$ & $\mathrm{V}_{f_{s} \text { (soluçãoiônica) }}^{0} / \mathrm{cm}^{3} \cdot \mathrm{mol}^{-1}$ \\
\hline 283,15 & $V_{f_{s}}^{0}=93,34$ \\
288,15 & $V_{f_{s}}^{0}=93,92$ \\
293,15 & $V_{f_{s}}^{0}=94,49$ \\
298,15 & $V_{f_{s}}^{0}=95,05$ \\
303,15 & $V_{f_{s}}^{0}=95,60$
\end{tabular}


Tabela 25 - Volumes molares aparentes à diluição infinita da xilose em solução iônica de 0,10 $\underline{\mathrm{mol} \cdot \mathrm{kg}^{-1}, \text { a diferentes temperaturas }}$

$\mathrm{T} / \mathrm{K}$

283,15

288,15

293,15

298,15

303,15
$\mathrm{V}_{f_{s} \text { (soluçãoiônica) }}^{0} / \mathrm{cm}^{3} \cdot \mathrm{mol}^{-1}$

$V_{f_{s}}^{0}=93,04$

$V_{f_{s}}^{0}=93,62$

$V_{f_{s}}^{0}=94,20$

$V_{f_{s}}^{0}=94,76$

$V_{f_{s}}^{0}=95,32$

Fonte: Autor

Tabela 26 - Volumes de transferência da xilose da água para solução iônica de $0,025 \mathrm{~mol} \cdot \mathrm{kg}^{-1}$, a diferentes temperaturas

\begin{tabular}{|c|c|c|c|}
\hline $\mathrm{T} / \mathrm{K}$ & $\mathrm{V}_{f_{s} \text { (soluçãoiônica) }}^{0} / \mathrm{cm}^{3} \cdot \mathrm{mol}^{-1}$ & $\mathrm{~V}_{f_{\mathrm{s}} \text { (água) }}^{0} / \mathrm{cm}^{3} \cdot \mathrm{mol}^{-1}$ & $\Delta \mathrm{V}_{\mathrm{ts}} / \mathrm{cm}^{3} \cdot \mathrm{mol}^{-1}$ \\
\hline 283,15 & $V_{f_{s}}^{0}=92,68$ & $V_{f_{s}}^{0}=93,07$ & $-0,39$ \\
\hline 288,15 & $V_{f_{s}}^{0}=93,33$ & $V_{f_{s}}^{0}=93,74$ & $-0,41$ \\
\hline 293,15 & $V_{f_{s}}^{0}=94,02$ & $V_{f_{s}}^{0}=94,45$ & $-0,43$ \\
\hline 298,15 & $V_{f_{s}}^{0}=94,68$ & $V_{f_{s}}^{0}=95,14$ & $-0,46$ \\
\hline 303,15 & $V_{f_{s}}^{0}=95,33$ & $V_{f_{s}}^{0}=95,82$ & $-0,49$ \\
\hline
\end{tabular}

Fonte: Autor

Tabela 27 - Volumes de transferência da xilose da água para solução iônica de 0,050 mol. $\mathrm{kg}^{-1}$, a diferentes temperaturas

\begin{tabular}{cccc}
\hline $\mathrm{T} / \mathrm{K}$ & $\mathrm{V}_{f_{s} \text { (solucãoiônica) }}^{0} / \mathrm{cm}^{3} \cdot \mathrm{mol}^{-1}$ & $\mathrm{~V}_{f_{\mathrm{s}} \text { (agua) }}^{0} / \mathrm{cm}^{3} \cdot \mathrm{mol}^{-1}$ & $\Delta \mathrm{V}_{\mathrm{ts}} / \mathrm{cm}^{3} \cdot \mathrm{mol}^{-1}$ \\
\hline 283,15 & $V_{f_{s}}^{0}=93,13$ & $V_{f_{s}}^{0}=93,07$ & 0,06 \\
288,15 & $V_{f_{s}}^{0}=93,70$ & $V_{f_{s}}^{0}=93,74$ & $-0,04$ \\
293,15 & $V_{f_{s}}^{0}=94,28$ & $V_{f_{s}}^{0}=94,45$ & $-0,17$ \\
298,15 & $V_{f_{s}}^{0}=94,82$ & $V_{f_{s}}^{0}=95,14$ & $-0,32$ \\
303,15 & $V_{f_{s}}^{0}=95,38$ & $V_{f_{s}}^{0}=95,82$ & $-1,44$
\end{tabular}


Tabela 28 - Volumes de transferência da xilose da água para solução iônica de $0,075 \mathrm{~mol} \cdot \mathrm{kg}^{-1}$, a diferentes temperaturas

\begin{tabular}{|c|c|c|c|}
\hline $\mathrm{T} / \mathrm{K}$ & $\mathrm{V}_{f_{s} \text { (soluçãoiônica) }}^{0} / \mathrm{cm}^{3} \cdot \mathrm{mol}^{-1}$ & $\mathrm{~V}_{f_{\mathrm{s}} \text { (água) }}^{0} / \mathrm{cm}^{3} \cdot \mathrm{mol}^{-1}$ & $\Delta \mathrm{V}_{\mathrm{ts}} / \mathrm{cm}^{3} \cdot \mathrm{mol}^{-1}$ \\
\hline 283,15 & $V_{f_{s}}^{0}=93,34$ & $V_{f_{s}}^{0}=93,07$ & 0,27 \\
\hline 288,15 & $V_{f_{s}}^{0}=93,92$ & $V_{f_{s}}^{0}=93,74$ & 0,18 \\
\hline 293,15 & $V_{f_{s}}^{0}=94,49$ & $V_{f_{s}}^{0}=94,45$ & 0,04 \\
\hline 298,15 & $V_{f_{s}}^{0}=95,05$ & $V_{f_{s}}^{0}=95,14$ & $-0,09$ \\
\hline 303,15 & $V_{f_{s}}^{0}=95,60$ & $V_{f_{s}}^{0}=95,82$ & $-0,22$ \\
\hline
\end{tabular}

Fonte: Autor

Tabela 29 - Volumes de transferência da xilose da água para solução iônica de $0,10 \mathrm{~mol} \cdot \mathrm{kg}^{-1}$, a diferentes temperaturas

\begin{tabular}{|c|c|c|c|}
\hline $\mathrm{T} / \mathrm{K}$ & $\mathrm{V}_{f_{s} \text { (soluçãoiônica) }}^{0} / \mathrm{cm}^{3} \cdot \mathrm{mol}^{-1}$ & $\mathrm{~V}_{f_{\mathrm{s}} \text { (água) }}^{0} / \mathrm{cm}^{3} \cdot \mathrm{mol}^{-1}$ & $\Delta \mathrm{V}_{\mathrm{ts}} / \mathrm{cm}^{3} \cdot \mathrm{mol}^{-1}$ \\
\hline 283,15 & $V_{f_{s}}^{0}=93,04$ & $V_{f_{s}}^{0}=93,07$ & $-0,03$ \\
\hline 288,15 & $V_{f_{s}}^{0}=93,62$ & $V_{f_{s}}^{0}=93,74$ & $-0,12$ \\
\hline 293,15 & $V_{f_{s}}^{0}=94,20$ & $V_{f_{s}}^{0}=94,45$ & $-0,25$ \\
\hline 298,15 & $V_{f_{s}}^{0}=94,76$ & $V_{f_{s}}^{0}=95,14$ & $-0,38$ \\
\hline 303,15 & $V_{f_{s}}^{0}=95,32$ & $V_{f_{s}}^{0}=95,82$ & $-0,50$ \\
\hline
\end{tabular}

Fonte: Autor

Os valores de $S_{\mathrm{v}}$ para todos os sistemas contendo xilose são pequenos, o que indica que possivelmente as interações xilose-xilose são fracas e diminuem com o aumento da temperatura. Com base no modelo de "cosphere overlap" (DESNOYERS et al, 1969), para o sistema contendo xilose parece que há predominância dos efeitos (i), (iii) e (iv).

\subsubsection{Sistema Sacarose}

As figuras 53 - 57 apresentam o comportamento da correlação do volume molar aparente das soluções de sacarose em água pura e nas soluções iônicas de concentração de $0,025,0,05,0,075$ e $0,1 \mathrm{~mol} \cdot \mathrm{kg}^{-1}$, respectivamente, descrita pela equação (20), a diferentes temperaturas. 
Figura 53 - Volume molar aparente da sacarose em água pura, em função da raiz quadrada da molalidade da sacarose, a diferentes temperaturas e pressão atmosférica: $\square 283,15 \mathrm{~K}$; $\bigcirc 288,15$ $\mathrm{K} ; \diamond 293,15 \mathrm{~K} ; \triangle 298,15 \mathrm{~K} ; \times 303,15 \mathrm{~K}$. As linhas representam a correlação usando a equação (20)

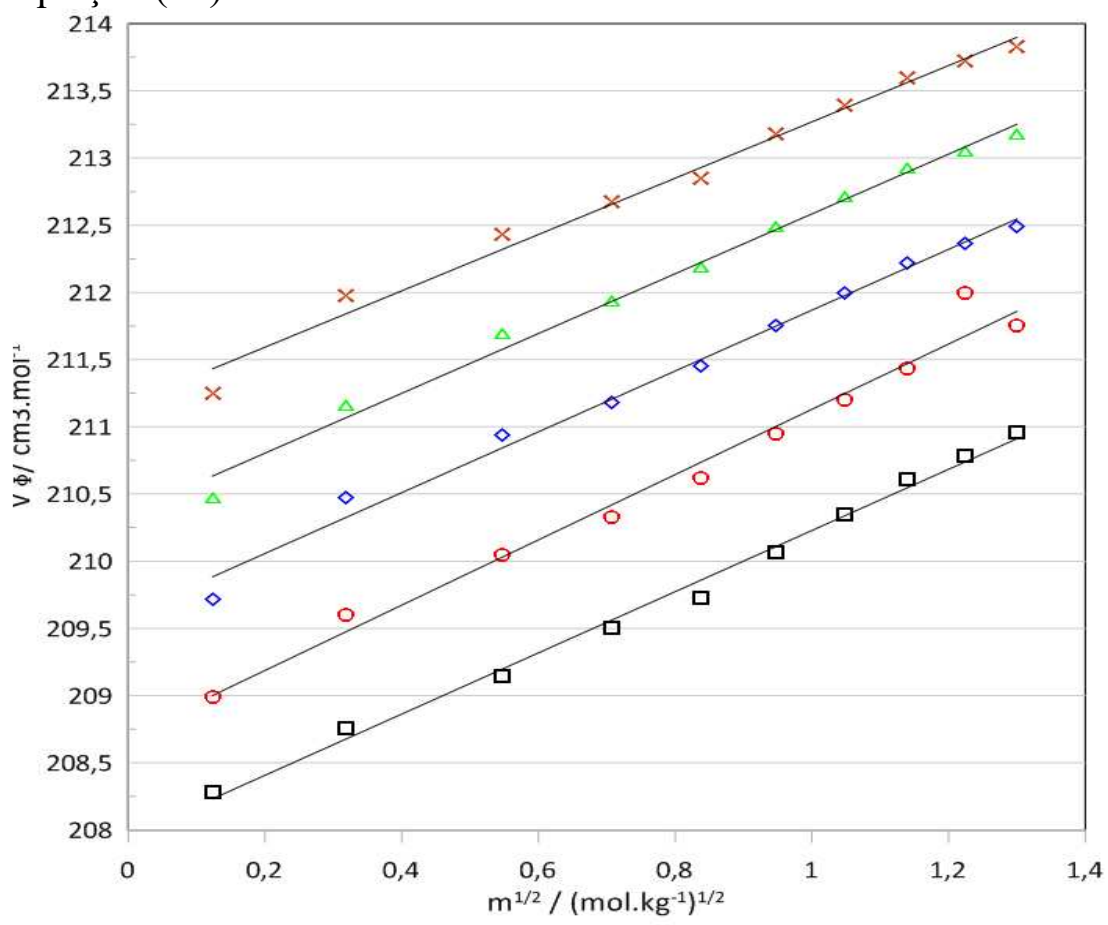

Fonte: Autor

Figura 54 - Volume molar aparente da sacarose em solução iônica de $0,025 \mathrm{~mol} \cdot \mathrm{kg}^{-1}$, em função da raiz quadrada da molalidade da sacarose, a diferentes temperaturas e pressão atmosférica: 283,15 K; $\bigcirc 288,15 \mathrm{~K} ; \diamond 293,15 \mathrm{~K} ; \triangle 298,15 \mathrm{~K} ; \times 303,15 \mathrm{~K}$. As linhas representam a correlação usando a equação (20)

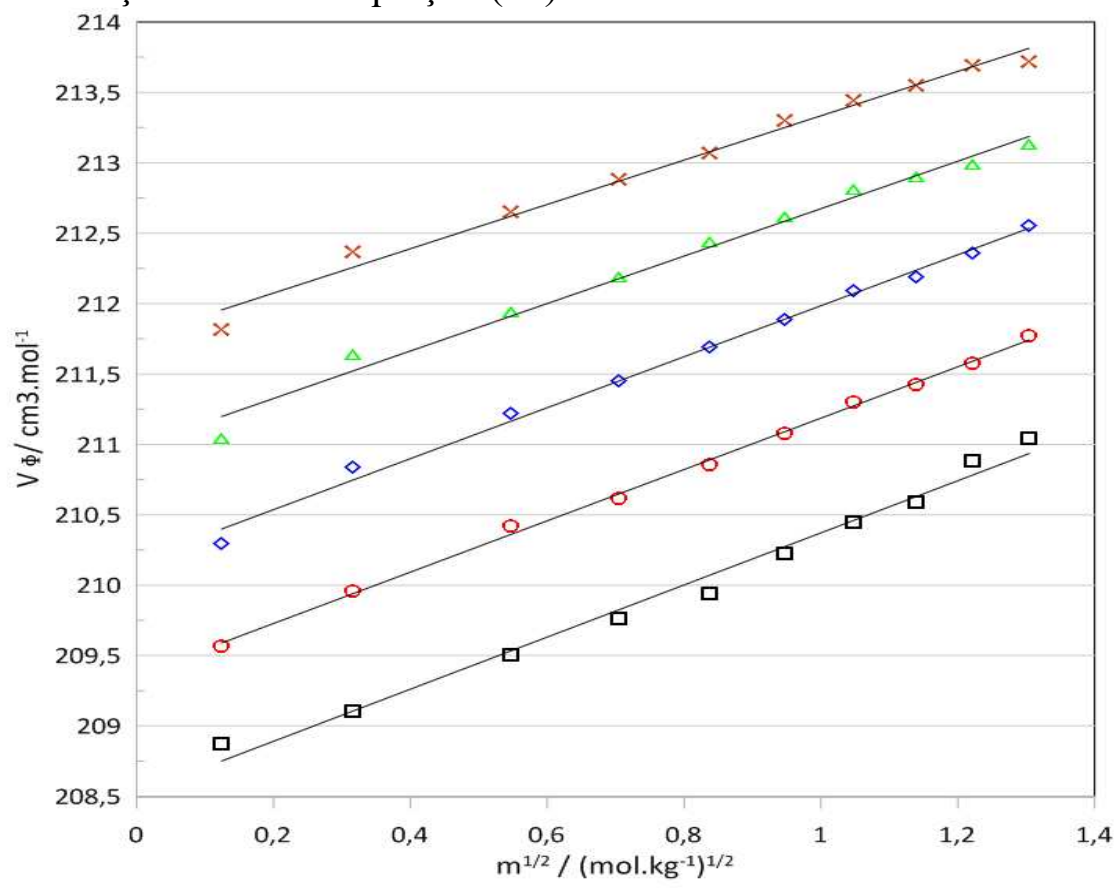

Fonte: Autor 
Figura 55 - Volume molar aparente da sacarose em solução iônica de $0,050 \mathrm{~mol} \cdot \mathrm{kg}^{-1}$, em função da raiz quadrada da molalidade da sacarose, a diferentes temperaturas e pressão atmosférica: 283,15 K; $\bigcirc 288,15 \mathrm{~K} ; \diamond 293,15 \mathrm{~K} ; \triangle 298,15 \mathrm{~K} ; \times 303,15 \mathrm{~K}$. As linhas representam a correlação usando a equação (20)

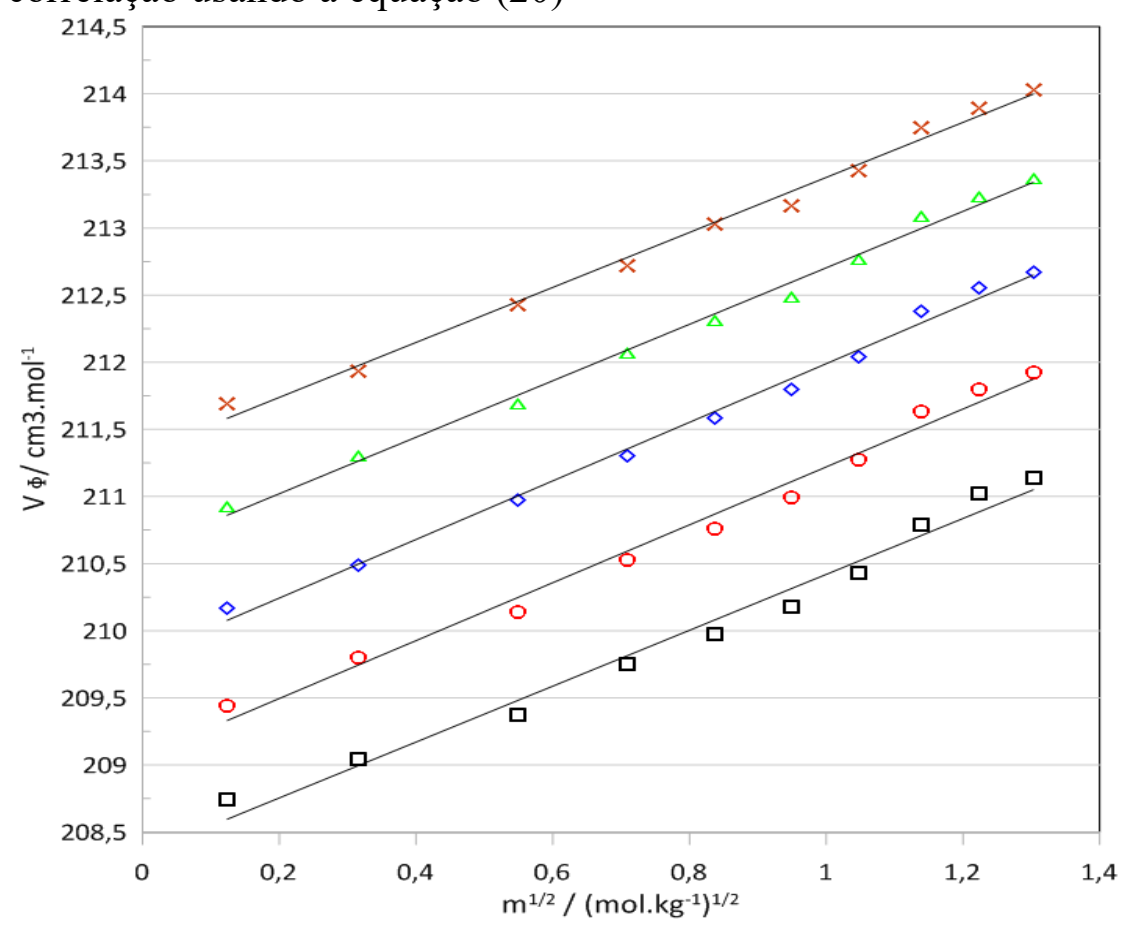

Fonte: Autor

Figura 56 - Volume molar aparente da sacarose em solução iônica de $0,075 \mathrm{~mol} \cdot \mathrm{kg}^{-1}$, em função da raiz quadrada da molalidade da sacarose, a diferentes temperaturas e pressão atmosférica: $283,15 \mathrm{~K} ; \bigcirc 288,15 \mathrm{~K} ; \diamond 293,15 \mathrm{~K} ; \triangle 298,15 \mathrm{~K} ; \times 303,15 \mathrm{~K}$. As linhas representam a correlação usando a equação (20)

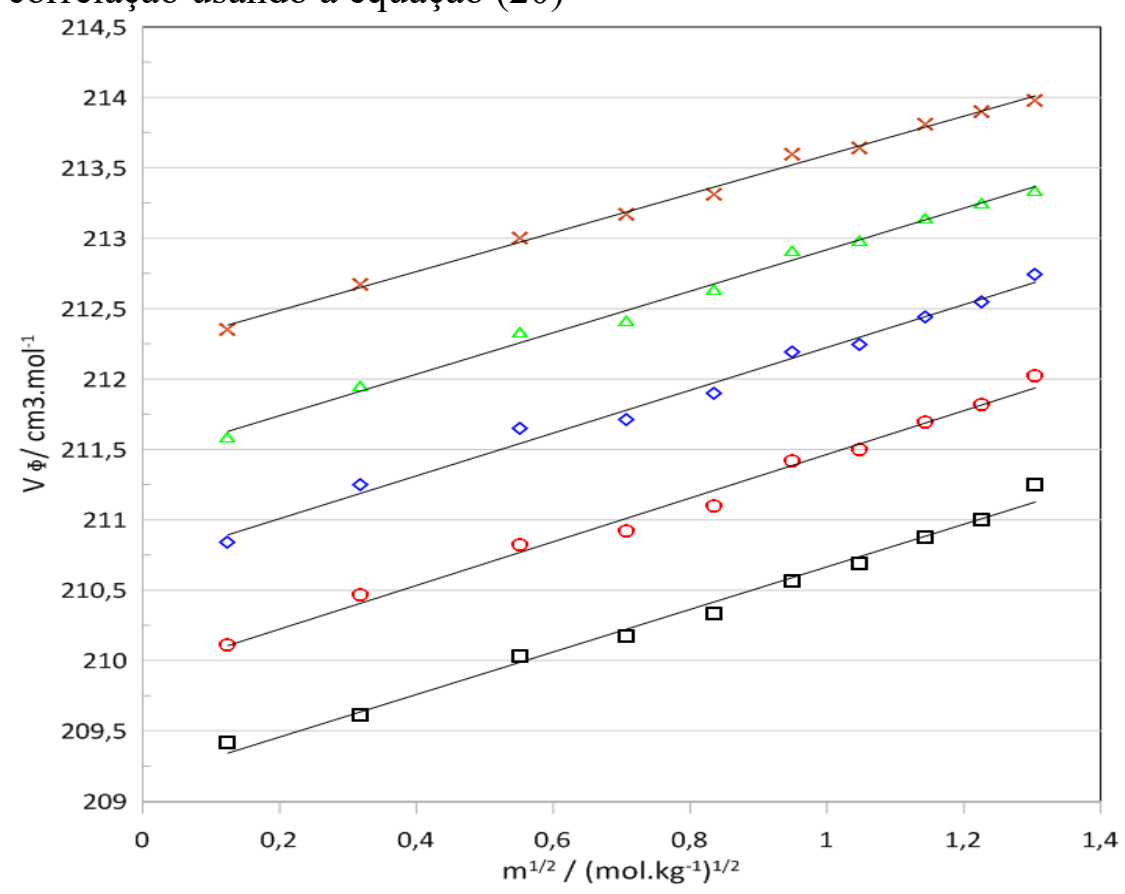

Fonte: Autor 
Figura 57 - Volume molar aparente da sacarose em solução iônica de $0,10 \mathrm{~mol} \cdot \mathrm{kg}^{-1}$, em função da raiz quadrada da molalidade da sacarose, a diferentes temperaturas e pressão atmosférica: $283,15 \mathrm{~K} ; \bigcirc 288,15 \mathrm{~K} ; \diamond 293,15 \mathrm{~K} ; \triangle 298,15 \mathrm{~K} ; \times 303,15 \mathrm{~K}$. As linhas representam a correlação usando a equação (20)

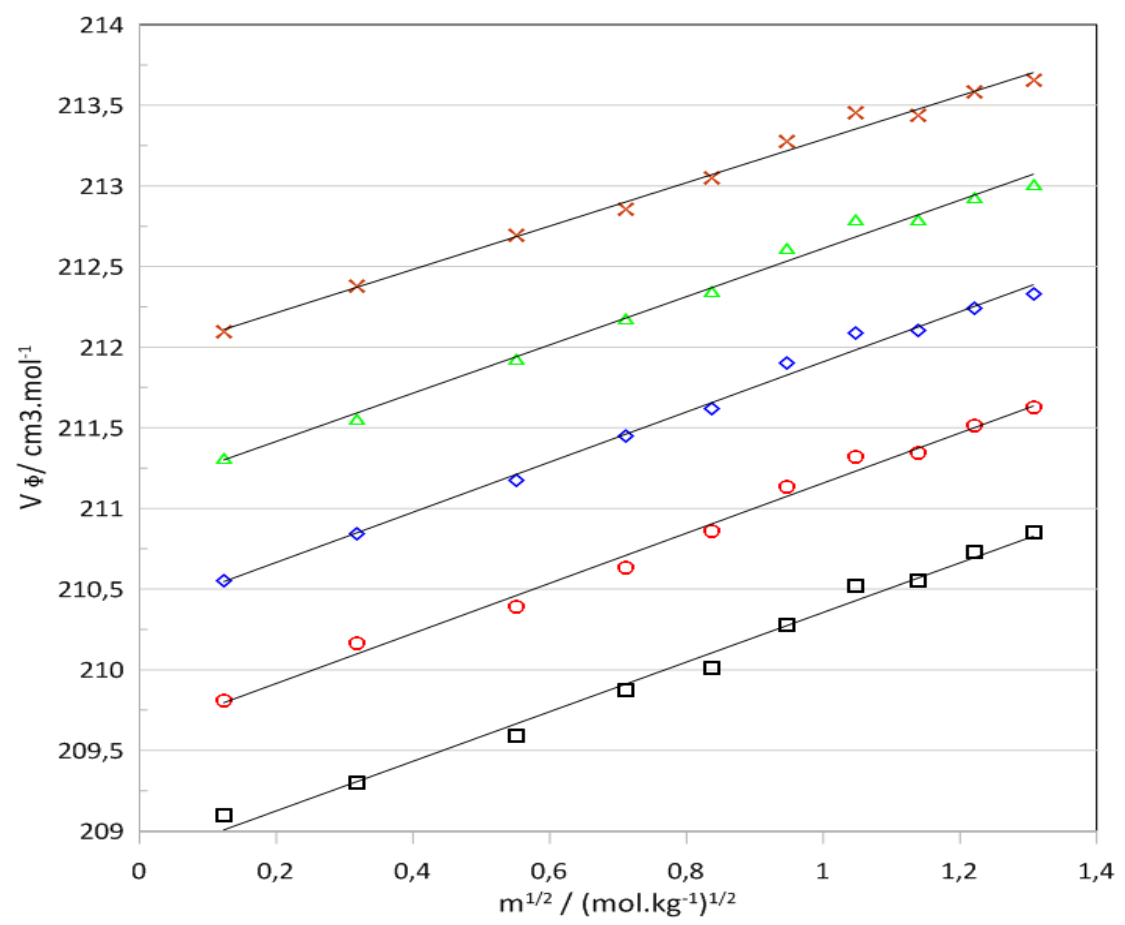

Fonte: Autor

As tabelas 30 e 31 apresentam, respectivamente, as equações que descrevem as correlações do volume molar aparente da sacarose em água pura e os valores do volume molar aparente à diluição infinita da glicose em água pura.

As tabelas 32-35 apresentam as equações que descrevem as correlações do volume molar aparente da sacarose nas soluções iônica de concentração de 0,025, 0,05, 0,075 e 0,1 $\mathrm{mol} \cdot \mathrm{kg}^{-1}$, como uma função da molalidade.

As tabelas 36-39 apresentam os valores do volume molar aparente à diluição infinita da sacarose nas soluções iônicas de concentração de $0,025,0,05,0,075$ e $0,1 \mathrm{~mol} \cdot \mathrm{kg}^{-1}$, respectivamente, a diferentes temperaturas.

As tabelas 40-43 apresentam os valores dos volumes de transferência da sacarose da água para as soluções iônicas de concentração de $0,025,0,05,0,075 \mathrm{e} 0,1 \mathrm{~mol} \cdot \mathrm{kg}^{-1}$, a diferentes temperaturas. 
Tabela 30 - Equações de ajuste usando a equação (20) para as soluções de sacarose em água pura, a diferentes temperaturas

\begin{tabular}{ccc}
\hline $\mathrm{T} / \mathrm{K}$ & Equação & $\mathrm{R}^{2}$ \\
\hline 283,15 & $\mathrm{~V}_{f_{S}}=207,951543+2,277161 ¥ m^{\frac{1}{2}}$ & 0,994300 \\
288,15 & $\mathrm{~V}_{f_{S}}=208,756880+2,312458 ¥ m^{\frac{1}{2}}$ & 0,996345 \\
293,15 & $\mathrm{~V}_{f_{S}}=209,604780+2,263345 ¥ m^{\frac{1}{2}}$ & 0,990902 \\
298,15 & $\mathrm{~V}_{f_{S}}=210,359086+2,225169 ¥ m^{\frac{1}{2}}$ & 0,991709 \\
303,15 & $\mathrm{~V}_{f_{S}}=211,173282+2,096038 ¥ m^{\frac{1}{2}}$ & 0,974066 \\
\hline
\end{tabular}

Fonte: Autor

Para as soluções de sacarose em água pura os valores de ajuste da reta só não apresentam um resultado satisfatório para a temperatura mais alta.

Tabela 31 - Volumes molares aparentes à diluição infinita da sacarose em água pura, a diferentes temperaturas

\begin{tabular}{cc}
\hline $\mathrm{T} / \mathrm{K}$ & $\mathrm{V}_{f_{\mathrm{s}} \text { (água) }}^{0} / \mathrm{cm}^{3} \cdot \mathrm{mol}^{-1}$ \\
\hline 283,15 & $V_{f_{s}^{0}}^{0}=207,95$ \\
288,15 & $V_{f_{s}}^{0}=208,46$ \\
293,15 & $V_{f_{s}^{0}}^{0}=209,60$ \\
298,15 & $V_{f_{s}}^{0}=210,36$ \\
303,15 & $V_{f_{s}}^{0}=211,17$
\end{tabular}

Fonte: Autor

Tabela 32 - Equações de ajuste usando a equação (20) para as soluções de sacarose em solução iônica de $0,025 \mathrm{~mol} \cdot \mathrm{kg}^{-1}$, a diferentes temperaturas

\begin{tabular}{ccc}
\hline $\mathrm{T} / \mathrm{K}$ & \multicolumn{1}{c}{ Equação } & $\mathrm{R}^{2}$ \\
\hline 283,15 & $\mathrm{~V}_{f_{S}}=208,521292+1,850647 ¥ m^{\frac{1}{2}}$ & 0,987486 \\
288,15 & $\mathrm{~V}_{f_{s}}=209,363665+1,823060 ¥ m^{\frac{1}{2}}$ & 0,998180 \\
293,15 & $\mathrm{~V}_{f_{S}}=210,174515+1,810646 ¥ m^{\frac{1}{2}}$ & 0,994365 \\
298,15 & $\mathrm{~V}_{f_{s}}=210,989447+1,685213 ¥ m^{\frac{1}{2}}$ & 0,987149 \\
303,15 & $\mathrm{~V}_{f_{s}}=211,760128+1,574262 ¥ m^{\frac{1}{2}}$ & 0,987064 \\
\hline
\end{tabular}


Para as soluções de sacarose em solução iônica de $0,025 \mathrm{~mol} \cdot \mathrm{kg}^{-1}$ os valores de ajuste da reta não apresentam uma regularidade.

Tabela 33 - Equações de ajuste usando a equação (20) para as soluções de sacarose em solução iônica de $0,050 \mathrm{~mol} \cdot \mathrm{kg}^{-1}$, a diferentes temperaturas

\begin{tabular}{ccc}
\hline $\mathrm{T} / \mathrm{K}$ & \multicolumn{1}{c}{ Equação } & $\mathrm{R}^{2}$ \\
\hline 283,15 & $\mathrm{~V}_{f_{S}}=208,338543+2,081386 ¥ m^{\frac{1}{2}}$ & 0,982332 \\
288,15 & $\mathrm{~V}_{f_{S}}=209,064084+2,156321 ¥ m^{\frac{1}{2}}$ & 0,987447 \\
293,15 & $\mathrm{~V}_{f_{S}}=209,807373+2,181947 ¥ m^{\frac{1}{2}}$ & 0,994084 \\
298,15 & $\mathrm{~V}_{f_{S}}=210,600275+2,103295 ¥ m^{\frac{1}{2}}$ & 0,993974 \\
303,15 & $\mathrm{~V}_{f_{S}}=211,328595+2,048496 ¥ m^{\frac{1}{2}}$ & 0,992667 \\
\hline
\end{tabular}

Fonte: Autor

Para as soluções de sacarose em solução iônica de $0,050 \mathrm{~mol} \cdot \mathrm{kg}^{-1}$ os valores de ajuste da reta apresentam valores satisfatórios para temperaturas mais altas.

Tabela 34 - Equações de ajuste usando a equação (20) para as soluções de sacarose em solução iônica de $0,075 \mathrm{~mol} \cdot \mathrm{kg}^{-1}$, a diferentes temperaturas

\begin{tabular}{ccc}
\hline $\mathrm{T} / \mathrm{K}$ & \multicolumn{1}{c}{ Equação } & $\mathrm{R}^{2}$ \\
\hline 283,15 & $\mathrm{~V}_{f_{S}}=209,154454+1,511398 ¥ m^{\frac{1}{2}}$ & 0,988913 \\
288,15 & $\mathrm{~V}_{f_{S}}=209,913128+1,551531 ¥ m^{\frac{1}{2}}$ & 0,988747 \\
293,15 & $\mathrm{~V}_{f_{S}}=210,703887+1,520375 ¥ m^{\frac{1}{2}}$ & 0,989027 \\
298,15 & $\mathrm{~V}_{f_{S}}=211,444703+1,473750 ¥ m^{\frac{1}{2}}$ & 0,992827 \\
303,15 & $\mathrm{~V}_{f_{S}}=212,211157+1,379613 ¥ m^{\frac{1}{2}}$ & 0,994921 \\
\hline
\end{tabular}

Fonte: Autor

Para as soluções de sacarose em solução iônica de $0,075 \mathrm{~mol} \cdot \mathrm{kg}^{-1}$ os valores de ajuste da reta apresentam valores satisfatórios para temperaturas mais altas. 
Tabela 35 - Equações de ajuste usando a equação (20) para as soluções de sacarose em solução iônica de $0,10 \mathrm{~mol} \cdot \mathrm{kg}^{-1}$, a diferentes temperaturas

\begin{tabular}{ccc}
\hline $\mathrm{T} / \mathrm{K}$ & \multicolumn{1}{c}{ Equação } & $\mathrm{R}^{2}$ \\
\hline 283,15 & $\mathrm{~V}_{f_{S}}=208,817384+1,537965 ¥ m^{\frac{1}{2}}$ & 0,989392 \\
288,15 & $\mathrm{~V}_{f_{S}}=209,604449+1,553203 ¥ m^{\frac{1}{2}}$ & 0,991278 \\
293,15 & $\mathrm{~V}_{f_{S}}=210,355040+1,554496 ¥ m^{\frac{1}{2}}$ & 0,992934 \\
298,15 & $\mathrm{~V}_{f_{S}}=211,116844+1,496048 ¥ m^{\frac{1}{2}}$ & 0,991950 \\
303,15 & $\mathrm{~V}_{f_{s}}=211,944336+1,344958 ¥ m^{\frac{1}{2}}$ & 0,991785 \\
\hline
\end{tabular}

Fonte: Autor

Para as soluções de sacarose em solução iônica de $0,10 \mathrm{~mol} \cdot \mathrm{kg}^{-1}$ os valores de ajuste da reta somente não apresentam valor satisfatórios para sua temperatura mais baixa.

Tabela 36 - Volumes molares aparentes à diluição infinita da sacarose em solução iônica de $\underline{0,025 \mathrm{~mol} \cdot \mathrm{kg}^{-1}, \text { a diferentes temperaturas }}$

\begin{tabular}{cc}
$\mathrm{T} / \mathrm{K}$ & $\mathrm{V}_{f_{s} \text { (soluçãoiônica) }}^{0} / \mathrm{cm}^{3} \cdot \mathrm{mol}^{-1}$ \\
\hline 283,15 & $V_{f_{s}}^{0}=208,52$ \\
288,15 & $V_{f_{s}}^{0}=209,36$ \\
293,15 & $V_{f_{s}}^{0}=210,17$ \\
298,15 & $V_{f_{s}}^{0}=210,99$ \\
303,15 & $V_{f_{s}}^{0}=211,76$ \\
\hline
\end{tabular}

Fonte: Autor

Tabela 37 - Volumes molares aparentes à diluição infinita da sacarose em solução iônica de $\underline{0,050 \mathrm{~mol} \cdot \mathrm{kg}^{-1}, \text { a diferentes temperaturas }}$

$\mathrm{T} / \mathrm{K}$

$\mathrm{V}_{f_{s} \text { (soluçãoiônica) }}^{0} / \mathrm{cm}^{3} \cdot \mathrm{mol}^{-1}$

\begin{tabular}{ll}
\hline 283,15 & $V_{f_{s}}^{0}=208,34$ \\
288,15 & $V_{f_{s}}^{0}=209,06$ \\
293,15 & $V_{f_{s}}^{0}=209,80$ \\
298,15 & $V_{f_{s}}^{0}=210,60$ \\
303,15 & $V_{f_{s}}^{0}=211,33$ \\
\hline
\end{tabular}

Fonte: Autor 
Tabela 38 - Volumes molares aparentes à diluição infinita da sacarose em solução iônica de $\underline{0,075 \mathrm{~mol} \cdot \mathrm{kg}^{-1}, \text { a diferentes temperaturas }}$

\begin{tabular}{cc}
$\mathrm{T} / \mathrm{K}$ & $\mathrm{V}_{f_{s} \text { (soluçãoînica) }}^{0} / \mathrm{cm}^{3} \cdot \mathrm{mol}^{-1}$ \\
\hline 283,15 & $V_{f_{s}}^{0}=209,15$ \\
288,15 & $V_{f_{s}}^{0}=209,91$ \\
293,15 & $V_{f_{s}}^{0}=210,70$ \\
298,15 & $V_{f_{s}}^{0}=211,44$ \\
303,15 & $V_{f_{s}}^{0}=212,21$ \\
\hline
\end{tabular}

Fonte: Autor

Tabela 39 - Volumes molares aparentes à diluição infinita da sacarose em solução iônica de $\underline{0,10 \mathrm{~mol} \cdot \mathrm{kg}^{-1}, \text { a diferentes temperaturas }}$

$\begin{array}{lc}\mathrm{T} / \mathrm{K} & \mathrm{V}_{f_{s} \text { (soluçãoiônica) }}^{0} / \mathrm{cm}^{3} \cdot \mathrm{mol}^{-1} \\ 283,15 & V_{f_{s}}^{0}=208,82 \\ 288,15 & V_{f_{s}}^{0}=209,60 \\ 293,15 & V_{f_{s}}^{0}=210,35 \\ 298,15 & V_{f_{s}}^{0}=211,12 \\ 303,15 & V_{f_{s}}^{0}=211,94\end{array}$

Fonte: Autor

Tabela 40 - Volumes de transferência da sacarose da água para solução iônica de $0,025 \mathrm{~mol} \cdot \mathrm{kg}^{-}$ 1 , a diferentes temperaturas

\begin{tabular}{|c|c|c|c|}
\hline $\mathrm{T} / \mathrm{K}$ & $\mathrm{V}_{f_{s} \text { (soluçãoionica) }}^{0} / \mathrm{cm}^{3} \cdot \mathrm{mol}^{-1}$ & $\mathrm{~V}_{f_{\mathrm{s}} \text { (água) }}^{0} / \mathrm{cm}^{3} \cdot \mathrm{mol}^{-1}$ & $\Delta \mathrm{V}_{\mathrm{ts}} / \mathrm{cm}^{3} \cdot \mathrm{mol}^{-1}$ \\
\hline 283,15 & $V_{f_{s}}^{0}=208,52$ & $V_{f_{s}}^{0}=207,95$ & 0,57 \\
\hline 288,15 & $V_{f_{s}}^{0}=209,36$ & $V_{f_{s}}^{0}=208,46$ & 0,60 \\
\hline 293,15 & $V_{f_{s}}^{0}=210,17$ & $V_{f_{s}}^{0}=209,60$ & 0,57 \\
\hline 298,15 & $V_{f_{s}}^{0}=210,99$ & $V_{f_{s}}^{0}=210,36$ & 0,63 \\
\hline 303,15 & $V_{f_{s}}^{0}=211,76$ & $V_{f_{s}}^{0}=211,17$ & 0,59 \\
\hline
\end{tabular}


Tabela 41 - Volumes de transferência da sacarose da água para solução iônica de 0,050 $\mathrm{mol} \cdot \mathrm{kg}^{-1}$, a diferentes temperaturas

\begin{tabular}{|c|c|c|c|}
\hline $\mathrm{T} / \mathrm{K}$ & $\mathrm{V}_{f_{s} \text { (soluçãoiônica) }}^{0} / \mathrm{cm}^{3} \cdot \mathrm{mol}^{-1}$ & $\mathrm{~V}_{\mathrm{f}_{\mathrm{s}} \text { (água) }}^{0} / \mathrm{cm}^{3} \cdot \mathrm{mol}^{-1}$ & $\Delta \mathrm{V}_{\mathrm{ts}} / \mathrm{cm}^{3} \cdot \mathrm{mol}^{-1}$ \\
\hline 283,15 & $V_{f_{s}}^{0}=208,34$ & $V_{f_{s}}^{0}=207,95$ & 0,39 \\
\hline 288,15 & $V_{f_{s}}^{0}=209,06$ & $V_{f_{s}}^{0}=208,46$ & 0,30 \\
\hline 293,15 & $V_{f_{s}}^{0}=209,80$ & $V_{f_{s}}^{0}=209,60$ & 0,20 \\
\hline 298,15 & $V_{f_{s}}^{0}=210,60$ & $V_{f_{s}}^{0}=210,36$ & 0,24 \\
\hline 303,15 & $V_{f_{s}}^{0}=211,33$ & $V_{f_{s}}^{0}=211,17$ & 0,16 \\
\hline
\end{tabular}

Fonte: Autor

Tabela 42 - Volumes de transferência da sacarose da água para solução iônica de 0,075 $\mathrm{mol} \cdot \mathrm{kg}^{-1}$, a diferentes temperaturas

\begin{tabular}{cccc}
\hline $\mathrm{T} / \mathrm{K}$ & $\mathrm{V}_{f_{s} \text { (soluçãoiônica) }}^{0} / \mathrm{cm}^{3} \cdot \mathrm{mol}^{-1}$ & $\mathrm{~V}_{f_{\mathrm{s}} \text { (água) }}^{0} / \mathrm{cm}^{3} \cdot \mathrm{mol}^{-1}$ & $\Delta \mathrm{V}_{\mathrm{ts}} / \mathrm{cm}^{3} \cdot \mathrm{mol}^{-1}$ \\
\hline 283,15 & $V_{f_{s}}^{0}=209,15$ & $V_{f_{s}}^{0}=207,95$ & 1,20 \\
288,15 & $V_{f_{s}}^{0}=209,91$ & $V_{f_{s}}^{0}=208,46$ & 1,15 \\
293,15 & $V_{f_{s}}^{0}=210,70$ & $V_{f_{s}}^{0}=209,60$ & 1,10 \\
298,15 & $V_{f_{s}}^{0}=211,44$ & $V_{f_{s}}^{0}=210,36$ & 1,08 \\
303,15 & $V_{f_{s}^{0}}^{0}=212,21$ & $V_{f_{s}}^{0}=211,17$ & 1,03 \\
\hline
\end{tabular}

Fonte: Autor

Tabela 43 - Volumes de transferência da sacarose da água para solução iônica de 0,10 $\mathrm{mol} \cdot \mathrm{kg}^{-1}$, a diferentes temperaturas

\begin{tabular}{|c|c|c|c|}
\hline $\mathrm{T} / \mathrm{K}$ & $\mathrm{V}_{f_{s} \text { (soluçãoiônica) }}^{0} / \mathrm{cm}^{3} \cdot \mathrm{mol}^{-1}$ & $\mathrm{~V}_{f_{\mathrm{s}} \text { (água) }}^{0} / \mathrm{cm}^{3} \cdot \mathrm{mol}^{-1}$ & $\Delta \mathrm{V}_{\mathrm{ts}} / \mathrm{cm}^{3} \cdot \mathrm{mol}^{-1}$ \\
\hline 283,15 & $V_{f_{s}}^{0}=208,82$ & $V_{f_{s}}^{0}=207,95$ & 0,87 \\
\hline 288,15 & $V_{f_{s}}^{0}=209,60$ & $V_{f_{s}}^{0}=208,46$ & 0,84 \\
\hline 293,15 & $V_{f_{s}}^{0}=210,35$ & $V_{f_{s}}^{0}=209,60$ & 0,75 \\
\hline 298,15 & $V_{f_{s}}^{0}=211,12$ & $V_{f_{s}}^{0}=210,36$ & 0,76 \\
\hline 303,15 & $V_{f_{s}}^{0}=211,94$ & $V_{f_{s}}^{0}=211,17$ & 0,77 \\
\hline
\end{tabular}


Os valores do volume molar aparente à diluição infinita de todos os sacarídeos estudados aumentaram com o aumento da temperatura e concentração do sacarídeo. Houve também um aumento com o crescimento da cadeia carbônica seguindo a ordem: $\mathrm{D}(+)$-xilose $<\mathrm{D}(+)$-glicose $<$ Sacarose.

A magnitude dos valores de $S_{\mathrm{v}}$ para todas os sistemas sacarose estudados é pequena, o que indica que possivelmente que as interações sacarídeos-sacarídeos são fracas. Os valores de $S_{\mathrm{v}}$ diminuem com o aumento da temperatura.

Com base no modelo de "cosphere overlap" (DESNOYERS et al, 1969), para o sistema contendo sacarose, é de se supor que os efeitos do tipo (ii) devem prevalecer sobre os outros efeitos.

As tabelas 44-46 apresentam os valores dos volumes de transferência dos sacarídeos da água para as soluções contendo líquidos iônicos, $\Delta \mathrm{V}_{\mathrm{ts}}$, a diferentes temperaturas e concentrações.

Tabela 44 - Valores do volume de transferência da $\mathrm{D}(+)$-glicose da água para solução iônica

\begin{tabular}{ccccc}
\hline $\mathrm{T} / \mathrm{K}$ & $0,025 \mathrm{~mol} \cdot \mathrm{kg}^{-1}$ & $0,05 \mathrm{~mol} \cdot \mathrm{kg}^{-1}$ & $0,075 \mathrm{~mol} \cdot \mathrm{kg}^{-1}$ & $0,1 \mathrm{~mol} \cdot \mathrm{kg}^{-1}$ \\
\hline 283,15 & 0,01 & $-0,23$ & $-0,10$ & 0,12 \\
288,15 & $-0,01$ & $-0,24$ & $-0,11$ & 0,11 \\
293,15 & 0,03 & $-0,19$ & $-0,05$ & 0,12 \\
298,15 & 0,00 & $-0,21$ & $-0,03$ & 0,11 \\
303,15 & $-0,07$ & $-0,28$ & $-0,07$ & 0,11
\end{tabular}

Fonte: Autor

Tabela 45 - Valores do volume de transferência da $\mathrm{D}(+)$-xilose da água para solução iônica

\begin{tabular}{ccccc}
\hline $\mathrm{T} / \mathrm{K}$ & $0,025 \mathrm{~mol} \cdot \mathrm{kg}^{-1}$ & $0,05 \mathrm{~mol} \cdot \mathrm{kg}^{-1}$ & $0,075 \mathrm{~mol} \cdot \mathrm{kg}^{-1}$ & $0,1 \mathrm{~mol} \cdot \mathrm{kg}^{-1}$ \\
\hline 283,15 & $-0,27$ & 0,03 & $-0,54$ & $-0,27$ \\
288,15 & $-0,41$ & $-0,07$ & $-0,53$ & $-0,24$ \\
293,15 & $-0,43$ & $-0,19$ & $-0,52$ & $-0,24$ \\
298,15 & $-0,46$ & $-0,35$ & $-0,53$ & $-0,25$ \\
303,15 & $-0,49$ & $-1,47$ & $-0,46$ & $-0,23$ \\
\hline
\end{tabular}


Tabela 46-Valores do volume de transferência da sacarose da água para solução

\begin{tabular}{ccccc}
\hline $\mathrm{T} / \mathrm{K}$ & $0,025 \mathrm{~mol} \cdot \mathrm{kg}^{-1}$ & $0,05 \mathrm{~mol} \cdot \mathrm{kg}^{-1}$ & $0,075 \mathrm{~mol} \cdot \mathrm{kg}^{-1}$ & $0,1 \mathrm{~mol} \cdot \mathrm{kg}^{-1}$ \\
\hline 283,15 & 0,57 & 0,39 & 1,20 & 0,87 \\
288,15 & 0,60 & 0,30 & 1,15 & 0,84 \\
293,15 & 0,57 & 0,20 & 1,10 & 0,75 \\
298,15 & 0,63 & 0,24 & 1,08 & 0,76 \\
303,15 & 0,59 & 0,16 & 1,03 & 0,77 \\
\hline
\end{tabular}

Fonte: Autor

Para o sistema contendo a $\mathrm{D}(+)$-glicose é possível observar valores positivos e negativos para os volumes de transferência. Para os sistemas contendo xilose, os valores dos volumes de transferência foram negativos. Finalmente, para o sistema contendo sacarose, os valores dos volumes de transferência são positivos. 


\section{CONCLUSÃO}

No presente estudo foram determinados dados experimentais de densidade de soluções de sacarídeos $(\mathrm{D}(+)$-xilose, $\mathrm{D}(+)$-glicose e sacarose) em soluções aquosas contendo o líquido iônico dicianamida de 1-etil-3-metilimidazólio [EMIM][DCA] a diferentes concentrações e temperaturas. As concentrações do sacarídeos variaram entre $\left(m=0,015-1,7 \mathrm{~mol} \cdot \mathrm{kg}^{-1}\right)$ enquanto as concentrações das soluções iônicas foram de 0,$025 ; 0,050 ; 0,075$ e $0,10 \mathrm{~mol} \cdot \mathrm{kg}^{-1}$. Os resultados experimentais foram obtidos nas temperaturas de 283,15, 288,15, 293,15, 298, 15 e 303,15 K. Com os resultados experimentais das densidades e fazendo uso do formalismo termodinâmico, foram calculados os volumes molares aparentes, os volumes molares aparentes à diluição infinita e os volumes de transferência dos sacarídeos da água para as soluções iônicas.

Para todos os sacarídeos estudados, os valores das densidades das soluções aumentaram com o aumento da concentração do sacarídeo e do líquido iônico, e diminuíram com o aumento da temperatura. Observou-se uma dificuldade em se medir a densidade em pequenas concentrações, o que ficou evidente ao se ajustar a equação (20) a uma reta, não foi possível obter valores satisfatórios de $\mathrm{R}^{2}$ em diversas temperaturas e concentrações de líquido iônico.

Os valores dos volumes molares aparentes e dos volumes molares aparentes à diluição infinita aumentaram com o aumento da temperatura e da molalidade do sacarídeo seguindo a ordem: Sacarose $>\mathrm{D}(+)$-glicose $>\mathrm{D}(+)$-xilose.

A magnitude dos valores de $S_{\mathrm{v}}$ obtidas para todos os sistemas estudados é pequena, o que indica que possivelmente as interações sacarídeo-sacarídeo são fracas e tendem a diminuir com o aumento da temperatura.

O comportamento do volume molar de transferência dos sacarídeos da água para as soluções iônicas não apresentou um comportamento uniforme, não podendo tirar conclusões para os sistemas contendo glicose. Entretanto, para os sistemas contendo xilose, parece que as interações do tipo interações hidrofóbicas-iônicas, hidrofílicas-iônicas e hidrofóbicashidrofóbicas entre a xilose e o líquido iônico devem ser predominantes. Todavia, para os sistemas contendo a sacarose as interações hidrofílicas-hidrofóbicas devem prevalecer sobre os demais efeitos.

Como sugestão para trabalhos futuros, recomenda-se estender o estudo termodinâmicos para outras propriedades termodinâmicas como a velocidade do som, viscosidade e entalpia de solução. Recomenda-se também realizar estudos espectroscópicos dos sistemas estudados para tirar conclusões mais aprofundadas das interações existentes nesses sistemas. 


\section{REFERÊNCIAS}

ACREE W. E. Thermodynamics properties of nonelectrolyte solution. Orlando, Academic Press, 1984

ARIKAWA, H.; MATSUMOTO, K.; FUJIKI, T. Polyhydroxy alkano ate production from sucrose by Cupriavidus necator strains harboring csc genes grom Eschrichia coli W. Biotechnological Products and Process Engineering. Germany, v.101, p- 7947-7507, 2017.

BANIPAL, K. P.; AGGARWAL, N.; BANIPAL, S. T. Effects of phosphate-based monobasic and tribasic inorganic salts on hydration characteristics of saccharides and their derivatives. Journal of Molecular Liquids. Índia, v.211, p.78-89, 2015.

BANIPAL, K. P.; AGGARWAL, N.; BANIPAL, S. T. Viscosities of Some Saccharides in Aqueous Solutions of Phosphate-Based Inorganic Salts. Journal of Chemical \& Engineering Data. Índia, v.61, p-1992-2001, 2016.

BANIPAL, K. P.; ARTI, S.; BANIPAL, S. T. Volumetric, viscometric and H NMR spectroscopic studies in (polydydroxy solute $+\mathrm{CTAB}+\mathrm{H} 2 \mathrm{O}$ ) ternary solutions. J. Chem. Thermodynamics. India, v.112, p. 13-22, 2017.

BANIPAL, K. P.; CHAHAL, K. A.; SINGH, V.; BANIPAL, S. T. Rheological behaviour of some saccharides in aqueous potassium chloride solutions over temperature range (288.15 to 318.15) K. J. Chem. Thermodynamics. Índia, v.42, p.1024-1035, 2010.

BANIPAL, P. K.;CHAHAL NEE HUNDAL, A. K.; BANIPAL, T. S. Effect of magnesium chloride (2:1 electrolyte) on the aqueous solution behavior of some saccharides over the temperature range of $288.15-318.15 \mathrm{~K}$ : a volumetric approach. Carbohydrate, India v. 345, p. $2262-2271,2010$.

BANIPAL, K. P.; KAUR, K.; BANIPAL, S. T. Modulation in physico-chemical characteristics of some polyhydroxy solutes in present of L-glycine: Volumetric and NMR spectroscopic approach. Fluid Phase Equilibria. Índia, v.402, p.113-123, 2015. 
BANIPAL, P. K.; BANIPAL, T. S.; AHLUWALIA, J. C.; LARK, B. S. Partial molar heat capacities and volumes of transfer of some saccharides from water to aqueous sodium chloride solutions at $\mathrm{T}=298.15 \mathrm{~K}$. The Journal of Chemical Thermodynamics, India, v.34, p. 1825$1846,2002$.

BI, W.; ZHOU, J. ROW, K. H. Separation of xylose and glucose on different silica-confined ionic liquid stationary phases. Analytica Chimica Acta. Republic of Korea, v.677, p. 162$168,2010$.

BUZZEO, M. C.; EVANS, R. G.; COMPTON, R. G. Non haloaluminate room temperature ionic liquids in electrochemistry-A review. Chem Phys Chem. v. 5, p. 1106-1120, 2004.

CARNEIRO, P. Aristides; RODRIGUEZ, Oscar; MACEDO, A. Eugênia. Fructose and Glucose Dissolution in Ionic Liquids: Solubility and Thermodynamic Modeling. Industrial \& Engineering Chemistry Research. Portugal, v.52, p. 3424-3435, 2013.

CARNEIRO, P. A.; RODRIGUEZ, O.; MACEDO, A. E. Solubility of monosaccharides in ionic liquids - Experimental data and modeling. Fluid Phase Equilibria. Portugal, v.314, p. 22-28, 2012.

CONSIDINE. Chemical and process technology encyclopedia. Los Angeles: McGraw-Hill Book Company, 1974.

CRESTANI, C.E.; BERNARDO, A.; COSTA, C. B.B; GIULIETTI, M. Experimental data and estimation of sucrose solubility in impure solutions. Journal of Food Engineering. Brazil, v.2018, p.14-23, 2018.

DESNOYERS, J. E.; AREL, M.; PERRON, G.; JOLICOEUR, C. Apparent molal volumes of alkali halides in water at 25.deg.. Influence of structural hydration interactions on the concentration dependence. The Journal of Physical Chemistry. Canada, v. 78, p. 3346-3351, 1968. 
DE VISSER, C.; PERRON, G.; DESNOYERS, J. E. Volumes and heat capacities of ternary aqueous systems at $25^{\circ} \mathrm{C}$. Mixtures of urea, tert-butyl alcohol, dimethyl formamide, and water. The Journal of Chemical Thermodynamics, Canada, v. 99, p. 5894 - 5900, 1977.

DHONDGE, S. S.; MOSES, M. J.; DESHMUKH, W. D.; PALIWAL, J. L.; TANGDE, M. V.; DHONDGE, S. A. Physicochemical study of solute-solute and solute-solvent interactions of aqueous binary mixtures of L-alanine methyl ester hydrochloride and L-valine methyl ester hydrochloride at different temperatures: Volumetric and compressional studies. The Journal of Chemical Thermodynamics. India, v.115, p.217-225, 2017.

FANG, B.; ZHANG, C.; WANG, G.; WANG, M.; JI, Y. A glucose oxidase aim mobilization platform for glucose biosensor using $\mathrm{ZnO}$ hollow nanospheres. Sensor and Actuators B: Chemical. China, v.155, p-304-310, 2011.

JIN, H. X.; CHEN, H. Y. Volumetric properties of 1-butyl-3-methyimidazolium tetrafluroborate - glucose - water systems. Journal of Chemical \& Engineering Data,v. 57, p. 1134-1138, 2012.

KAUR, G.; BANIPAL, T.S. Partial molar volumes of transfer of some saccharides from water to aqueous cupric chloride and zinc chloride solutions at $298.15 \mathrm{~K}$. Indian Journal of Chemistry, India, v. 43A, p. 35 - 40, 2004.

KIM, H. S.; PANI, R.; HÁ, H. S.; KOO, Y.-M.; YINGLING, G. Y. The role of hydrogen bonding in water-mediated glucose solubility in ionic liquids. Journal of Molecular Liquids. Republic of Korea, v.166, p. 25-30, 2012.

MANIN, A. N.; SHMUKLER, L. E.; SAFONOVA, L. P.; PERLOVICH, G. L. Partial molar volumes of some drug and pro-drug substances in 1-octanol at $T=298.15 \mathrm{~K}$. The Journal of Chemical Thermodynamics. Rússia, v. 42, p. 429-435, 2010.

MCMILLAN, W. G.; MAYER, J. E.; The statistical thermodynamics of multicomponent systems. Journal of Chemical Physics. Estados Unidos, v. 13, p. 276-305, 1945. 
MARSH, K.N.; BOXALL, J.A.;LICHTENTHALER, R. Room temperature ionic liquids and their mixtures-A review. Fluid Phase Equilibria, v. 219, p. 93-98, 2004.

MOHAN, M.; GOUD, V.; BANERJEE, T. Solubility of glucose, xylose, fructose and galactose in ionic liquids: Experimental and theorical studies using a continuum salvation model. Fluid Phase Equilibria. Índia, v.395 p.33-43, 2015.

OHNO, H.; FUKUMOTO, K. Amino acid ionic liquids. Accounts of Chemical Research. Japão, v. 40, p. 1122-1129, 2007.

ORCHILlÉS,A. V.; MIGUEL, P. J.; GONZÁlEZ-ALFARO, V.; VERCHER, E.; MARTÍNEZ-ANDREU, A. 1-Ethyl-3-methylimidazolium dicyanamide as a very efficient entrainer for the extractive distillation of the acetone + methanol system. Journal of Chemical \& Engineering Data, v. 57, p. 394-399, 2012.

PADUSZYNSKI, K; OKUNIEWSKI, M; DOMANSKA, U. An effect of cation functionalization on thermophysical properties of ionic liquids and solubility of glucose in them - Measurements na PC-SAFT calculations. The Journal of Chemical Thermodynamics. Poland, v.92, p. 81-90, 2016.

PLECHKOVA, N.V.; SEDDON, K.R. Applications of ionic liquids in the chemical industry. Chemical Society Reviews. Inglaterra, v. 37, p. 123-150, 2008.

ROMERO, C.M.; NEGRETE, F. Effect of temperature on partial molar volumes and viscosities of aqueous solutions of $\alpha$-DL- aminobutyric acid, DL- norvaline and DL- norleucine. Physics and Chemistry of Liquid. Colômbia, v. 42, p. 261-267, 2004.

SHEKAARI, H.; KAZEMPOUR, A. Thermodynamic properties of D-glucose in aqueous 1hexyl-3-methylimidazolium bromide solutions at 298.15 K. Fluid Phase Equilibria, Irã,v. 336, p. $122-127$, Sept 2012.

SINGH, V.; BANIPAL, K. P.; BANIPAL, S. T.; GARDAS, L. R. Volumetric properties of 1butyl-3-methylimidazolium bromide in aqueous solutions of $\mathrm{D}(-)$-ribose and $\mathrm{D}(-)$-arabinose at different temperatures. Journal of Molecular Liquids. Índia, v.209, p.352-357, 2015. 
SINGH, V.; CHOTARAY, P. K.; GARDAS, R. L. Volumetric and ultrasonic properties of ternary (sucrose + water + protic ionic liquid) solutions. Índia, The Journal of Chemical Thermodynamics, v. 89, p. 60-68, 2015.

SINGH, V.; CHHOTARAY, P. K.; GARDAS, R. L. Modulation of volumetric properties of $\mathrm{D}(+)$-glucose in aqueous 3-hydroxypropylammonium acetate solutions. Índia, Journal of Molecular Liquids. India, v.220, p. 150-154, 2016.

SINGH, V.; BANIPAL, K. P.; GARDAS, L. R.; BANIPAL, S. T. Speed of sound and apparent molar isentropic compression of 1-butyl-3-methylimidazolium bromide in aqueous monosaccharide solutions. Journal of Molecular Liquids. India, v.223, p.54-59, 2016.

SMIRNOVA, N. A.; SAFONOVA, E. A. Ionic liquids as surfactants. Russian Journal of Physical Chemistry A. Russia, v. 84, p. 1695-1704, 2010.

SORENSON, J.M.; HURA, G.; SOPER, A.K.; PERTSENLIDIS, A.; GORDEN, T.H. Determining the role of hydration forces in protein folding. The Journal of Physical Chemistry B. Estados Unidos, v. 103, p. 5413-5426, 1999.

SUNEETHA, P.; KRISHNA, T. S.; GOWRISANKAR, M.; RAMACHANDRAM, D. Volumetric, acoustic and spectroscopic study of 1-butyl-3-methylimidazolium trifluoromethanesulfonate with alkoxyalkanols at different temperatures. Journal of Molecular Liquids. Índia, v.238, p.170-183, 2017.

TOME, L.I.N.; JORGE, M.; GOMES, J.R.B.; COUTINHO, J.A.P. Molecular dynamics simulation studies of the interactions between ionic liquids and amino acids in aqueous solution. The Journal of Physical Chemistry B. Portugal, v. 116, p. 1831-1842, 2012.

VERMA, C.;MISHRA, A.; CHAUHAN, S.; VERMA, P.; SRIVASTAVA, V.;QURAISHI, M. A.; EBENSO, E. E. Dissolution of cellulose in ionic liquids and their mixed cosolvents: A review. Sustainable Chemistry and Pharmacy. v.13, p. 100-162, 2019. 
WASSERSCHEID, P.; KEIM, W. Ionic liquids-new "solution” for transition metal catalysis. Angewandt Chemie International Edition, v. 39, p. 3772-3789, 2000.

WASSERSCHEID, P.; WELTON, T. Ionic Liquids in synthesis. Wiley, Hoboken, 2003.

YU, Y.; WU, H. Kinetics and mechanism of glucose decomposition in hot-compressed water: effect of initial glucose concentration. Industrial \& Engineering Chemistry Research. Australia, v.50, p. 10500-10508, 2011.

ZAFFARINI-MOATTAR, M.T; SHEKKARI, H.; AGHA, E. M. H. Effect of ionic liquids 1octyl-3-methyl imidazolium bromide or 1-octyl-3-methyl imidazolium chloride on thermophysical properties and taste behavior of sucrose in aqueous media at different temperatures: Volumetric, compressibility and viscometric properties. Food Chemistry. Irã, v.295, p.662-670, 2019.

ZAFARANI-MOATTAR, M. T.; SHEKAARI, H.; MAZAHER, E. The study of solute-solute and solute-solvent interactions in aqueous solutions containing sucrose and ionic liquid, 1butyl-3-methylimidazolium bromide at different temperatures. Journal of Molecular Liquids. Irã, v. 212, p. 930-940, 2015.

ZAMANI, Z.; NADERI, O.; SADEGHI, R. Soulting-out effect of carbohydrates on the surface active ionic liquid 1-decyl-3-methylimidazolium bromide in aqueous solutions. The Journal of Chemical Thermodynamics. Irã, v.116, p.289-298, 2018.

ZANG, F.; FANG, Z. Hydrolysis of cellulose to glucose at the low temperature of $423 \mathrm{~K}$ with CaFe2O4-based solid catalyst. Bioresource Technology. China, v.124, p. 440-445, 2012.

ZHAO, H.; XIA, S.; MA, P. Use of ionic liquids as 'green' solvents for extractions. Journal of Chemical Technology and Biotechnology. China, v. 80, p. 1089-1209, 2005.

ZHUO, $\mathrm{K}$ et al. Volumetric properties of D-galactose in aqueous $\mathrm{HCl}$ solution at 278.15 to 118 . 15 K. Journal of Molecular Liquids, China, v.147, p. 186 - 190, Apr 2009. 
APÊNDICE A - CÁLCULO DAS INCERTEZAS 
Medidas realizadas em equipamentos sejam elas viscosidade, densidade ou qualquer outra, possuem incertezas intrínsecas, sendo elas do próprio aparelho ou erros feitos por operadores do equipamento.

A incerteza da molalidade do sacarídeo $\left(m_{S}\right)$ é função da massa do sacarídeo $\left(m_{S}\right)$ e da massa da solução pura $\left(m_{o}\right)$. Conforme equação (A.1):

$$
u\left(m_{s}\right)=f\left(m_{s}, m_{0}\right)
$$

Partindo-se da definição da molalidade, acrescentando já o fator de conversão de quilo para quilograma de massa da solução pura, tem-se a equação (A.2):

$$
m_{s}=\frac{100 ¥ m_{s}}{m_{0} ¥ M_{s}}
$$

Pode-se chegar à derivada da molalidade em função da massa de sacarídeo, através da equação (A.3):

$$
\frac{\partial m_{s}}{\partial m_{s}}=\frac{1000}{m_{0} ¥ M_{s}}
$$

Também é possível calcular a derivada da molalidade em função da massa da solução. Vide relação (A.4).

$$
\frac{\partial m_{s}}{\partial m_{0}}=\frac{1000 ¥ m_{s}}{m_{0}{ }^{2} ¥ M_{s}}
$$

A partir das equações (A.3) e (A.4) a incerteza da molalidade do sacarídeo foi calculada, conforme o "Guidelines for evaluating and expressing the uncertainty of NIST measurement results" (TN1297, 1994), gerando as equações (A.5) e (A.6).

$$
\begin{gathered}
u\left(m_{s}\right) \underline{\mathrm{a}} \sqrt{\left(\frac{\partial m_{s}}{\partial m_{s}}\right)^{2} ¥ u^{2}\left(m_{s}\right)+\left(\frac{\partial m_{s}}{\partial m_{0}}\right)^{2} ¥ u^{2}\left(m_{0}\right)} \\
u\left(m_{s}\right) \underline{\underline{a}} \sqrt{\left(\frac{1000}{m_{0} ¥ M_{s}}\right)^{2} ¥ u^{2}\left(m_{s}\right)+\left(\frac{1000 ¥ m_{s}}{m_{0}^{2} ¥ M_{s}}\right)^{2} ¥ u^{2}\left(m_{0}\right)}
\end{gathered}
$$

A incerteza do volume molar aparente $\left(V_{\phi s}\right)$ é função do molalidade do sacarídeo $\left(m_{s}\right)$, densidade da solução com sacarídeo $(\rho)$ e densidade da solução pra $\left(\rho_{0}\right)$, demonstrada na função (A.7):

$$
u\left(V_{f_{s}}\right)=f\left(m_{s}, r, r_{0}\right)
$$


Partindo-se da equação (2) exposta no item 2.3:

$$
\mathrm{V}_{f_{s}}=\left(\frac{\mathrm{M}_{s}}{\rho}\right)-\frac{1000 \times\left(\rho-\rho_{0}\right)}{\mathrm{m}_{\mathrm{s}} \times \rho \times \rho_{0}}
$$

e rearranjando seus termos (equação A.8),

$$
\mathrm{V}_{f_{s}}=\left(\frac{\mathrm{M}_{s}}{\rho}\right)-\frac{1000}{\mathrm{~m}_{\mathrm{s}} \times \rho_{0}}+\frac{1000}{\mathrm{~m}_{\mathrm{s}} \times \rho}
$$

é possível calcular a derivada do volume molar aparente em função da molalidade do sacarídeo, através da equação (A.9):

$$
\frac{\partial \mathrm{V}_{f_{s}}}{\partial \mathrm{m}_{\mathrm{s}}}=1+\frac{1000}{\mathrm{~m}_{\mathrm{s}}^{2} \times \rho_{0}}-\frac{1000}{\mathrm{~m}_{\mathrm{s}}^{2} \times \rho}
$$

Também é possível calcular a derivada do volume molar aparente em função da densidade da solução de sacarídeo e a derivada do volume molar aparente em função da densidade da solução pura, utilizando respectivamente as equações (A.10) e (A.11):

$$
\begin{gathered}
\frac{\partial \mathrm{V}_{f_{s}}}{\partial \rho}=-\frac{\mathrm{M}_{\mathrm{s}}}{\rho^{2}}-\frac{1000}{\mathrm{~m}_{\mathrm{s}}{ }^{2} \times \rho} \\
\frac{\partial \mathrm{V}_{f_{s}}}{\partial \rho_{0}}=1+\frac{1000}{\mathrm{~m}_{\mathrm{s}}{ }^{2} \times \rho_{0}{ }^{2}}
\end{gathered}
$$

Utilizando novamente o NIST, obtêm-se as equações finais (A.12) e (A.13):

$$
u\left(\mathrm{~V}_{f_{s}}\right) \underline{a} \sqrt{\left(\frac{\partial \mathrm{V}_{f_{s}}}{\partial \mathrm{m}_{\mathrm{s}}}\right)^{2} ¥ u^{2}\left(m_{s}\right)+\left(\frac{\partial \mathrm{V}_{f_{s}}}{\partial \rho}\right)^{2} ¥ u^{2}(\rho)+\left(\frac{\partial \mathrm{V}_{f_{s}}}{\partial \rho_{0}}\right)^{2} ¥ u^{2}\left(\rho_{0}\right)}
$$

$u\left(\mathrm{~V}_{f_{s}}\right) \underline{\mathrm{a}}$

$\sqrt{\left(1+\frac{1000}{\mathrm{~m}_{\mathrm{s}}{ }^{2} \times \rho_{0}}-\frac{1000}{\mathrm{~m}_{\mathrm{s}}{ }^{2} \times \rho}\right)^{2} ¥ u^{2}\left(m_{s}\right)+\left(-\frac{\mathrm{M}_{\mathrm{s}}}{\rho^{2}}-\frac{1000}{\mathrm{~m}_{\mathrm{s}}{ }^{2} \times \rho}\right)^{2} ¥ u^{2}(\rho)+\left(1+\frac{1000}{\mathrm{~m}_{\mathrm{s}}{ }^{2} \times \rho_{0}{ }^{2}}\right)^{2} ¥ u^{2}\left(\rho_{0}\right)}$ 
APÊNDICE B - TABELA - DENSIDADES ÁGUA E SOLUÇÕES IÔNICAS PURAS 
As tabelas B.1 - B.5 apresentam as médias das medidas de densidade da água pura e das soluções iônicas, nas temperaturas estudadas.

Tabela B.1 - Densidade da água pura em diversas temperaturas

\begin{tabular}{cc}
\hline $\mathrm{T} / \mathrm{K}$ & $\rho / \mathrm{cm}^{3} \cdot \mathrm{mol}^{-1}$ \\
\hline 283,15 & 0,99970 \\
288,15 & 0,99911 \\
293,15 & 0,99821 \\
298,15 & 0,99705 \\
303,15 & 0,99565 \\
\hline
\end{tabular}

Fonte: Autor

Tabela B.2 - Densidade da solução iônica a $0,025 \mathrm{~mol} \cdot \mathrm{kg}^{-1} \mathrm{em}$ diversas temperaturas

\begin{tabular}{cc}
\hline $\mathrm{T} / \mathrm{K}$ & $\rho / \mathrm{cm}^{3} \cdot \mathrm{mol}^{-1}$ \\
\hline 283,15 & 1,00029 \\
288,15 & 0,99966 \\
293,15 & 0,99874 \\
298,15 & 0,99755 \\
303,15 & 0,99613 \\
\hline
\end{tabular}

Fonte: Autor

Tabela B.3 - Densidade da solução iônica a $0,050 \mathrm{~mol} \cdot \mathrm{kg}^{-1} \mathrm{em}$ diversas temperaturas

\begin{tabular}{cc}
\hline $\mathrm{T} / \mathrm{K}$ & $\rho / \mathrm{cm}^{3} \cdot \mathrm{mol}^{-1}$ \\
\hline 283,15 & 1,00084 \\
288,15 & 1,00017 \\
293,15 & 0,99921 \\
298,15 & 0,99800 \\
303,15 & 0,99655 \\
\hline
\end{tabular}

Fonte: Autor 
Tabela B.4 - Densidade da solução iônica a $0,075 \mathrm{~mol} \cdot \mathrm{kg}^{-1} \mathrm{em}$ diversas temperaturas

\begin{tabular}{cc}
\hline $\mathrm{T} / \mathrm{K}$ & $\rho / \mathrm{cm}^{3} \cdot \mathrm{mol}^{-1}$ \\
\hline 283,15 & 1,00143 \\
288,15 & 1,00074 \\
293,15 & 0,99975 \\
298,15 & 0,99851 \\
303,15 & 0,99704 \\
\hline
\end{tabular}

Fonte: Autor

Tabela B.5 - Densidade da solução iônica a $0,10 \mathrm{~mol} \cdot \mathrm{kg}^{-1}$ em diversas temperaturas

\begin{tabular}{cc}
\hline $\mathrm{T} / \mathrm{K}$ & $\rho / \mathrm{cm}^{3} \cdot \mathrm{mol}^{-1}$ \\
\hline 283,15 & 1,00194 \\
288,15 & 1,00120 \\
293,15 & 1,00019 \\
298,15 & 0,99892 \\
303,15 & 0,99743 \\
\hline
\end{tabular}

Fonte: Autor 
APÊNDICE C - TABELA - SISTEMA XILOSE 
A tabela C.1 apresenta os valores das densidades e volumes molares aparentes do sistema contendo xilose a diferentes concentrações e temperaturas.

Tabela C.1 - Resultados experimentais do sistema contendo D(+)-xilose

\begin{tabular}{|c|c|c|c|c|}
\hline $\mathrm{T} / \mathrm{K}$ & $\begin{array}{c}\text { m (EMIM DCA }) / \\
\text { mol. } \mathrm{kg}^{-1}\end{array}$ & $\begin{array}{c}\text { m (sacarídeo) / } \\
\text { mol.kg-1 }\end{array}$ & $\rho / \mathrm{g} \cdot \mathrm{cm}^{-3}$ & $\mathrm{~V}_{f_{s}} / \mathrm{cm}^{3} \cdot \mathrm{mol}^{-1}$ \\
\hline \multirow[t]{10}{*}{283,15} & 0,000 & 1,70296 & 1,08091 & 94,76 \\
\hline & & 1,50042 & 1,07254 & 94,70 \\
\hline & & 1,30157 & 1,06408 & 94,59 \\
\hline & & 1,10052 & 1,05517 & 94,50 \\
\hline & & 0,90634 & 1,04626 & 94,38 \\
\hline & & 0,70363 & 1,03655 & 94,30 \\
\hline & & 0,50005 & 1,02646 & 94,11 \\
\hline & & 0,30456 & 1,01636 & 93,88 \\
\hline & & 0,10297 & 1,00547 & 93,56 \\
\hline & & 0,01492 & 1,00055 & 93,07 \\
\hline \multirow[t]{10}{*}{288,15} & 0,000 & 1,70296 & 1,07955 & 95,27 \\
\hline & & 1,50042 & 1,07124 & 95,23 \\
\hline & & 1,30157 & 1,06287 & 95,12 \\
\hline & & 1,10052 & 1,05404 & 95,04 \\
\hline & & 0,90634 & 1,04521 & 94,93 \\
\hline & & 0,70363 & 1,03559 & 94,86 \\
\hline & & 0,50005 & 1,02560 & 94,68 \\
\hline & & 0,30456 & 1,01560 & 94,46 \\
\hline & & 0,10297 & 1,00482 & 94,17 \\
\hline & & 0,01492 & 0,99995 & 93,77 \\
\hline \multirow[t]{6}{*}{293,15} & 0,000 & 1,70296 & 1,07799 & 95,73 \\
\hline & & 1,50042 & 1,06976 & 95,68 \\
\hline & & 1,30157 & 1,06144 & 95,59 \\
\hline & & 1,10052 & 1,05268 & 95,51 \\
\hline & & 0,90634 & 1,04392 & 95,42 \\
\hline & & 0,70363 & 1,03437 & 95,37 \\
\hline
\end{tabular}




\begin{tabular}{|c|c|c|c|c|}
\hline $\mathrm{T} / \mathrm{K}$ & $\begin{array}{c}\text { m (EMIM DCA) / } \\
\text { mol.kg }{ }^{-1}\end{array}$ & $\begin{array}{c}\mathrm{m} \text { (sacarídeo) / } \\
\text { mol. } \mathrm{kg}^{-1}\end{array}$ & $\rho / \mathrm{g} . \mathrm{cm}^{-3}$ & $\mathrm{~V}_{f_{S}} / \mathrm{cm}^{3} \cdot \mathrm{mol}^{-1}$ \\
\hline \multirow[t]{4}{*}{293,15} & 0,000 & 0,50005 & 1,02446 & 95,21 \\
\hline & & 0,30456 & 1,01452 & 95,10 \\
\hline & & 0,10297 & 1,00386 & 94,79 \\
\hline & & 0,01492 & 0,99904 & 94,47 \\
\hline \multirow[t]{10}{*}{298,15} & 0,000 & 1,70296 & 1,07625 & 96,15 \\
\hline & & 1,50042 & 1,06807 & 96,11 \\
\hline & & 1,30157 & 1,05981 & 96,03 \\
\hline & & 1,10052 & 1,05112 & 95,95 \\
\hline & & 0,90634 & 1,04242 & 95,86 \\
\hline & & 0,70363 & 1,03294 & 95,82 \\
\hline & & 0,50005 & 1,02310 & 95,67 \\
\hline & & 0,30456 & 1,01322 & 95,62 \\
\hline & & 0,10297 & 1,00264 & 95,43 \\
\hline & & 0,01492 & 0,99787 & 95,19 \\
\hline \multirow[t]{10}{*}{303,15} & 0,000 & 1,70296 & 1,07435 & 96,54 \\
\hline & & 1,50042 & 1,06622 & 96,50 \\
\hline & & 1,30157 & 1,05801 & 96,42 \\
\hline & & 1,10052 & 1,04936 & 96,36 \\
\hline & & 0,90634 & 1,04072 & 96,27 \\
\hline & & 0,70363 & 1,03131 & 96,22 \\
\hline & & 0,50005 & 1,02149 & 96,16 \\
\hline & & 0,30456 & 1,01169 & 96,11 \\
\hline & & 0,10297 & 1,00119 & 95,98 \\
\hline & & 0,01492 & 0,99646 & 95,93 \\
\hline \multirow[t]{5}{*}{283,15} & 0,025 & 1,70913 & 1,08187 & 94,66 \\
\hline & & 1,50053 & 1,07333 & 94,53 \\
\hline & & 1,30524 & 1,06501 & 94,41 \\
\hline & & 1,10513 & 1,05615 & 94,29 \\
\hline & & 0,90548 & 1,04696 & 94,17 \\
\hline
\end{tabular}




\begin{tabular}{|c|c|c|c|c|}
\hline $\mathrm{T} / \mathrm{K}$ & $\begin{array}{c}\mathrm{m}(\text { EMIM DCA }) / \\
\text { mol. } \mathrm{kg}^{-1}\end{array}$ & $\begin{array}{c}\mathrm{m} \text { (sacarídeo }) / \\
\text { mol. } \mathrm{kg}^{-1}\end{array}$ & $\rho / \mathrm{g} \cdot \mathrm{cm}^{-3}$ & $\mathrm{~V}_{f_{S}} / \mathrm{cm}^{3} \cdot \mathrm{mol}^{-1}$ \\
\hline \multirow[t]{5}{*}{283,15} & 0,025 & 0,70235 & 1,03720 & 94,08 \\
\hline & & 0,50289 & 1,02727 & 93,91 \\
\hline & & 0,30325 & 1,01693 & 93,66 \\
\hline & & 0,10128 & 1,00599 & 93,21 \\
\hline & & 0,01517 & 1,00115 & 92,67 \\
\hline \multirow[t]{10}{*}{288,15} & 0,025 & 1,70913 & 1,08047 & 95,17 \\
\hline & & 1,50053 & 1,07201 & 95,05 \\
\hline & & 1,30524 & 1,06378 & 94,93 \\
\hline & & 1,10513 & 1,05498 & 94,83 \\
\hline & & 0,90548 & 1,04588 & 94,71 \\
\hline & & 0,70235 & 1,03622 & 94,62 \\
\hline & & 0,50289 & 1,02639 & 94,45 \\
\hline & & 0,30325 & 1,01614 & 94,21 \\
\hline & & 0,10128 & 1,00530 & 93,83 \\
\hline & & 0,01517 & 1,00051 & 93,35 \\
\hline \multirow[t]{10}{*}{293,15} & 0,025 & 1,70913 & 1,07888 & 95,63 \\
\hline & & 1,50053 & 1,07049 & 95,51 \\
\hline & & 1,30524 & 1,06232 & 95,40 \\
\hline & & 1,10513 & 1,05359 & 95,31 \\
\hline & & 0,90548 & 1,04456 & 95,20 \\
\hline & & 0,70235 & 1,03497 & 95,12 \\
\hline & & 0,50289 & 1,02522 & 94,97 \\
\hline & & 0,30325 & 1,01506 & 94,75 \\
\hline & & 0,10128 & 1,00431 & 94,46 \\
\hline & & 0,01517 & 0,99957 & 94,05 \\
\hline \multirow[t]{4}{*}{298,15} & 0,025 & 1,70913 & 1,07711 & 96,05 \\
\hline & & 1,50053 & 1,06878 & 95,93 \\
\hline & & 1,30524 & 1,06062 & 95,86 \\
\hline & & 1,10513 & 1,05200 & 95,74 \\
\hline
\end{tabular}




\begin{tabular}{|c|c|c|c|c|}
\hline $\mathrm{T} / \mathrm{K}$ & $\begin{array}{c}\text { m (EMIM DCA }) / \\
\text { mol. } \mathrm{kg}^{-1}\end{array}$ & $\begin{array}{c}\mathrm{m} \text { (sacarídeo) / } \\
\text { mol. } \mathrm{kg}^{-1}\end{array}$ & $\rho / \mathrm{g} . \mathrm{cm}^{-3}$ & $\mathrm{~V}_{f_{s}} / \mathrm{cm}^{3} \cdot \mathrm{mol}^{-1}$ \\
\hline \multirow[t]{6}{*}{298,15} & 0,025 & 0,90548 & 1,04303 & 95,64 \\
\hline & & 0,70235 & 1,03351 & 95,57 \\
\hline & & 0,50289 & 1,02381 & 95,47 \\
\hline & & 0,30325 & 1,01372 & 95,30 \\
\hline & & 0,10128 & 1,00307 & 95,00 \\
\hline & & 0,01517 & 0,99837 & 94,76 \\
\hline \multirow[t]{10}{*}{303,15} & 0,025 & 1,70913 & 1,07522 & 96,41 \\
\hline & & 1,50053 & 1,06688 & 96,34 \\
\hline & & 1,30524 & 1,05872 & 96,32 \\
\hline & & 1,10513 & 1,05022 & 96,15 \\
\hline & & 0,90548 & 1,04130 & 96,06 \\
\hline & & 0,70235 & 1,03182 & 96,03 \\
\hline & & 0,50289 & 1,02220 & 95,92 \\
\hline & & 0,30325 & 1,01218 & 95,76 \\
\hline & & 0,10128 & 1,00160 & 95,56 \\
\hline & & 0,01517 & 0,99694 & 95,48 \\
\hline \multirow[t]{10}{*}{283,15} & 0,050 & 1,70740 & 1,08234 & 94,65 \\
\hline & & 1,50304 & 1,07394 & 94,55 \\
\hline & & 1,30132 & 1,06533 & 94,45 \\
\hline & & 1,10038 & 1,05642 & 94,35 \\
\hline & & 0,88847 & 1,04666 & 94,22 \\
\hline & & 0,70388 & 1,03781 & 94,10 \\
\hline & & 0,50818 & 1,02808 & 93,95 \\
\hline & & 0,30870 & 1,01775 & 93,77 \\
\hline & & 0,10422 & 1,00670 & 93,45 \\
\hline & & 0,01494 & 1,00170 & 93,26 \\
\hline \multirow[t]{3}{*}{288,15} & 0,050 & 1,70740 & 1,08092 & 95,15 \\
\hline & & 1,50304 & 1,07259 & 95,06 \\
\hline & & 1,30132 & 1,06406 & 94,97 \\
\hline
\end{tabular}




\begin{tabular}{|c|c|c|c|c|}
\hline $\mathrm{T} / \mathrm{K}$ & $\begin{array}{c}\text { m (EMIM DCA) / } \\
\text { mol. } \mathrm{kg}^{-1}\end{array}$ & $\begin{array}{c}\mathrm{m} \text { (sacarídeo) / } \\
\text { mol. } \mathrm{kg}^{-1}\end{array}$ & $\rho / \mathrm{g} . \mathrm{cm}^{-3}$ & $\mathrm{~V}_{f_{S}} / \mathrm{cm}^{3} \cdot \mathrm{mol}^{-1}$ \\
\hline \multirow[t]{7}{*}{288,15} & 0,050 & 1,10038 & 1,05524 & 94,87 \\
\hline & & 0,88847 & 1,04556 & 94,75 \\
\hline & & 0,70388 & 1,03680 & 94,63 \\
\hline & & 0,50818 & 1,02715 & 94,49 \\
\hline & & 0,30870 & 1,01692 & 94,32 \\
\hline & & 0,10422 & 1,00597 & 94,02 \\
\hline & & 0,01494 & 1,00102 & 93,82 \\
\hline \multirow[t]{10}{*}{293,15} & 0,050 & 1,70740 & 1,07931 & 95,60 \\
\hline & & 1,50304 & 1,07104 & 95,52 \\
\hline & & 1,30132 & 1,06257 & 95,44 \\
\hline & & 1,10038 & 1,05382 & 95,34 \\
\hline & & 0,88847 & 1,04422 & 95,23 \\
\hline & & 0,70388 & 1,03553 & 95,13 \\
\hline & & 0,50818 & 1,02596 & 95,00 \\
\hline & & 0,30870 & 1,01581 & 94,84 \\
\hline & & 0,10422 & 1,00496 & 94,57 \\
\hline & & 0,01494 & 1,00005 & 94,39 \\
\hline \multirow[t]{10}{*}{298,15} & 0,050 & 1,70740 & 1,07755 & 96,00 \\
\hline & & 1,50304 & 1,06933 & 95,93 \\
\hline & & 1,30132 & 1,06091 & 95,85 \\
\hline & & 1,10038 & 1,05221 & 95,77 \\
\hline & & 0,88847 & 1,04267 & 95,67 \\
\hline & & 0,70388 & 1,03404 & 95,58 \\
\hline & & 0,50818 & 1,02454 & 95,46 \\
\hline & & 0,30870 & 1,01446 & 95,32 \\
\hline & & 0,10422 & 1,00369 & 95,08 \\
\hline & & 0,01494 & 0,99883 & 94,91 \\
\hline \multirow[t]{2}{*}{303,15} & 0,050 & 1,70740 & 1,07563 & 96,37 \\
\hline & & 1,50304 & 1,06745 & 96,31 \\
\hline
\end{tabular}




\begin{tabular}{|c|c|c|c|c|}
\hline $\mathrm{T} / \mathrm{K}$ & $\begin{array}{c}\text { m (EMIM DCA) / } \\
\text { mol. } \mathrm{kg}^{-1}\end{array}$ & $\begin{array}{c}\mathrm{m} \text { (sacarídeo) / } \\
\text { mol. } \mathrm{kg}^{-1}\end{array}$ & $\rho / \mathrm{g} . \mathrm{cm}^{-3}$ & $\mathrm{~V}_{f_{S}} / \mathrm{cm}^{3} \cdot \mathrm{mol}^{-1}$ \\
\hline \multirow[t]{8}{*}{303,15} & 0,050 & 1,30132 & 1,05907 & 96,24 \\
\hline & & 1,10038 & 1,05041 & 96,18 \\
\hline & & 0,88847 & 1,04092 & 96,10 \\
\hline & & 0,70388 & 1,03235 & 96,00 \\
\hline & & 0,50818 & 1,02290 & 95,92 \\
\hline & & 0,30870 & 1,01290 & 95,78 \\
\hline & & 0,10422 & 1,00220 & 95,61 \\
\hline & & 0,01494 & 0,99738 & 95,43 \\
\hline \multirow[t]{10}{*}{283,15} & 0,075 & 1,70219 & 1,08229 & 94,87 \\
\hline & & 1,50416 & 1,07428 & 94,71 \\
\hline & & 1,30015 & 1,06565 & 94,57 \\
\hline & & 1,10236 & 1,05692 & 94,46 \\
\hline & & 0,90337 & 1,04781 & 94,32 \\
\hline & & 0,70017 & 1,03815 & 94,13 \\
\hline & & 0,49891 & 1,02818 & 93,88 \\
\hline & & 0,30191 & 1,01799 & 93,57 \\
\hline & & 0,10013 & 1,00705 & 93,12 \\
\hline & & 0,01517 & 1,00227 & 92,65 \\
\hline \multirow[t]{10}{*}{288,15} & 0,075 & 1,70219 & 1,08098 & 95,28 \\
\hline & & 1,50416 & 1,07296 & 95,18 \\
\hline & & 1,30015 & 1,06439 & 95,06 \\
\hline & & 1,10236 & 1,05573 & 94,95 \\
\hline & & 0,90337 & 1,04672 & 94,79 \\
\hline & & 0,70017 & 1,03713 & 94,62 \\
\hline & & 0,49891 & 1,02724 & 94,40 \\
\hline & & 0,30191 & 1,01713 & 94,14 \\
\hline & & 0,10013 & 1,00629 & 93,75 \\
\hline & & 0,01517 & 1,00156 & 93,34 \\
\hline 293,15 & 0,075 & 1,70219 & 1,07942 & 95,69 \\
\hline
\end{tabular}




\begin{tabular}{|c|c|c|c|c|}
\hline $\mathrm{T} / \mathrm{K}$ & $\begin{array}{c}\text { m (EMIM DCA) / } \\
\text { mol.kg }{ }^{-1}\end{array}$ & $\begin{array}{c}\mathrm{m} \text { (sacarídeo) / } \\
\text { mol. } \mathrm{kg}^{-1}\end{array}$ & $\rho / \mathrm{g} . \mathrm{cm}^{-3}$ & $\mathrm{~V}_{f_{S}} / \mathrm{cm}^{3} \cdot \mathrm{mol}^{-1}$ \\
\hline \multirow[t]{9}{*}{293,15} & 0,075 & 1,50416 & 1,07144 & 95,60 \\
\hline & & 1,30015 & 1,06290 & 95,51 \\
\hline & & 1,10236 & 1,05429 & 95,42 \\
\hline & & 0,90337 & 1,04533 & 95,30 \\
\hline & & 0,70017 & 1,03582 & 95,13 \\
\hline & & 0,49891 & 1,02600 & 94,95 \\
\hline & & 0,30191 & 1,01598 & 94,71 \\
\hline & & 0,10013 & 1,00524 & 94,39 \\
\hline & & 0,01517 & 1,00056 & 94,03 \\
\hline \multirow[t]{10}{*}{298,15} & 0,075 & 1,70219 & 1,07766 & 96,08 \\
\hline & & 1,50416 & 1,06972 & 96,00 \\
\hline & & 1,30015 & 1,06121 & 95,93 \\
\hline & & 1,10236 & 1,05265 & 95,86 \\
\hline & & 0,90337 & 1,04374 & 95,75 \\
\hline & & 0,70017 & 1,03429 & 95,61 \\
\hline & & 0,49891 & 1,02454 & 95,45 \\
\hline & & 0,30191 & 1,01459 & 95,27 \\
\hline & & 0,10013 & 1,00395 & 94,94 \\
\hline & & 0,01517 & 0,99931 & 94,74 \\
\hline \multirow[t]{10}{*}{303,15} & 0,075 & 1,70219 & 1,07570 & 96,45 \\
\hline & & 1,50416 & 1,06780 & 96,38 \\
\hline & & 1,30015 & 1,05935 & 96,31 \\
\hline & & 1,10236 & 1,05084 & 96,25 \\
\hline & & 0,90337 & 1,04195 & 96,19 \\
\hline & & 0,70017 & 1,03253 & 96,11 \\
\hline & & 0,49891 & 1,02284 & 95,99 \\
\hline & & 0,30191 & 1,01297 & 95,83 \\
\hline & & 0,10013 & 1,00242 & 95,60 \\
\hline & & 0,01517 & 0,99783 & 95,46 \\
\hline
\end{tabular}




\begin{tabular}{|c|c|c|c|c|}
\hline $\mathrm{T} / \mathrm{K}$ & $\begin{array}{c}\mathrm{m}(\text { EMIM DCA }) / \\
\text { mol. } \mathrm{kg}^{-1}\end{array}$ & $\begin{array}{c}\mathrm{m} \text { (sacarídeo }) / \\
\text { mol. } \mathrm{kg}^{-1}\end{array}$ & $\rho / \mathrm{g} \mathrm{cm}^{-3}$ & $\mathrm{~V}_{f_{S}} / \mathrm{cm}^{3} \cdot \mathrm{mol}^{-1}$ \\
\hline \multirow[t]{10}{*}{283,15} & 0,10 & 1,70083 & 1,08283 & 94,81 \\
\hline & & 1,50209 & 1,07471 & 94,70 \\
\hline & & 1,30164 & 1,06621 & 94,59 \\
\hline & & 1,10101 & 1,05739 & 94,44 \\
\hline & & 0,90199 & 1,04827 & 94,31 \\
\hline & & 0,70491 & 1,03889 & 94,15 \\
\hline & & 0,50424 & 1,02894 & 93,97 \\
\hline & & 0,30124 & 1,01845 & 93,70 \\
\hline & & 0,10131 & 1,00763 & 93,36 \\
\hline & & 0,01506 & 1,00280 & 92,88 \\
\hline \multirow[t]{10}{*}{288,15} & 0,10 & 1,70083 & 1,08141 & 95,27 \\
\hline & & 1,50209 & 1,07335 & 95,17 \\
\hline & & 1,30164 & 1,06490 & 95,08 \\
\hline & & 1,10101 & 1,05615 & 94,95 \\
\hline & & 0,90199 & 1,04710 & 94,84 \\
\hline & & 0,70491 & 1,03778 & 94,72 \\
\hline & & 0,50424 & 1,02793 & 94,54 \\
\hline & & 0,30124 & 1,01754 & 94,30 \\
\hline & & 0,1013 & 1,00683 & 93,98 \\
\hline & & 0,01506 & 1,00205 & 93,57 \\
\hline \multirow[t]{9}{*}{293,15} & 0,10 & 1,70083 & 1,07977 & 95,71 \\
\hline & & 1,50209 & 1,07177 & 95,62 \\
\hline & & 1,30164 & 1,06340 & 95,52 \\
\hline & & 1,10101 & 1,05468 & 95,43 \\
\hline & & 0,90199 & 1,04571 & 95,32 \\
\hline & & 0,70491 & 1,03645 & 95,23 \\
\hline & & 0,50424 & 1,02667 & 95,09 \\
\hline & & 0,30124 & 1,01636 & 94,91 \\
\hline & & 0,10131 & 1,00576 & 94,61 \\
\hline
\end{tabular}




\begin{tabular}{|c|c|c|c|c|}
\hline $\mathrm{T} / \mathrm{K}$ & $\begin{array}{c}\text { m (EMIM DCA) / } \\
\text { mol.kg-1 }\end{array}$ & $\begin{array}{c}\text { m (sacarídeo) / } \\
\text { mol.kg-1 }\end{array}$ & $\rho /{\mathrm{g} . \mathrm{cm}^{-3}}^{-3}$ & $\mathrm{~V}_{f_{S}} / \mathrm{cm}^{3} \cdot \mathrm{mol}^{-1}$ \\
\hline 293,15 & 0,10 & 0,01506 & 1,00103 & 94,27 \\
\hline \multirow[t]{10}{*}{298,15} & 0,10 & 1,70083 & 1,07799 & 96,10 \\
\hline & & 1,50209 & 1,07003 & 96,02 \\
\hline & & 1,30164 & 1,06169 & 95,94 \\
\hline & & 1,10101 & 1,05303 & 95,86 \\
\hline & & 0,90199 & 1,04411 & 95,76 \\
\hline & & 0,70491 & 1,03491 & 95,69 \\
\hline & & 0,50424 & 1,02519 & 95,59 \\
\hline & & 0,30124 & 1,01496 & 95,43 \\
\hline & & 0,10131 & 1,00445 & 95,16 \\
\hline & & 0,01506 & 0,99976 & 94,99 \\
\hline \multirow[t]{10}{*}{303,15} & 0,10 & 1,70083 & 1,07603 & 96,47 \\
\hline & & 1,50209 & 1,06811 & 96,40 \\
\hline & & 1,30164 & 1,05981 & 96,33 \\
\hline & & 1,10101 & 1,05119 & 96,26 \\
\hline & & 0,90199 & 1,04231 & 96,19 \\
\hline & & 0,70491 & 1,03317 & 96,12 \\
\hline & & 0,50424 & 1,02351 & 96,04 \\
\hline & & 0,30124 & 1,01334 & 95,93 \\
\hline & & 0,10131 & 1,00290 & 95,82 \\
\hline & & 0,01506 & 0,99826 & 95,71 \\
\hline
\end{tabular}

As incertezas referentes aos valores da tabela são $u(T)=0,01 \mathrm{~K}, u(m)=0,0001 \mathrm{~mol} \cdot \mathrm{kg}^{-1}, u(\rho)=0,0001 \mathrm{~g} \cdot \mathrm{cm}^{-3}, u\left(V_{\varphi}\right)=$ $0,01 \mathrm{~cm}^{3} \cdot \mathrm{mol}^{-1}$

Fonte: Autor 
APÊNDICE D - TABELA - SISTEMA GLICOSE 
A tabela D.1 apresenta os valores das densidades e volumes molares aparentes, do sistema contendo glicose a diferentes concentrações e temperaturas.

Tabela D.1 - Resultados experimentais do sistema contendo glicose

\begin{tabular}{|c|c|c|c|c|}
\hline $\mathrm{T} / \mathrm{K}$ & $\begin{array}{c}\text { m (EMIM DCA) / } \\
\text { mol.kg }{ }^{-1}\end{array}$ & $\begin{array}{c}\text { m (sacarídeo) / } \\
\text { mol.kg-1 }\end{array}$ & $\rho / \mathrm{g} . \mathrm{cm}^{-3}$ & $\mathrm{~V}_{f_{S}} / \mathrm{cm}^{3} \cdot \mathrm{mol}^{-1}$ \\
\hline \multirow[t]{10}{*}{283,15} & 0,000 & 1,69599 & 1,09756 & 111,56 \\
\hline & & 1,49752 & 1,08779 & 111,53 \\
\hline & & 1,30061 & 1,07791 & 111,33 \\
\hline & & 1,09992 & 1,06726 & 111,24 \\
\hline & & 0,90029 & 1,05622 & 111,11 \\
\hline & & 0,69577 & 1,04438 & 111,00 \\
\hline & & 0,49927 & 1,03255 & 110,74 \\
\hline & & 0,30082 & 1,01996 & 110,58 \\
\hline & & 0,10065 & 1,00666 & 110,25 \\
\hline & & 0,01521 & 1,00077 & 109,70 \\
\hline \multirow[t]{10}{*}{288,15} & 0,000 & 1,69599 & 1,09617 & 112,10 \\
\hline & & 1,49752 & 1,08656 & 112,02 \\
\hline & & 1,30061 & 1,07666 & 111,90 \\
\hline & & 1,09992 & 1,06610 & 111,81 \\
\hline & & 0,90029 & 1,05518 & 111,66 \\
\hline & & 0,69577 & 1,04340 & 111,60 \\
\hline & & 0,49927 & 1,03167 & 111,36 \\
\hline & & 0,30082 & 1,01919 & 111,22 \\
\hline & & 0,10065 & 1,00601 & 110,88 \\
\hline & & 0,01521 & 1,00017 & 110,38 \\
\hline \multirow[t]{6}{*}{293,15} & 0,000 & 1,69599 & 1,09459 & 112,58 \\
\hline & & 1,49752 & 1,08504 & 112,51 \\
\hline & & 1,30061 & 1,07521 & 112,40 \\
\hline & & 1,09992 & 1,06472 & 112,31 \\
\hline & & 0,90029 & 1,05387 & 112,18 \\
\hline & & 0,69577 & 1,04218 & 112,12 \\
\hline
\end{tabular}




\begin{tabular}{|c|c|c|c|c|}
\hline $\mathrm{T} / \mathrm{K}$ & $\begin{array}{c}\mathrm{m}(\text { EMIM DCA }) / \\
\text { mol. } \mathrm{kg}^{-1}\end{array}$ & $\begin{array}{c}\mathrm{m} \text { (sacarídeo }) / \\
\text { mol. } \mathrm{kg}^{-1}\end{array}$ & $\rho / \mathrm{g} . \mathrm{cm}^{-3}$ & $\mathrm{~V}_{f_{S}} / \mathrm{cm}^{3} \cdot \mathrm{mol}^{-1}$ \\
\hline \multirow[t]{4}{*}{293,15} & 0,000 & 0,49927 & 1,03054 & 111,87 \\
\hline & & 0,30082 & 1,01814 & 111,76 \\
\hline & & 0,10065 & 1,00506 & 111,42 \\
\hline & & 0,01521 & 0,99926 & 111,08 \\
\hline \multirow[t]{10}{*}{298,15} & 0,000 & 1,69599 & 1,09284 & 113,02 \\
\hline & & 1,49752 & 1,08333 & 112,96 \\
\hline & & 1,30061 & 1,07357 & 112,85 \\
\hline & & 1,09992 & 1,06314 & 112,78 \\
\hline & & 0,90029 & 1,05236 & 112,64 \\
\hline & & 0,69577 & 1,04074 & 112,59 \\
\hline & & 0,49927 & 1,02915 & 112,40 \\
\hline & & 0,30082 & 1,01684 & 112,29 \\
\hline & & 0,10065 & 1,00385 & 111,97 \\
\hline & & 0,01521 & 0,99809 & 111,79 \\
\hline \multirow[t]{10}{*}{303,15} & 0,000 & 1,69599 & 1,09094 & 113,42 \\
\hline & & 1,49752 & 1,08147 & 113,37 \\
\hline & & 1,30061 & 1,07176 & 113,26 \\
\hline & & 1,09992 & 1,06138 & 113,19 \\
\hline & & 0,90029 & 1,05064 & 113,09 \\
\hline & & 0,69577 & 1,03909 & 113,03 \\
\hline & & 0,49927 & 1,02754 & 112,90 \\
\hline & & 0,30082 & 1,01530 & 112,83 \\
\hline & & 0,10065 & 1,00239 & 112,63 \\
\hline & & 0,01521 & 0,99668 & 112,52 \\
\hline \multirow[t]{5}{*}{283,15} & 0,025 & 1,69524 & 1,09781 & 111,75 \\
\hline & & 1,49784 & 1,08821 & 111,66 \\
\hline & & 1,30436 & 1,07849 & 111,51 \\
\hline & & 1,09992 & 1,06767 & 111,42 \\
\hline & & 0,89704 & 1,05651 & 111,26 \\
\hline
\end{tabular}




\begin{tabular}{|c|c|c|c|c|}
\hline $\mathrm{T} / \mathrm{K}$ & $\begin{array}{c}\mathrm{m}(\text { EMIM DCA }) / \\
\text { mol. } \mathrm{kg}^{-1}\end{array}$ & $\begin{array}{c}\mathrm{m} \text { (sacarídeo }) / \\
\text { mol. } \mathrm{kg}^{-1}\end{array}$ & $\rho / \mathrm{g} . \mathrm{cm}^{-3}$ & $\mathrm{~V}_{f_{S}} / \mathrm{cm}^{3} \cdot \mathrm{mol}^{-1}$ \\
\hline & & 0,70190 & 1,04530 & 111,08 \\
\hline & & 0,50189 & 1,03324 & 110,92 \\
\hline & & 0,30024 & 1,02052 & 110,66 \\
\hline & & 0,10068 & 1,00729 & 110,25 \\
\hline & & 0,01580 & 1,00144 & 109,76 \\
\hline \multirow[t]{10}{*}{288,15} & 0,025 & 1,69524 & 1,09640 & 112,27 \\
\hline & & 1,49784 & 1,08687 & 112,19 \\
\hline & & 1,30436 & 1,07722 & 112,05 \\
\hline & & 1,09992 & 1,06648 & 111,97 \\
\hline & & 0,89704 & 1,05540 & 111,84 \\
\hline & & 0,70190 & 1,04429 & 111,65 \\
\hline & & 0,50189 & 1,03232 & 111,52 \\
\hline & & 0,30024 & 1,01971 & 111,27 \\
\hline & & 0,10068 & 1,00659 & 110,87 \\
\hline & & 0,01580 & 1,00079 & 110,42 \\
\hline \multirow[t]{10}{*}{293,15} & 0,025 & 1,69524 & 1,09480 & 112,75 \\
\hline & & 1,49784 & 1,08532 & 112,68 \\
\hline & & 1,30436 & 1,07574 & 112,55 \\
\hline & & 1,09992 & 1,06507 & 112,48 \\
\hline & & 0,89704 & 1,05407 & 112,35 \\
\hline & & 0,70190 & 1,04303 & 112,18 \\
\hline & & 0,50189 & 1,03115 & 112,05 \\
\hline & & 0,30024 & 1,01862 & 111,85 \\
\hline & & 0,10068 & 1,00560 & 111,51 \\
\hline & & 0,01580 & 0,99985 & 111,09 \\
\hline \multirow[t]{4}{*}{298,15} & 0,025 & 1,69524 & 1,09302 & 113,19 \\
\hline & & 1,49784 & 1,08361 & 113,12 \\
\hline & & 1,30436 & 1,07408 & 112,99 \\
\hline & & 1,09992 & 1,06347 & 112,93 \\
\hline
\end{tabular}




\begin{tabular}{|c|c|c|c|c|}
\hline $\mathrm{T} / \mathrm{K}$ & $\begin{array}{c}\text { m (EMIM DCA) / } \\
\text { mol.kg }{ }^{-1}\end{array}$ & $\begin{array}{c}\mathrm{m} \text { (sacarídeo) / } \\
\text { mol. } \mathrm{kg}^{-1}\end{array}$ & $\rho / \mathrm{g} . \mathrm{cm}^{-3}$ & $\mathrm{~V}_{f_{S}} / \mathrm{cm}^{3} \cdot \mathrm{mol}^{-1}$ \\
\hline \multirow[t]{6}{*}{298,15} & 0,025 & 0,89704 & 1,05253 & 112,82 \\
\hline & & 0,70190 & 1,04156 & 112,65 \\
\hline & & 0,50189 & 1,02976 & 112,52 \\
\hline & & 0,30024 & 1,01730 & 112,34 \\
\hline & & 0,10068 & 1,00436 & 112,06 \\
\hline & & 0,01580 & 0,99865 & 111,78 \\
\hline \multirow[t]{10}{*}{303,15} & 0,025 & 1,69524 & 1,09110 & 113,59 \\
\hline & & 1,49784 & 1,08173 & 113,53 \\
\hline & & 1,30436 & 1,07224 & 113,41 \\
\hline & & 1,09992 & 1,06169 & 113,36 \\
\hline & & 0,89704 & 1,05081 & 113,25 \\
\hline & & 0,70190 & 1,03990 & 113,09 \\
\hline & & 0,50189 & 1,02815 & 112,99 \\
\hline & & 0,30024 & 1,01576 & 112,85 \\
\hline & & 0,10068 & 1,00290 & 112,63 \\
\hline & & 0,01580 & 0,99723 & 112,48 \\
\hline \multirow[t]{10}{*}{283,15} & 0,050 & 1,70368 & 1,09872 & 111,72 \\
\hline & & 1,50294 & 1,08902 & 111,60 \\
\hline & & 1,29843 & 1,07862 & 111,53 \\
\hline & & 1,10051 & 1,06827 & 111,33 \\
\hline & & 0,90313 & 1,05741 & 111,18 \\
\hline & & 0,70582 & 1,04603 & 111,06 \\
\hline & & 0,50028 & 1,03372 & 110,74 \\
\hline & & 0,30010 & 1,02105 & 110,51 \\
\hline & & 0,10086 & 1,00782 & 110,05 \\
\hline & & 0,01533 & 1,00191 & 109,55 \\
\hline \multirow[t]{3}{*}{288,15} & 0,050 & 1,70368 & 1,09728 & 112,24 \\
\hline & & 1,50294 & 1,08765 & 112,13 \\
\hline & & 1,29843 & 1,07732 & 112,08 \\
\hline
\end{tabular}




\begin{tabular}{|c|c|c|c|c|}
\hline $\mathrm{T} / \mathrm{K}$ & $\begin{array}{c}\text { m (EMIM DCA) / } \\
\text { mol.kg }{ }^{-1}\end{array}$ & $\begin{array}{c}\mathrm{m} \text { (sacarídeo) / } \\
\text { mol. } \mathrm{kg}^{-1}\end{array}$ & $\rho / \mathrm{g} . \mathrm{cm}^{-3}$ & $\mathrm{~V}_{f_{S}} / \mathrm{cm}^{3} \cdot \mathrm{mol}^{-1}$ \\
\hline \multirow[t]{6}{*}{288,15} & 0,050 & 0,90313 & 1,05626 & 111,76 \\
\hline & & 0,70582 & 1,04498 & 111,65 \\
\hline & & 0,50028 & 1,03278 & 111,32 \\
\hline & & 0,30010 & 1,02020 & 111,15 \\
\hline & & 0,10086 & 1,00709 & 110,68 \\
\hline & & 0,01533 & 1,00123 & 110,23 \\
\hline \multirow[t]{10}{*}{293,15} & 0,050 & 1,70368 & 1,09565 & 112,72 \\
\hline & & 1,50294 & 1,08608 & 112,61 \\
\hline & & 1,29843 & 1,07582 & 112,57 \\
\hline & & 1,10051 & 1,06560 & 112,40 \\
\hline & & 0,90313 & 1,05490 & 112,27 \\
\hline & & 0,70582 & 1,04369 & 112,18 \\
\hline & & 0,50028 & 1,03158 & 111,85 \\
\hline & & 0,30010 & 1,01909 & 111,70 \\
\hline & & 0,10086 & 1,00607 & 111,31 \\
\hline & & 0,01533 & 1,00026 & 110,92 \\
\hline \multirow[t]{10}{*}{298,15} & 0,050 & 1,70368 & 1,09385 & 113,16 \\
\hline & & 1,50294 & 1,08434 & 113,06 \\
\hline & & 1,29843 & 1,07413 & 113,02 \\
\hline & & 1,10051 & 1,06396 & 112,87 \\
\hline & & 0,90313 & 1,05333 & 112,75 \\
\hline & & 0,70582 & 1,04219 & 112,66 \\
\hline & & 0,50028 & 1,03015 & 112,36 \\
\hline & & 0,30010 & 1,01775 & 112,19 \\
\hline & & 0,10086 & 1,00481 & 111,87 \\
\hline & & 0,01533 & 0,99904 & 111,63 \\
\hline \multirow[t]{3}{*}{303,15} & 0,050 & 1,70368 & 1,09190 & 113,56 \\
\hline & & 1,50294 & 1,08243 & 113,46 \\
\hline & & 1,29843 & 1,07227 & 113,44 \\
\hline
\end{tabular}




\begin{tabular}{|c|c|c|c|c|}
\hline $\mathrm{T} / \mathrm{K}$ & $\begin{array}{c}\text { m (EMIM DCA) / } \\
\text { mol. } \mathrm{kg}^{-1}\end{array}$ & $\begin{array}{c}\mathrm{m} \text { (sacarídeo) / } \\
\text { mol. } \mathrm{kg}^{-1}\end{array}$ & $\rho / \mathrm{g} . \mathrm{cm}^{-3}$ & $\mathrm{~V}_{f_{S}} / \mathrm{cm}^{3} \cdot \mathrm{mol}^{-1}$ \\
\hline \multirow[t]{7}{*}{303,15} & 0,050 & 1,10051 & 1,06216 & 113,28 \\
\hline & & 0,90313 & 1,05159 & 113,16 \\
\hline & & 0,70582 & 1,04050 & 113,08 \\
\hline & & 0,50028 & 1,02850 & 112,84 \\
\hline & & 0,30010 & 1,01618 & 112,67 \\
\hline & & 0,10086 & 1,00331 & 112,43 \\
\hline & & 0,01533 & 0,99758 & 112,35 \\
\hline \multirow[t]{10}{*}{283,15} & 0,075 & 1,70076 & 1,09916 & 111,69 \\
\hline & & 1,49847 & 1,08936 & 111,57 \\
\hline & & 1,30602 & 1,07975 & 111,37 \\
\hline & & 1,09383 & 1,06851 & 111,27 \\
\hline & & 0,89244 & 1,05745 & 111,06 \\
\hline & & 0,69983 & 1,04628 & 110,98 \\
\hline & & 0,50123 & 1,03429 & 110,83 \\
\hline & & 0,29900 & 1,02154 & 110,52 \\
\hline & & 0,09976 & 1,00830 & 110,17 \\
\hline & & 0,01507 & 1,00246 & 109,64 \\
\hline \multirow[t]{10}{*}{288,15} & 0,075 & 1,70076 & 1,09770 & 112,20 \\
\hline & & 1,49847 & 1,08796 & 112,10 \\
\hline & & 1,30602 & 1,07846 & 111,88 \\
\hline & & 1,09383 & 1,06727 & 111,81 \\
\hline & & 0,89244 & 1,05629 & 111,62 \\
\hline & & 0,69983 & 1,04522 & 111,53 \\
\hline & & 0,50123 & 1,03331 & 111,41 \\
\hline & & 0,29900 & 1,02067 & 111,09 \\
\hline & & 0,09976 & 1,00753 & 110,81 \\
\hline & & 0,01507 & 1,00174 & 110,33 \\
\hline \multirow[t]{2}{*}{293,15} & 0,075 & 1,70076 & 1,09605 & 112,67 \\
\hline & & 1,49847 & 1,08637 & 112,58 \\
\hline
\end{tabular}




\begin{tabular}{|c|c|c|c|c|}
\hline $\mathrm{T} / \mathrm{K}$ & $\begin{array}{c}\text { m (EMIM DCA }) / \\
\text { mol. } \mathrm{kg}^{-1}\end{array}$ & $\begin{array}{c}\mathrm{m} \text { (sacarídeo) / } \\
\text { mol. } \mathrm{kg}^{-1}\end{array}$ & $\rho /{\mathrm{g} . \mathrm{cm}^{-3}}^{-3}$ & $\mathrm{~V}_{f_{s}} / \mathrm{cm}^{3} \cdot \mathrm{mol}^{-1}$ \\
\hline \multirow[t]{8}{*}{293,15} & 0,075 & 1,30602 & 1,07693 & 112,36 \\
\hline & & 1,09383 & 1,06581 & 112,31 \\
\hline & & 0,89244 & 1,05491 & 112,12 \\
\hline & & 0,69983 & 1,04389 & 112,08 \\
\hline & & 0,50123 & 1,03206 & 111,99 \\
\hline & & 0,29900 & 1,01953 & 111,64 \\
\hline & & 0,09976 & 1,00648 & 111,45 \\
\hline & & 0,01507 & 1,00074 & 111,04 \\
\hline \multirow[t]{10}{*}{298,15} & 0,075 & 1,70076 & 1,09423 & 113,11 \\
\hline & & 1,49847 & 1,08461 & 113,02 \\
\hline & & 1,30602 & 1,07522 & 112,81 \\
\hline & & 1,09383 & 1,06416 & 112,77 \\
\hline & & 0,89244 & 1,05332 & 112,59 \\
\hline & & 0,69983 & 1,04236 & 112,57 \\
\hline & & 0,50123 & 1,03061 & 112,48 \\
\hline & & 0,29900 & 1,01814 & 112,20 \\
\hline & & 0,09976 & 1,00519 & 112,01 \\
\hline & & 0,01507 & 0,99949 & 111,76 \\
\hline \multirow[t]{10}{*}{303,15} & 0,075 & 1,70076 & 1,09226 & 113,50 \\
\hline & & 1,49847 & 1,08269 & 113,42 \\
\hline & & 1,30602 & 1,07327 & 113,28 \\
\hline & & 1,09383 & 1,06231 & 113,21 \\
\hline & & 0,89244 & 1,05151 & 113,06 \\
\hline & & 0,69983 & 1,04063 & 113,02 \\
\hline & & 0,50123 & 1,02895 & 112,93 \\
\hline & & 0,29900 & 1,01652 & 112,78 \\
\hline & & 0,09976 & 1,00367 & 112,58 \\
\hline & & 0,01507 & 0,99801 & 112,49 \\
\hline 283,15 & 0,10 & 1,70195 & 1,09969 & 111,72 \\
\hline
\end{tabular}




\begin{tabular}{|c|c|c|c|c|}
\hline $\mathrm{T} / \mathrm{K}$ & $\begin{array}{c}\text { m (EMIM DCA) / } \\
\text { mol.kg }{ }^{-1}\end{array}$ & $\begin{array}{c}\mathrm{m} \text { (sacarídeo) / } \\
\text { mol. } \mathrm{kg}^{-1}\end{array}$ & $\rho / \mathrm{g} . \mathrm{cm}^{-3}$ & $\mathrm{~V}_{f_{s}} / \mathrm{cm}^{3} \cdot \mathrm{mol}^{-1}$ \\
\hline \multirow[t]{9}{*}{283,15} & 0,10 & 1,50032 & 1,08987 & 111,65 \\
\hline & & 1,30016 & 1,07979 & 111,52 \\
\hline & & 1,10511 & 1,06950 & 111,43 \\
\hline & & 0,90150 & 1,05828 & 111,33 \\
\hline & & 0,70072 & 1,04679 & 111,12 \\
\hline & & 0,50272 & 1,03486 & 111,00 \\
\hline & & 0,30356 & 1,02234 & 110,71 \\
\hline & & 0,10083 & 1,00892 & 110,38 \\
\hline & & 0,01510 & 1,00300 & 109,79 \\
\hline \multirow[t]{10}{*}{288,15} & 0,10 & 1,70195 & 1,09820 & 112,23 \\
\hline & & 1,50032 & 1,08845 & 112,18 \\
\hline & & 1,30016 & 1,07847 & 112,03 \\
\hline & & 1,10511 & 1,06822 & 111,98 \\
\hline & & 0,90150 & 1,05710 & 111,87 \\
\hline & & 0,70072 & 1,04569 & 111,69 \\
\hline & & 0,50272 & 1,03385 & 111,58 \\
\hline & & 0,30356 & 1,02143 & 111,31 \\
\hline & & 0,10083 & 1,00812 & 111,01 \\
\hline & & 0,01510 & 1,00225 & 110,48 \\
\hline \multirow[t]{10}{*}{293,15} & 0,10 & 1,70195 & 1,09653 & 112,70 \\
\hline & & 1,50032 & 1,08684 & 112,65 \\
\hline & & 1,30016 & 1,07694 & 112,50 \\
\hline & & 1,10511 & 1,06675 & 112,45 \\
\hline & & 0,90150 & 1,05568 & 112,38 \\
\hline & & 0,70072 & 1,04435 & 112,20 \\
\hline & & 0,50272 & 1,03260 & 112,09 \\
\hline & & 0,30356 & 1,02026 & 111,86 \\
\hline & & 0,10083 & 1,00705 & 111,55 \\
\hline & & 0,01510 & 1,00122 & 111,19 \\
\hline
\end{tabular}




\begin{tabular}{|c|c|c|c|c|}
\hline $\mathrm{T} / \mathrm{K}$ & $\begin{array}{c}\text { m (EMIM DCA) / } \\
\text { mol.kg-1 }\end{array}$ & $\begin{array}{c}\mathrm{m} \text { (sacarídeo) / } \\
\text { mol. } \mathrm{kg}^{-1}\end{array}$ & $\rho / \mathrm{g} \cdot \mathrm{cm}^{-3}$ & $\mathrm{~V}_{f_{s}} / \mathrm{cm}^{3} \cdot \mathrm{mol}^{-1}$ \\
\hline \multirow[t]{10}{*}{298,15} & 0,10 & 1,70195 & 1,09469 & 113,13 \\
\hline & & 1,50032 & 1,08506 & 113,08 \\
\hline & & 1,30016 & 1,07521 & 112,94 \\
\hline & & 1,10511 & 1,06507 & 112,91 \\
\hline & & 0,90150 & 1,05408 & 112,83 \\
\hline & & 0,70072 & 1,04281 & 112,66 \\
\hline & & 0,50272 & 1,03113 & 112,56 \\
\hline & & 0,30356 & 1,01886 & 112,35 \\
\hline & & 0,10083 & 1,00573 & 112,11 \\
\hline & & 0,01510 & 0,99994 & 111,90 \\
\hline \multirow[t]{10}{*}{303,15} & 0,10 & 1,70195 & 1,09270 & 113,53 \\
\hline & & 1,50032 & 1,08312 & 113,48 \\
\hline & & 1,30016 & 1,07330 & 113,36 \\
\hline & & 1,10511 & 1,06323 & 113,32 \\
\hline & & 0,90150 & 1,05229 & 113,25 \\
\hline & & 0,70072 & 1,04106 & 113,12 \\
\hline & & 0,50272 & 1,02944 & 113,04 \\
\hline & & 0,30356 & 1,01722 & 112,92 \\
\hline & & 0,10083 & 1,00418 & 112,77 \\
\hline & & 0,01510 & 0,998440 & 112,63 \\
\hline
\end{tabular}

As incertezas referentes aos valores da tabela são $u(T)=0,01 \mathrm{~K}, u(m)=0,0001 \mathrm{~mol} \cdot \mathrm{kg}^{-1}, u(\rho)=0,00001 \mathrm{~g} \cdot \mathrm{cm}^{-3}, u\left(V_{\varphi}\right)$ $=0,01 \mathrm{~cm}^{3} \cdot \mathrm{mol}^{-1}$

Fonte: Autor 
APÊNDICE E- TABELA - SISTEMA SACAROSE 
A tabela E.1 apresenta os valores das densidades e volumes molares aparentes do sistema contendo sacarose a diferentes concentrações e temperaturas.

Tabela E.1 - Resultado experimentais do sistema contendo sacarose

\begin{tabular}{|c|c|c|c|c|}
\hline $\mathrm{T} / \mathrm{K}$ & $\begin{array}{c}\text { m (EMIM DCA) / } \\
\text { mol. } \mathrm{kg}^{-1}\end{array}$ & $\begin{array}{c}\text { m (sacarídeo) / } \\
\text { mol. } \mathrm{kg}^{-1}\end{array}$ & $\rho / \mathrm{g} . \mathrm{cm}^{-3}$ & $\mathrm{~V}_{f_{s}} / \mathrm{cm}^{3} \cdot \mathrm{mol}^{-1}$ \\
\hline \multirow[t]{10}{*}{283,15} & \multirow[t]{10}{*}{0,000} & 1,69090 & 1,16343 & 210,95 \\
\hline & & 1,49837 & 1,14949 & 210,78 \\
\hline & & 1,29998 & 1,13412 & 210,61 \\
\hline & & 1,09955 & 1,11755 & 210,35 \\
\hline & & 0,89886 & 1,09970 & 210,06 \\
\hline & & 0,70079 & 1,08071 & 209,73 \\
\hline & & 0,49901 & 1,05970 & 209,51 \\
\hline & & 0,29971 & 1,03726 & 209,14 \\
\hline & & 0,10131 & 1,01295 & 208,76 \\
\hline & & 0,01512 & 1,00172 & 208,28 \\
\hline \multirow[t]{10}{*}{288,15} & \multirow[t]{10}{*}{0,000} & 1,69090 & 1,16176 & 211,75 \\
\hline & & 1,49837 & 1,14790 & 211,60 \\
\hline & & 1,29998 & 1,13263 & 211,44 \\
\hline & & 1,09955 & 1,11616 & 211,20 \\
\hline & & 0,89886 & 1,09841 & 210,95 \\
\hline & & 0,70079 & 1,07956 & 210,62 \\
\hline & & 0,49901 & 1,05873 & 210,33 \\
\hline & & 0,29971 & 1,03641 & 210,04 \\
\hline & & 0,10131 & 1,01227 & 209,60 \\
\hline & & 0,01512 & 1,00111 & 208,99 \\
\hline \multirow[t]{6}{*}{293,15} & \multirow[t]{6}{*}{0,000} & 1,69090 & 1,15993 & 212,49 \\
\hline & & 1,49837 & 1,14613 & 212,36 \\
\hline & & 1,29998 & 1,13094 & 212,22 \\
\hline & & 1,09955 & 1,11456 & 212,00 \\
\hline & & 0,89886 & 1,09692 & 211,75 \\
\hline & & 0,70079 & 1,07817 & 211,46 \\
\hline
\end{tabular}




\begin{tabular}{|c|c|c|c|c|}
\hline $\mathrm{T} / \mathrm{K}$ & $\begin{array}{c}\mathrm{m}(\text { EMIM DCA }) / \\
\text { mol.kg-1 }\end{array}$ & $\begin{array}{c}\mathrm{m} \text { (sacarídeo) / } \\
\text { mol.kg-1 }\end{array}$ & $\rho / \mathrm{g} . \mathrm{cm}^{-3}$ & $\mathrm{~V}_{f_{S}} / \mathrm{cm}^{3} \cdot \mathrm{mol}^{-1}$ \\
\hline \multirow[t]{4}{*}{293,15} & 0,000 & 0,49901 & 1,05747 & 211,18 \\
\hline & & 0,29971 & 1,03528 & 210,94 \\
\hline & & 0,10131 & 1,0113 & 210,47 \\
\hline & & 0,01512 & 1,00021 & 209,72 \\
\hline \multirow[t]{10}{*}{298,15} & 0,000 & 1,69090 & 1,15794 & 213,18 \\
\hline & & 1,49837 & 1,14421 & 213,05 \\
\hline & & 1,29998 & 1,12909 & 212,92 \\
\hline & & 1,09955 & 1,11279 & 212,72 \\
\hline & & 0,89886 & 1,09523 & 212,49 \\
\hline & & 0,70079 & 1,07659 & 212,19 \\
\hline & & 0,49901 & 1,05599 & 211,94 \\
\hline & & 0,29971 & 1,03392 & 211,69 \\
\hline & & 0,10131 & 1,01007 & 211,17 \\
\hline & & 0,01512 & 0,99903 & 210,47 \\
\hline \multirow[t]{10}{*}{303,15} & 0,000 & 1,69090 & 1,15582 & 213,83 \\
\hline & & 1,49837 & 1,14214 & 213,72 \\
\hline & & 1,29998 & 1,12709 & 213,59 \\
\hline & & 1,09955 & 1,11086 & 213,40 \\
\hline & & 0,89886 & 1,09338 & 213,18 \\
\hline & & 0,70079 & 1,07485 & 212,85 \\
\hline & & 0,49901 & 1,05431 & 212,67 \\
\hline & & 0,29971 & 1,03235 & 212,43 \\
\hline & & 0,10131 & 1,00861 & 211,98 \\
\hline & & 0,01512 & 0,99763 & 211,25 \\
\hline \multirow[t]{5}{*}{283,15} & 0,025 & 1,70183 & 1,16457 & 211,04 \\
\hline & & 1,49299 & 1,14945 & 210,88 \\
\hline & & 1,29810 & 1,13450 & 210,59 \\
\hline & & 1,09981 & 1,11799 & 210,45 \\
\hline & & 0,89777 & 1,09999 & 210,22 \\
\hline
\end{tabular}




\begin{tabular}{|c|c|c|c|c|}
\hline $\mathrm{T} / \mathrm{K}$ & $\begin{array}{c}\text { m (EMIM DCA) / } \\
\text { mol.kg } \text { pg }^{-1}\end{array}$ & $\begin{array}{c}\mathrm{m} \text { (sacarídeo) / } \\
\text { mol.kg-1 }\end{array}$ & $\rho / \mathrm{g} . \mathrm{cm}^{-3}$ & $\mathrm{~V}_{f_{S}} / \mathrm{cm}^{3} \cdot \mathrm{mol}^{-1}$ \\
\hline \multirow[t]{5}{*}{283,15} & 0,025 & 0,70041 & 1,08107 & 209,94 \\
\hline & & 0,49777 & 1,05999 & 209,76 \\
\hline & & 0,29768 & 1,03747 & 209,51 \\
\hline & & 0,10005 & 1,01332 & 209,10 \\
\hline & & 0,01534 & 1,00231 & 208,87 \\
\hline \multirow[t]{10}{*}{288,15} & 0,025 & 1,70183 & 1,16298 & 211,77 \\
\hline & & 1,49299 & 1,14800 & 211,58 \\
\hline & & 1,29810 & 1,13298 & 211,43 \\
\hline & & 1,09981 & 1,11658 & 211,30 \\
\hline & & 0,89777 & 1,09871 & 211,08 \\
\hline & & 0,70041 & 1,07988 & 210,86 \\
\hline & & 0,49777 & 1,05899 & 210,61 \\
\hline & & 0,29768 & 1,03660 & 210,42 \\
\hline & & 0,10005 & 1,01262 & 209,96 \\
\hline & & 0,01534 & 1,00168 & 209,57 \\
\hline \multirow[t]{10}{*}{293,15} & 0,025 & 1,70183 & 1,16105 & 212,56 \\
\hline & & 1,49299 & 1,14618 & 212,36 \\
\hline & & 1,29810 & 1,13128 & 212,19 \\
\hline & & 1,09981 & 1,11496 & 212,09 \\
\hline & & 0,89777 & 1,09719 & 211,89 \\
\hline & & 0,70041 & 1,07847 & 211,69 \\
\hline & & 0,49777 & 1,05771 & 211,45 \\
\hline & & 0,29768 & 1,03547 & 211,22 \\
\hline & & 0,10005 & 1,01162 & 210,84 \\
\hline & & 0,01534 & 1,00075 & 210,29 \\
\hline \multirow[t]{4}{*}{298,15} & 0,025 & 1,70183 & 1,15920 & 213,13 \\
\hline & & 1,49299 & 1,14433 & 212,99 \\
\hline & & 1,29810 & 1,12941 & 212,90 \\
\hline & & 1,09981 & 1,11317 & 212,81 \\
\hline
\end{tabular}




\begin{tabular}{|c|c|c|c|c|}
\hline $\mathrm{T} / \mathrm{K}$ & $\begin{array}{c}\text { m (EMIM DCA) / } \\
\text { mol.kg }{ }^{-1}\end{array}$ & $\begin{array}{c}\mathrm{m} \text { (sacarídeo) / } \\
\text { mol. } \mathrm{kg}^{-1}\end{array}$ & $\rho / \mathrm{g} . \mathrm{cm}^{-3}$ & $\mathrm{~V}_{f_{s}} / \mathrm{cm}^{3} \cdot \mathrm{mol}^{-1}$ \\
\hline \multirow[t]{6}{*}{298,15} & 0,025 & 0,89777 & 1,09549 & 212,62 \\
\hline & & 0,70041 & 1,07686 & 212,44 \\
\hline & & 0,49777 & 1,05622 & 212,19 \\
\hline & & 0,29768 & 1,03410 & 211,94 \\
\hline & & 0,10005 & 1,01036 & 211,64 \\
\hline & & 0,01534 & 0,99955 & 211,04 \\
\hline \multirow[t]{10}{*}{303,15} & 0,025 & 1,70183 & 1,15713 & 213,72 \\
\hline & & 1,49299 & 1,14218 & 213,69 \\
\hline & & 1,29810 & 1,12740 & 213,55 \\
\hline & & 1,09981 & 1,11125 & 213,44 \\
\hline & & 0,89777 & 1,09361 & 213,30 \\
\hline & & 0,70041 & 1,07510 & 213,07 \\
\hline & & 0,49777 & 1,05452 & 212,88 \\
\hline & & 0,29768 & 1,03250 & 212,66 \\
\hline & & 0,10005 & 1,00887 & 212,37 \\
\hline & & 0,01534 & 0,99811 & 211,81 \\
\hline \multirow[t]{10}{*}{283,15} & 0,050 & 1,69701 & 1,16458 & 211,14 \\
\hline & & 1,49753 & 1,15012 & 211,02 \\
\hline & & 1,29538 & 1,13456 & 210,79 \\
\hline & & 1,09839 & 1,11841 & 210,43 \\
\hline & & 0,90105 & 1,10087 & 210,18 \\
\hline & & 0,69939 & 1,08149 & 209,98 \\
\hline & & 0,50298 & 1,06112 & 209,75 \\
\hline & & 0,30052 & 1,03841 & 209,37 \\
\hline & & 0,09933 & 1,01381 & 209,04 \\
\hline & & 0,01533 & 1,00289 & 208,74 \\
\hline \multirow[t]{3}{*}{288,15} & 0,050 & 1,69701 & 1,16287 & 211,92 \\
\hline & & 1,49753 & 1,14852 & 211,80 \\
\hline & & 1,29538 & 1,13299 & 211,64 \\
\hline
\end{tabular}




\begin{tabular}{|c|c|c|c|c|}
\hline $\mathrm{T} / \mathrm{K}$ & $\begin{array}{c}\mathrm{m}(\text { EMIM DCA }) / \\
\text { mol.kg-1 }\end{array}$ & $\begin{array}{c}\mathrm{m} \text { (sacarídeo) / } \\
\text { mol.kg-1 }\end{array}$ & $\rho / \mathrm{g} . \mathrm{cm}^{-3}$ & $\mathrm{~V}_{f_{S}} / \mathrm{cm}^{3} \cdot \mathrm{mol}^{-1}$ \\
\hline \multirow[t]{7}{*}{288,15} & 0,050 & 1,09839 & 1,11696 & 211,28 \\
\hline & & 0,90105 & 1,09957 & 211,00 \\
\hline & & 0,69939 & 1,08034 & 210,76 \\
\hline & & 0,50298 & 1,06010 & 210,53 \\
\hline & & 0,30052 & 1,03753 & 210,14 \\
\hline & & 0,09933 & 1,01307 & 209,80 \\
\hline & & 0,01533 & 1,00221 & 209,44 \\
\hline \multirow[t]{10}{*}{293,15} & 0,050 & 1,69701 & 1,16096 & 212,67 \\
\hline & & 1,49753 & 1,14670 & 212,55 \\
\hline & & 1,29538 & 1,13128 & 212,38 \\
\hline & & 1,09839 & 1,11533 & 212,04 \\
\hline & & 0,90105 & 1,09802 & 211,79 \\
\hline & & 0,69939 & 1,07890 & 211,58 \\
\hline & & 0,50298 & 1,05881 & 211,30 \\
\hline & & 0,30052 & 1,03635 & 210,97 \\
\hline & & 0,09933 & 1,01205 & 210,49 \\
\hline & & 0,01533 & 1,00124 & 210,17 \\
\hline \multirow[t]{10}{*}{298,15} & 0,050 & 1,69701 & 1,15892 & 213,37 \\
\hline & & 1,49753 & 1,14475 & 213,23 \\
\hline & & 1,29538 & 1,12939 & 213,09 \\
\hline & & 1,09839 & 1,11351 & 212,77 \\
\hline & & 0,90105 & 1,09632 & 212,49 \\
\hline & & 0,69939 & 1,07727 & 212,32 \\
\hline & & 0,50298 & 1,05727 & 212,07 \\
\hline & & 0,30052 & 1,03495 & 211,69 \\
\hline & & 0,09933 & 1,01076 & 211,30 \\
\hline & & 0,01533 & 1,00001 & 210,92 \\
\hline \multirow[t]{2}{*}{303,15} & 0,050 & 1,69701 & 1,15674 & 214,03 \\
\hline & & 1,49753 & 1,14264 & 213,90 \\
\hline
\end{tabular}




\begin{tabular}{|c|c|c|c|c|}
\hline $\mathrm{T} / \mathrm{K}$ & $\begin{array}{c}\mathrm{m}(\text { EMIM DCA }) / \\
\text { mol.kg-1 }\end{array}$ & $\begin{array}{c}\mathrm{m} \text { (sacarídeo) / } \\
\text { mol.kg-1 }\end{array}$ & $\rho / \mathrm{g} . \mathrm{cm}^{-3}$ & $\mathrm{~V}_{f_{S}} / \mathrm{cm}^{3} \cdot \mathrm{mol}^{-1}$ \\
\hline \multirow[t]{8}{*}{303,15} & 0,050 & 1,29538 & 1,12736 & 213,74 \\
\hline & & 1,09839 & 1,11155 & 213,43 \\
\hline & & 0,90105 & 1,09443 & 213,17 \\
\hline & & 0,69939 & 1,07545 & 213,03 \\
\hline & & 0,50298 & 1,05558 & 212,72 \\
\hline & & 0,30052 & 1,03333 & 212,43 \\
\hline & & 0,09933 & 1,00927 & 211,93 \\
\hline & & 0,01533 & 0,99856 & 211,69 \\
\hline \multirow[t]{10}{*}{283,15} & 0,075 & 1,70205 & 1,16533 & 211,25 \\
\hline & & 1,50112 & 1,15098 & 211,00 \\
\hline & & 1,30561 & 1,13587 & 210,88 \\
\hline & & 1,09722 & 1,11864 & 210,69 \\
\hline & & 0,89995 & 1,10105 & 210,56 \\
\hline & & 0,69874 & 1,08180 & 210,34 \\
\hline & & 0,49920 & 1,06113 & 210,17 \\
\hline & & 0,30454 & 1,03932 & 210,03 \\
\hline & & 0,10068 & 1,01457 & 209,61 \\
\hline & & 0,01549 & 1,00355 & 209,41 \\
\hline \multirow[t]{10}{*}{288,15} & 0,075 & 1,70205 & 1,16363 & 212,02 \\
\hline & & 1,50112 & 1,14932 & 211,82 \\
\hline & & 1,30561 & 1,13431 & 211,70 \\
\hline & & 1,09722 & 1,11722 & 211,50 \\
\hline & & 0,89995 & 1,09971 & 211,42 \\
\hline & & 0,69874 & 1,08066 & 211,09 \\
\hline & & 0,49920 & 1,06012 & 210,92 \\
\hline & & 0,30454 & 1,03842 & 210,82 \\
\hline & & 0,10068 & 1,01381 & 210,46 \\
\hline & & 0,01549 & 1,00286 & 210,11 \\
\hline 293,15 & 0,075 & 1,70205 & 1,16174 & 212,74 \\
\hline
\end{tabular}




\begin{tabular}{|c|c|c|c|c|}
\hline $\mathrm{T} / \mathrm{K}$ & $\begin{array}{c}\text { m (EMIM DCA) / } \\
\text { mol.kg }{ }^{-1}\end{array}$ & $\begin{array}{c}\mathrm{m} \text { (sacarídeo) / } \\
\text { mol. } \mathrm{kg}^{-1}\end{array}$ & $\rho / \mathrm{g} . \mathrm{cm}^{-3}$ & $\mathrm{~V}_{f_{s}} / \mathrm{cm}^{3} \cdot \mathrm{mol}^{-1}$ \\
\hline \multirow[t]{9}{*}{293,15} & 0,075 & 1,50112 & 1,14750 & 212,55 \\
\hline & & 1,30561 & 1,13257 & 212,44 \\
\hline & & 1,09722 & 1,11558 & 212,25 \\
\hline & & 0,89995 & 1,09815 & 212,19 \\
\hline & & 0,69874 & 1,07920 & 211,90 \\
\hline & & 0,49920 & 1,05879 & 211,71 \\
\hline & & 0,30454 & 1,03721 & 211,65 \\
\hline & & 0,10068 & 1,01275 & 211,25 \\
\hline & & 0,01549 & 1,00186 & 210,84 \\
\hline \multirow[t]{10}{*}{298,15} & 0,075 & 1,70205 & 1,15981 & 213,34 \\
\hline & & 1,50112 & 1,14551 & 213,25 \\
\hline & & 1,30561 & 1,13066 & 213,14 \\
\hline & & 1,09722 & 1,11373 & 212,98 \\
\hline & & 0,89995 & 1,09641 & 212,91 \\
\hline & & 0,69874 & 1,07755 & 212,64 \\
\hline & & 0,49920 & 1,05727 & 212,41 \\
\hline & & 0,30454 & 1,03580 & 212,33 \\
\hline & & 0,10068 & 1,01145 & 211,95 \\
\hline & & 0,01549 & 1,00061 & 211,58 \\
\hline \multirow[t]{10}{*}{303,15} & 0,075 & 1,70205 & 1,15764 & 213,98 \\
\hline & & 1,50112 & 1,14340 & 213,90 \\
\hline & & 1,30561 & 1,12860 & 213,81 \\
\hline & & 1,09722 & 1,11176 & 213,64 \\
\hline & & 0,89995 & 1,09450 & 213,60 \\
\hline & & 0,69874 & 1,07574 & 213,31 \\
\hline & & 0,49920 & 1,05551 & 213,17 \\
\hline & & 0,30454 & 1,03418 & 213,00 \\
\hline & & 0,10068 & 1,00993 & 212,67 \\
\hline & & 0,01549 & 0,99914 & 212,35 \\
\hline
\end{tabular}




\begin{tabular}{|c|c|c|c|c|}
\hline $\mathrm{T} / \mathrm{K}$ & $\begin{array}{c}m(\text { EMIM DCA }) / \\
\text { mol. } \mathrm{kg}^{-1}\end{array}$ & $\begin{array}{c}m \text { (sacarídeo) } / \\
\text { mol. } \mathrm{kg}^{-1}\end{array}$ & $\rho / \mathrm{g} . \mathrm{cm}^{-3}$ & $\mathrm{~V}_{f_{s}} / \mathrm{cm}^{3} \cdot \mathrm{mol}^{-1}$ \\
\hline \multirow[t]{10}{*}{283,15} & \multirow[t]{10}{*}{0,10} & 1,70905 & 1,16678 & 210,85 \\
\hline & & 1,49086 & 1,15093 & 210,73 \\
\hline & & 1,29926 & 1,13611 & 210,55 \\
\hline & & 1,09754 & 1,11922 & 210,52 \\
\hline & & 0,89714 & 1,10141 & 210,28 \\
\hline & & 0,69973 & 1,08251 & 210,01 \\
\hline & & 0,50487 & 1,06229 & 209,87 \\
\hline & & 0,30469 & 1,03988 & 209,59 \\
\hline & & 0,10054 & 1,01500 & 209,30 \\
\hline & & 0,01516 & 1,00393 & 209,10 \\
\hline \multirow[t]{10}{*}{288,15} & \multirow[t]{10}{*}{0,10} & 1,70905 & 1,16501 & 211,62 \\
\hline & & 1,49086 & 1,14926 & 211,51 \\
\hline & & 1,29926 & 1,13453 & 211,34 \\
\hline & & 1,09754 & 1,11775 & 211,32 \\
\hline & & 0,89714 & 1,10002 & 211,13 \\
\hline & & 0,69973 & 1,08125 & 210,86 \\
\hline & & 0,50487 & 1,06121 & 210,63 \\
\hline & & 0,30469 & 1,03892 & 210,39 \\
\hline & & 0,10054 & 1,01418 & 210,16 \\
\hline & & 0,01516 & 1,00318 & 209,81 \\
\hline \multirow[t]{9}{*}{293,15} & \multirow[t]{9}{*}{0,10} & 1,70905 & 1,16311 & 212,33 \\
\hline & & 1,49086 & 1,14742 & 212,24 \\
\hline & & 1,29926 & 1,13275 & 212,10 \\
\hline & & 1,09754 & 1,11606 & 212,09 \\
\hline & & 0,89714 & 1,09844 & 211,90 \\
\hline & & 0,69973 & 1,07979 & 211,62 \\
\hline & & 0,50487 & 1,05984 & 211,45 \\
\hline & & 0,30469 & 1,03769 & 211,18 \\
\hline & & 0,10054 & 1,01310 & 210,84 \\
\hline
\end{tabular}




\begin{tabular}{|c|c|c|c|c|}
\hline $\mathrm{T} / \mathrm{K}$ & $\begin{array}{c}\mathrm{m}(\text { EMIM DCA }) / \\
\text { mol.kg-1 }\end{array}$ & $\begin{array}{c}\mathrm{m} \text { (sacarídeo) / } \\
\text { mol.kg-1 }\end{array}$ & $\rho / \mathrm{g} . \mathrm{cm}^{-3}$ & $\mathrm{~V}_{f_{S}} / \mathrm{cm}^{3} \cdot \mathrm{mol}^{-1}$ \\
\hline 293,15 & 0,10 & 0,01516 & 1,00215 & 210,55 \\
\hline \multirow[t]{10}{*}{298,15} & 0,10 & 1,70905 & 1,16104 & 213,00 \\
\hline & & 1,49086 & 1,14542 & 212,93 \\
\hline & & 1,29926 & 1,13083 & 212,79 \\
\hline & & 1,09754 & 1,11422 & 212,79 \\
\hline & & 0,89714 & 1,09668 & 212,61 \\
\hline & & 0,69973 & 1,07812 & 212,35 \\
\hline & & 0,50487 & 1,05827 & 212,18 \\
\hline & & 0,30469 & 1,03623 & 211,93 \\
\hline & & 0,10054 & 1,01177 & 211,55 \\
\hline & & 0,01516 & 1,00087 & 211,31 \\
\hline \multirow[t]{10}{*}{303,15} & 0,10 & 1,70905 & 1,15884 & 213,65 \\
\hline & & 1,49086 & 1,14329 & 213,58 \\
\hline & & 1,29926 & 1,12877 & 213,44 \\
\hline & & 1,09754 & 1,11222 & 213,46 \\
\hline & & 0,89714 & 1,09477 & 213,27 \\
\hline & & 0,69973 & 1,07627 & 213,05 \\
\hline & & 0,50487 & 1,05653 & 212,85 \\
\hline & & 0,30469 & 1,03456 & 212,70 \\
\hline & & 0,10054 & 1,01022 & 212,38 \\
\hline & & 0,01516 & 0,99938 & 212,10 \\
\hline
\end{tabular}

As incertezas referentes aos valores da tabela são $u(T)=0,01 \mathrm{~K}, u(m)=0,0001 \mathrm{~mol} \cdot \mathrm{kg}^{-1}, u(\rho)=0,0001 \mathrm{~g} \cdot \mathrm{cm}^{-3}, u\left(V_{\varphi}\right)$ $=0,01 \mathrm{~cm}^{3} \cdot \mathrm{mol}^{-1}$

Fonte: Autor 